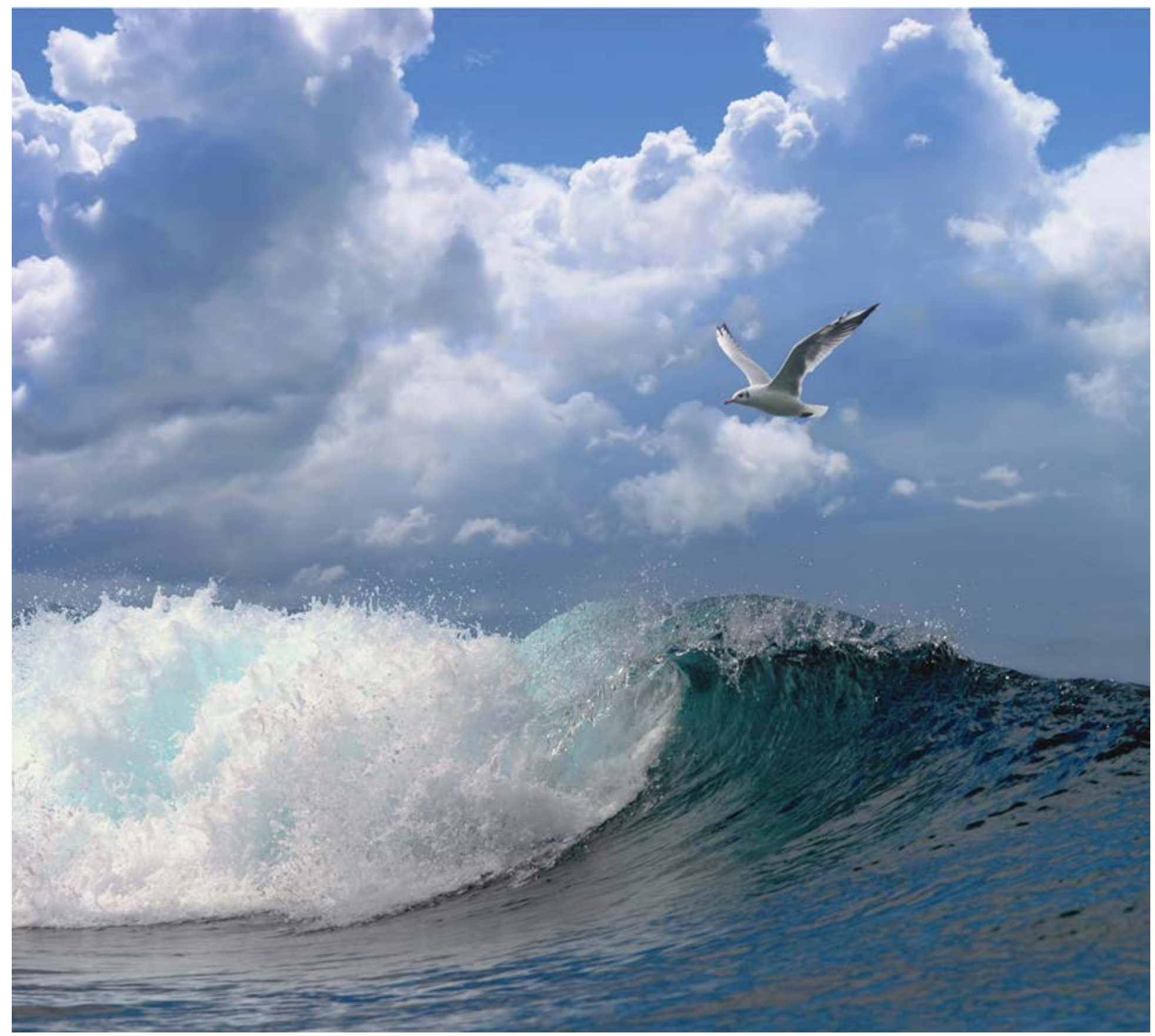

\title{
Soortenlijst Nederlandse Noordzee
}

Auteurs: O.G. Bos ${ }^{1}$, A. Gittenberger ${ }^{2}$, I.J. de Boois ${ }^{1}$, M. van Asch ${ }^{1}$, J.T. van der Wal ${ }^{1}$, J. Cremer ${ }^{1}$ B.van der Hoorn ${ }^{3}$, S. Pieterse ${ }^{3}$, P.A.J. Bakker $^{3}$
Wageningen University \&

Research Rapport C125/16A

\footnotetext{
1. Wageningen Marine Research (www.wur.nl/marine-research)

2. GiMaRIS, BioScience Park Leiden, J.H. Oortweg 21, 2333 CH Leiden (http://www.gimaris.com/)

3. Naturalis Biodiversity Center, Postbus 9517, 2300 RA Leiden (www.naturalis.nl)
} 


\section{Soortenlijst Nederlandse Noordzee}

Auteur(s): $\quad$ O.G. Bos $^{1}$, A. Gittenberger ${ }^{2}$, I.J. de Boois ${ }^{1}$, M. van Asch ${ }^{1}$, J.T. van der Wal ${ }^{1}$, J. Cremer $^{1}$, B. van der Hoorn ${ }^{3}$, S. Pieterse ${ }^{3}$, P.A.J. Bakker ${ }^{3}$

Publicatiedatum: 31 december 2016

Dit onderzoek is uitgevoerd door Wageningen Marine Research in opdracht van en gefinancierd door het Ministerie van Economische Zaken, in het kader van het Beleidsondersteunend onderzoekthema 'Mariene Biodiversiteit' (projectnummer BO-11-018.02-066)

Wageningen Marine Research, Den Helder, december 2016

Wageningen Marine Research rapport C125/16 A

DOI nummer: https://doi.org/10.18174/401117

1. Wageningen Marine Research (www.wur.nl/marine-research)

2. GiMaRIS, BioScience Park Leiden, J.H. Oortweg 21, $2333 \mathrm{CH}$ Leiden (http://www.gimaris.com/)

3. Naturalis Biodiversity Center, Postbus 9517, 2300 RA Leiden (www.naturalis.nl) 
O.G. Bos, A. Gittenberger, I. de Boois, M. van Asch, J.T van der Wal, J. Cremer, B. van der Hoorn, S. Pieterse, P.A.J. Bakker (2016). Soortenlijst Nederlandse Noordzee. Wageningen Marine Research rapport C125/16. DOI: https://doi.org/10.18174/401117

Sleutelwoorden: soortenlijst, Noordzee, biodiversiteit

Opdrachtgever: Ministerie EZ

T.a.v.: E. Knegtering

Postbus 20401

2500 EK Den Haag

BO-11-018.02-066

Wageningen Marine Research Wageningen UR is ISO 9001:2008 gecertificeerd. 


\section{Inhoud}

Samenvatting

$1 \quad$ Inleiding

4

$\begin{array}{lll}1.1 & \text { Aanleiding en achtergrond } & 7\end{array}$

1.2 Kennisvraag

1.3 Doelstellingen

2 Methoden

2.1 Aanpak

2.2 Informatiebronnen

2.2.1 Meercellige algen en wieren

2.2.2 Bodemdieren (benthos)

2.2.3 Vissen

2.2.4 Zeezoogdieren

2.2.5 Vogels

2.3 Kenmerken per soort

2.4 Status voorkomen

2.5 Taxonomie en soortnamen

2.6 Verspreiding

2.7 Habitat (zoet/brak/marien)

2.8 Substraat (hard/zacht)

2.9 Beleidsstatus

2.10 Definitie 'Soortenlijst'

3 Resultaten

3.1 Soortenlijsten

3.2 Aantallen soorten

3.3 Exoten

3.4 Verspreiding

3.5 Hard en zacht substraat

4

\section{Discussie}

4.1 Aantal soorten

4.2 Exoten

4.3 Verspreiding

4.4 Hard en zacht substraat

4.5 Identificatie en verwerking data

4.6 Vervolgstappen

5 Dankwoord

6 Kwaliteitsborging

Literatuur

Verantwoording

Bijlage 1 Soortenlijst

Bijlage 2 Beleidssoorten 


\section{Samenvatting}

In dit rapport is een soortenlijst opgesteld voor de Nederlandse Noordzee in opdracht van het ministerie van Economische Zaken. $\mathrm{Er}$ is behoefte aan een concrete lijst van inheemse en nietinheemse Noordzeesoorten omdat het rijk direct en indirect werkt aan behoud en duurzaam gebruik van de van nature voorkomende biodiversiteit van het Nederlandse deel van de Noordzee, aan beleid over "Bouwen met Noordzeenatuur" en aan het volgen van niet-inheemse soorten (exoten) in de Noordzee.

Een vanuit het Nederlands Soortenregister (NSR; www.nederlandsesoorten.nl) gegenereerde lijst met Nederlandse zoutwatersoorten (maart 2016; $n=1991$ soorten) is in dit project aangevuld met 233 soorten uit verschillende databases en uit de literatuur. Indien een bron ook informatie bevatte over vastgestelde soorten in andere zoute gebieden in Nederland dan de Noordzee, is die informatie ook meegenomen. Andersom zijn soortendatabases en -studies die uitsluitend betrekking hadden op zoute wateren anders dan de Noordzee (b.v. Waddenzee of Delta), niet beschouwd. Per soort is aangegeven welke status de soort heeft. Hierbij is de 'status voorkomen' gebruikt zoals gehanteerd in het NSR. Dit is een code die aangeeft of de soort nog nader moet worden ingedeeld (categorie 0), oorspronkelijk in de Nederlandse Noordzee voorkomt (1), hier als exoot is beland (2) of om andere redenen is opgenomen (3 en 4). Deze categorieën zijn ingedeeld in subcategorieën die verdere detaillering geven.

Totaal aantal zout- en brakwatersoorten

Inclusief de in dit onderzoek gedane aanvullingen, bedraagt het totaal aan meercellige zout- en brakwatersoorten in Nederland 2224 soorten. Hiervan worden 1909 soorten (86\%) beschouwd als constant, periodiek of incidenteel aanwezig (NSR-categorieën 0a, 1, 1a, 1b, 2a, 2b, 2c). Deze soorten vormen de nadere uitgangsverzameling in dit onderzoek. De overige soorten (NSR-categorieën $0,2 d$, $3 a, 3 b, 3 c, 3 d$ en 4 ) vallen daarbuiten.

\section{Aantallen Noordzeesoorten}

Van de Nederlandse mariene meercellige soorten $(N=1909)$, zijn er $1284(67 \%)$ vastgesteld voor de Noordzee. Daarvan zijn er 71 soorten (6\%) exoot (NSR-categorieën 2, 2a en 2b) en 1205 inheems (NSR-categorieën 1, 1a, 1b). Van de 1284 soorten zijn er 622 vastgesteld voor de Noordzeekustzone (0-20m) en 847 voor de diepere delen van de Noordzee. Van vastgestelde bodembewonende Noordzeesoorten zijn er 812 gebonden aan zacht substraat en 524 gebonden aan hard substraat.

\section{Status voorkomen Noordzeesoorten in Nederland}

Van de Nederlandse Noordzeesoorten $(n=1284$ ) wordt circa $21 \%$ incidenteel waargenomen (NSRsubcategorie $1 b)$. Het gaat hierbij om soorten zoals diverse algen en wieren, trekvogels, en walvissen en dolfijnen, die niet permanent aanwezig zijn.

\section{Soortenrijkdom}

Van de 26 fyla in de bovengenoemde zout- en brakwatersoortenlijst ( $N=1909$ soorten), zijn wereldwijd in totaal ca. 214,124 geaccepteerde mariene soorten vastgesteld in het World Register of Marine Species (WoRMS). Dit betekent dat voor die fyla in Nederland tenminste $0.89 \%$ van de wereldwijd bekende soortenrijkdom voorkomt. Voor de Noordzee ( $n=1284$ soorten) bedraagt dit percentage $0.60 \%$. De soortenlijst is wat aantallen soorten per soortgroep betreft goed vergelijkbaar met de Belgische Noordzeesoortenlijst uit 2010. De Belgische mariene soortenlijst kent voor 19 fyla een soortenrijkdom van 1793 soorten. Door verschil in opzet en aanpak van de soortenlijst en in geografische afbakening verschillen de lijsten wel in aantallen soorten per fylum.

Verder dragen deze mariene soorten $(N=1909)$ zo'n 4-5\% bij aan het totaal van $36,219-47,800$ in Nederland vastgestelde soorten (zowel land als water). De Noordzee en de andere in dit rapport beschouwde zoutwatergebieden omvatten samen ca. $62 \%$ van het totale Nederlandse oppervlak 
(inclusief NCP). Dat de mariene soorten toch slechts 4-5\% van de totale Nederlandse soortenrijkdom vormen is voor een belangrijk deel in verband te brengen met de grote verscheidenheid aan habitats op land en de grotere habitatcomplexiteit. In zee zijn fysieke gradiënten minder steil en extremen kleiner en is er daardoor vaak een kleinere habitatdiversiteit op grotere ruimtelijke schalen. Op land dragen vooral insecten en schimmels (resp. 19244 en ruim 10 duizend soorten) bij aan de soortenrijkdom, terwijl de mariene lijst maar 7 insectensoorten telt en schimmels niet zijn beschouwd. Op een hoger taxonomisch niveau is de biodiversiteit van de zee juist groter. Zo komen verschillende dierfyla uitsluitend-en-alleen in zout water voor, en niet op land.

\section{Mariene soortenrijkdom per fylum}

De meest soortenrijke fyla (indeling volgens Noordijk et al. 2010a) in de zout- en brakwatersoortenlijst ( $N=1909)$ zijn: geleedpotigen (Arthropoda: 418 soorten), chordadieren (Chordata: 313), weekdieren (Mollusca: 296), ringwormen (Annelida: 254), holtedieren/neteldieren (Cnidaria: 142), roodwieren (Rhodophyta: 140), heterokontofyta (83), mosdiertjes (Bryozoa: 68), groenwieren (Chlorophyta: 54), sponzen (Porifera: 30), nematoden (Nematoda: 28), stekelhuidigen (Echinodermata: 25) en snoerwormen (Nemertea: 21). De rest van de fyla kende elk minder dan 5 soorten. Voor circa 49\% van de 1789 soorten is een Nederlandse naam beschikbaar. Voor de Noordzee ( $n=1284$ soorten) staan de aantallen soorten per fylum in Figuur 1.

\section{Exoten}

Van de zout- en brakwaterwatersoorten $(N=1909)$ zijn er 147 (ongeveer $8 \%$ ) te beschouwen als exoot (NSR-categorieën 2, 2a, 2b). Van de Noordzeesoorten ( $n=1284$ ) zijn er 76 exoot $(6 \%)$.

\section{Verspreiding zout- en brakwatersoorten}

Voor 1648 (86\%) van de 1909 zout- en brakwatersoorten is ook informatie verzameld over in welke zoutwatergebieden ze zijn vastgesteld. Voor de hele Noordzee zijn 1284 soorten vastgesteld. Voor de Noordzeekustzone (ca 0-20 m diep) 622 soorten en voor de Noordzee offshore (ca 20-60 m diep) 847 soorten. Verder zijn er 429 zout- en brakwatersoorten vastgesteld voor de Oosterschelde, 258 voor de Westerschelde, 200 voor de Grevelingen en tenminste 523 voor de Waddenzee. De nadruk lag in dit onderzoek op de Noordzeesoorten: databases en literatuur over de overige gebieden zijn niet meegenomen en daarom zullen de soortenlijsten voor die gebieden niet compleet zijn. Ook de Noordzeelijst is nog niet helemaal compleet: er zijn zoutwatersoorten die nog niet toegekend zijn aan de Noordzeelijst, omdat niet alle verspreidingsinformatie meegenomen kon worden binnen dit project. In het rapport staan aanbevelingen hoe de lijst completer gemaakt kan worden.

\section{Habitat mariene soorten: hard/ zacht substraat}

Ook is voor bodemdieren informatie over de habitat opgenomen (hard/zacht substraat), op basis van de locatie van bemonstering en/of op basis van literatuuronderzoek. In totaal is aan 814 van de 1898 soorten zacht substraat toegekend als habitat, en aan 524 van de 1902 hard substraat als habitat. Voor de Noordzeesoorten $(n=1284)$ gaat het om dezelfde aantallen (zacht substraat: 814 ; hard substraat 524) omdat de indeling alleen gebaseerd is op databases en literatuur over de Noordzee. Voor de overige soortgroepen is niet vastgesteld op welk substraat ze leven of is de indeling niet of vaak niet van toepassing (bv. voor kwallen, vogels, vissen, zoogdieren).

\section{Noordzeesoortenlijst}

De Noordzeesoortenlijst is opgenomen in Bijlage 1 van dit rapport. Ook zal de lijst als interactieve lijst beschikbaar komen in het door Naturalis Biodiversity Center beheerde Nederlands Soortenregister (NSR; www.nederlandsesoorten.nl) en in het Informatiehuis Marien (www.informatiehuismarien.nl). Een uitgebreidere lijst met bronvermeldingen is als Excel-bestand beschikbaar via de auteurs en Researchgate. 


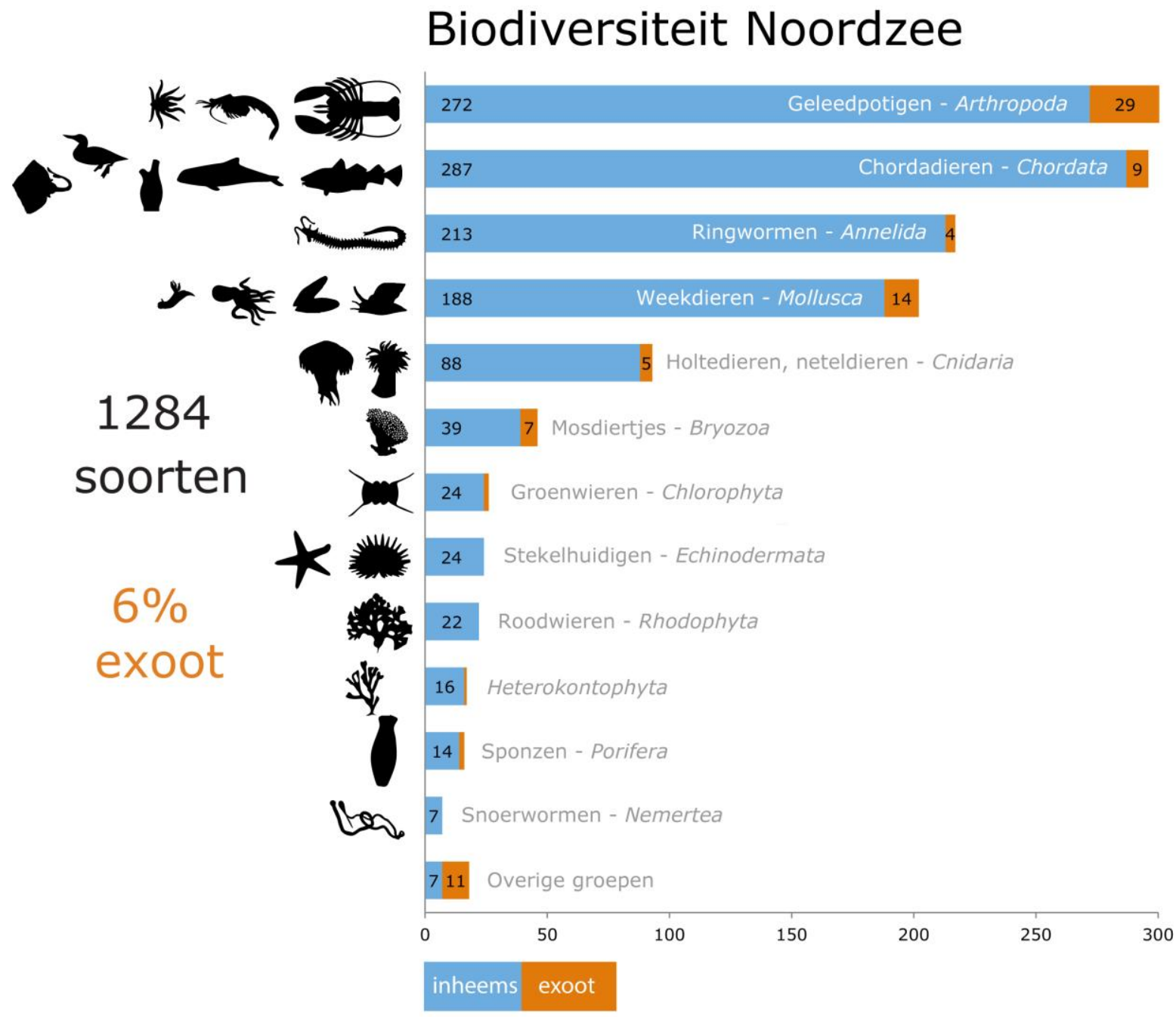

OG Bos - Wageningen Marine Research - Project Soortenlijst Nederlandse Noordzee - BO-11-018.02-066 20/12/2016

Figuur 1. Soortenrijkdom in de Noordzee. 


\section{$1 \quad$ Inleiding}

\subsection{Aanleiding en achtergrond}

Het rijk werkt vanuit internationale en Europese kaders direct en indirect aan behoud en duurzaam gebruik van de van nature aanwezige biodiversiteit van het Nederlandse deel van de Noordzee. De aanleiding om een soortenlijst voor de Nederlandse Noordzee te maken is de behoefte van het ministerie van Economische Zaken om een beter beeld van die biodiversiteit te krijgen en daarnaast om het begrip "Noordzeenatuur" in het beleid over "Bouwen met Noordzee-natuur" te kunnen concretiseren. Het rijk heeft verschillende toekomstbeelden geschetst en beleidsvoornemens geformuleerd voor "Bouwen met Noordzeenatuur" (Ministerie van Economische Zaken 2014, Ministerie van Infrastructuur en Milieu \& Ministerie van Economische Zaken 2014, 2015a en b). Daarbij wordt bij het concept "Bouwen met Noordzee-natuur" gedacht aan combinaties van gebruik van de Noordzee waarbij tegelijk natuurwaarden worden versterkt. Meer specifiek kennen kavelbesluiten voor aankomende windparken inmiddels een voorschrift dat de te versterken "natuurwaarden" al meer afbakent: "De vergunninghouder spant zich aantoonbaar in om het windpark zodanig te ontwerpen en te realiseren dat het park actief bijdraagt aan versterking van een gezonde zee en versterking van behoud en duurzaam gebruik van soorten en habitats die van nature in Nederland voorkomen." (b.v. Ministerie van Economische Zaken 2016). Toegespitst op de Noordzee kan dat laatste worden opgevat als versterking van behoud en duurzaam gebruik van soorten en habitats die van nature in de Nederlandse Noordzee voorkomen. De vraag is nu onder meer wat dan de soorten zijn die van nature in de Nederlandse Noordzee voorkomen.

Daarnaast stelt het kabinet vanuit de EU Kaderrichtlijn Mariene Strategie (KRM) dat een goede Milieutoestand van de Noordzee voor 2020 onder meer impliceert dat de biologische diversiteit wordt behouden en ook dat op het Nederlandse deel van de Noordzee onder meer "exoten" die biodiversiteit bedreigen (Ministerie van Infrastructuur en Milieu \& Ministerie van Economische Zaken, Landbouw \& Innovatie 2012). In OSPAR- en KRM-verband wordt inmiddels gewerkt aan respectievelijk indicatoren en "criteria" met betrekking tot niet-inheemse mariene soorten. Dit roept nu de vraag op welke de niet-inheemse soorten (exoten) zijn van de Nederlandse Noordzee.

Samengevat is er behoefte aan een lijst die zowel aangeeft welke inheemse als niet-inheemse soorten voor de Nederlandse Noordzee zijn vastgesteld. Beoogde doelgroepen zijn beleidsmakers, adviesbureaus, initiatiefnemers en burgers. Een dergelijke lijst is echter ook interessant voor onderzoekers, vrijwilligers zoals sportduikers en strandwachters die zich met monitoring bezig houden, voor natuurorganisaties en voor de beroeps- en sportvisserij.

\subsection{Kennisvraag}

Wat zijn de van nature en de niet van nature voorkomende soorten van de Nederlandse Noordzee (= biodiversiteit in de Nederlandse Noordzee)?

\subsection{Doelstellingen}

- Het opstellen van een lijst van Nederlandse zoutwatersoorten (beperkt tot meercelligen), in het bijzonder voor de Noordzee.

- Het karakteriseren van deze soorten in termen van hun status van voorkomen (oorspronkelijk, exoot, etc.) volgens de codering van Naturalis (zie Tabel 3). 
- Het karakteriseren van de verspreiding van de soorten, voor zover mogelijk, naar (a) habitat (zoet/brak/zout), (b) geografisch deelgebied (offshore/kustzone/Waddenzee/Oosterschelde/ Westerschelde/Voordelta) en (c) sedimenttype (hard/zacht substraat).

- Het online beschikbaar stellen van de soortenlijst via het Nederlands Soortenregister (www.nederlandsesoorten. $\mathrm{nl}$ ) en via het Informatiehuis Marien (www.informatiehuismarien.nl). 


\section{Methoden}

\section{$2.1 \quad$ Aanpak}

Uitgangspunt voor de opgestelde Soortenlijst Nederlandse Noordzee was een in maart 2016 gegenereerde lijst van meercellige soorten die in het door Naturalis Biodiversity Center beheerde Nederlands Soortenregister (NSR) ${ }^{1}$ waren aangemerkt als zout- of brakwatersoorten. De lijst bevatte 1991 soorten. Per soort is in het NSR de volgende informatie weergegeven: de status van voorkomen (oorspronkelijk, exoot, etc.), de habitat (zoet, brak, marien), de bron van de waarneming (referentie) en de naam van de verantwoordelijke expert voor de gegevens van de soort in het NSR. Het bestand biedt geen informatie over in welke Nederlandse zoute wateren (Noordzee, Waddenzee, of andere gebieden) de soorten zijn vastgesteld.

Het NSR, van waaruit de lijst met zout- en brakwatersoorten werd gegenereerd, is in de loop der tijd door experts voor bepaalde soortgroepen opgebouwd en was -voor de zoutwatersoorten- nog niet vergeleken met soortenlijsten vanuit verschillende databases van Wageningen Marine Research (IMARES), Rijkswaterstaat (RWS), en een aantal recente publicaties (rapporten en verspreidingsatlassen).

In dit project is de uit het NSR gegenereerde soortenlijst aangevuld met ontbrekende soorten uit nieuwe bronnen (zie Tabel 1), om zo tot een vollediger lijst te komen voor de Nederlandse Noordzee. Voor de meeste soorten is, op basis van de locatie van bemonstering of op basis van literatuur, ook informatie opgenomen over de zoutwatergebieden waarin de soort is vastgesteld (Noordzee offshore, Noordzeekustzone, Westerschelde, Oosterschelde, Grevelingen, Waddenzee). Voor benthossoorten is waar mogelijk informatie toegevoegd over het sedimenttype (hard/zacht substraat) waaraan de soort gebonden is. Ook is informatie toegevoegd over de habitat (zout/brak/zoet) indien niet aanwezig.

De focus lag op informatie over of soorten in de Noordzee zijn vastgesteld, maar indien een bron ook informatie bevatte over of een soort in andere zoutwatergebieden in Nederland is vastgesteld, is die informatie ook meegenomen. Andersom zijn soortendatabases en -studies die uitsluitend betrekking hadden op zoute wateren anders dan de Noordzee (bv. op de Waddenzee of delta) niet beschouwd.

Fouten bij het vergelijken van soortenlijsten kunnen ontstaan doordat bij veel soorten (meerdere) verschillende wetenschappelijke namen voor een soort worden gebruikt (synoniemen) of doordat soorten onder verkeerd gespelde wetenschappelijke namen in databases staan. Ook komt het voor dat soorten in de loop der jaren gesplitst zijn in meerdere soorten, zijn samengevoegd tot één soort, of verkeerd zijn gedetermineerd, omdat ze op een andere soort lijken. Tussen taxonomen kan verschil in inzicht bestaan in wat de juiste wetenschappelijke naam van een soort is, maar dit lijkt vooral bij terrestrische soorten een probleem te zijn. Voor mariene soorten is het wereldwijd gebruikte World Register of Marine Species (WoRMS) ${ }^{2}$ opgericht om tot een eenduidige geaccepteerde naam per soort te komen.

In dit project is eerst per database, verspreidingsatlas, rapport of andere bron een soortenlijst gemaakt, waar mogelijk aangevuld met informatie uit die bron over de habitat en verspreiding van een soort. Die lijsten per bron zijn vervolgens gecontroleerd met behulp van WoRMS om tot een eenduidige naam per soort te komen met een unieke soortcode (AphiaID). Vervolgens zijn de verschillende soortenlijsten en de NSR-lijst met behulp van een database gecombineerd tot een enkele lijst met de AphiaID-code als verbindend element. Als laatste is de lijst gecontroleerd door een

\footnotetext{
${ }^{1}$ www.nederlandsesoorten. $\mathrm{nl} /$ node/13

${ }^{2}$ www.marinespecies.org
} 
specialist (Arjan Gittenberger, GiMaRIS) om met name vermeldingen van benthossoorten die het vermoedelijke gevolg zijn van onwaarschijnlijke en/of inconsistente determinaties, uit de lijst te halen. 


\subsection{Informatiebronnen}

De soortenlijst voor de Nederlandse Noordzee is opgebouwd uit een basislijst van maart 2016 uit het NSR, aangevuld met soorten uit de bronnen uit Tabel 1. Taxa op een hoger niveau dan soorten (genus, familie, orde, etc.) zijn uitgesloten (bv. Elachista sp., Hippoporina sp., Schizoporella sp.).

Tabel 1. Overzicht gebruikte informatiebronnen om de NSR-soortenlijst van maart 2016 aan te vullen met soorten.

\begin{tabular}{|c|c|c|c|c|}
\hline $\begin{array}{l}\text { Ecosysteem- } \\
\text { component }\end{array}$ & Naam & Type bron & Instituut & Referentie \\
\hline \multirow[t]{9}{*}{ Benthos } & BEAST & database & $\begin{array}{l}\text { Wageningen } \\
\text { Marine Research }\end{array}$ & $\begin{array}{l}\text { Wageningen Marine Research } \\
\text { Database BEAST }\end{array}$ \\
\hline & WOT Schelpdiersurvey & database & $\begin{array}{l}\text { Wageningen } \\
\text { Marine Research }\end{array}$ & $\begin{array}{l}\text { Wageningen Marine Research } \\
\text { Database WOT Schelpdieren }\end{array}$ \\
\hline & Schelpdierenatlas & verspreidingsatlas & St. ANEMOON & De Bruyne et al. (2013) \\
\hline & $\begin{array}{l}\text { Atlas of the Megabenthos } \\
\text { (incl small fish) on the } \\
\text { Dutch Continental Shelf }\end{array}$ & verspreidingsatlas & NIOZ & Witbaard et al. (2013) \\
\hline & $\begin{array}{l}\text { Atlas of the zoobenthos of } \\
\text { the Dutch Continental } \\
\text { Shelf }\end{array}$ & verspreidingsatlas & RWS & Holtmann et al. (1996) \\
\hline & $\begin{array}{l}\text { MWTL (incl. data } \\
\text { Klaverbank survey 2015) }\end{array}$ & databases & RWS & RWS-databases MWTL \\
\hline & $\begin{array}{l}\text { Offshore Windpark } \\
\text { Egmond aan Zee (OWEZ) }\end{array}$ & rapport & $\begin{array}{l}\text { Bureau } \\
\text { Waardenburg; } \\
\text { NIOZ }\end{array}$ & $\begin{array}{l}\text { Bouma \& Lengkeek (2012); } \\
\text { Bergman et al. (2012) }\end{array}$ \\
\hline & Klaverbank & rapport & Ecosub & Van Moorsel (2003) \\
\hline & Losse waarnemingen & $\begin{array}{l}\text { nieuwberichten op } \\
\text { internet }\end{array}$ & $\begin{array}{l}\text { St. Duik de } \\
\text { Noordzee } \\
\text { Schoon/St. } \\
\text { ANEMOON }\end{array}$ & \\
\hline \multirow[t]{2}{*}{$\begin{array}{l}\text { Vogels }+ \\
\text { zeezoogdieren }\end{array}$} & $\begin{array}{l}\text { European Seabirds at Sea } \\
\text { (ESAS) database }\end{array}$ & database & $\begin{array}{l}\text { Wageningen } \\
\text { Marine Research }\end{array}$ & ESAS-database \\
\hline & Waarneming.nl & database & Waarneming.nl & Waarneming.nl \\
\hline
\end{tabular}

\subsubsection{Meercellige algen en wieren}

In het Nederlands Soortenregister (NSR) is een zeer uitgebreide lijst opgenomen van algen en wieren. De onderzochte databases en soortenlijsten bevatten geen extra informatie over deze groep. De oorspronkelijke lijst van het NSR is daarom niet verder aangevuld voor deze groep. 


\subsubsection{Bodemdieren (benthos)}

Aanvullende gegevens over benthossoorten (in dit rapport: bodemdieren behalve vis) zijn uit diverse bronnen afkomstig (Tabel 1). Allereerst is de WOT (Wettelijke Onderzoekstaken) schelpdiersurveydatabase gebruikt. Deze jaarlijkse bemonstering ${ }^{3}$ is opgezet voor bestandsschattingen van commerciële schelpdiersoorten (mossel, kokkel, Spisula sp., Ensis sp.), maar ook alle andere benthossoorten worden gedetermineerd. Een tweede bron is de BEAST-database, waarin losse projectmatige benthosbemonsteringen van Wageningen Marine Research worden opgeslagen, zoals projecten in relatie tot zandsuppleties of zoals de bemonstering van de Borkumse Stenen (Coolen et al. 2015). Verder zijn soortenlijsten uit de MWTL-monitoring van Rijkswaterstaat gebruikt. Het gaat daarbij om niet alleen om de bemonstering van 100 standaardlocaties met een box corer op zacht sediment, maar ook om de bemonstering van de Klaverbank in 2015.

Daarnaast is geput uit verschillende publicaties over monitoring van windparken op de Noordzee (Offshore windpark Egmond aan Zee: Bergman et al. 2012, Bouma \& Lengkeek 2012; Prinses Amalia windpark: Vanagt \& Faasse 2014, Lock et al. 2014) en van wrakken (Lengkeek et al. 2013). Ook de soortenlijst uit een schelpdierenatlas voor het Noordzeegebied (De Bruyne et al. 2013) is verwerkt. In die atlas staat onder meer per soort in een tabel aangeduid in welk Natura 2000-gebied of andere ecologische bijzondere gebieden de soort voorkomt. Daarnaast is voor elke soort een verspreidingskaartje aanwezig. Verder geraadpleegde atlassen met soortenlijsten en verspreidingskaarten zijn de 'Ecologische Atlas Noordzee' (Lindeboom et al. 2008), 'Atlas of the Megabenthos (incl. small fish) on the Dutch Continental Shelf of the North Sea' (Witbaard et al. 2013) en de 'Atlas of the zoobenthos of the Dutch Continental Shelf' (Holtmann et al. 1996). Verder zijn enkele losse waarnemingen toegevoegd (mosdiertjes: Faasse et al. 2016; naaktslakken uit nieuwsberichten ${ }^{4}$ ).

\subsubsection{Vissen}

Aanvullende gegevens over vissoorten zijn allereerst afkomstig uit de database FRISBE van Wageningen Marine Research, waarin de bemonsteringen staan die zijn uitgevoerd aan boord van onderzoeksschepen op zee, evenals bemonsteringen die tijdens commerciële visreizen aan boord van o.a. kotters worden uitgevoerd (Tabel 2). De bemonsteringen zijn gericht op vis, maar ook benthossoorten worden zoveel mogelijk op naam gebracht. Daarnaast is gebruik gemaakt van de internationale gegevens, verzameld door buitenlandse instituten die tijdens de International Bottom Trawl Survey (IBTS) zijn verzameld en die opgeslagen zijn in de ICES-database DATRAS (datras.ices.dk). Tabel 2 toont welke datasets voor deze onderzoeksvraag zijn gebruikt.

De stations van de Noordzeedekkende bemonsteringen zijn geselecteerd op basis van hun ligging in ICES-kwadranten ( 1 lengtegraad x 0.5 breedtegraad) binnen de Nederlandse Noordzee. Sommige van deze vakken steken een beetje uit in buitenlands water, maar het is te verwachten dat het effect daarvan op de soortensamenstelling te verwaarlozen is op de schaal waarop de bemonstering plaats heeft gevonden. Voor de soorten uit de databases FRISBE of DATRAS die nog niet in het NSR voorkwamen en die dus als 'nieuw' zijn aangemerkt is gekeken of ze alleen in precies die randgebieden voorkomen. Als dat zo was, zijn ze niet meegenomen in de selectie. Voor de Noordzeekustzone zijn gegevens uit de Demersal Young Fish Survey (DFS) en garnalenbemonstering aan boord van de kotters gebruikt. Ruimtelijke selectie vond plaats voor de DFS op basis van gebiedscodes, voor de garnalenvisserij op basis van uitsluiting van de Waddenzee. Voor de Oosterschelde, Westerschelde en Waddenzee zijn gegevens uit de DFS gebruikt. De Westerscheldeankerkuilbemonstering vindt alleen plaats in de Westerschelde, de Eems-Dollard ankerkuilbemonstering alleen in de Eems-Dollard (toegevoegd aan Waddenzee), de Project Mainport

\footnotetext{
${ }^{3}$ http://www.wageningenur.nl/nl/Expertises-Dienstverlening/Wettelijke-Onderzoekstaken/Centrum-voor-Visserijonderzoek1/Onderzoek/Schelpdieronderzoek.htm
}

${ }^{4}$ Bv. https://www.naturetoday.com/int//nl/nature-reports/message/?msg=22840 
Rotterdam (PMR) bemonstering heeft plaatsgevonden in de Zuid-Hollandse en Zeeuwse kustzone (toegevoegd aan Kustzone).

Specifieke informatie over bij welke substraten vissoorten werden aangetroffen is niet bekend, maar de visbemonsteringen vinden overwegend plaats op zacht substraat. Daarom zijn benthossoorten (in dit rapport: bodemsoorten behalve vis) uit deze surveys aangemerkt als zacht-substraatsoorten.

Voor de 'nieuw' aangeleverde soorten is de betrouwbaarheid van de identificatie op basis van expert judgement en bekende kanttekeningen (bijv. door ICES-werkgroep voor de International Bottom Trawl Survey (IBTSWG)) getoetst. Bij gerede twijfel over de juiste identificatie, is de soort uit de lijst verwijderd.

De algemene verspreiding van vissoorten is met behulp van een recente visatlas (Heessen et al. 2014) vastgesteld. 
Tabel 2. Geanalyseerde vissurveys binnen de databases van Wageningen Marine Research (FRISBE) en ICES (DATRAS). Records zijn meegenomen indien ze vallen binnen de grenzen van het Nederlands Continentaal Plat (NCP) (i.e. de ICES-rechthoeken die vallen binnen de grens van het NCP). De tijdreeksen omvatten de jaren zoals aangegeven in de tabel.

\begin{tabular}{|c|c|c|c|}
\hline Gebied & Naam & Periode & Metadata records \\
\hline Noordzee (NCP) & Boomkorsurvey (BTS) & 1985-2015 & $\begin{array}{l}\text { www.bodc.ac.uk/data/information_and_inventories/edmed } \\
\text { /report/4801/ }\end{array}$ \\
\hline Noordzee (NCP) & $\begin{array}{l}\text { International Bottom } \\
\text { Trawl Survey (IBTS) }\end{array}$ & $1985-2015$ & $\begin{array}{l}\text { www.bodc.ac.uk/data/information_and_inventories/edmed } \\
\text { /report/4798/ }\end{array}$ \\
\hline $\begin{array}{l}\text { Noordzeekustzone, } \\
\text { Waddenzee, } \\
\text { Oosterschelde, } \\
\text { Westerschelde }\end{array}$ & $\begin{array}{l}\text { Demersal Young Fish } \\
\text { Survey (DFS) }\end{array}$ & $1985-2015$ & $\begin{array}{l}\text { www.bodc.ac.uk/data/information_and_inventories/edmed } \\
\text { /report/4800/ }\end{array}$ \\
\hline Noordzee (NCP) & $\begin{array}{l}\text { Bemonstering aan } \\
\text { boord van } \\
\text { commerciële kotters } \\
\text { (demersaal) }\end{array}$ & $1999-2015$ & $\begin{array}{l}\text { www.bodc.ac.uk/data/information_and_inventories/edmed } \\
\text { /report/4797/ }\end{array}$ \\
\hline $\begin{array}{l}\text { Noordzee }(\mathrm{NCP}) \text {, } \\
\text { Waddenzee }\end{array}$ & $\begin{array}{l}\text { Bemonstering aan } \\
\text { boord van } \\
\text { commerciële kotters } \\
\text { (garnaal) }\end{array}$ & $2008-2015$ & $\begin{array}{l}\text { www.bodc.ac.uk/data/information_and_inventories/edmed } \\
\text { /report/4795/ }\end{array}$ \\
\hline Kustzone & $\begin{array}{l}\text { Bemonstering van } \\
\text { commerciële staand } \\
\text { want visserij }\end{array}$ & & $\begin{array}{l}\text { Geen metadatarecord; de bemonstering omvat het } \\
\text { uitzoeken en doormeten van vangsten op de kustgebonden } \\
\text { staand want visserij. }\end{array}$ \\
\hline Noordzee (NCP) & $\begin{array}{l}\text { Sole Net Survey } \\
\text { (SNS) }\end{array}$ & $1985-2015$ & $\begin{array}{l}\text { www.bodc.ac.uk/data/information_and_inventories/edmed } \\
\text { /report/4799/ }\end{array}$ \\
\hline Westerschelde & $\begin{array}{l}\text { Westerschelde } \\
\text { Ankerkuilvisserij }\end{array}$ & $2007-2015$ & $\begin{array}{l}\text { www.bodc.ac.uk/data/information_and_inventories/edmed } \\
\text { /report/5826/ }\end{array}$ \\
\hline $\begin{array}{l}\text { Eems-Dollard } \\
\text { (Waddenzee) }\end{array}$ & $\begin{array}{l}\text { Eems-Dollard } \\
\text { Ankerkuilvisserij }\end{array}$ & $2007-2015$ & $\begin{array}{l}\text { geen metadatarecord, bemonstering uitgevoerd door } \\
\text { Bioconsult; }\end{array}$ \\
\hline $\begin{array}{l}\text { Kustzone Zuid- } \\
\text { Holland/Zeeland }\end{array}$ & $\begin{array}{l}\text { Bemonstering PMR } \\
\text { Maasvlakte }\end{array}$ & $\begin{array}{l}2004-2007 ; \\
2009-2013 ; \\
2015\end{array}$ & $\begin{array}{l}\text { www.bodc.ac.uk/data/information_and_inventories/edmed } \\
\text { /report/5834/ }\end{array}$ \\
\hline
\end{tabular}

$\mathrm{Na}$ vergelijking van de soortenlijsten uit bovenstaande datasets met de gegenereerde NSR-lijst bleek dat een aantal vissoorten niet op de NSR-lijst stonden. Wel stonden ze in het NSR zelf, maar dan alleen als voorkomend in 'zoet'. (Naturalis heeft de habitat-categorieën 'zout' en 'brak' inmiddels aan het NSR toegevoegd.)

\subsubsection{Zeezoogdieren}

Voor zeezoogdieren zijn soortenlijsten geanalyseerd uit de bruinvisdatabase (luchttellingen) van Wageningen Marine Research en de ESAS-database (zie ook hieronder) (Tabel 1). Voor zeezoogdieren bleek de NSR-lijst al compleet te zijn. NB. De zeezoogdieren zijn nog niet opgenomen als 'voorkomend in de Noordzee' (zie 2.6) door de focus op andere diergroepen.

\subsubsection{Vogels}

Voor vogelwaarnemingen is geput uit de database European Seabirds At Sea (ESAS), een internationale database waarin data van verschillende projecten van Wageningen Marine Research rondom zeevogelmonitoring verzameld zijn. ESAS is een samenwerkingsverband tussen verschillende landen die aan de Noordzee grenzen en die surveys uitvoeren op de Noordzee. De data worden gezamenlijk in een database opgeslagen. Voor de soorten zijn op basis van coördinaten de surveys geselecteerd die op het NCP zijn uitgevoerd. De surveys zijn zowel vanuit het vliegtuig als vanuit een schip uitgevoerd en gemonitord worden de vogels, zeezoogdieren en zo mogelijk vissen. Voor Wageningen Marine Research zijn de beheerders Mardik Leopold, Jenny Cremer en Jan Tjalling van de Wal.

Ook is de gegenereerde NSR-lijst vergeleken met de waarnemingen aanwezig in www.waarneming.nl. Er zijn veel vogelsoorten die op hun trektocht over of langs de Noordzee vliegen, maar die geen echte zeevogels zijn. In dit rapport worden alleen die soorten meegenomen die daadwerkelijk afhankelijk zijn van de zee. De lijst is daartoe gecheckt door een specialist (G. Keijl, Naturalis Biodiversity 
Center). De vergelijking van de bovengenoemde databases met de gegenereerde NSR-lijst leverde geen aanvullende soorten op. Wel is aan een aantal soorten uit de bestaande NSR-lijst van 93 vogelsoorten de habitat 'marien' toegekend, waardoor het totaal aantal zout- en brakwater vogelsoorten in het NSR is toegenomen tot 110 soorten. 


\subsection{Kenmerken per soort}

Aan de in dit rapport opgestelde soortenlijst zijn de volgende kenmerken per soort toegekend, die in onderstaande paragrafen worden uitgelegd:

Status voorkomen: "oorspronkelijk" (gedifferentieerd naar 1, 1a, of $1 \mathrm{~b}$ ) of "exoot" (met onderverdeling $2 a, 2 b, 2 c$, of $2 d$ ) of overig (categorie 3 of 4 ), of "te beoordelen" $(0,0 a)$ volgens de codering van het NSR.

Habitat: (zoet/brak/marien). De meeste soorten zijn exclusief marien, maar een aantal ook brak en/of zoet.

Verspreiding: in welke onderscheiden geografische deelgebieden is een soort vastgesteld: Noordzeekustzone (0-20 m), Noordzee offshore (20-60 m), Noordzee totaal (kustzone + offshore: 0$60 \mathrm{~m}$ diepte), Waddenzee, Westerschelde, Oosterschelde, Grevelingen. Er is een indeling gemaakt die vanuit biologisch perspectief en vanuit het beleid betekenisvol is.

Substraat: (hard/zacht): Alleen voor bodemsoorten (benthos). Of een benthische soort op hard of zacht substraat voorkomt, is van belang voor een deel van de beleidsinspanningen die daar expliciet op is gericht (bv. natuurinclusief bouwen m.b.t. de funderingen van windparken).

Taxonomie: De taxonomische indeling per soort is weergegeven op een drietal manieren: zoals gehanteerd door het NSR, door WoRMS ${ }^{2}$ en door Noordijk et al. (2010a). De soortnaam die als juist wordt beschouwd is die conform WoRMS. Synoniemen uit overige bronnen zijn ook genoemd. De Nederlandse soortnaam is weergegeven conform het NSR, St. Anemoon en het Zeeboek (Van der Mark et al. 2014).

Beleidsstatus: Per soort is weergeven of de soort valt onder een bijlage (II, IV, V) van de Habitatrichtlijn (HR) of onder art. 12 of bijlage I van de Vogelrichtlijn; of er Natura 2000-gebieden voor de soort zijn aangewezen ( 6 gebieden); of de soort een "typische soort" is voor habitattypen ( 8 hoofdtypen) conform de HR; of de soort een "indicatorsoort" is voor habitatcategorieën (6 categorieën) conform de Kaderrichtlijn Mariene Strategie; of de soort onder een beleidsplan valt ( 3 categorieën); of de soort op de OSPAR-lijst van bedreigde soorten en habitats staat; of de soort op een nationale rode lijst staat (i.e. voor zoogdieren of vissen; 5 categorieën).

\subsection{Status voorkomen}

Voor de status van het voorkomen worden door Naturalis en in dit rapport de onderstaande categorieën gehanteerd (Tabel 3). De in de gegenereerde NSR-lijst aanwezige soorten waren in het verleden al van een status van voorkomen voorzien. De ontbrekende statussen van aanvullende soorten zijn toegekend door een specialist (A. Gittenberger, GiMaRIS) op basis van literatuuronderzoek en expert-judgement.

De lijst die in dit rapport is opgesteld met Nederlandse mariene soorten, inclusief voor de Noordzee, bestaat uit soorten uit de NSR-categorieën $0 a, 1,1 a, 1 b, 2,2 a, 2 b$ en 2c. De overige soorten (NSRcategorieën $0,2 d, 3 a, 3 b, 3 c, 3 d$ en 4 ) vallen daarbuiten. 
Tabel 3. Overzicht gebruikte categorieën van voorkomen van soorten (bron: Nederlands Soortenregister (http://www.nederlandsesoorten.nl/node/15)).

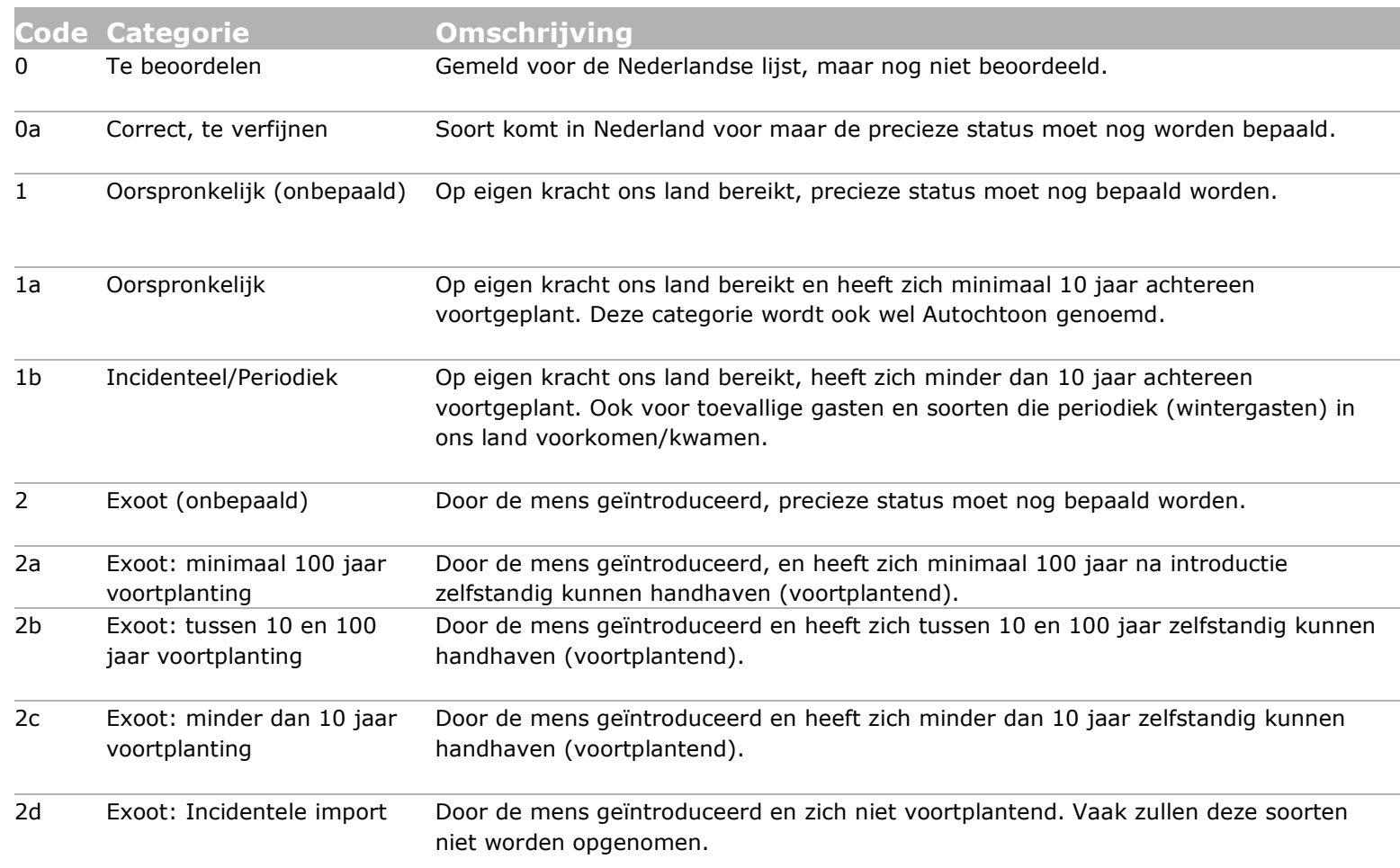

NB. Voor langlevende soorten als bomen alleen 2a Ingeburgerd (min. drie generaties, 3 locaties) en $2 c$ en $2 d$. Criteria NHN.

3a Onvoldoende gegevens

Gemeld voor Nederland, maar de status is onduidelijk. Bijvoorbeeld namen zonder adequate bronvermelding, incidentele waarnemingen waaraan geen interpretatie te geven is of in de literatuur vermelde twijfelachtige vondsten waarvan geen bewijsmateriaal bewaard is gebleven. Uitleg in opmerkingenveld.

\begin{tabular}{lll}
\hline 3b Onterecht gemeld & $\begin{array}{l}\text { Gemeld voor Nederland, maar onterecht, bijvoorbeeld als gevolg van een } \\
\text { determinatiefout. }\end{array}$ \\
\hline 3c $\quad$ Verwacht & $\begin{array}{l}\text { Is niet gemeld voor Nederland, maar komt er mogelijk wel voor (of kan er op korte } \\
\text { termijn terecht komen) op basis van waarnemingen in het buitenland. }\end{array}$ \\
\hline 3d $\quad$ Auct & $\begin{array}{l}\text { Onterecht gebruikte naam, bijvoorbeeld als gevolg van een fout in een } \\
\text { determinatietabel (auct nec - gevallen). Alleen voor soorten die niet in Nederland } \\
\text { voorkomen. Indien bekend is dat de naam voor Nederland is gemeld, dan wordt } 3 b \\
\text { gekozen. In opmerkingenveld wordt aangeven welke soort bedoeld werd. }\end{array}$
\end{tabular}
andere reden toch wenselijk is dat ze worden opgenomen. 


\subsection{Taxonomie en soortnamen}

In de soortenlijst is de wetenschappelijke indeling per soort opgenomen (1) zoals gehanteerd door het NSR, (2) zoals gegenereerd door WoRMS en (3) zoals gehanteerd door een standaardwerk over de Nederlandse biodiversiteit (Noordijk et al. 2010a). Verder wordt als de juiste wetenschappelijke soortnaam gehanteerd de soortnaam conform WoRMS. Ook zijn synoniemen van wetenschappelijke namen uit de verschillende bronnen weergegeven. Nederlandse soortnamen zijn afkomstig uit het NSR, Stichting ANEMOON (De Bruyne et al., 2013) en het Zeeboek (Van der Mark et al. 2014).

\section{$2.6 \quad$ Verspreiding}

De onderscheiden geografische deelgebieden waarin een soort kan zijn vastgesteld zijn: Noordzeekustzone (0-20 m), Noordzee offshore (> $20 \mathrm{~m})$, Noordzee totaal (kustzone + offshore), Waddenzee, Westerschelde, Oosterschelde en Grevelingen (Figuur 2). Deze indeling is heel grofschalig en is niet gebaseerd op strikte dieptelijnen.

In welke gebieden soorten zijn vastgesteld is bepaald op basis van de informatie in gebruikte datasets, verspreidingsatlassen en literatuur (Tabel 4). Bij een aantal datasets is er binnen de dataset onderscheid gemaakt in verschillende gebieden zoals bij de WOT-schelpdiersurvey en de vissurveys. Andere datasets zijn afkomstig van een enkele locatie, zoals een offshorewindpark of een bepaald gebied. Een voorbeeld: soorten gerapporteerd voor de Klaverbank zijn in ieder geval Noordzeeoffshore-soorten. In het Excel-bestand (zie paragraaf 2.10) staat de informatie per dataset in detail weergegeven.

$\mathrm{Na}$ deze eerste toekenning aan gebieden bleven honderden soorten over waarvoor niet kon worden bepaald in welke zoute wateren ze waren vastgesteld. Dit gaat om soorten die oorspronkelijk al in het NSR stonden. Voor deze resterende soorten is vervolgens de bron zoals genoemd in het Nederlands Soortenregister (NSR) opgezocht waarin de verspreiding van de soort beschreven staat. Dit zijn veelal determinatiegidsen en overzichtsartikelen (checklists) van soortengroepen (Tabel 4).

Een voorbeeld: voor algen en wieren zijn de gebieden waarin de soorten zijn vastgesteld bepaald op basis van tekst uit de "Flora van de Nederlandse Zeewieren" van Stegenga \& Mol (1983). Voor deze groep specifiek geldt dat veel soortnamen en ook de taxonomie zelf in de loop der tijd sterk veranderd zijn, waardoor het matchen van de huidige soortnaam met die uit het boek zelf tijdrovend werk is. Een specifiek probleem met wieren en algen is dat er vaak slechts enkele waarnemingen bekend zijn, dat determinatie moeilijk is, en dat ze vaak aanspoelen vanuit andere landen. Voor elk van de soorten is de vindplaats omgezet in een gebied. De beschrijvingen van de vindplaatsen in deze literatuur zijn meestal specifiek (bv. "oesterputten van Yerseke" of "haven van Terschelling") maar ook vaak veel algemener (bv. "laag eulitoraal, niet zeldzaam in meer geëxponeerde gebieden"). Beide typen omschrijvingen zijn vertaald naar een indeling in bovengenoemde gebieden. Dit is gedocumenteerd in een apart Excel-bestand, dat later is gecombineerd met de soortenlijst via MS Access.

Aan-/afwezigheid verspreidingsdata: Per soort is per bron (data of literatuur) weergeven of de soort aanwezig (1), afwezig (0) was, of dat er geen data was. Als de soort in geen enkele databron een 0 of 1 scoort, mist er nog verspreidingsinformatie, en is er geen data beschikbaar.

Aan/afwezigheid soort per gebied: Om de aanwezigheid van een soort in een gebied vast te stellen, is per soort per gebied gecontroleerd of de optelsom van de waarden vanuit de verschillende bronnen groter was dan 1 (zie Excel-bestand, paragraaf 2.10). Hierbij geldt: optelsom > 1: soort aanwezig; optelsom 0 of geen data beschikbaar: soort is afwezig. 


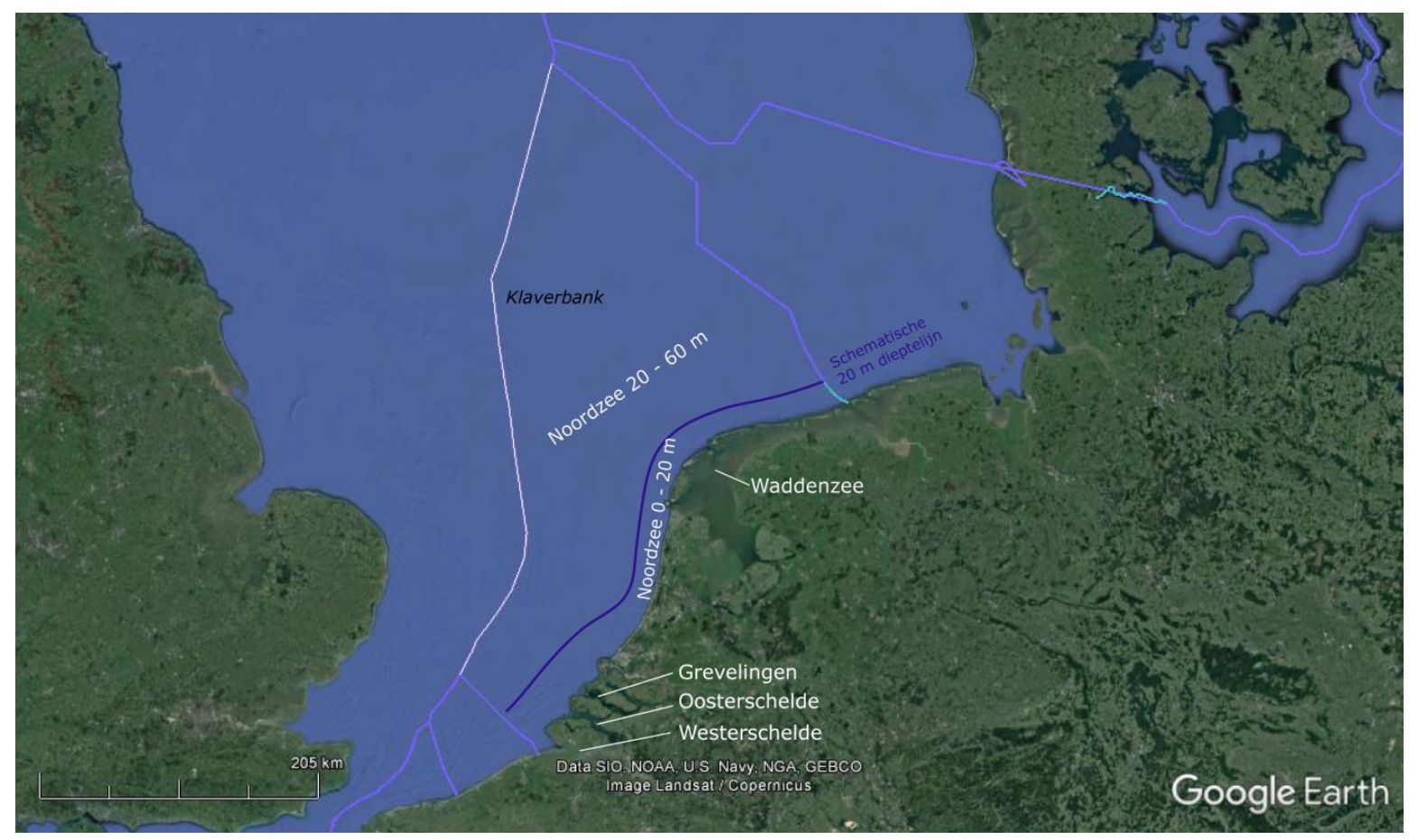

Figuur 2. Overzichtskaart van de Nederlandse Noordzee met gebieden waarnaar de soorten in dit rapport zijn ingedeeld (in witte letters): Noordzee, Noordzeekustzone (0-20 m), Noordzee offshore (20-60 m), Waddenzee, Westerschelde, Oosterschelde en Grevelingen (bron kaart: Google Earth).

Tabel 4. Overzicht van aanvullende literatuur gebruikt voor het vaststellen van verspreiding van soorten. Dit betreft voornamelijk literatuur zoals ook door het NSR gebruikt.

\begin{tabular}{ll}
\hline Algen/wieren & Stegenga \& Mol (1983) \\
\hline Sponzen & Van Soest et al. (1997, 2007); Henkel \& Janussen (2011) \\
\hline Hydroidpoliepen & Vervoort \& Faasse (2009) \\
\hline Mosdiertjes & Faasse et al. (2013, 2016), Faasse \& De Blauwe (2004) \\
\hline Zeespinnen & Wolff (1976) \\
\hline Zeemijten & Bartsch \& Smit (2006) \\
\hline Vlokreeftjes & Faasse \& Stikvoort (2002), Faasse \& Van Moorsel (2000) \\
\hline Pissebedden & Huwae \& Rappe (2003) \\
\hline Krabben en kreeften & Holthuis \& Herebout (1986) \\
\hline Vissen & Nijssen \& De Groot (1987); Sportvisserij Nederland (2009) \\
\hline Walvissen/dolfijnen & Van der Meij \& Camphuysen (2006); Camphuysen \& Peet (2006) \\
\hline Schildpadden & Brongersma (1972)
\end{tabular}




\subsection{Habitat (zoet/brak/marien)}

$\mathrm{Er}$ is in beperkte mate gecontroleerd of de soorten van de gegenereerde NSR-lijst een juiste habitataanduiding hadden. Bij de nieuw toegevoegde soorten is de habitat 'marien' standaard toegekend. Een aantal trekvissoorten stond ten onrechte niet in de gegeneerde NSR-lijst omdat ze als voorkomend in de habitat 'zoet' waren gekarakteriseerd, maar niet in 'brak' en/of 'marien'. (De betreffende records zijn in het NSR inmiddels daarvoor gecorrigeerd.) De visdatabases bevatten een aantal records van zoetwatervissen in zout water, die terecht niet vervolgens als 'zout' aangemerkt zijn in het NSR. Als de spuisluizen van de Afsluitdijk worden opengezet kunnen zoetwatervissen namelijk naar de Waddenzee uitspoelen. Ook in de ESAS-zeevogeldatabase staan veel waarnemingen van soorten die op zee gezien zijn, maar die niet tot de echte zeevogels behoren omdat ze slechts overvliegen of migreren. De vogelsoorten zelf en de habitats van de vogelsoorten zijn in dit project door een specialist herzien (G. Keijl, Naturalis). De vogelsoorten met als habitat 'marien' zijn meegenomen als soorten voor de Noordzeesoortenlijst. Er worden geen resultaten gepresenteerd over het toekende habitat, omdat aan elke soort in principe de habitat 'marien' is toegekend en niet gecontroleerd is of de soort ook in brak of zoet water voorkomt (behalve voor de vogels).

\subsection{Substraat (hard/zacht)}

Voor bodemsoorten (behalve vis) is tevens het type substraat (hard/zacht) waaraan de soorten zijn gebonden aangeduid. Dit is afgeleid uit locaties van de surveys waarin de soort is aangetroffen ( Tabel 5) en zou daarom fouten kunnen bevatten (bv. zachtsubstraatsoorten die, omdat ze bij de Klaverbank zijn waargenomen, als hardsubstraatsoorten zijn aangeduid). Er is hierbij dus niet naar de biologie van de soorten gekeken. 
Tabel 5. Overzicht datasets en hun ruimtelijke dekking en type substraat (zie ook Tabel 1). Bijvoorbeeld, de MWTL-Noordzee database van Rijkswaterstaat bevat benthosdata van 100 locaties verspreid op niet-stenig substraat in de Noordzee. Daarom zegt deze dataset iets over de verspreiding van soorten in het gebied 'NL Noordzee $(0-60 \mathrm{~m})$ ', en over het substraat 'zacht substraat'. NA = geen onderscheid mogelijk tussen substraten op basis van de data/literatuurbron. Het Offshore windpark Egmond aan Zee (OWEZ) en het Prinses Amalia windpark (PAWP) staan op de grens tussen kustzone en diepere Noordzee en worden hier tot beide gerekend. De soorten in de Grevelingen zijn alleen op basis van aanvullende literatuur vastgesteld (Tabel 4 ).

\begin{tabular}{|c|c|c|c|c|c|c|c|c|c|c|}
\hline & 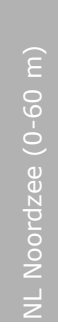 & 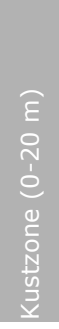 & 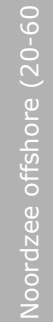 & $\begin{array}{l}0 \\
d \\
N \\
\frac{1}{0} \\
\frac{0}{0} \\
\frac{\pi}{0} \\
3\end{array}$ & 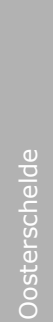 & $\begin{array}{l}\frac{0}{0} \\
\frac{0}{d} \\
\frac{5}{u} \\
\frac{1}{d} \\
\frac{d}{4} \\
\frac{1}{3}\end{array}$ & 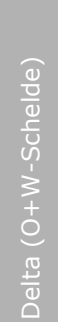 & 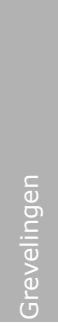 & 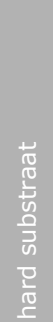 & 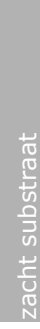 \\
\hline $\begin{array}{l}\text { BEAST-database van Wageningen Marine Research (geraadpleegd in } \\
\text { maart 2016) }\end{array}$ & $\mathrm{x}$ & - & - & - & - & - & - & - & $\mathrm{x}$ & $\mathrm{x}$ \\
\hline $\begin{array}{l}\text { Frisbee-database van Wageningen Marine Research (geraadpleegd in } \\
\text { maart 2016) }\end{array}$ & $\mathrm{x}$ & $\mathrm{x}$ & $\mathrm{x}$ & $\mathrm{x}$ & $\mathrm{x}$ & $\mathrm{x}$ & $\mathrm{x}$ & - & - & $\mathrm{x}$ \\
\hline DATRAS-database van ICES (geraadpleegd in maart 2016) & $\mathrm{x}$ & - & $\mathrm{x}$ & - & - & - & - & - & - & $x$ \\
\hline $\begin{array}{l}\text { Schelpdierdatabase van Wageningen Marine Research (geraadpleegd in } \\
\text { maart 2016) }\end{array}$ & $x$ & $x$ & - & $x$ & - & - & $x$ & - & $x$ & - \\
\hline $\begin{array}{l}\text { ESAS-database van Wageningen Marine Research (geraadpleegd in } \\
\text { maart 2016) }\end{array}$ & $x$ & - & - & - & - & - & - & - & - & - \\
\hline $\begin{array}{l}\text { RWS_Klaverbank_2015 (voorlopige resultaten Klaverbank survey in } \\
\text { 2015) }\end{array}$ & $x$ & - & $x$ & - & - & - & - & - & $x$ & - \\
\hline MWTL-database van Rijkswaterstaat & $x$ & - & - & - & - & - & - & - & - & $\mathrm{x}$ \\
\hline Van Moorsel (2003) (rapport over Klaverbank-soorten) & $x$ & - & $\mathrm{x}$ & - & - & - & - & - & $\mathrm{x}$ & - \\
\hline De Bruyne et al. (2013) (schelpdierenatlas Noordzeegebied) & $\mathrm{x}$ & $x$ & $\mathrm{x}$ & $\mathrm{x}$ & $x$ & $\mathrm{x}$ & $x$ & - & - & $x$ \\
\hline Lindeboom et al. (2008) (Ecologische atlas Noordzee) & $x$ & $x$ & $\mathrm{x}$ & - & - & - & - & - & - & $\mathrm{x}$ \\
\hline $\begin{array}{l}\text { Lengkeek et al. (2013) (rapport over soorten op scheepswrakken op } \\
\text { het Nederlands Continentaal Plat) }\end{array}$ & $\mathrm{x}$ & - & - & - & - & - & - & - & $\mathrm{x}$ & - \\
\hline Heessen et al. (2014) (visatlas Noordzee en Baltische zee) & $x$ & $x$ & $\mathrm{x}$ & - & - & - & - & - & - & $\mathrm{x}$ \\
\hline Vanagt \& Faasse (2014) (rapport over hardsubstraatfauna PAWP) & $x$ & $x$ & $x$ & - & - & - & - & - & $\mathrm{x}$ & - \\
\hline Lock et al. (2014) (rapport over zachtsubstraatfauna PAWP) & $\mathrm{x}$ & $\mathrm{x}$ & $\mathrm{x}$ & - & - & - & - & - & - & $\mathrm{x}$ \\
\hline Bergman et al. (2012) (rapport over macrobenthossoorten OWEZ) & $\mathrm{x}$ & $\mathrm{x}$ & - & - & - & - & - & - & - & $\mathrm{x}$ \\
\hline Bouma \& Lengkeek (2012) (rapport over hardsubstraatsoorten OWEZ & $x$ & $x$ & - & - & - & - & - & - & $x$ & - \\
\hline $\begin{array}{l}\text { Witbaard et al. (2013) (megabenthos-atlas Nederlands Continentaal } \\
\text { Plat) }\end{array}$ & $x$ & $x$ & $x$ & - & - & - & - & - & - & $x$ \\
\hline $\begin{array}{l}\text { Gittenberger et al. (2015) (rapport over inheemse en uitheemse } \\
\text { soorten in de Nederlandse Waddenzee) }\end{array}$ & - & - & - & $x$ & - & - & - & - & NA & NA \\
\hline
\end{tabular}




\section{$2.9 \quad$ Beleidsstatus}

Informatie over de beleidsmatige status per soort en diverse bijbehorende bronnen is aangeleverd door het Ministerie van Economische Zaken (E. Knegtering) en tezamen met een enkele aanvullende bron uit de online EZ-database "soorten en gebieden in wetgeving en beleid" verwerkt tot een aantal deellijsten (zie Bijlage 2 met soortenlijsten en referenties; aan de lijsten kunnen geen rechten worden ontleend).

\subsection{Definitie 'Soortenlijst'}

In dit rapport wordt bedoeld met "de soortenlijst": de in dit rapport opgestelde lijst (i.e. de gegenereerde NSR-lijst met aanvullingen) met soorten van zout of brak water die periodiek of incidenteel voorkomen van zowel oorspronkelijke soorten als exoten. Hierbij is aangehouden:

- Periodiek of incidenteel aanwezig: alle soorten in de NSR-categorieën 0a, 1, 1a, 1b, 2a, 2b, 2c.

- $\quad$ Periodiek aanwezig: alle soorten in de NSR-categorie 1, 1a, 2a, 2b, 2c Incidenteel aanwezig: alle soorten in de NSR-categorie $1 \mathrm{~b}$

De Noordzee-soortenlijst is een selectie uit de gehele Nederlandse zout- en brakwatersoortenlijst en kan worden gemaakt door als geografisch deelgebied te kiezen: Noordzee $(0-60 \mathrm{~m})$.

In Bijlage 1 is de soortenlijst opgenomen, met een beperkt aantal velden. In het Excel-bestand behorende bij dit rapport is alle basisinformatie opgenomen die ten grondslag ligt aan de informatie in de soortenlijst. 


\subsection{Soortenlijsten}

De Noordzeesoortenlijst is in beknopte vorm weergeven in Bijlage 1. De vogels zijn uit praktisch oogpunt in de resultaten apart weergegeven, omdat ze als aparte lijst zijn aangeleverd in het begin van het project. De beleidssoorten zijn weergegeven in Bijlage 2. Via het Nederlands Soortenregister (www.nederlandsesoorten. $\mathrm{nl}$ ) is de soortenlijst interactief te raadplegen. Via het Informatiehuis Marien (www.informatiehuismarien.nl) zijn dit rapport en de soortenlijst als PDF beschikbaar. Een uitgebreide versie van de soortenlijst, met per soort detailinformatie over in welke database en in welke literatuur de soort voorkomt, is online als Excel-bestand beschikbaar (Wageningse bibliotheek en Researchgate).

\subsection{Aantallen soorten}

Zout- en brakwatersoorten

Door Naturalis is in maart 2016 een lijst van 1991 zout- en brakwatersoorten (inclusief 93 soorten vogels) gegenereerd uit het Nederlands Soortenregister (NSR). Hiervan werden 1583 soorten (incl. alle vogelsoorten) beschouwd als aanwezig (NSR-categorieën 0a, 1, 1a, 1b, 2a, 2b, 2c) en vielen 357 soorten in een van de andere NSR-categorieën (0, 2d, 3 en 4).

In dit rapport is de lijst van maart 2016 aangevuld met 233 soorten (incl 17 vogelsoorten), waarmee het totaal aantal zout- en brakwatersoorten op de totaallijst komt op 2224 soorten incl. 110 vogelsoorten (categorieën $0,1,2,3,4$ en alle subcategorieën daaronder).

Van de 2224 zout- en brakwatersoorten worden in totaal 1909 soorten (86\%) (incl. 109 vogelsoorten) beschouwd als aanwezig (NSR-categorieën 0a, 1, 1a, 1b, 2a, 2b, 2c en alle vogelsoorten) en de rest als afwezig (categorieën 0, 2d,3a, 3b, 3c, 3d en 4). Deze 1909 soorten vormen de nadere uitgangsverzameling in dit onderzoek. De incidentele exoten (2d: geïntroduceerd, zich niet voortplantend) worden niet meegeteld, omdat ze vaak niet in het NSR worden opgenomen (zie Tabel 3). In totaal is aan 1648 zout- en brakwatersoorten een locatie toegekend en aan 261 soorten nog niet (NSR-categorieën 0a, 1, 1a, 1b, 2a, 2b, 2c) (zie verder paragraaf 3.4 'Verspreiding').

\section{Noordzeesoorten}

De Noordzeesoortenlijst bestaat uit de lijst met soorten waarvoor als verspreidingsgebied de Noordzee kon worden toegekend aan de hand van databases en literatuur (zie 2.6). Aan 1284 soorten (incl. 108 vogelsoorten) van bovenstaande 2224 soorten is het gebied Noordzee toegekend (NSRcategorieën $0 a, 1,1 a, 1 b, 2 a, 2 b, 2 c$ en 108 vogelsoorten met als habitat'marien'(Tabel 8).

Nieuwe soorten in dit rapport ten opzichte van gegenereerde NSR-lijst uit maart 2016

De 'nieuwe' soorten op de in dit rapport opgestelde lijst zijn vooral bodemdieren (excl. vissen). De oorspronkelijke NSR-lijst was al geheel bijgewerkt voor de zeezoogdiersoorten, is herzien en aangevuld voor de vogelsoorten en bijna geheel bijgewerkt voor de vissoorten. Een aantal eencelligen is van de oorspronkelijke NSR-lijst verwijderd.

Nederlandse namen: Voor circa 49\% van de 1909 zout- en brakwatersoorten (incl. vogels) is een Nederlandse naam beschikbaar. Voor de Noordzeesoorten is dit $51 \%$ van de 1284 soorten.

\section{Soortenrijkdom fyla}

De vier meest soortenrijke fyla binnen de zout- en brakwatersoorten die meer dan de helft van de totale soortenrijkdom omvatten zijn de geleedpotigen (Arthropoda) met 414 soorten, chordadieren (Chordata) met 313 soorten (incl. vogels), weekdieren (Mollusca) met 296 soorten, en de ringwormen 
(Annelida) met 254 soorten. Voor de Noordzeesoorten zijn dit dezelfde groepen: Geleedpotigen (Arthropoda) met 303 soorten, chordadieren (Chordata) met 296 soorten (incl. vogels), de ringwormen (Annelida) met 218 soorten en de weekdieren (Mollusca) met 202 soorten (Tabel 6).

Tabel 6. Soortenrijkdom per fylum met de meest soortenrijke klassen voor het totaal aan mariene soorten en voor de Noordzee (cat. voorkomen 0a, 1, 1a, 1b, 2, 2a, 2b, 2c, zie Tabel 3).

\begin{tabular}{lrr} 
Fylum & Zout- en brakwatersoorten & Noordzeesoorten \\
Geleedpotigen - Arthropoda & 418 & 303 \\
\hline Chordadieren - Chordata & 313 & 296 \\
\hline Weekdieren - Mollusca & 296 & 202 \\
\hline Ringwormen - Annelida & 254 & 218 \\
\hline Holtedieren, neteldieren - Cnidaria & 142 & 93 \\
\hline Roodwieren - Rhodophyta & 140 & 22 \\
\hline Heterokontophyta & 83 & 17 \\
\hline Mosdiertjes - Bryozoa & 68 & 46 \\
\hline Groenwieren - Chlorophyta & 54 & 26 \\
\hline Sponzen - Porifera & 30 & 16 \\
\hline Nematoden - Nematoda & 28 & 2 \\
\hline Stekelhuidigen - Echinodermata & 25 & 24 \\
\hline Snoerwormen - Nemertea & 21 & 7 \\
\hline
\end{tabular}




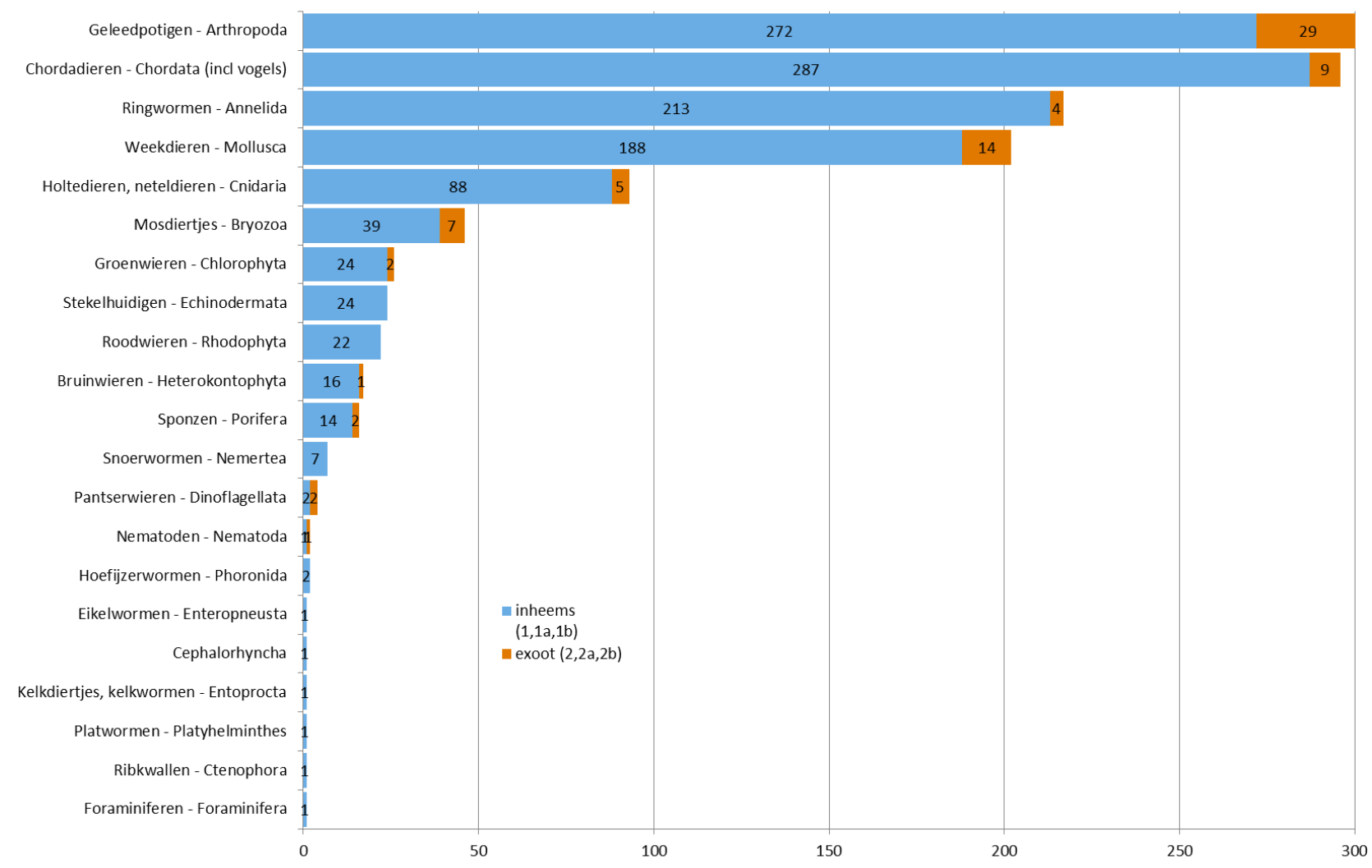

Figuur 3. Totale aantallen Noordzeesoorten per fylum (oorspronkelijk: NSR categorieën 1, 1a,1b; exoot: 2, 2a, 2b, 2c, zie Tabel 3)

\subsection{Exoten}

Zout- en brakwatersoorten (alle gebieden; NSR-categorieën 0a, 1, 1a, 1b, 2, 2a, 2b, 2c)

Het totaal aantal zout- en brakwatersoorten in de Nederlandse zoute wateren is 1909 . Hiervan is circa $8 \%$ exoot (147 soorten). Geen van de vogelsoorten uit de gegenereerde NSR-lijst is exoot. In Figuur 3 is het aantal exoten per fylum aangegeven voor alle zout- en brakwatersoorten tezamen. In aantallen soorten dragen vooral de geleedpotigen (43 soorten), weekdieren ( 21 soorten) en ringwormen (15 soorten), mosdiertjes (13 soorten) en chordadieren (13 soorten) (Tabel 7).

In het NSR heeft elke exoot een zogeheten exotenpaspoort, waarin meer informatie over de verspreiding, de vector en moment van introductie staat. Binnen dit project is voor de aanvullende soorten exoten, die niet op de gegenereerde NSR-lijst stonden, ook een paspoort aangemaakt. De informatie uit deze paspoorten is inmiddels opgenomen in het NSR en wordt in dit rapport verder niet behandeld.

Noordzeesoorten (NSR-categorieën 0a, 1, 1a, 1b, 2, 2a, 2b, 2c)

Het totaal aantal Noordzeesoorten is 1284 , waarvan 76 soorten exoot (ca. 6\%). Geen van de vogelsoorten is exoot. In aantallen soorten dragen vooral de geleedpotigen (29 soorten), weekdieren (14 soorten), mosdiertjes (7 soorten) en chordadieren (9 soorten) (Tabel 8). 


\subsection{Verspreiding}

In Tabel 7 is het aantal soorten per zoutwatergebied weergegeven (excl. vogels). Indien bij toekenning van het gebied de Noordzee aan een soort geen nadere specificatie mogelijk was, is voor gehele Noordzee gekozen (Noordzee $(0-60 \mathrm{~m}$ ) (zie ook 2.6). Voor vogels is geen poging gedaan ze aan gebieden toe te kennen. Vogels waaraan de habitat 'marien' is toekend (109 van de 110 soorten) zijn beschouwd als Noordzeesoorten.

Van de 1909 zout -en brakwatersoorten (NSR categorieën 0a, 1, 1a, 1b, 2, 2a, 2b, 2c) is voor 1648 $(86 \%)$ soorten (incl. vogels) de locatie vastgesteld op basis van data en/of literatuuronderzoek. Voor 261 soorten is nog geen locatie vastgesteld (maar dit kan alsnog d.m.v. literatuuronderzoek) (Tabel $7)$.

Van de lijst van 1909 zout- en brakwatersoorten zijn 1284 soorten (67\%) vastgesteld voor de Noordzee. De aantallen soorten voor de andere zoute gebieden staan in Tabel 7. Omdat de focus in dit rapport ligt bij de Noordzee, zullen de lijsten voor de overige zoute gebieden minder compleet zijn (zie paragraaf 2.6). 


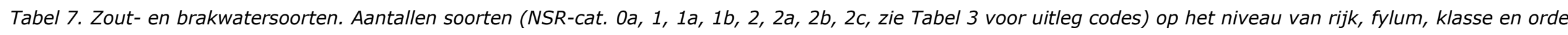

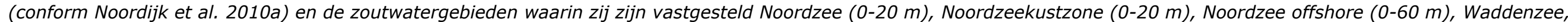

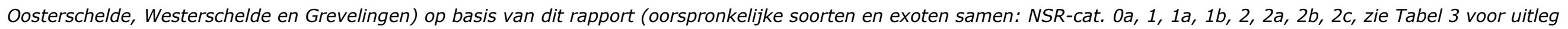
codes). Data afwezig: (nog) geen data gevonden voor verspreiding. Data aanwezig: data aanwezig voor verspreiding. Donkergrijs: rijk. Lichtgrijs: fylum.

\begin{tabular}{|c|c|c|c|c|c|c|c|c|c|c|c|c|c|c|c|c|c|}
\hline $\begin{array}{l}\text { Soortgroep Soortgroep } \\
\text { Rijk } \\
\text { Fylum } \\
\text { Klasse } \\
\text { Orde } \\
\end{array}$ & 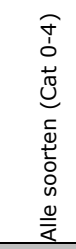 & 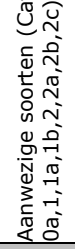 & 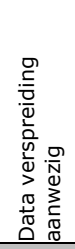 & 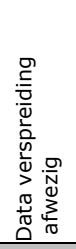 & 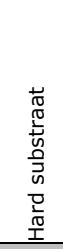 & 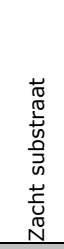 & 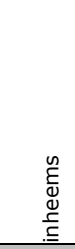 & 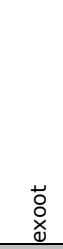 & 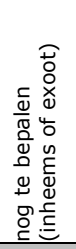 & 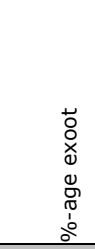 & 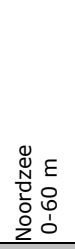 & 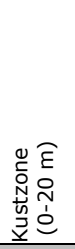 & 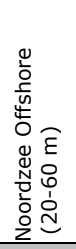 & 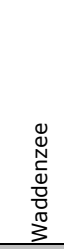 & 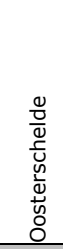 & 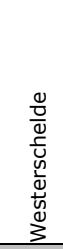 & 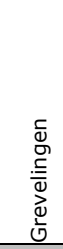 \\
\hline 1.Planten & 201 & 197 & 197 & & 4 & 1 & 179 & 18 & & $9.1 \%$ & 48 & 47 & 4 & 66 & 72 & 46 & 36 \\
\hline 1.Roodwieren - Rhodophyta & 143 & 140 & 140 & & & & 127 & 13 & & $9.3 \%$ & 22 & 22 & & 35 & 45 & 23 & 18 \\
\hline 2.Groenwieren - Chlorophyta & 55 & 54 & 54 & & 4 & 1 & 51 & 3 & & $5.6 \%$ & 26 & 25 & 4 & 29 & 25 & 22 & 18 \\
\hline 3.Vaatplanten - Tracheophyta & 3 & 3 & 3 & & & 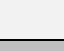 & 1 & 2 & & $66.7 \%$ & & & 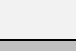 & 2 & 2 & 1 & \\
\hline 2.Chromoalveolata (supergroep) & 93 & 88 & 88 & & 1 & 1 & 82 & 6 & & $6.8 \%$ & 22 & 19 & 4 & 28 & 35 & 13 & 23 \\
\hline 1. Heterokontophyta & 87 & 83 & 83 & & & 1 & 79 & 4 & & $4.8 \%$ & 17 & 16 & & 27 & 34 & 12 & 23 \\
\hline 1.Geelgroene algen - Tribophyceae & 1 & 1 & 1 & & & & 1 & & & $0.0 \%$ & & & & & & & \\
\hline 2.Bruinwieren - Phaeophyceae & 86 & 82 & 82 & & & 1 & 78 & 4 & & $4.9 \%$ & 17 & 16 & & 27 & 34 & 12 & 23 \\
\hline 2.Pantserwieren - Dinoflagellata & 5 & 4 & 4 & & & & 2 & 2 & & $50.0 \%$ & 4 & 3 & 3 & 1 & 1 & 1 & \\
\hline 1.Dinophyceae & 5 & 4 & 4 & & & & 2 & 2 & & $50.0 \%$ & 4 & 3 & 3 & 1 & 1 & 1 & \\
\hline 3.Foraminiferen - Foraminifera & 1 & 1 & 1 & & 1 & & 1 & & & $0.0 \%$ & 1 & & 1 & & & & \\
\hline 3.Dieren & 1820 & 1515 & 1254 & 261 & 519 & 812 & 1388 & 123 & 4 & $8.1 \%$ & 1106 & 556 & 839 & 429 & 322 & 199 & 141 \\
\hline 3.Dieren (incl. vogels) & 1930 & 1624 & 1363 & 261 & 519 & 812 & 1497 & 123 & 4 & $7.6 \%$ & 1214 & 556 & 839 & 429 & 322 & 199 & 141 \\
\hline 01.Sponzen - Porifera & 32 & 30 & 29 & 1 & 13 & 6 & 23 & 7 & & $23.3 \%$ & 16 & 4 & 16 & 7 & 15 & 1 & \\
\hline 1.Kalksponzen - Calcarea & 5 & 5 & 5 & & 2 & 1 & 4 & 1 & & $20.0 \%$ & 2 & 1 & 2 & 3 & 2 & & \\
\hline 2.Kiezelsponzen - Demospongia & 26 & 24 & 23 & 1 & 11 & 5 & 18 & 6 & & $25.0 \%$ & 14 & 3 & 14 & 4 & 12 & 1 & \\
\hline 3.Overige sponzen & 1 & 1 & 1 & & & & 1 & & & $0.0 \%$ & & & & & 1 & & \\
\hline 02.Ribkwallen - Ctenophora & 5 & 5 & 3 & 2 & & 1 & 4 & 1 & & $20.0 \%$ & 1 & 1 & 1 & 3 & & & \\
\hline 03. Holtedieren, neteldieren - Cnidaria & 183 & 142 & 127 & 15 & 44 & 43 & 135 & 7 & & $4.9 \%$ & 93 & 74 & 59 & 58 & 57 & 31 & 22 \\
\hline $\begin{array}{l}\text { 1.Bloemdieren (zeeanemonen en koralen) - } \\
\text { Anthozoa }\end{array}$ & 31 & 27 & 17 & 10 & 13 & 12 & 24 & 3 & & $11.1 \%$ & 17 & 9 & 17 & 8 & 1 & 1 & \\
\hline 2.Hydroïdpoliepen en staatkwallen - Hydrozoa & 143 & 107 & 105 & 2 & 27 & 27 & 103 & 4 & & $3.7 \%$ & 71 & 61 & 37 & 46 & 56 & 30 & 22 \\
\hline 3.Kwallen - Scyphozoa & 6 & 6 & 5 & 1 & 4 & 4 & 6 & & & $0.0 \%$ & 5 & 4 & 5 & 4 & & & \\
\hline 4.Overige holtedieren & 3 & 2 & & 2 & & & 2 & & & $0.0 \%$ & & & & & & & \\
\hline
\end{tabular}




\begin{tabular}{|c|c|c|c|c|c|c|c|c|c|c|c|c|c|c|c|c|c|}
\hline 04.Pijlwormen - Chaetognatha & 3 & 2 & & 2 & & & 2 & & & $0.0 \%$ & & & & & & & \\
\hline 05.Platwormen - Platyhelminthes & 6 & 3 & 1 & 2 & 1 & & 3 & & & $0.0 \%$ & 1 & 1 & 1 & & & & \\
\hline 06.Kaakmondjes - Gnathostomulida & 1 & 1 & & 1 & & & 1 & & & $0.0 \%$ & & & & & & & \\
\hline 07.Kelkdiertjes, kelkwormen - Entoprocta & 7 & 5 & 1 & 4 & & 1 & 4 & 1 & & $20.0 \%$ & 1 & & & & & & \\
\hline 08.Kransdiertjes - Cycliophora & 1 & 1 & & 1 & & & 1 & & & $0.0 \%$ & & & & & & & \\
\hline 09.Mosdiertjes - Bryozoa & 77 & 68 & 61 & 7 & 31 & 15 & 55 & 13 & & $19.1 \%$ & 46 & 31 & 39 & 28 & 38 & 24 & 12 \\
\hline 10. Hoefijzerwormen - Phoronida & 2 & 2 & 2 & & 1 & 1 & 2 & & & $0.0 \%$ & 2 & 1 & 2 & & & & \\
\hline 11.Snoerwormen - Nemertea & 23 & 21 & 8 & 13 & 3 & 4 & 20 & 1 & & $4.8 \%$ & 7 & 3 & 7 & 1 & & & \\
\hline 12.Ringwormen - Annelida & 349 & 254 & 221 & 33 & 106 & 200 & 238 & 15 & 1 & $5.9 \%$ & 218 & 60 & 178 & 46 & 3 & & 2 \\
\hline 1.Borstelwormen - Polychaeta & 314 & 226 & 206 & 20 & 102 & 188 & 214 & 11 & 1 & $4.9 \%$ & 204 & 60 & 170 & 46 & 3 & & 2 \\
\hline 2.Pindawormen - Sipuncula & 8 & 8 & 5 & 3 & 4 & 4 & 8 & & & $0.0 \%$ & 5 & & 5 & & & & \\
\hline 3.Overige ringwormen & 27 & 20 & 10 & 10 & & 8 & 16 & 4 & & $20.0 \%$ & 9 & & 3 & & & & \\
\hline 13.Weekdieren - Mollusca & 337 & 296 & 242 & 54 & 108 & 133 & 275 & 21 & & $7.1 \%$ & 202 & 113 & 166 & 89 & 122 & 72 & 66 \\
\hline 1.Schildvoetigen - Caudofoveata & 1 & 1 & 1 & & & 1 & 1 & & & $0.0 \%$ & 1 & & 1 & & & & \\
\hline 2.Keverslakken - Polyplacophora & 6 & 5 & 3 & 2 & 1 & 1 & 5 & & & $0.0 \%$ & 3 & 1 & 1 & 1 & 1 & 1 & 1 \\
\hline 3.Tweekleppigen - Bivalvia & 141 & 121 & 105 & 16 & 51 & 79 & 107 & 14 & & $11.6 \%$ & 95 & 50 & 87 & 38 & 38 & 28 & 23 \\
\hline 4.Slakken - Gastropoda & 176 & 156 & 124 & 32 & 53 & 44 & 149 & 7 & & $4.5 \%$ & 94 & 55 & 69 & 46 & 79 & 41 & 38 \\
\hline 5.Inktvissen - Cephalopoda & 13 & 13 & 9 & 4 & 3 & 8 & 13 & & & $0.0 \%$ & 9 & 7 & 8 & 4 & 4 & 2 & 4 \\
\hline 14.Cephalorhyncha & 3 & 3 & 1 & 2 & 1 & 1 & 3 & & & $0.0 \%$ & 1 & & 1 & & & & \\
\hline 1.Stekelwormen - Kinorhyncha & 2 & 2 & & 2 & & & 2 & & & $0.0 \%$ & & & & & & & \\
\hline 2.Priapuliden - Priapulida & 1 & 1 & 1 & & 1 & 1 & 1 & & & $0.0 \%$ & 1 & & 1 & & & & \\
\hline 15.Nematoden - Nematoda & 29 & 28 & 2 & 26 & 1 & & 27 & 1 & & $3.6 \%$ & 2 & 1 & 2 & 1 & 1 & 1 & 1 \\
\hline 16.Beerdiertjes & 5 & 5 & & 5 & & & 5 & & & $0.0 \%$ & & & & & & & \\
\hline 17.Geleedpotigen - Arthropoda & 490 & 418 & 335 & 83 & 139 & 265 & 372 & 43 & 3 & $10.3 \%$ & 303 & 141 & 220 & 110 & 75 & 61 & 35 \\
\hline 1.Zeespinnen - Pycnogonida & 12 & 10 & 7 & 3 & 2 & 4 & 9 & 1 & & $10.0 \%$ & 5 & & 4 & & 6 & 6 & 3 \\
\hline 2.Spinachtigen - Arachnida & 20 & 20 & 17 & 3 & & & 19 & & 1 & $0.0 \%$ & 13 & 13 & 11 & 9 & 7 & 6 & \\
\hline $\begin{array}{l}\text { 3.Watervlooien en kieuwpootkreeften - } \\
\text { Branchiopoda }\end{array}$ & 8 & 6 & & 6 & & & 5 & 1 & & $16.7 \%$ & & & & & & & \\
\hline 4.Roeipootkreeftjes (subklasse) - Copepoda & 27 & 26 & 4 & 22 & & & 22 & 4 & & $15.4 \%$ & & & & 1 & 3 & & 2 \\
\hline 5.Mosselkreeftjes - Ostracoda & 3 & 3 & & 3 & & & 3 & & & $0.0 \%$ & & & & & & & \\
\hline 6.Echte kreeftachtigen - Malacostraca & 384 & 327 & 294 & 33 & 128 & 255 & 293 & 32 & 2 & $9.8 \%$ & 275 & 121 & 196 & 93 & 58 & 48 & 29 \\
\hline 1.Leptostraca & 1 & 1 & 1 & & & 1 & 1 & & & $0.0 \%$ & 1 & & 1 & & & & \\
\hline 2. Overige echte kreeftachtigen & 1 & 1 & 1 & & 1 & 1 & 1 & & & $0.0 \%$ & 1 & & 1 & & & & \\
\hline 2.Bidsprinkhaankreeften - Stomatopoda & 2 & 2 & 2 & & 1 & 1 & 2 & & & $0.0 \%$ & 1 & 1 & 1 & & 1 & 1 & \\
\hline 3.Aasgarnalen - Mysida & 22 & 20 & 19 & 1 & 8 & 18 & 17 & 2 & 1 & $10.0 \%$ & 19 & 3 & 15 & 3 & 3 & 2 & 2 \\
\hline 4.Vlokreeftjes - Amphipoda & 173 & 140 & 130 & 10 & 53 & 115 & 126 & 13 & 1 & $9.3 \%$ & 121 & 52 & 76 & 42 & 30 & 27 & 17 \\
\hline 5.Pissebedden - Isopoda & 58 & 46 & 39 & 7 & 21 & 29 & 37 & 9 & & $19.6 \%$ & 36 & 19 & 32 & 15 & 6 & 5 & 3 \\
\hline
\end{tabular}




\begin{tabular}{|c|c|c|c|c|c|c|c|c|c|c|c|c|c|c|c|c|c|}
\hline 6. Naaldkreeftjes - Tanaidacea & 10 & 9 & 5 & 4 & 3 & 4 & 7 & 2 & & $22.2 \%$ & 5 & 3 & 5 & 1 & 3 & 2 & \\
\hline 7.Zeekomma's - Cumacea & 27 & 24 & 23 & 1 & 8 & 23 & 24 & & & $0.0 \%$ & 23 & 9 & 13 & 8 & 5 & 3 & 4 \\
\hline 8.Krill - Euphasiacea & 2 & 2 & 2 & & 1 & 2 & 2 & & & $0.0 \%$ & 2 & 1 & 2 & & & & 1 \\
\hline 9.Tienpotigen - Decapoda & 88 & 82 & 72 & 10 & 32 & 61 & 76 & 6 & & $7.3 \%$ & 66 & 33 & 50 & 24 & 10 & 8 & 2 \\
\hline 7.Insecten - Insecta & 8 & 7 & 1 & 6 & 1 & & 5 & 2 & & $28.6 \%$ & 1 & 1 & 1 & 1 & & & \\
\hline 8. Overige geleedpotigen & 28 & 19 & 12 & 7 & 8 & 6 & 16 & 3 & & $15.8 \%$ & 9 & 6 & 8 & 6 & 1 & 1 & 1 \\
\hline 1.Eendenmosselen en zeepokken - Sessilia & 16 & 12 & 8 & 4 & 6 & 4 & 9 & 3 & & $25.0 \%$ & 6 & 4 & 5 & 4 & 1 & 1 & 1 \\
\hline 2.Eendenmosselen en zeepokken - Lepadiformes & 6 & 3 & 1 & 2 & & 1 & 3 & & & $0.0 \%$ & 1 & & 1 & & & & \\
\hline 3.Overige geleedpotigen & 6 & 4 & 3 & 1 & 2 & 1 & 4 & & & $0.0 \%$ & 2 & 2 & 2 & 2 & & & \\
\hline 18.Stekelhuidigen - Echinodermata & 29 & 25 & 24 & 1 & 18 & 24 & 25 & & & $0.0 \%$ & 24 & 11 & 24 & 8 & & & \\
\hline 1.Slangsterren - Ophiuroidea & 10 & 8 & 8 & & 7 & 8 & 8 & & & $0.0 \%$ & 8 & 6 & 8 & 3 & & & \\
\hline 2.Zee-egels - Echinoidea & 8 & 7 & 7 & & 6 & 7 & 7 & & & $0.0 \%$ & 7 & 3 & 7 & 3 & & & \\
\hline 3.Zeekomkommers - Holothuroidea & 5 & 4 & 4 & & 2 & 4 & 4 & & & $0.0 \%$ & 4 & & 4 & & & & \\
\hline 4.Zeesterren - Asteroidea & 6 & 6 & 5 & 1 & 3 & 5 & 6 & & & $0.0 \%$ & 5 & 2 & 5 & 2 & & & \\
\hline 19.Eikelwormen - Enteropneusta & 4 & 2 & 1 & 1 & & 1 & 2 & & & $0.0 \%$ & 1 & & & & & & \\
\hline 20.Chordadieren - Chordata exl vogels & 234 & 204 & 196 & 8 & 53 & 117 & 191 & 13 & & $6.4 \%$ & 188 & 115 & 123 & 78 & 11 & 9 & 3 \\
\hline 20.Chordadieren - Chordata incl vogels & 344 & 313 & 305 & 8 & 53 & 117 & 300 & 13 & 0 & $4.2 \%$ & 296 & 115 & 123 & 78 & 11 & 9 & 3 \\
\hline 1.Manteldieren - Tunicata (subfylum) & 28 & 19 & 18 & 1 & 11 & 9 & 9 & 10 & & $52.6 \%$ & 15 & 7 & 13 & 10 & 7 & 5 & 2 \\
\hline 2.Lancetvisjes - Cephalochordata (subfylum) & 1 & 1 & 1 & & 1 & 1 & 1 & & & $0.0 \%$ & 1 & & 1 & & & & \\
\hline 3.Rondbekken - Cyclostomata & 3 & 2 & 2 & & & 2 & 2 & & & $0.0 \%$ & 2 & 2 & 2 & 2 & & & \\
\hline 4. Kraakbeenvissen - Chondrichthyes & 26 & 25 & 25 & & 1 & 10 & 25 & & & $0.0 \%$ & 25 & 5 & 10 & & & & \\
\hline 5.Straalvinnigen - Actinopterygii & 138 & 123 & 123 & & 40 & 94 & 120 & 3 & & $2.4 \%$ & 119 & 78 & 91 & 60 & 4 & & 1 \\
\hline 6.Zoogdieren - Mammalia & 32 & 30 & 23 & 7 & & 1 & 30 & & & $0.0 \%$ & 22 & 19 & 6 & 6 & & 4 & \\
\hline 7.Reptielen - Reptilia & 6 & 4 & 4 & & & & 4 & & & $0.0 \%$ & 4 & 4 & & & & & \\
\hline TOTAAL (excl. vogels) & 2114 & 1800 & 1539 & 261 & 524 & 814 & 1649 & 147 & 4 & $8.2 \%$ & 1176 & 622 & 847 & 523 & 429 & 258 & 200 \\
\hline 8. Vogels - Aves & 110 & 109 & 109 & & & & 109 & & & & 108 & & & & & & \\
\hline TOTAAL incl. vogels & 2224 & 1909 & 1648 & 261 & 524 & 814 & 1758 & 147 & 4 & $7.7 \%$ & 1284 & 622 & 847 & 523 & 429 & 258 & 200 \\
\hline $\begin{array}{l}\text { Percentage t.o.v. TOTAAL aantal aanwezige soorten (N } \\
\text { = 1909: NSR Cat 0a, 1, 1a, 1b, 2, 2a, 2b, 2c, incl } \\
\text { vogels) }\end{array}$ & & $100 \%$ & $86.3 \%$ & $13.7 \%$ & $27.4 \%$ & $42.6 \%$ & $92.1 \%$ & $7.7 \%$ & $0.2 \%$ & & $67.3 \%$ & $\begin{array}{r}32.6 \\
\% \\
\end{array}$ & $44.4 \%$ & $27.4 \%$ & $22.5 \%$ & $13.5 \%$ & $10.5 \%$ \\
\hline
\end{tabular}




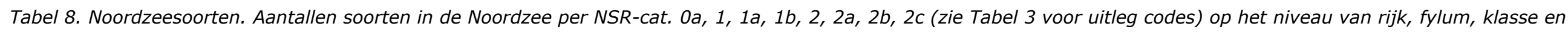

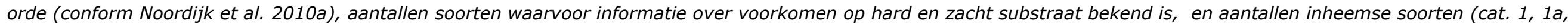

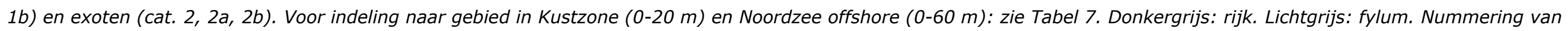
taxonomische niveaus volgt die in Tabel 7 (ontbrekende nummers: groepen niet in Noordzee aanwezig).

\begin{tabular}{|c|c|c|c|c|c|c|c|c|c|c|c|c|c|c|c|c|}
\hline $\begin{array}{l}\text { Soortgroep Soortgroep } \\
\text { Rijk } \\
\text { Fylum } \\
\text { Klasse } \\
\text { Orde } \\
\end{array}$ & 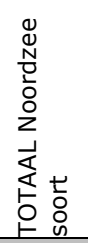 & 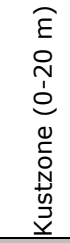 & 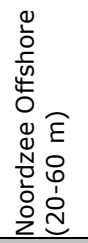 & 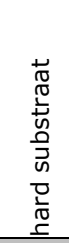 & 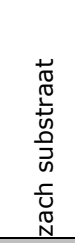 & $\begin{array}{l}0 \\
0 \\
0 \\
0 \\
0 \\
0 \\
0 \\
z\end{array}$ & $\begin{array}{l}r \\
\stackrel{1}{0} \\
0 \\
\widetilde{N} \\
\tilde{n}\end{array}$ & 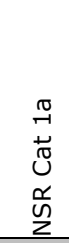 & 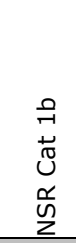 & $\begin{array}{l}\sim \\
\stackrel{N}{0} \\
U \\
0 \\
N \\
z\end{array}$ & 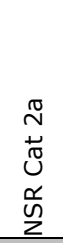 & $\begin{array}{l}\text { N } \\
\text { N } \\
\text { U } \\
\text { ज̃ } \\
z\end{array}$ & 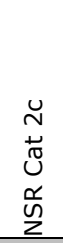 & 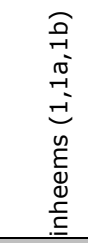 & 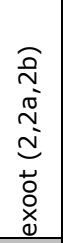 & 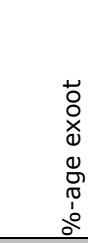 \\
\hline 1.Planten & 48 & 47 & 4 & 4 & 1 & & & 45 & 1 & & 2 & & & 46 & 2 & $4.2 \%$ \\
\hline 1.Roodwieren - Rhodophyta & 22 & 22 & & & & & & 21 & 1 & & & & & 22 & & $0.0 \%$ \\
\hline 2.Groenwieren - Chlorophyta & 26 & 25 & 4 & 4 & 1 & & & 24 & & & 2 & & & 24 & 2 & $7.7 \%$ \\
\hline 2.Chromoalveolata (supergroep) & 22 & 19 & 4 & 1 & 1 & & & 19 & & & & 2 & 1 & 19 & 3 & $13.6 \%$ \\
\hline 1. Heterokontophyta & 17 & 16 & & & 1 & & & 16 & & & & 1 & & 16 & 1 & $5.9 \%$ \\
\hline 2.Bruinwieren - Phaeophyceae & 17 & 16 & & & 1 & & & 16 & & & & 1 & & 16 & 1 & $5.9 \%$ \\
\hline 2.Pantserwieren - Dinoflagellata & 4 & 3 & 3 & & & & & 2 & & & & 1 & 1 & 2 & 2 & $50.0 \%$ \\
\hline 1.Dinophyceae & 4 & 3 & 3 & & & & & 2 & & & & 1 & 1 & 2 & 2 & $50.0 \%$ \\
\hline 3.Foraminiferen - Foraminifera & 1 & & 1 & 1 & & & & 1 & & & & & & 1 & & $0.0 \%$ \\
\hline 3.Dieren (excl vogels) & 1106 & 556 & 839 & 519 & 810 & 3 & 73 & 763 & 196 & 5 & 15 & 38 & 13 & 1032 & 71 & $6.4 \%$ \\
\hline 3.Dieren (incl vogels) & 1214 & 556 & 839 & 519 & 810 & 3 & 73 & 793 & 274 & 5 & 15 & 38 & 13 & 1140 & 71 & $5.8 \%$ \\
\hline 01.Sponzen - Porifera & 16 & 4 & 16 & 13 & 6 & & 1 & 12 & 1 & & 1 & 1 & & 14 & 2 & $12.5 \%$ \\
\hline 1.Kalksponzen - Calcarea & 2 & 1 & 2 & 2 & 1 & & & 2 & & & & & & 2 & & $0.0 \%$ \\
\hline 2.Kiezelsponzen - Demospongia & 14 & 3 & 14 & 11 & 5 & & 1 & 10 & 1 & & 1 & 1 & & 12 & 2 & $14.3 \%$ \\
\hline 02.Ribkwallen - Ctenophora & 1 & 1 & 1 & & 1 & & & 1 & & & & & & 1 & & $0.0 \%$ \\
\hline 03.Holtedieren, neteldieren - Cnidaria & 93 & 74 & 59 & 44 & 43 & & 2 & 84 & 2 & & 3 & 2 & & 88 & 5 & $5.4 \%$ \\
\hline $\begin{array}{l}\text { 1.Bloemdieren (zeeanemonen en koralen) - } \\
\text { Anthozoa }\end{array}$ & 17 & 9 & 17 & 13 & 12 & & 1 & 11 & 2 & & 2 & 1 & & 14 & 3 & $17.6 \%$ \\
\hline 2.Hydroïdpoliepen en staatkwallen - Hydrozoa & 71 & 61 & 37 & 27 & 27 & & 1 & 68 & & & 1 & 1 & & 69 & 2 & $2.8 \%$ \\
\hline 3.Kwallen - Scyphozoa & 5 & 4 & 5 & 4 & 4 & & & 5 & & & & & & 5 & & $0.0 \%$ \\
\hline 05.Platwormen - Platyhelminthes & 1 & 1 & 1 & 1 & & & & 1 & & & & & & 1 & & $0.0 \%$ \\
\hline
\end{tabular}




\begin{tabular}{|c|c|c|c|c|c|c|c|c|c|c|c|c|c|c|c|c|}
\hline 07.Kelkdiertjes, kelkwormen - Entoprocta & 1 & & & & 1 & & & 1 & & & & & & 1 & & $0.0 \%$ \\
\hline 09.Mosdiertjes - Bryozoa & 46 & 31 & 39 & 31 & 15 & & 1 & 35 & 3 & & 2 & 2 & 3 & 39 & 7 & $15.2 \%$ \\
\hline 10. Hoefijzerwormen - Phoronida & 2 & 1 & 2 & 1 & 1 & & & 1 & 1 & & & & & 2 & & $0.0 \%$ \\
\hline 11.Snoerwormen - Nemertea & 7 & 3 & 7 & 3 & 4 & & & 7 & & & & & & 7 & & $0.0 \%$ \\
\hline 12.Ringwormen - Annelida & 218 & 60 & 178 & 106 & 200 & & 16 & 194 & 3 & & 1 & 3 & & 213 & 4 & $1.8 \%$ \\
\hline 1.Borstelwormen - Polychaeta & 204 & 60 & 170 & 102 & 188 & & 13 & 183 & 3 & & 1 & 3 & & 199 & 4 & $2.0 \%$ \\
\hline 2.Pindawormen - Sipuncula & 5 & & 5 & 4 & 4 & & & 5 & & & & & & 5 & & $0.0 \%$ \\
\hline 3.Overige ringwormen & 9 & & 3 & & 8 & & 3 & 6 & & & & & & 9 & & $0.0 \%$ \\
\hline 13.Weekdieren - Mollusca & 202 & 113 & 166 & 108 & 133 & & 1 & 131 & 56 & & 4 & 7 & 3 & 188 & 14 & $6.9 \%$ \\
\hline 1.Schildvoetigen - Caudofoveata & 1 & & 1 & & 1 & & & 1 & & & & & & 1 & & $0.0 \%$ \\
\hline 2.Keverslakken - Polyplacophora & 3 & 1 & 1 & 1 & 1 & & & 3 & & & & & & 3 & & $0.0 \%$ \\
\hline 3.Tweekleppigen - Bivalvia & 95 & 50 & 87 & 51 & 79 & & 1 & 59 & 26 & & 4 & 4 & 1 & 86 & 9 & $9.5 \%$ \\
\hline 4.Slakken - Gastropoda & 94 & 55 & 69 & 53 & 44 & & & 63 & 26 & & & 3 & 2 & 89 & 5 & $5.3 \%$ \\
\hline 5.Inktvissen - Cephalopoda & 9 & 7 & 8 & 3 & 8 & & & 5 & 4 & & & & & 9 & & $0.0 \%$ \\
\hline 14.Cephalorhyncha & 1 & & 1 & 1 & 1 & & & 1 & & & & & & 1 & & $0.0 \%$ \\
\hline 2.Priapuliden - Priapulida & 1 & & 1 & 1 & 1 & & & 1 & & & & & & 1 & & $0.0 \%$ \\
\hline 15.Nematoden - Nematoda & 2 & 1 & 2 & 1 & & & & 1 & & & & 1 & & 1 & 1 & $50.0 \%$ \\
\hline 17.Geleedpotigen - Arthropoda & 303 & 141 & 220 & 139 & 264 & & 45 & 207 & 20 & 3 & 3 & 17 & 6 & 272 & 29 & $9.6 \%$ \\
\hline 1.Zeespinnen - Pycnogonida & 5 & & 4 & 2 & 4 & & & 5 & & & & & & 5 & & $0.0 \%$ \\
\hline 2.Spinachtigen - Arachnida & 13 & 13 & 11 & & & & & 13 & & & & & & 13 & & $0.0 \%$ \\
\hline 6.Echte kreeftachtigen - Malacostraca & 275 & 121 & 196 & 128 & 254 & & 45 & 183 & 18 & 3 & 2 & 16 & 6 & 246 & 27 & $9.8 \%$ \\
\hline 1.Leptostraca & 1 & & 1 & & 1 & & & 1 & & & & & & 1 & & $0.0 \%$ \\
\hline 2. Overige echte kreeftachtigen & 1 & & 1 & 1 & 1 & & 1 & & & & & & & 1 & & $0.0 \%$ \\
\hline 2.Bidsprinkhaankreeften - Stomatopoda & 1 & 1 & 1 & 1 & 1 & & & 1 & & & & & & 1 & & $0.0 \%$ \\
\hline 3.Aasgarnalen - Mysida & 19 & 3 & 15 & 8 & 18 & & 1 & 17 & & & & & 1 & 17 & 1 & $5.3 \%$ \\
\hline 4.Vlokreeftjes - Amphipoda & 121 & 52 & 76 & 53 & 115 & & 31 & 73 & 5 & 3 & 1 & 5 & 2 & 109 & 11 & $9.1 \%$ \\
\hline 5.Pissebedden - Isopoda & 36 & 19 & 32 & 21 & 29 & & 2 & 24 & 1 & & & 8 & 1 & 27 & 9 & $25.0 \%$ \\
\hline 6.Naaldkreeftjes - Tanaidacea & 5 & 3 & 5 & 3 & 4 & & 1 & 3 & & & & & 1 & 4 & 1 & $20.0 \%$ \\
\hline 7.Zeekomma's - Cumacea & 23 & 9 & 13 & 8 & 23 & & 7 & 16 & & & & & & 23 & & $0.0 \%$ \\
\hline 8.Krill - Euphasiacea & 2 & 1 & 2 & 1 & 2 & & & 2 & & & & & & 2 & & $0.0 \%$ \\
\hline 9.Tienpotigen - Decapoda & 66 & 33 & 50 & 32 & 60 & & 3 & 46 & 12 & & 1 & 3 & 1 & 61 & 5 & $7.6 \%$ \\
\hline 7.Insecten - Insecta & 1 & 1 & 1 & 1 & & & & 1 & & & & & & 1 & & $0.0 \%$ \\
\hline 8. Overige geleedpotigen & 9 & 6 & 8 & 8 & 6 & & & 5 & 2 & & 1 & 1 & & 7 & 2 & $22.2 \%$ \\
\hline 1.Eendenmosselen en zeepokken - Sessilia & 6 & 4 & 5 & 6 & 4 & & & 3 & 1 & & 1 & 1 & & 4 & 2 & $33.3 \%$ \\
\hline $\begin{array}{l}\text { 2.Eendenmosselen en zeepokken - } \\
\text { Lepadiformes }\end{array}$ & 1 & & 1 & & 1 & & & & 1 & & & & & 1 & & $0.0 \%$ \\
\hline
\end{tabular}


3.Overige geleedpotigen 18.Stekelhuidigen - Echinodermata

1.Slangsterren - Ophiuroidea

2.Zee-egels - Echinoidea

3.Zeekomkommers - Holothuroidea

4.Zeesterren - Asteroidea

19. Eikelwormen - Enteropneusta

20.Chordadieren - Chordata (exl vogels)

20.Chordadieren - Chordata (incl vogels)

1.Manteldieren - Tunicata (subfylum)

2.Lancetvisjes - Cephalochordata (subfylum)

3.Rondbekken - Cyclostomata

4.Kraakbeenvissen - Chondrichthyes

5.Straalvinnigen - Actinopterygii

6.Zoogdieren - Mammalia

7.Reptielen - Reptilia

Totaal (exl vogels)

8. Vogels - Aves

Totaal (incl vogels)

Percentage

\begin{tabular}{|c|c|c|c|c|c|c|c|c|c|c|c|c|c|c|c|}
\hline 2 & 2 & 2 & 2 & 1 & & & 2 & & & & & & 2 & & $0.0 \%$ \\
\hline 24 & 11 & 24 & 18 & 24 & & 5 & 16 & 3 & & & & & 24 & & $0.0 \%$ \\
\hline 8 & 6 & 8 & 7 & 8 & & 1 & 7 & & & & & & 8 & & $0.0 \%$ \\
\hline 7 & 3 & 7 & 6 & 7 & & & 7 & & & & & & 7 & & $0.0 \%$ \\
\hline 4 & & 4 & 2 & 4 & & 4 & & & & & & & 4 & & $0.0 \%$ \\
\hline 5 & 2 & 5 & 3 & 5 & & & 2 & 3 & & & & & 5 & & $0.0 \%$ \\
\hline 1 & & & & 1 & & 1 & & & & & & & 1 & & $0.0 \%$ \\
\hline 188 & 115 & 123 & 53 & 116 & & 1 & 71 & 107 & 2 & 1 & 5 & 1 & 179 & 9 & $4.8 \%$ \\
\hline 296 & 115 & 123 & 53 & 116 & & 1 & 101 & 185 & 2 & 1 & 5 & 1 & 287 & 9 & $3.0 \%$ \\
\hline 15 & 7 & 13 & 11 & 9 & & 1 & 6 & 1 & 1 & 1 & 5 & & 8 & 7 & $46.7 \%$ \\
\hline 1 & & 1 & 1 & 1 & & & 1 & & & & & & 1 & & $0.0 \%$ \\
\hline 2 & 2 & 2 & & 2 & & & 1 & 1 & & & & & 2 & & $0.0 \%$ \\
\hline 25 & 5 & 10 & 1 & 10 & & & 3 & 22 & & & & & 25 & & $0.0 \%$ \\
\hline 119 & 78 & 91 & 40 & 93 & & & 55 & 62 & 1 & & & 1 & 117 & 2 & $1.7 \%$ \\
\hline 22 & 19 & 6 & & 1 & & & 5 & 17 & & & & & 22 & & $0.0 \%$ \\
\hline 4 & 4 & & & & & & & 4 & & & & & 4 & & $0.0 \%$ \\
\hline 1176 & 622 & 847 & 524 & 812 & 3 & 73 & 827 & 197 & 5 & 17 & 40 & 14 & 1097 & 76 & $6.5 \%$ \\
\hline 108 & & & & & & & 30 & 78 & & & & & 108 & & 0 \\
\hline 1284 & 622 & 847 & 524 & 812 & 3 & 73 & 857 & 275 & 5 & 17 & 40 & 14 & 1205 & 76 & $5.9 \%$ \\
\hline $0.0 \%$ & $48.4 \%$ & $66.0 \%$ & $40.8 \%$ & $63.2 \%$ & $0.2 \%$ & $5.7 \%$ & $66.7 \%$ & $21.4 \%$ & $0.4 \%$ & $1.3 \%$ & $3.1 \%$ & $1.1 \%$ & $93.8 \%$ & $5.9 \%$ & $0.0 \%$ \\
\hline
\end{tabular}




\subsection{Hard en zacht substraat}

Voor 524 van de 1909 zout en brakwatersoorten is vastgesteld dat ze op hard substraat voorkomen en voor 814 soorten is vastgesteld dat ze op zacht substraat voorkomen (Tabel 7). Voor de Noordzee gaat het om dezelfde aantallen, omdat deze data specifiek uit studies en databases van de Noordzee afkomstig zijn (hard substraat: 524; zacht substraat 814; totale Noordzeesoortenlijst: 1284 soorten) (Tabel 8). Niet alle soortgroepen leven in, op of nabij de bodem, zoals bv. diverse chordadieren (vogels, vissoorten, zoogdiersoorten). 


\section{Discussie}

\subsection{Aantal soorten}

In dit project is een groot aantal bronnen geraadpleegd om tot een zo volledig mogelijke soortenlijst voor de Nederlandse Noordzee te komen (zie 3.2). Van de fyla waarvan in Nederland mariene soorten zijn vastgesteld zijn er wereldwijd ca. 214,124 geaccepteerde mariene soorten (WoRMS, december 2016; uitgebreide info over soortenaantallen in Appeltans et al. 2012) (Tabel 9). Tenminste 0.89\% van de wereldbiodiversiteit voor die fyla is aanwezig in de Nederlandse zoute wateren (Noordzee: $0.60 \%)$.

Het Belgische mariene soortenregister (Vandepitte et al. 2010) bestaat uit een soortgelijke lijst als deze, gebaseerd op literatuur en databases, die bovendien nog gecheckt is door specialisten per soortgroep. In die lijst zijn ook eencelligen beschreven en wordt het strand meegenomen als vindplaats. De orde van grootte van het aantal soorten (1793) is gelijk aan het aantal in gevonden in dit rapport (i.e. 1902 soorten voor zout- en brakwater en 1284 voor de Noordzee), met in totaal 2187 soorten in het Belgische deel van de Noordzee. De meerderheid van die soorten bestaat uit evertebraten waarbij de nematoden de meest soortenrijke groep vormen (473 soorten). In onze lijst staan maar 28 nematodensoorten, wat erop duidt dat deze groep onderbelicht is in Nederland, aangezien te verwachten valt, op basis van gelijkenis van de Belgische en Nederlandse Noordzee, dat er ongeveer gelijke aantallen soorten aanwezig zullen zijn per groep. In de Belgische lijst zijn binnen de vertebraten (chordadieren) vissen (127 soorten) en vogels (75 soorten) het meest talrijk, eveneens vergelijkbaar met de aantallen in de Nederlandse lijst. Voor zowel de vergelijking met het wereldwijde soortenregister (WoRMS) als het Belgische soortenregister geldt dat door het hanteren van verschillende taxonomische indelingen de aantallen soorten per soortgroep niet helemaal goed vergelijkbaar zijn (Tabel 9). Ook geldt dat binnen dit project door tijdgebrek voor de Nederlandse lijst voor 261 soorten nog geen locatie is vastgesteld (zie ook 3.1).

De in dit onderzoek ontwikkelde soortenlijst lijkt een goed en actueel beeld te geven van de meercellige soorten die in de Nederlandse Noordzee zijn vastgesteld. De lijst zal iets minder accuraat zijn voor de overige zoute wateren (Waddenzee, Westerschelde, Oosterschelde, Grevelingen), omdat de focus lag op bronnen die gedeeltelijk of geheel betrekking hadden op de Noordzee. Toch zullen in dit rapport ook nog Noordzeesoorten ontbreken of dubbel in staan om verschillende redenen.

- De locatie van de soort is binnen dit project nog niet vastgesteld d.m.v. aanvullende literatuur (geldt voor 261 soorten). Een aantal van deze soorten zal ongetwijfeld wel in de Noordzee voorkomen, maar moet nog worden bevestigd d.m.v. literatuuronderzoek of door middel van databases. Dit is enkel een kwestie van verder de literatuur uitzoeken, wat binnen dit project niet meer mogelijk was.

- De soort is wel waargenomen, maar nog niet in wetenschappelijke of grijze literatuur vastgelegd omdat het onderzoek nog loopt, of omdat er geen financiering, mankracht of tijd beschikbaar is om de waarneming verder uit te werken (dit gaat waarschijnlijk om kleine aantallen soorten), bv. de monitoring van soorten op wrakken tijdens duikexpedities door St. Duik de Noordzee Schoon en St. ANEMOON.

- De soort is onterecht geclassificeerd als NSR-categorie '3b' 'onterecht gemeld'. Mogelijk zijn er soorten die vooralsnog in deze categorie zijn gestopt, maar die intussen wel geïdentificeerd zijn als aanwezige soort. Tussen verschillende specialisten kan hierover verschil van inzicht bestaan.

- De soort is inmiddels wel vastgelegd in de literatuur, maar die bron was tijdens de looptijd van dit onderzoek nog niet beschikbaar, bv. Faasse (2016); Faasse et al. (2016b): 4 nieuwe kelkdiertjes (Loxosomella compressa, L. harmeri, L. varians en L. phascolosomata; Beukhof et al. (2016): 1 mosdiertje waarvan de NSR status nu nog als ' $3 \mathrm{~b}$ ' 'onterecht gemeld' is vastgesteld: Cribrilina punctate)

- De soort is wel bemonsterd, maar bleef onopgemerkt. Niet alle onderzoek heeft tot doel alle soorten tot soortniveau uit te zoeken. Bij vissurveys worden vissoorten goed gedetermineerd en wordt daarnaast getracht ook alle benthossoorten op naam te brengen, maar bij tijdgebrek heeft determinatie van vissen prioriteit. 
- De soort is nog nooit bemonsterd. Er zijn tal van locaties, zoals natuurlijk of kunstmatig hard substraat (scheepswrakken, olie-/gasplatforms, steenriffen), die relatief weinig tot niet onderzocht zijn. Met gericht duikend veldwerk (Lengkeek et al. 2013), promotieonderzoek (J.W.P. Coolen, WUR) en verschillende duikexpedities (Stichting Duik de Noordzee Schoon) is de afgelopen jaren op die manier nog een aantal voor de Nederlandse Noordzee nieuwe soorten ontdekt, niet alleen duikend (Schrieken et al. 2011, 2013; Gittenberger et al.2011, 2013a, 2013b), maar ook op opgeviste spooknetten (Faasse et al. 2016).

- In dit project is ervoor gekozen om uit te gaan van voor ons toegankelijke data en studies. Het bijeenbrengen van nog niet betrokken instituten of specialisten zal mogelijk nog extra gegevens kunnen opleveren (zie ook 4.6).

- $\quad$ De groep is onderbelicht, zoals bijvoorbeeld de nematoden (zie discussie hierboven). Soorten determineren is heel specialistisch werk dat door relatief weinigen wordt beheerst. Specialisten die zich in een enkele groep specialiseren en gerichte monsters nemen vinden waarschijnlijk sneller nieuwe soorten.

- De soort staat dubbel in de lijst, omdat binnen WoRMS nog fouten kent (mogelijk het geval bij bv. Spio decoratus en Paraspio decorata).

- Nieuwe technieken zoals DNA-metabarcoding ${ }^{5}$ zullen ongetwijfeld nieuwe soorten aan het licht brengen. Hiervoor kunnen bv. gemengde sedimentmonsters of schraapmonsters van aangroei op stenen, boeien, windturbinepalen of scheepswrakken etc. gebruikt worden. Om nieuwe soorten vast te stellen, moet elders in de wereld al een DNA-barcode zijn opgesteld voor die soort en in een wereldwijde database zijn opgenomen. Op dit moment wordt voor de Nederlandse en Belgische Noordzee de database van DNA-barcodes uitgebreid om zoveel mogelijk soorten te omvatten. Daarvoor moeten soorten eerst geïdentificeerd worden, en moet voor die soort de unieke barcode geregistreerd worden. Hieraan dragen verschillende projecten bij van o.a. het ILVO (Oostende) en Wageningen Marine Research (RECON-project, J.W.P. Coolen).

- Hoewel de hier opgestelde lijst een groot deel van de totale Nederlandse mariene en Noordzee-biodiversiteit weergeeft, is een aantal groepen expliciet buiten beschouwing gelaten, vooral groepen eencelligen. Niet beschouwd zijn eencellige algen, schimmels, protozoa, bacteriën, archaea-bacteriën en virussen. Hierbij gaat het waarschijnlijk in totaal om nog grote aantallen niet beschouwde soorten (honderden).

- In de toekomst zullen verder nog voor Nederland nieuwe soorten zelfstandig de Noordzee in trekken door klimaatverandering en daarmee gepaard gaande verandering in leefgebieden.

Daarnaast zullen er nog een aantal soorten in de lijst staan die er niet in thuishoren, bv. omdat deze soorten zijn uitgespoeld met zoet water. Het gaat hierbij om met name kleine kreeftachtigen en een enkele vis die algemeen voorkomen in zoet tot licht brak water.

\subsubsection{Vergelijking met soortenrijkdom op het land}

In Nederland wordt het totaal aantal vastgestelde soorten op land en in water geschat op tussen de 36,219 (Nederlands Soortenregister, november 2016) en 47,800 (Noordijk et al. 2010a). Dat betekent dat de in dit rapport vastgestelde mariene soortenrijkdom daaraan tussen de 4.0 en $5.3 \%$ bijdraagt (Noordzee: ca $2.7-3.5 \%$ ).

De Nederlandse mariene soortenlijst betreft zoutwatergebieden met een gezamenlijk oppervlak van ca. 60 duizend $\mathrm{km}^{2}$, bestaande uit het Nederlandse deel van de Noordzee van ca. 57 duizend km² (Ministerie van Infastructuur en Milieu \& Ministerie van Economische Zaken, Landbouw \& Innovatie, 2012) en de overige gebieden van ca. $3406 \mathrm{~km}^{2}$ (Waddenzee, Eems, Dollard: $2562 \mathrm{~km}^{2}$; Oosterschelde: $346 \mathrm{~km}^{2}$; Westerschelde: $299 \mathrm{~km}^{2}$; Grevelingen: ca $\left.139 \mathrm{~km}^{2}\right)^{6}$. Het landoppervlak incl.

\footnotetext{
${ }_{6}^{5} \mathrm{https}: / /$ en.wikipedia.org/wiki/DNA_barcoding

${ }^{6}$ http://www.synbiosys.alterra.nl/natura2000/gebiedendatabase. $a s p x$ ?subj=n2k\&groep=9\&id=n2k115 en CBS: https://www.cbs.nl/nl-nl/nieuws/2016/08/minder-landbouw-meer-natuur
} 
buiten- en binnenwateren van Nederland is ca. $41543 \mathrm{~km}^{2}\left(^{7}\right)$ en excl. buiten- en binnenwateren ca. $37220 \mathrm{~km}^{2}$. Toch dragen de mariene soorten slechts $4-5 \%$ bij aan de totale soortenrijkdom van Nederland. Dit komt omdat landmilieus in het algemeen fysiek complexer zijn, voornamelijk door habitats die planten creëren (boven- en ondergronds), en op land fysieke gradiënten vaak steiler zijn en extremen vaak groter. Daardoor is op land een grotere habitatdiversiteit op kleinere ruimtelijke schalen, dan in de meeste mariene milieus (Grosberg et al. 2012).

Ook mondiaal geldt dat het zeeoppervlak groter is dan het landoppervlak, terwijl het totaal aantal bekende landsoorten aanzienlijk groter is (May 1994). Schattingen voor de totale soortenrijkdom van de aarde, inclusief onontdekte soorten, zijn $5 \pm 3$ miljoen eukariote soorten (Costello et al. 2013) en voor de zee circa 0.7-1 miljoen soorten (Appeltans et al. 2012). Vooral insecten (kevers, vliegen, vlinders) maken een groot deel uit van de soortenrijkdom op land (Gray 1997). Voor Nederland zijn er maar liefst 19,244 soorten gevestigde insecten vastgesteld, ofwel circa $42 \%$ van de totale Nederlandse soortenrijkdom (Noordijk et al. 2010b), tegen 7 gevestigde mariene insectensoorten. Bovendien zijn er in ons land ook nog eens ruim 10 duizend gevestigde schimmelsoorten vastgesteld, circa $22 \%$ van de totale Nederlandse soortenrijkdom (Noordijk et al. 2010b). Deze groep is niet in de mariene lijst is meegenomen.

Op een hoger taxonomisch niveau is de biodiversiteit van de zee juist rijker dan die op land (zie ook Gould 1990 en May 1994). Grassle et al. (1991, p3) geven aan dat van alle 28 in het mariene milieu voorkomende dier-fyla er wel 13 endemisch zijn, dus uitsluitend-en-alleen in zee voorkomen, veel meer dan van de fyla die in zoet water (geen endimische groepen), land (1 endemische groep) of symbiotisch (4 endemische groepen) voorkomen. Onder de door Grassle et al. (1991) genoemde voor zee endemische dierfyla, vallen in ieder geval de in onze lijst opgenomen fyla van de holtedieren of neteldieren (Cnidaria), pijlwormen (Chaetognatha), kaakmondjes (Gnathostomulida) en Cephalorhyncha en daarnaast, binnen het fylum van de ringwormen (Annelida), de nu als klasse aangemerkte groep van de zandwormen (Echiura).

\footnotetext{
${ }^{7}$ https://nl.wikipedia.org/wiki/Lijst_van_landen_naar_oppervlakte
} 
Tabel 9. Vergelijking tussen aantallen soorten in de Noordzee (voor de NSR-cat. 0a, 1, 1a, 1b, 2, 2a, 2b, 2c; zie Tabel 3 voor uitleg codes) op het niveau van rijk, fylum, klasse en orde (conform Noordijk et al. 2010a), en de aantallen soorten gevonden in de Belgische Noordzee (Van de Pitte et al., 2010) en het aantal geaccepteerde mariene soorten wereldwijd (WoRMS, december 2016). NA= geen goede vergelijking mogelijk, door verschillen in taxonomische indeling).

\begin{tabular}{|c|c|c|c|c|c|c|}
\hline & 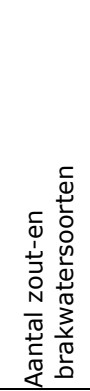 & 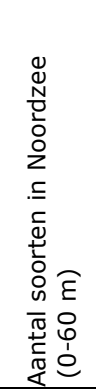 & 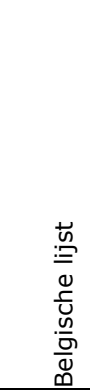 & 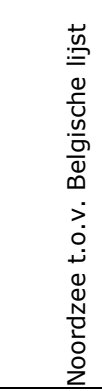 & 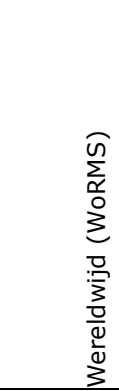 & 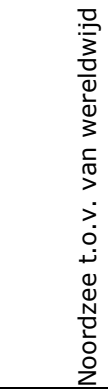 \\
\hline \multicolumn{7}{|l|}{ 1.Planten } \\
\hline 1.Roodwieren - Rhodophyta & 140 & 22 & 45 & $49 \%$ & 8178 & $0.27 \%$ \\
\hline 2.Groenwieren - Chlorophyta & 54 & 26 & 46 & $57 \%$ & 3249 & $0.80 \%$ \\
\hline 3.Vaatplanten - Tracheophyta & 3 & & NA & NA & 312 & $0.00 \%$ \\
\hline \multicolumn{7}{|l|}{ 2.Chromoalveolata (supergroep) } \\
\hline 1. Heterokontophyta & 83 & 17 & NA & NA & NA & NA \\
\hline 2.Pantserwieren - Dinoflagellata & 4 & 4 & NA & NA & NA & NA \\
\hline 3.Foraminiferen - Foraminifera & 1 & 1 & NA & NA & 8992 & $0.01 \%$ \\
\hline \multicolumn{7}{|l|}{ 3.Dieren } \\
\hline 01.Sponzen - Porifera & 30 & 16 & 34 & $47 \%$ & 8560 & $0.19 \%$ \\
\hline 02.Ribkwallen - Ctenophora & 5 & 1 & 3 & $33 \%$ & 197 & $0.51 \%$ \\
\hline 03. Holtedieren, neteldieren - Cnidaria & 142 & 93 & 49 & $190 \%$ & 11489 & $0.81 \%$ \\
\hline 04.Pijlwormen - Chaetognatha & 2 & & 1 & NA & 131 & $0.00 \%$ \\
\hline 05.Platwormen - Platyhelminthes & 3 & 1 & 161 & $1 \%$ & 12851 & $0.01 \%$ \\
\hline 06.Kaakmondjes - Gnathostomulida & 1 & & 1 & NA & 101 & $0.00 \%$ \\
\hline $\begin{array}{l}\text { 07.Kelkdiertjes, kelkwormen - } \\
\text { Entoprocta }\end{array}$ & 5 & 1 & 1 & $100 \%$ & 181 & $0.55 \%$ \\
\hline 08.Kransdiertjes - Cycliophora & 1 & & NA & NA & 2 & $0.00 \%$ \\
\hline 09.Mosdiertjes - Bryozoa & 68 & 46 & 92 & $50 \%$ & 6163 & $0.75 \%$ \\
\hline 10. Hoefijzerwormen - Phoronida & 2 & 2 & 1 & $200 \%$ & 11 & $18 \%$ \\
\hline 11.Snoerwormen - Nemertea & 21 & 7 & 10 & $70 \%$ & 1363 & $0.51 \%$ \\
\hline 12.Ringwormen - Annelida & 254 & 218 & $\mathrm{NA}$ & NA & 12904 & $1.69 \%$ \\
\hline 13.Weekdieren - Mollusca & 296 & 202 & 128 & $158 \%$ & 46546 & $0.43 \%$ \\
\hline 14.Cephalorhyncha & 3 & 1 & NA & NA & 236 & $0.42 \%$ \\
\hline 15.Nematoden - Nematoda & 28 & 2 & 473 & $0.42 \%$ & 6514 & $0.03 \%$ \\
\hline 16.Beerdiertjes - Tardigrada & 5 & & 0 & NA & 205 & $0.00 \%$ \\
\hline 17.Geleedpotigen - Arthropoda & 418 & 303 & 522 & $58 \%$ & 56236 & $0.54 \%$ \\
\hline 18.Stekelhuidigen - Echinodermata & 25 & 24 & 27 & $89 \%$ & 7279 & $0.33 \%$ \\
\hline 19.Eikelwormen - Enteropneusta & 2 & 1 & 0 & $0 \%$ & 130 & $0.77 \%$ \\
\hline 20.Chordadieren - Chordata & 313 & 296 & 199 & $149 \%$ & 22294 & $1.33 \%$ \\
\hline TOTAAL & 1909 & 1284 & 1793 & & 214124 & $0.60 \%$ \\
\hline
\end{tabular}

\subsection{Exoten}

In deze soortenlijst is een aantal gegevens over bemonsteringen bij havens niet beschouwd. In die havens is niettemin nog een aantal exoten waargenomen die niet op onze lijst staan (mededeling A. Gittenberger). In onze lijst ligt het percentage op $8 \%$ exoten, afkomstig van bv. de oesterimport voor oesterkweek in de Oosterschelde en uit ballastwater dat wordt geloosd in de vele havens. In de Belgische Noordzee is zo'n 4\% van de soorten (188 soorten) aangemerkt als exoot of driftsoort (Vandepitte et al. 2010). Omdat België geen delta met oesterkweek kent, zou dit een reden kunnen zijn voor het lagere aantal exoten. Ook zijn in de Belgische lijst andere soortgroepen (zoals eencelligen) meegenomen, waardoor de berekening op andere getallen zal berusten. 


\subsection{Verspreiding}

In dit project is getracht voor elke soort de aan- of afwezigheid in de Noordzee vast te stellen en voor ca $86 \%$ van de 1909 soorten is dit gelukt. Van circa 261 soorten is op dit moment nog niet bepaald in welke zoute wateren ze zijn vastgesteld. Voor een behoorlijk aantal soorten is een beschrijvende tekst over het voorkomen omgezet in een toekenning aan locaties (zie paragraaf 2.6). Hiervoor geldt dat bij de interpretatie van beschrijvingen fouten gemaakt kunnen zijn in de toekenning van soorten aan deze gebieden. De lijst is mogelijk minder compleet voor de kustgebieden/delta, omdat de focus lag op bronnen die gedeeltelijk of geheel betrekking hadden op de Noordzee (zie paragraaf 2.6).

\subsection{Hard en zacht substraat}

In dit rapport is de habitat (hard/zacht substraat) waaraan de soort is gebonden bepaald op basis van habitatclassificaties van de bemonsteringslocaties. Maar er zijn ook gebieden, zoals de Klaverbank, die als hardsubstraatgebieden zijn geclassificeerd, terwijl er ook zacht substraat voorkomt. Ook zullen er hardsubstraatsoorten zijn die zijn bemonsterd op zachte bodems omdat ze bv. op schelpen groeien.

\subsection{Identificatie en verwerking data}

De soortenlijst in dit rapport is niet per soortgroep nog eens door betreffende specialisten voor die groepen nader gecheckt. Daarom zal de lijst nog een aantal onvolkomenheden bevatten. Doordat soortnamen in de loop der tijd kunnen veranderen, kunnen gebruikte databases altijd enige onduidelijkheden bevatten. Een aantal soorten stond onder een 'oude' wetenschappelijke naam in de database, bv. de gewone zager Nereis virens, Sars, 1835 (heet nu Alitta virens (M. Sars, 1835) als geaccepteerde wetenschappelijke naam). In een aantal bronnen stonden soorten vermeld onder verschillende synoniemen. In die gevallen zijn de regels per synoniem samengevoegd tot 1 soort. Verder stonden er in een rapport over wrakken (Lengkeek et al. 2013) bij de vrijwilligersdata ook soorten die op een aantal Belgische wrakken waren gevonden (mededeling A. Gittenberger). Die zijn weer uit de lijst gehaald.

Een aantal soorten uit verschillende bronnen is waarschijnlijk niet goed geïdentificeerd: bv. de naam Aora typica (betreft een vlokreeftensoort) moet zijn: Aora gracilis; de naam Eubranchus tricolor (betreft een slakkensoort) moet zijn: Polycera faeroensis; de naam Chamelea gallina (betreft een tweekleppige; RWS Klaverbank 2015) moet zijn: Chamelea striatula). Deze soorten zijn nu onder de juiste wetenschappelijke naam opgenomen. Een andere verkeerd geïdentificeerde soort is bv. de krab Hemigrapsus penicillatus. De juiste naam moet zijn: Hemigrapsus takanoi. Deze soort is wel in de lijst blijven staan, maar dan onder categorie 3b ('misidentificatie').

De bronnen bevatten meestal geen informatie over de auteur behorende bij de soort. Toch is de vermelding van de auteur van groot belang. Bij matching met WoRMS kan dit verwarring opleveren, omdat de soortnaam zonder auteur niet uniek hoeft te zijn. Wanneer bijvoorbeeld gezocht wordt naar de gewone zeester Asterias rubens, geeft WoRMS de volgende opties:

\footnotetext{
Asterias rubens Olivi, 1792 accepted as Echinaster (Echinaster) sepositus (Retzius, 1783)

Asterias rubens Johnston, 1836 accepted as Luidia ciliaris (Philippi, 1837)

Asterias rubens Murdoch, 1885 accepted as Asterias amurensis Lutken, 1871

Asterias rubens Linnaeus, 1758

Asterias rubens var. migratum Sladen, 1878 accepted as Asterias amurensis Lutken, 1871

Asterias rubens violacea O.F. Müller, 1776 accepted as $\quad$ Asterias rubens Linnaeus, 1758
}

Hierbij is uiteraard gekozen voor Asterias rubens Linnaeus, 1758. Als regel is er vanuit gegaan dat de verantwoordelijke taxonoom de op dat moment geaccepteerde naam heeft toegekend aan de soort. Bij twijfel is verder uitgezocht wat het verspreidingsgebied van de betreffende soort was. 
Verder troffen we in de gegenereerde NSR-lijst nog een aantal soorten aan dat niet in WoRMS voorkwam. Mogelijk gaat het om synoniemen van soorten die wel in WoRMS staan, maar waarvan het synoniem nog niet opgenomen is, en/of zoetwatersoorten die per ongeluk de habitat 'zout' in de NSR toegekend hebben gekregen, of om soorten die nog niet in WoRMS zijn opgenomen.

\subsection{Vervolgstappen}

Een aantal wenselijke vervolgstappen om de bruikbaarheid en de kwaliteit van voorliggende soortenlijst te verbeteren zijn:

- Verspreiding: van circa 261 van de 1909 soorten is op dit moment nog niet bepaald in welke Nederlandse zoutwatergebieden ze zijn vastgesteld (zie 3.4). Dit zou alsnog gedaan kunnen worden door allereerst voor die soorten de bijbehorende bron uit het NSR nader te bestuderen. Hiervoor is door Naturalis al voorwerk verricht. Verder kunnen specifieke monitoringsgegevens van de Oosterschelde (bv. Stichting ANEMOON), Westerschelde (bv. NIOZ-Yerseke), Waddengebied (bv. NIOZ-Texel) en bv. rapporten over exoten in havens van GiMaRIS langs de huidige soortenlijst gelegd worden.

- Ook is aan te bevelen de soortenlijst per groep door specialisten nader te laten controleren. Zij zullen gegarandeerd nog opmerkingen hebben, nieuwe soorten aandragen of onterecht genoemde soorten van de lijst afhalen.

- Of een soort onterecht geclassificeerd is als NSR-categorie ' $3 b^{\prime}$ ' 'onterecht gemeld' kan door specialisten worden vastgesteld door deze soorten stuk voor stuk na te lopen. De selectie van deze soorten is eenvoudig mogelijk in de uitgebreide soortenlijst.

- Soortkenmerken: In een vervolgtraject zouden deze mogelijke discrepanties kunnen worden verminderd (zie 4.6). Van veel bodemdieren is vanuit ander onderzoek al een hele reeks 'traits' (kenmerken) bekend waaronder voorkeuren voor hard en zacht substraat, die in projecten zoals 'BENTHIS' ${ }^{8}$ worden gebruikt om bv. effecten van visserij op bodemdieren te modelleren. Mogelijk kunnen de verschillende lijsten in een vervolgtraject naast elkaar gelegd worden of nader door specialisten worden aangevuld.

- $\quad$ EUNIS \& exoten: in het kader van de Kaderrichtlijn Mariene Strategie wordt in OSPARverband een exotenindicator ontwikkeld, waaraan in Nederland door Rijkswaterstaat wordt bijgedragen. Voor het berekenen van indicatoren over 'Non Indigenous Species (NIS)', zoals 'NIS-2: Rate of new introductions of NIS (per defined period)'), kan het wenselijk zijn dat per exoot wordt vastgesteld in welke EUNIS-habitat ${ }^{9}$ deze voorkomt. Dit betekent dat voor de soorten die in NSR-categorie 2 vallen, de ruimtelijke verspreiding binnen EUNIS-habitats zou kunnen worden vastgesteld (Tabel 5). Het gaat daarbij om circa 147 soorten (categorie 2, 2a, 2b), waarvan voor circa 23 de verspreiding niet bekend is.

- De afgelopen jaren zijn door vrijwilligers data verzameld van soorten aanwezig op en rondom enkele tientallen scheepswrakken in de Noordzee (o.a. tijdens expedities van Stichting Duik de Noordzee Schoon). Daarbij is een aantal voor Nederlandse wateren nieuwe soorten ontdekt, die zijn meegenomen in de huidige lijst. Een rapportage over deze data zou waardevol zijn om ook de biodiversiteit van wrakken beter in kaart te brengen, maar voor de opwerking van deze data is nog tijd en geld nodig. Voor gelijksoortige data in de Zeeuwse wateren is al een aantal rapporten verschenen ('Duiken gebruiken Deel 3: Gmelig Meyling et al. 2013) .

- Identificatie van een aantal groepen: mogelijk zijn in het verleden misidentificaties gemaakt van bv. wormen in de MWTL-datasets. Dit betekent dat een specialist nog zou moeten nagaan

\footnotetext{
${ }^{8}$ www.benthis.eu

${ }^{9}$ EUNIS = European Information System (http://www.emodnet-

seabedhabitats.eu/default.aspx?page $=1974 \&$ LAYERS $=$ EUSM2016\&zoom $=6 \& Y=53.53904738478245 \& X=2.9019324671$ 295505)
} 
of het waarschijnlijk is dat bepaalde soorten inderdaad aanwezig zijn geweest, of dat het om andere soorten gaat.

- $\quad$ Er zijn mogelijkheden om de huidige lijst uit te breiden met eencelligen op basis van dataseries van de Continuous Plankton Recorder (CPR) (SAHFOS), de fytoplanktonmonitoring door het NIOZ (Texel) en de planktonmonitoring door RWS (diverse locaties op de Noordzee).

- De hier ontwikkelde soortenlijst zou, ter verbetering, in een vervolgtraject breed verspreid moeten worden onder specialisten en in de duikwereld, om na te gaan of er nog soorten gemist zijn.

- $\quad$ Er zijn verschillende projecten waarbij 'traits' (kenmerken) van bodemdieren worden gebruikt om de bodemfauna te beschrijven. Door koppeling van bestanden kan de soortenlijst nog worden voorzien van betere informatie over bijvoorbeeld voorkomen op hard/zacht substraat.

Deze suggesties kunnen mogelijk in een vervolgtraject worden opgepakt. 


\section{$5 \quad$ Dankwoord}

We bedanken Serge Rotteveel (RWS) voor het leveren van gegevens uit de RWS MWTL monitoring, Steve Geelhoed (Wageningen Marine Research) voor het leveren van gegevens vanuit de bruinvisvliegtuigmonitoring, en Hans Verdaat (Wageningen Marine Research) voor gegevens uit waarneming.nl en Guido Keijl (Naturalis) voor het controleren van de vogellijst. 


\section{$6 \quad$ Kwaliteitsborging}

Wageningen Marine Research beschikt over een ISO 9001:2008 gecertificeerd kwaliteitsmanagementsysteem (certificaatnummer: 187378-2015-AQ-NLD-RvA). Dit certificaat is geldig tot 15 september 2018. De organisatie is gecertificeerd sinds 27 februari 2001. De certificering is uitgevoerd door DNV Certification B.V.

Sinds 2010 wordt op Wageningen Marine Research jaarlijks een determinatietoets voor demersale vis en benthos afgenomen (o.a. De Boois, 2016). De parate kennis van Wageningen Marine Research medewerkers en externen die voor Wageningen Marine Research monsters verwerken wordt hierbij getoetst. In alle gevallen wordt er zorg voor gedragen dat tijdens surveys en monitoring aan boord van commerciële schepen voldoende mensen aan boord zijn die aantoonbaar in staat zijn om minimaal $80 \%$ van de soorten goed op naam te brengen.

Soortgelijke toetsen worden ook jaarlijks uitgevoerd voor zoetwatervis en voor schelpdieren.

Daarnaast is in 2013 en 2016 een determinatietoets voor haaien en roggen georganiseerd volgens dezelfde methodiek als de toets voor demersale vis en benthos (De Boois en Bolle, 2013).

Sinds 2011 wordt op Wageningen Marine Research jaarlijks een schelpdierdeterminatietoets afgenomen waarbij de parate kennis van voor het onderzoek relevante medewerkers wordt getoetst (Troost \& Perdon, 2016).

In dit rapport zijn decimalen weergegeven met een punt en duizendtallen onderscheiden met een komma. 


\section{Literatuur}

Appeltans W et al. (2012) The Magnitude of Global Marine Species Diversity. Current Biology 22:2189-2202

Bartsch, I. \& Smit H. (2006) Een checklist van de Nederlandse zeemijten (Acari: Halacardoidea) Nederlandse Faunistische Mededelingen 25:1-8. (http://repository.naturalis.nl/document/159673SimilarFile).

Bergman, M., Duineveld, G., Daan, R., Mulder, M. \& Ubels S. (2012) Impact of OWEZ wind farm on the local macrobenthos community, Report OWEZ_R_261_T2_20121010, NIOZ. (http://www.noordzeewind.nl/wpcontent/uploads/2012/12/OWEZ_R_261_T2_20121010_benthos_final.pdf).

Beukhof ED, Coolen JWP, van der Weide BE, Cuperus J, de Blauwe H, Lust J (2016) Records of five bryozoan species from offshore gas platforms rare for the Dutch North Sea. Marine Biodiversity Records 9:91

Bouma, S. \& Lengkeek, W. (2012) Benthic communities on hard substrates of the offshore wind farm Egmond aan Zee (OWEZ) Including results of samples collected in scour holes. Report OWEZ_R_266_T1_20120206_hard_substrate, Bureau Waardenburg (http://www.noordzeewind.nl/wpcontent/uploads/2012/10/OWEZ_R_266_T1_20120206_hard_substrate.pdf).

Brongersma, L.D. (1972) European Atlantic turtles. Zoologische Verhandelingen 121:1-318.

Camphuysen K. \& Peet G. (2006) Walvissen en dolfijnen in de Noordzee / Whales and dolphins in the North Sea, Vol, Fontaine Uitgevers BV, 's Graveland / Stichting De Noordzee, Utrecht

Coolen, J.W.P., Bos, O.G., Glorius, S., Lengkeek, W., Cuperus, J., Van der Weide, B. \& Aguera, A. (2015) Reefs, sand and reef-like sand: A comparison of the benthic biodiversity of habitats in the Dutch Borkum Reef Grounds. Journal of Sea Research: 103, 84-92. (http://dx.doi.org/10.1016/j.seares.2015.06.010).

Costello MJ, May RM, Stork NE (2013) Can We Name Earth's Species Before They Go Extinct? Science 339:413De Boois, I.J. (2016). Species identification workshop 2016: demersal fish and macrozoobenthos. IMARES internal report 16.003.

De Boois I.J., \& Bolle, L.J. (2013). Species identification workshops 2012 and 2013: Gobies and Elasmobranchs. IMARES internal report 13.009.

De Bruyne, R., Van Leeuwen, S., Gmelig Meyling, A. \& Daan, R. (eds) (2013) Schelpdieren van het Nederlandse Noordzeegebied: ecologische atlas van de mariene weekdieren (Mollusca), Uitgeverij Tirion, Utrecht; Stichting Anemoon, Lisse.

Faasse, M. \& De Blauwe, H. (2004) Faunistisch overzicht van de mariene mosdiertjes van Nederland (Bryozoa: Stenolaemata, Gymnolaemata. Nederlandse Faunistische Mededelingen:17-54. (http://www.vliz.be/en/imis?refid=97130).

Faasse, M. \& Stikvoort, E. (2002) Mariene en estuariene vlokreeftjes van zachte bodems in het Deltagebied (Crustacea: Gammaridea). Nederlandse Faunistische Mededelingen 17:57-86. (www.repository.naturalis.nl/document/46314)

Faasse, M. \& Van Moorsel, G. (2000) Nieuwe en minder bekende vlokreeftjes van sublitorale harde bodems in het Deltagebied (Crustacea: Amphipoda: Gammaridae). Nederlandse Faunistische Mededelingen 11:19-44. (repository.naturalis.nl/document/41522).

Faasse, M., Van Moorsel, G. \& Tempelman, D. (2013) Moss animals of the Dutch part of the North Sea and coastal waters of the Netherlands (Bryozoa). Nederlandse Faunistische Mededelingen 41:1-14. (http://www.repository.naturalis.nl/document/621036).

Faasse, M.A., Coolen, J.W.P., Gittenberger, A. \& Schrieken, N. (2016a) Nieuwe mosdiertjes van Noordzeewrakken (Bryozoa). Nederlandse Faunistische Mededelingen 46:43-48.

Faasse, M.A. (2016). Meer informatie over soortenrijkdom Noordzeebodem uit bodemschaaf. De Levende Natuur 117:86-89.

Faasse, M.A., Van Haaren, T., Van Moorsel, G.W.N.M. \& Tempelman, D. (2016b). De eerste vondsten van solitaire kelkdiertjes (Entoprocta: Solitaria) in Nederland: Loxosomella compressa, L. harmeri, L. varians en L. phascolosomata. Het Zeepaard 76(1) : $33-40$. 
Gittenberger, A., Rensing, M., Dekker, R., Niemantverdriet, P., Schrieken, N. \& Stegenga H. (2014) Native and non-native species of the Dutch Wadden Sea in 2014. GiMaRIS report 2015_08.

Gittenberger A, Schrieken N, Lengkeek W (2011) Polycera faeroensis Lemche, 1929, and Doto dunnei Lemche, 1976, new for the Dutch fauna and the central North Sea (Gastropoda, Nudibranchia). Basteria: Tijdschrift van de Nederlandse Malacologische Vereniging 75:111-116.

Gittenberger A, Schrieken N, Coolen JWP, Gittenberger E (2013a) Shipwrecks, ascidians and Modiolarca subpicta (Bivalvia,Mytilidae,Musculinae). Basteria: Tijdschrift van de Nederlandse Malacologische Vereniging 77:75-82.

Gittenberger A, Schrieken N, Coolen JWP, Vlierhuis W (2013b) The Jewel anemone Corynactis viridis, a new order for The Netherlands (Cnidaria: Corallimorpharia). Nederlandse Faunistische Mededelingen 41:35-42.

Gmelig Meyling AW, Van Lente I, Schrieken N, Gittenberger A, De Bruyne RH (2013) Het Duiken Gebruiken 3. Gegevensanalyse van het Monitoringproject Onderwater Oever (MOO), Faunaonderzoek met sportduikers in Oosterschelde en Grevelingenmeer. Periode 1994 t/m 2012. Stichting Anemoon

Gould, S.J. (1990). Wonderful Life. The Burgess Shale and the nature of history. New York: W.W. Norton \& Company.

Grassle, J.F., Lasserre, P., McIntyre, A.D. \& Ray, G.C. (1991). Marine biodiversity and ecosystem function: a proposal for an international programme of research. Biology International 23:1-19.

Gray, J.S. (1997). Marine biodiversity: patterns, threats and conservation needs. Biodiversity and Conservation 6: 153-175.

Grosberg, R.K., Vermeij, G.J. \& Wainwright, P.C. (2012). Biodiversity in water and on land. Current Biology 22: R900-R903. Heessen, H.J.L., Daan, N. \& Ellis, J.R. (eds.) (2015) Fish atlas of the Celtic Sea, North Sea and Baltic Sea: based on international research-vessel surveys. Zeist: KNNV Publishing, Wageningen: Wageningen Academic Publishers.

Holthuis, L. B. and G. R. Heerebout (1986). De Nederlandse Decapoda (garnalen, kreeften en krabben) (herzien door J.P.H.M. Adema), Wetenschappelijke mededelingen K.N.N.V. 179. Koninklijke nederlandse natuurhistorische vereniging strandwerkgemeenschap.

Huwae, P. and G. Rappé (2003). Waterpissebedden : een determineertabel voor de zoet-, brak- en zoutwaterpissebedden van Nederland en België. Wetenschappelijke Mededeling 226. Utrecht, KNNV.

Henkel, D. \& Janussen, D. (2011) Redescription and new records of Celtodoryx ciocalyptoides (Demospongiae: Poecilosclerida) - A sponge invader in the North-East Atlantic Ocean of Asian origin? Journal of the Marine Biological Association of the United Kingdom 91:347-355.

Holtmann, S.E., Groenewold, A., Schrader, K.M.H., Asjes, J., Craeymeersch, J.A., Duinenveld, G.C.A., Van Bostelen, A.J. \& Van der Meer J. (1996) Atlas of the zoobenthos of the Dutch Continental Shelf. Ministry of Transport, Public Works and Water Management, North Sea Directorate: Rijswijk: 244 p.

Lengkeek, W., Didderen, K., Dorenbosch, M., Bouma, S. \& Waardenburg, H.W. (2013) Biodiversiteit van kunstmatige substraten - Een inventarisatie van 10 scheepswrakken op het NCP. Rapport 13226. Bureau Waardenburg, Culemborg.

Lindeboom, H.J., Dijkman, E.M., Bos, O.G., Meesters, E.H., Cremer, J.S.M., De Raad, I., Van Hal, R. \& Bosma A. (2008) Ecologische Atlas Noordzee ten behoeve van gebiedsbescherming. Wageningen IMARES. (http://edepot.wur.nl/251730).

Lock, K., Faasse, M. \& Vanagt T. (2014) An assessment of the soft sediment fauna six years after construction of the Princess Amalia Wind Farm. eCOAST report 2013002. (http://www.ecoast.be/content/documents/2013002\%20PAWP_T6_soft_sediment_benthos_final_j anuary_2014.pdf).

May, R.M. (1994). Biological diversity: differences between land and sea. Philosophical Transactions of the Royal Society B: 343: 105-111.

Ministerie van Economische Zaken (2014) Natuurambitie Grote Wateren 2050 en verder. Den Haag.

Ministerie van Economische Zaken (2016) Kavelbesluit I windenergiegebied Borssele. Staatscourant 2016, nr. 14428.

Ministerie van Infrastructuur en Milieu \& Ministerie van Economische Zaken (2014) Noordzee 2050 Gebiedsagenda. Den Haag.

Ministerie van Infrastructuur en Milieu \& Ministerie van Economische Zaken (2015a) Beleidsnota Noordzee 2016-2021. Den Haag. 
Ministerie van Infrastructuur en Milieu \& Ministerie van Economische Zaken (2015b) Mariene Strategie voor het Nederlandse deel van de Noordzee 2012-2020, deel 3. Den Haag.

Ministerie van Infastructuur en Milieu \& Ministerie van Economische Zaken, Landbouw \& Innovatie (2012) Mariene Strategie voor het Nederlandse deel van de Noordzee 2012-2020, deel 1. Den Haag.

Nijssen H. \& De Groot S.J. (1987) De vissen van Nederland, Vol. Stichting Uitgeverij KNNV

Noordijk, J., Van Loon, A.J., Van Nieukerken, E.J. \& Kleukers, R.M.J.C. (redactie) (2010a) De Nederlandse Biodiversiteit. Nederlands Centrum voor Biodiversiteit Naturalis \& European Invertebrate Survey Nederland, Leiden.

Noordijk, J., Koomen, P., Van Nieukerken, E.J. \& Kleukers, R.M.J.C. (2010b). Samengevat: de Nederlandse biodiversiteit bestaat uit wormen en insecten. In: Noordijk, J., Kleukers, R.M.J.C. \& Van Loon, A.J. (redactie). De Nederlandse biodiversiteit. Nederlandse Fauna 10. Leiden: Nederlands Centrum voor Biodiversiteit Naturalis \& European Invertebrate Survey - Nederland. pp.303-317.

Schrieken, N., Gittenberger, A., Coolen, J. \& Lengkeek, W. (2013) Marine fauna of hard substrata of the Cleaver Bank and Dogger Bank. Nederlandse Faunistische Mededelingen 41:69-78. (http://www.duikdenoordzeeschoon.nl/wpcontent/uploads/Marine_fauna_of_hard_substrata_of_the_Cleaver_Bank_and_Dogger_Bank.pdf).

Schrieken N, Gittenberger A, Lengkeek W (2011) First record of Xandarovula patula (Pennant, 1777) in the Dutch North Sea (Gastropoda, Ovulidae). Basteria: Tijdschrift van de Nederlandse Malacologische Vereniging 7:107-110.Sportvisserij Nederland (2012) Veldgids Nederlandse zeevissen. Sportvisserij Nederland, Bilthoven.

Stegenga, H. \& Mol, I. (1983) Flora van de Nederlandse zeewieren. KNNV, Hoogwoud.

Troost, K. \& Perdon, J. (2016) Species identification workshop 2015; Shellfish and other macrozoobenthos in Dutch coastal waters. Wageningen, IMARES Wageningen UR (University \& Research centre), IMARES internal report 16.001.

Van der Mark, C., Ates, R., De Boois, I., Bor, P., Buizer, B., Van der Burgt, F., Camphuysen, K., Dekker, W., Driessen, F., Den Hartog, K., Huijsman, M., Karremans, M., Oosterbaan, A., Otten, B.G., Perk, F., De Ruijter, E., De Ruijter, G., Van Santbrink, J., Schoenmaker, A., Van Soest, R., Stegenga, H. \& Tulp, A. (2014) Zeeboek. Determinatietabellen voor flora en fauna van de Nederlandse kust . Jeugdbondsuitgeverij, 's Graveland.

Van der Meij, S.E.T. \& Camphuysen, C.J. (2006) The distribution and diversity of whales and dolphins (Cetacea) in the southern North Sea: 1970-2005. Lutra 49:3-28.

Van Moorsel, G.W.N.M. 2003. Ecologie van de Klaverbank. Biotasurvey 2002. Ecosub, Doorn.

Van Soest, R.W., De Kluijver, M.J., Van Bragt, P.H., Faasse, M., Nijland, R., Beglinger, E.J., De Weerdt, W.H. \& De Voogd, N.J. (2007) Sponge invaders in Dutch coastal waters. Journal of the Marine Biological Association of the United Kingdom 87:1733-1748.

Van Soest, R.W.M. (1977) Marine and freshwater sponges (Porifera) of The Netherlands Zoologische Mededelingen 50:261-276. (http://www.repository.naturalis.nl/document/150700).

Vanagt, T.\& Faasse, M. (2014) Development of hard substratum fauna in the Princess Amalia Wind Farm: Monitoring six years after construction. eCOAST report 2013009. eCOAST, Oostende.(http://www.ecoast.be/content/documents/2013009_PAWP_hardsub_rapport_final_april _2014.pdf).

Vandepitte, L., Decock, W. \& Mees, J. (eds) (2010). Belgian Register of Marine Species,

compiled and validated by the VLIZ Belgian Marine Species Consortium. VLIZ Special Publication, 46.

Vlaams Instituut voor de Zee (VLIZ): Oostende, Belgium. 78 pp.

Vervoort, W. \& Faasse, M. (2009) Overzicht van de Nederlandse Leptolida (= Hydroida) (Cnidaria: Hydrozoa) Nederlandse Faunistische Mededelingen 32:5-207. (www.repository.naturalis.nl/document/478191).

Witbaard, R., Lavaleye, M.S.S., Duineveld, G.C.A., Bergman, M.J.N. (2013) Atlas of the Megabenthos (incl. small fish) on the Dutch Continental Shelf of the North Sea. NIOZ-rapport 2013-4. NIOZ, Texel. (www.vliz.be/imisdocs/publications/12/268712.pdf).

Wolff WJ (1976) Distribution of Pantopoda in the estuarine area in the southwestern part of the Netherlands. Journal of Sea Research 10:472-478

Wolff, W.J. (2005) Non-indigenous marine and estuarine species in The Netherlands. Zool Med Leiden 79:1-116. (http://repository.naturalis.nl/document/41874). 


\section{Verantwoording}

Rapport C125/16

Projectnummer: 4318100044

Dit rapport is met grote zorgvuldigheid tot stand gekomen. De wetenschappelijke kwaliteit is intern getoetst door een collega-onderzoeker en het verantwoordelijk lid van het managementteam van Wageningen Marine Research

Akkoord:

Joop W.P. Coolen

Onderzoeker benthische ecologie

Handtekening:

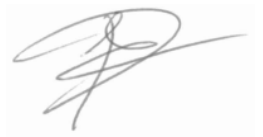

Datum:

23 december 2016

Akkoord:

Jakob Asjes

Manager integratie

Handtekening:

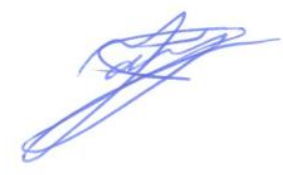

Datum:

23 december 2016 


\section{Bijlage 1 Soortenlijst Noordzee}

\section{LEGENDA}

Waarde in cellen: 1 =aanwezig, leeg=geen data of niet aanwezig.

De Noordzee-soortenlijst is een selectie uit de veel uitgebreidere lijst van Nederlandse zout- en brakwatersoorten (zie ook 'Methoden') en is gemaakt door als geografisch deelgebied te kiezen: Noordzee $(0-60 \mathrm{~m})$. De aanwezigheid in de Noordzee is vastgesteld op basis van databases en literatuur, waarbij geldt dat nog niet voor alle soorten de literatuur kon worden gecontroleerd (zie 'Discussie') en dus dat de lijst nog niet compleet is. Doel is om de lijst in de toekomst te verbeteren. Verder zijn alleen de soorten geselecteerd waarvoor geldt: periodiek of incidenteel aanwezig. Dit zijn alle soorten in de NSR-categorieën 0a, 1, 1a, 1b, 2a, 2b, 2c (zie 'Methoden').

Voor elke Noordzeesoort is aangegeven:

- Exoot/inheems/onbekend

- Taxonomische indeling volgens Noordijk et al. (2010a), tot op fylumniveau.

- $\quad$ De geaccepteerde AphiaID volgens WoRMS (www.marinespecies.org)

- De geaccepteerde wetenschappelijke naam en auteur volgens WoRMS (www.marinespecies.org)

- De Nederlandse naam uit het Nederlandse Soortenregister (NSR) en/of het Zeeboek (Van der Mark et al., 2014)

- Aanwezigheid in Noordzee (0-60 m, 02-10 m, 20-60 m) (zie 'Methoden')

- $\quad$ Aanwezigheid in een van de andere gebieden (Waddenzee, Oosterschelde, Westerschelde, Grevelingen)

- Aanwezigheid op hard en/of zacht substraat (zie 'Methoden')

Deze bijlage bevat twee tabellen:

Tabel B1.1: Noordzeesoorten behalve vogels.

Tabel B1.2: Noordzeevogels. 


\begin{tabular}{|c|c|c|c|c|c|c|c|c|c|c|c|c|c|c|c|}
\hline $\mathrm{Nr}$ & 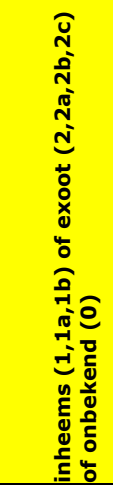 & Nr.Rijk & Nr.Phylum & 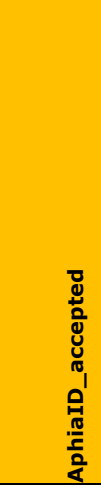 & Wetenschappelijke naam en auteur & $\begin{array}{l}\text { NL Naam uit NSR en/of } \\
\text { Zeeboek }\end{array}$ & 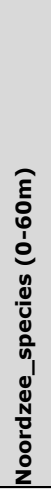 & 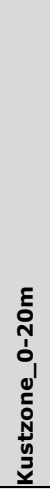 & 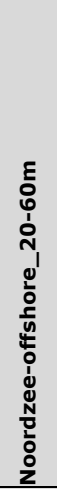 & 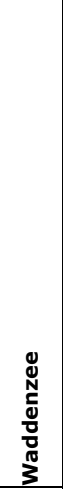 & 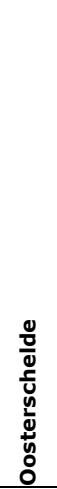 & 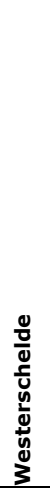 & 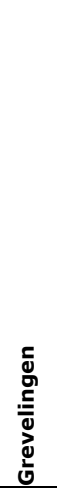 & 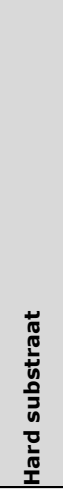 & 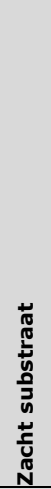 \\
\hline 1 & inheems & 1.Planten & 1.Roodwieren - Rhodophyta & 144354 & $\begin{array}{l}\text { Acrochaetium hallandicum (Kylin) G.Hamel, } \\
1927\end{array}$ & & 1 & 1 & & 1 & 1 & & & & \\
\hline 2 & inheems & 1.Planten & 1.Roodwieren - Rhodophyta & 144356 & $\begin{array}{l}\text { Acrochaetium humile (Rosenvinge) Børgesen, } \\
1915\end{array}$ & & 1 & 1 & & & 1 & & & & \\
\hline 3 & inheems & 1.Planten & 1.Roodwieren - Rhodophyta & 144386 & $\begin{array}{l}\text { Acrochaetium savianum (Meneghini) Nägeli, } \\
1862\end{array}$ & & 1 & 1 & & 1 & 1 & & 1 & & \\
\hline 4 & inheems & 1.Planten & 1.Roodwieren - Rhodophyta & 144387 & $\begin{array}{l}\text { Acrochaetium secundatum (Lyngbye) Nägeli, } \\
1858\end{array}$ & & 1 & 1 & & 1 & 1 & 1 & 1 & & \\
\hline 5 & inheems & 1.Planten & 1.Roodwieren - Rhodophyta & 144496 & $\begin{array}{l}\text { Aglaothamnion hookeri (Dillwyn) Maggs \& } \\
\text { Hommersand, } 1993\end{array}$ & & 1 & 1 & & 1 & 1 & 1 & 1 & & \\
\hline 6 & inheems & 1.Planten & 1.Roodwieren - Rhodophyta & 144501 & $\begin{array}{l}\text { Aglaothamnion tenuissimum (Bonnemaison) } \\
\text { Feldmann-Mazoyer, } 1941\end{array}$ & & 1 & 1 & & 1 & 1 & 1 & 1 & & \\
\hline 7 & inheems & 1.Planten & 1.Roodwieren - Rhodophyta & 144422 & Ahnfeltia plicata (Hudson) E.M.Fries, 1836 & & 1 & 1 & & & & & & & \\
\hline 8 & inheems & 1.Planten & 1.Roodwieren - Rhodophyta & 144545 & $\begin{array}{l}\text { Ceramium deslongchampsii Chauvin ex Duby, } \\
1830\end{array}$ & Hollands hoorntjeswier & 1 & 1 & & 1 & 1 & 1 & & & \\
\hline 9 & inheems & 1.Planten & 1.Roodwieren - Rhodophyta & 164103 & Colaconema daviesii (Dillwyn) Stegenga, 1985 & & 1 & 1 & & 1 & 1 & & & & \\
\hline 10 & inheems & 1.Planten & 1.Roodwieren - Rhodophyta & 503115 & $\begin{array}{l}\text { Colaconema hallandicum (Kylin) Afonso- } \\
\text { Carillo, Sanson, Sangil \& Diaz-Villa, } 2007\end{array}$ & & 1 & 1 & & 1 & 1 & & & & \\
\hline 11 & inheems & 1.Planten & 1.Roodwieren - Rhodophyta & 162875 & $\begin{array}{l}\text { Colaconema nemalionis (De Notaris ex } \\
\text { L.Dufour) Stegenga, } 1985\end{array}$ & & 1 & 1 & & 1 & 1 & & & & \\
\hline 12 & inheems & 1.Planten & 1.Roodwieren - Rhodophyta & 145490 & Erythrotrichia carnea (Dillwyn) J.Agardh, 1883 & & 1 & 1 & & 1 & 1 & 1 & 1 & & \\
\hline 13 & inheems & 1.Planten & 1.Roodwieren - Rhodophyta & 145712 & $\begin{array}{l}\text { Hildenbrandia rubra (Sommerfelt) Meneghini, } \\
1841\end{array}$ & Wijnrood korstwier & 1 & 1 & & 1 & 1 & 1 & 1 & & \\
\hline 14 & inheems & 1.Planten & 1.Roodwieren - Rhodophyta & 145650 & $\begin{array}{l}\text { Mastocarpus stellatus (Stackhouse) Guiry, } \\
1984\end{array}$ & Kernwier & 1 & 1 & & 1 & 1 & 1 & & & \\
\hline 15 & inheems & 1.Planten & 1.Roodwieren - Rhodophyta & 145664 & $\begin{array}{l}\text { Phyllophora pseudoceranoides (S.G.Gmelin) } \\
\text { Newroth \& A.R.A.Taylor, } 1971\end{array}$ & & 1 & 1 & & 1 & 1 & 1 & & & \\
\hline 16 & inheems & 1.Planten & 1.Roodwieren - Rhodophyta & 145202 & $\begin{array}{l}\text { Phymatolithon lenormandii (Areschoug) } \\
\text { W.H.Adey, } 1966\end{array}$ & Rose kalkkorstwier & 1 & 1 & & 1 & 1 & 1 & & & \\
\hline 17 & inheems & 1.Planten & 1.Roodwieren - Rhodophyta & 144639 & Polysiphonia fucoides (Hudson) Greville, 1824 & Donker buiswier & 1 & 1 & & 1 & 1 & 1 & 1 & & \\
\hline 18 & inheems & 1.Planten & 1.Roodwieren - Rhodophyta & 144431 & Porphyra linearis Greville, 1830 & & 1 & 1 & & 1 & 1 & 1 & & & \\
\hline 19 & inheems & 1.Planten & 1.Roodwieren - Rhodophyta & 144434 & Porphyra purpurea (Roth) C.Agardh, 1824 & Purperwier & 1 & 1 & & 1 & 1 & 1 & 1 & & \\
\hline 20 & inheems & 1.Planten & 1.Roodwieren - Rhodophyta & 145502 & $\begin{array}{l}\text { Sahlingia subintegra (Rosenvinge) Kornmann, } \\
1989\end{array}$ & & 1 & 1 & & 1 & 1 & 1 & 1 & & \\
\hline 21 & inheems & 1.Planten & 1.Roodwieren - Rhodophyta & 145688 & Stylonema alsidii (Zanardini) K.M.Drew, 1956 & & 1 & 1 & & 1 & 1 & 1 & 1 & & \\
\hline 22 & inheems & 1.Planten & 1.Roodwieren - Rhodophyta & 475211 & $\begin{array}{l}\text { Vertebrata lanosa (Linnaeus) T.A.Christensen, } \\
1967\end{array}$ & Klein buiswier & 1 & 1 & & 1 & 1 & 1 & 1 & & \\
\hline 23 & inheems & 1.Planten & 2.Groenwieren - Chlorophyta & 145950 & $\begin{array}{l}\text { Blidingia minima (Nägeli ex Kützing) Kylin, } \\
1947\end{array}$ & Klein darmwier & 1 & 1 & 1 & 1 & & & & 1 & \\
\hline
\end{tabular}

| 48 van 99 | Wageningen Marine Research rapport C125/16 


\begin{tabular}{|c|c|c|c|c|c|c|c|c|c|c|c|c|c|c|c|}
\hline 24 & inheems & 1.Planten & 2.Groenwieren - Chlorophyta & 144457 & Bryopsis plumosa (Hudson) C.Agardh, 1823 & Vederwier & 1 & 1 & & 1 & 1 & 1 & & & \\
\hline 25 & inheems & 1.Planten & 2.Groenwieren - Chlorophyta & 145020 & Chaetomorpha aerea (Dillwyn) Kützing, 1849 & & 1 & 1 & & & 1 & 1 & & & \\
\hline 26 & inheems & 1.Planten & 2.Groenwieren - Chlorophyta & 145029 & $\begin{array}{l}\text { Chaetomorpha melagonium (F.Weber \& Mohr) } \\
\text { Kützing, } 1845\end{array}$ & & 1 & 1 & & & 1 & 1 & & & \\
\hline 27 & inheems & 1.Planten & 2.Groenwieren - Chlorophyta & 145063 & $\begin{array}{l}\text { Cladophora ruchingeri (C.Agardh) Kützing, } \\
1845\end{array}$ & & 1 & 1 & & & & & & & \\
\hline 28 & inheems & 1.Planten & 2.Groenwieren - Chlorophyta & 145064 & Cladophora rupestris (Linnaeus) Kützing, 1843 & Rotswier takwier & 1 & 1 & & 1 & 1 & 1 & & & \\
\hline 29 & exoot & 1.Planten & 2.Groenwieren - Chlorophyta & 145086 & Codium fragile (Suringar) Hariot, 1889 & Viltwier & 1 & 1 & & 1 & 1 & 1 & & & \\
\hline 30 & exoot & 1.Planten & 2.Groenwieren - Chlorophyta & 370562 & $\begin{array}{l}\text { Codium fragile subsp. fragile (Suringar) } \\
\text { Hariot, } 1889\end{array}$ & & 1 & 1 & & 1 & 1 & 1 & 1 & & \\
\hline 31 & inheems & 1.Planten & 2.Groenwieren - Chlorophyta & 144903 & $\begin{array}{l}\text { Gomontia polyrhiza (Lagerheim) Bornet \& } \\
\text { Flahault, } 1888\end{array}$ & & 1 & 1 & & 1 & 1 & 1 & 1 & & \\
\hline 32 & inheems & 1.Planten & 2.Groenwieren - Chlorophyta & 145800 & $\begin{array}{l}\text { Prasiola stipitata Suhr ex Jessen, } 1848 \\
\end{array}$ & Dambordwier & 1 & 1 & 1 & & & & & 1 & \\
\hline 33 & inheems & 1.Planten & 2.Groenwieren - Chlorophyta & 144879 & Pseudendoclonium submarinum Wille, 1901 & & 1 & 1 & & 1 & 1 & 1 & 1 & & \\
\hline 34 & inheems & 1.Planten & 2.Groenwieren - Chlorophyta & 144413 & $\begin{array}{l}\text { Spongomorpha aeruginosa (Linnaeus) Hoek, } \\
1963\end{array}$ & & 1 & 1 & & 1 & & & & & \\
\hline 35 & inheems & 1.Planten & 2.Groenwieren - Chlorophyta & 144883 & $\begin{array}{l}\text { Syncoryne reinkei R.Nielsen \& P.M.Pedersen, } \\
1977\end{array}$ & & 1 & 1 & & & & & & & \\
\hline 36 & inheems & 1.Planten & 2.Groenwieren - Chlorophyta & 144884 & Tellamia contorta Batters, 1895 & & 1 & 1 & & 1 & 1 & 1 & 1 & & \\
\hline 37 & inheems & 1.Planten & 2.Groenwieren - Chlorophyta & 145925 & Ulothrix flacca (Dillwyn) Thuret, 1863 & & 1 & 1 & & 1 & 1 & 1 & 1 & & \\
\hline 38 & inheems & 1.Planten & 2.Groenwieren - Chlorophyta & 145930 & Ulothrix speciosa (Carmichael) Kützing, 1849 & & 1 & 1 & & 1 & 1 & 1 & 1 & & \\
\hline 39 & inheems & 1.Planten & 2.Groenwieren - Chlorophyta & 156078 & Ulva clathrata (Roth) C.Agardh, 1811 & & 1 & 1 & & 1 & 1 & 1 & & & \\
\hline 40 & inheems & 1.Planten & 2.Groenwieren - Chlorophyta & 234462 & Ulva compressa Linnaeus, 1753 & Plat darmwier & 1 & 1 & & 1 & 1 & 1 & 1 & & \\
\hline 41 & inheems & 1.Planten & 2.Groenwieren - Chlorophyta & 234471 & Ulva intestinalis Linnaeus, 1753 & & 1 & 1 & 1 & 1 & & & & 1 & \\
\hline 42 & inheems & 1.Planten & 2.Groenwieren - Chlorophyta & 145984 & Ulva lactuca Linnaeus, 1753 & Zeesla & 1 & & & 1 & & & & & 1 \\
\hline 43 & inheems & 1.Planten & 2.Groenwieren - Chlorophyta & 234474 & Ulva linza Linnaeus, 1753 & Breed darmwier & 1 & 1 & 1 & 1 & & & & 1 & \\
\hline 44 & inheems & 1.Planten & 2.Groenwieren - Chlorophyta & 145988 & Ulva pseudocurvata Koeman \& Hoek, 1981 & Gekromde zeesla & 1 & 1 & & 1 & 1 & 1 & 1 & & \\
\hline 45 & inheems & 1.Planten & 2.Groenwieren - Chlorophyta & 162545 & $\begin{array}{l}\text { Urospora bangioides (Harvey) Holmes \& } \\
\text { Batters, } 1891\end{array}$ & & 1 & 1 & & 1 & 1 & 1 & 1 & & \\
\hline 46 & inheems & 1.Planten & 2.Groenwieren - Chlorophyta & 144419 & $\begin{array}{l}\text { Urospora neglecta (Kornmann) Lokhorst \& } \\
\text { Trask, } 1981\end{array}$ & & 1 & 1 & & 1 & 1 & 1 & 1 & & \\
\hline 47 & inheems & 1.Planten & 2.Groenwieren - Chlorophyta & 144420 & $\begin{array}{l}\text { Urospora penicilliformis (Roth) Areschoug, } \\
1866\end{array}$ & & 1 & 1 & & 1 & 1 & 1 & 1 & & \\
\hline 48 & inheems & 1.Planten & 2.Groenwieren - Chlorophyta & 144421 & $\begin{array}{l}\text { Urospora wormskioldii (Mertens ex } \\
\text { Hornemann) Rosenvinge, } 1893\end{array}$ & & 1 & 1 & & 1 & 1 & 1 & 1 & & \\
\hline 49 & inheems & $\begin{array}{l}\text { 2.Chromoalveolata } \\
\text { (supergroep) }\end{array}$ & 1. Heterokontophyta & 145541 & $\begin{array}{l}\text { Ascophyllum nodosum (Linnaeus) Le Jolis, } \\
1863\end{array}$ & Knotswier & 1 & 1 & & 1 & 1 & 1 & 1 & & \\
\hline 50 & inheems & $\begin{array}{l}\text { 2.Chromoalveolata } \\
\text { (supergroep) }\end{array}$ & 1. Heterokontophyta & 145404 & Ectocarpus fasciculatus Harvey, 1841 & & 1 & 1 & & 1 & 1 & 1 & 1 & & \\
\hline 51 & inheems & $\begin{array}{l}\text { 2.Chromoalveolata } \\
\text { (supergroep) }\end{array}$ & 1. Heterokontophyta & 144937 & Elachista fucicola (Velley) Areschoug, 1842 & Dwergwier & 1 & 1 & & 1 & 1 & 1 & 1 & & \\
\hline 52 & inheems & $\begin{array}{l}\text { 2.Chromoalveolata } \\
\text { (supergroep) }\end{array}$ & 1. Heterokontophyta & 145546 & Fucus serratus Linnaeus, 1753 & Gezaagde zee-eik; gezaagde zeeeik & 1 & 1 & & 1 & 1 & 1 & 1 & & \\
\hline 53 & inheems & $\begin{array}{l}\text { 2.Chromoalveolata } \\
\text { (supergroep) }\end{array}$ & 1. Heterokontophyta & 145547 & Fucus spiralis Linnaeus, 1753 & Kleine zee-eik & 1 & 1 & & 1 & 1 & 1 & 1 & & \\
\hline 54 & inheems & $\begin{array}{l}\text { 2.Chromoalveolata } \\
\text { (supergroep) }\end{array}$ & 1. Heterokontophyta & 145324 & Giraudia sphacelarioides Derbès \& Solier, 1851 & & 1 & 1 & & 1 & 1 & 1 & 1 & & \\
\hline 55 & inheems & $\begin{array}{l}\text { 2.Chromoalveolata } \\
\text { (supergroep) }\end{array}$ & 1. Heterokontophyta & 145341 & Hecatonema terminale (Kützing) Kylin, 1937 & & 1 & 1 & & & & & & & \\
\hline 56 & inheems & $\begin{array}{l}\text { 2.Chromoalveolata } \\
\text { (supergroep) }\end{array}$ & 1. Heterokontophyta & 145351 & $\begin{array}{l}\text { Isthmoplea sphaerophora (Carmichael) Gobi, } \\
1878\end{array}$ & & 1 & 1 & & & & & & & \\
\hline 57 & inheems & $\begin{array}{l}\text { 2.Chromoalveolata } \\
\text { (supergroep) }\end{array}$ & 1. Heterokontophyta & 145724 & $\begin{array}{l}\text { Laminaria digitata (Hudson) J.V.Lamouroux, } \\
1813\end{array}$ & Vingerwier & 1 & 1 & & & & & & & \\
\hline 58 & inheems & $\begin{array}{l}\text { 2.Chromoalveolata } \\
\text { (supergroep) }\end{array}$ & 1. Heterokontophyta & 145865 & Petalonia zosterifolia (Reinke) Kuntze, 1898 & & 1 & 1 & & 1 & 1 & 1 & & & \\
\hline
\end{tabular}




\begin{tabular}{|c|c|c|c|c|c|c|c|c|c|c|c|c|c|c|c|}
\hline 59 & inheems & $\begin{array}{l}\text { 2.Chromoalveolata } \\
\text { (supergroep) }\end{array}$ & 1. Heterokontophyta & 144990 & $\begin{array}{l}\text { Pseudolithoderma extensum (P.L.Crouan \& } \\
\text { H.M.Crouan) S.Lund, } 1959\end{array}$ & & 1 & 1 & & 1 & & & & & \\
\hline 60 & inheems & $\begin{array}{l}\text { 2.Chromoalveolata } \\
\text { (supergroep) }\end{array}$ & 1. Heterokontophyta & 145001 & $\begin{array}{l}\text { Ralfsia verrucosa (Areschoug) Areschoug, } \\
1845\end{array}$ & Bruin korstwier & 1 & 1 & & 1 & 1 & 1 & 1 & & \\
\hline 61 & inheems & $\begin{array}{l}\begin{array}{l}\text { 2.Chromoalveolata } \\
\text { (supergroep) }\end{array} \\
\text { (sula }\end{array}$ & 1. Heterokontophyta & 234483 & $\begin{array}{l}\text { Saccharina latissima (Linnaeus) C.E.Lane, } \\
\text { C.Mayes, Druehl \& G.W.Saunders, } 2006\end{array}$ & Suikerwier & 1 & 1 & & 1 & 1 & & & & \\
\hline 62 & exoot & $\begin{array}{l}\begin{array}{l}\text { 2.Chromoalveolata } \\
\text { (supergroep) }\end{array} \\
\end{array}$ & 1. Heterokontophyta & 494791 & Sargassum muticum (Yendo) Fensholt, 1955 & Japans bessenwier & 1 & & & 1 & 1 & & 1 & & 1 \\
\hline 63 & inheems & $\begin{array}{l}\text { 2.Chromoalveolata } \\
\text { (supergroep) }\end{array}$ & 1. Heterokontophyta & 145902 & Sphacelaria rigidula Kützing, 1843 & & 1 & 1 & & 1 & 1 & 1 & 1 & & \\
\hline 64 & inheems & $\begin{array}{l}\begin{array}{l}\text { 2.Chromoalveolata } \\
\text { (supergroep) }\end{array} \\
\text { (sula }\end{array}$ & 1. Heterokontophyta & 145459 & $\begin{array}{l}\text { Spongonema tomentosum (Hudson) Kützing, } \\
1849\end{array}$ & & 1 & 1 & & 1 & 1 & & & & \\
\hline 65 & inheems & $\begin{array}{l}\text { 2.Chromoalveolata } \\
\text { (supergroep) }\end{array}$ & 1. Heterokontophyta & 145002 & Stragularia clavata (Harvey) G.Hamel, 1939 & & 1 & 1 & & 1 & 1 & 1 & 1 & & \\
\hline 66 & exoot & $\begin{array}{l}\text { 2.Chromoalveolata } \\
\text { (supergroep) }\end{array}$ & 2.Pantserwieren - Dinoflagellata & 109710 & Alexandrium leei Balech, 1985 & & 1 & & 1 & & & & & & \\
\hline 67 & inheems & $\begin{array}{l}\text { 2.Chromoalveolata } \\
\text { (supergroep) }\end{array}$ & 2.Pantserwieren - Dinoflagellata & 109714 & Alexandrium tamarense (Lebour) Balech, 1995 & & 1 & 1 & 1 & & 1 & & & & \\
\hline 68 & exoot & $\begin{array}{l}\text { 2.Chromoalveolata } \\
\text { (supergroep) }\end{array}$ & 2.Pantserwieren - Dinoflagellata & 233024 & $\begin{array}{l}\text { Karenia mikimotoi (Miyake } \& \text { Kominami ex } \\
\text { Oda) Gert Hansen \& Ø.Moestrup, } 2000\end{array}$ & & 1 & 1 & 1 & & & & & & \\
\hline 69 & inheems & $\begin{array}{l}\text { 2.Chromoalveolata } \\
\text { (supergroep) }\end{array}$ & 2.Pantserwieren - Dinoflagellata & 110316 & Prorocentrum triestinum J.Schiller, 1918 & & 1 & 1 & & 1 & & 1 & & & \\
\hline 70 & inheems & $\begin{array}{l}\text { 2.Chromoalveolata } \\
\text { (supergroep) }\end{array}$ & 3.Foraminiferen - Foraminifera & 113737 & Spirillina vivipara Ehrenberg, 1843 & & 1 & & 1 & & & & & 1 & \\
\hline 71 & inheems & 3.Dieren & 01.Sponzen - Porifera & 132233 & Leucosolenia variabilis Haeckel, 1870 & Witte buisjesspons & 1 & 1 & 1 & 1 & & & & 1 & \\
\hline 72 & inheems & 3.Dieren & 01.Sponzen - Porifera & 132251 & Sycon ciliatum (Fabricius, 1780) & Gewone zakspons zakspons & 1 & & 1 & 1 & & & & 1 & 1 \\
\hline 73 & inheems & 3.Dieren & 01.Sponzen - Porifera & 134121 & Cliona celata Grant, 1826 & Boorspons & 1 & & 1 & & & & & 1 & \\
\hline 74 & inheems & 3.Dieren & 01.Sponzen - Porifera & 165801 & $\begin{array}{l}\text { Halichondria (Halichondria) bowerbanki } \\
\text { Burton, } 1930\end{array}$ & Sliertige broodspons & 1 & & 1 & 1 & & & & 1 & 1 \\
\hline 75 & inheems & 3.Dieren & 01.Sponzen - Porifera & 165853 & $\begin{array}{l}\text { Halichondria (Halichondria) panicea (Pallas, } \\
1766 \text { ) }\end{array}$ & Broodspons; gewone broodspons & 1 & 1 & 1 & 1 & & & & 1 & 1 \\
\hline 76 & inheems & 3.Dieren & 01.Sponzen - Porifera & 132833 & Haliclona (Haliclona) oculata (Linnaeus, 1759) & Geweispons & 1 & & 1 & & & & & 1 & 1 \\
\hline 77 & inheems & 3.Dieren & 01.Sponzen - Porifera & 132883 & Haliclona (Soestella) xena De Weerdt, 1986 & Paarse buisjesspons & 1 & & 1 & 1 & & & & 1 & \\
\hline 78 & exoot & 3.Dieren & 01.Sponzen - Porifera & 132663 & Hymeniacidon perlevis (Montagu, 1814) & Piekjesspons & 1 & & 1 & 1 & 1 & & & 1 & \\
\hline 79 & inheems & 3.Dieren & 01.Sponzen - Porifera & 168587 & Mycale (Carmia) macilenta (Bowerbank, 1866) & & 1 & & 1 & & & & & 1 & \\
\hline 80 & exoot & 3.Dieren & 01.Sponzen - Porifera & 168589 & $\begin{array}{l}\text { Mycale (Carmia) micracanthoxea Buizer \& van } \\
\text { Soest, } 1977\end{array}$ & Grijze korstspons & 1 & & 1 & & 1 & 1 & & 1 & \\
\hline 81 & inheems & 3.Dieren & 01.Sponzen - Porifera & 169488 & Myxilla (Myxilla) rosacea (Lieberkühn, 1859) & Roze slijmspons & 1 & & 1 & & & & & 1 & \\
\hline 82 & inheems & 3.Dieren & 01.Sponzen - Porifera & 134282 & Suberites domuncula (Olivi, 1792) & & 1 & & 1 & & & & & 1 & \\
\hline 83 & inheems & 3.Dieren & 01.Sponzen - Porifera & 134285 & Suberites ficus & & 1 & 1 & 1 & & 1 & & & & 1 \\
\hline 84 & inheems & 3.Dieren & 01.Sponzen - Porifera & 150237 & Suberites pagurorum & & 1 & & 1 & & & & & & 1 \\
\hline 85 & inheems & 3.Dieren & 01.Sponzen - Porifera & 134303 & Suberites suberia (Montagu, 1814) & & 1 & & 1 & & & & & 1 & \\
\hline 86 & inheems & 3.Dieren & 01.Sponzen - Porifera & 134305 & Suberites virgultosus (Johnston, 1842) & & 1 & 1 & 1 & & 1 & & & & \\
\hline 87 & inheems & 3.Dieren & 02.Ribkwallen - Ctenophora & 106386 & Pleurobrachia pileus (O. F. Müller, 1776) & Zeeduifje zeedruif & 1 & 1 & 1 & 1 & & & & & 1 \\
\hline 88 & inheems & 3.Dieren & $\begin{array}{l}\text { 03. Holtedieren, neteldieren - } \\
\text { Cnidaria }\end{array}$ & 100803 & Actinia equina (Linnaeus, 1758) & $\begin{array}{l}\text { Rode paardenanemoon; } \\
\text { paardeanemoon }\end{array}$ & 1 & 1 & 1 & & & & & 1 & \\
\hline 89 & inheems & 3.Dieren & $\begin{array}{l}\text { 03.Holtedieren, neteldieren - } \\
\text { Cnidaria }\end{array}$ & 100986 & Actinothoe sphyrodeta (Gosse, 1858) & Margrietje & 1 & 1 & 1 & & & & & 1 & \\
\hline 90 & inheems & 3.Dieren & $\begin{array}{l}\text { 03.Holtedieren, neteldieren - } \\
\text { Cnidaria }\end{array}$ & 125333 & Alcyonium digitatum Linnaeus, 1758 & Doomansduim; dodemansduim & 1 & 1 & 1 & 1 & & & & 1 & 1 \\
\hline 91 & inheems & 3.Dieren & $\begin{array}{l}\text { 03.Holtedieren, neteldieren - } \\
\text { Cnidaria }\end{array}$ & 283798 & Cerianthus Iloydii Gosse, 1859 & Viltkokeranemoon & 1 & & 1 & & & & & 1 & 1 \\
\hline 92 & inheems & 3.Dieren & $\begin{array}{l}\text { 03. Holtedieren, neteldieren - } \\
\text { Cnidaria }\end{array}$ & 101016 & Corynactis viridis Allman, 1846 & Juweelanemoon & 1 & & 1 & & & & & 1 & \\
\hline
\end{tabular}

| 50 van 99 | Wageningen Marine Research rapport C125/16 


\begin{tabular}{|c|c|c|c|c|c|c|c|c|c|c|c|c|c|c|c|}
\hline 93 & exoot & 3.Dieren & $\begin{array}{l}\text { 03. Holtedieren, neteldieren - } \\
\text { Cnidaria }\end{array}$ & 100872 & Diadumene cincta Stephenson, 1925 & Golfbrekeranemoon & 1 & 1 & 1 & 1 & & & & 1 & \\
\hline 94 & exoot & 3.Dieren & $\begin{array}{l}\text { 03.Holtedieren, neteldieren - } \\
\text { Cnidaria }\end{array}$ & 395099 & Diadumene lineata (Verrill, 1869) & Groene golfbrekeranemoon & 1 & & 1 & 1 & 1 & 1 & & 1 & \\
\hline 95 & exoot & 3.Dieren & $\begin{array}{l}\text { 03.Holtedieren, neteldieren - } \\
\text { Cnidaria }\end{array}$ & 100880 & Edwardsia claparedii (Panceri, 1869) & & 1 & & 1 & & & & & & 1 \\
\hline 96 & inheems & 3.Dieren & $\begin{array}{l}03 . \text { Holtedieren, neteldieren - } \\
\text { Cnidaria }\end{array}$ & 100951 & Hormathia digitata & & 1 & & 1 & & & & & & 1 \\
\hline 97 & inheems & 3.Dieren & $\begin{array}{l}\text { 03.Holtedieren, neteldieren - } \\
\text { Cnidaria }\end{array}$ & 158251 & Metridium dianthus (Ellis, 1768) & Zeeanjelier & 1 & 1 & 1 & 1 & & & & 1 & 1 \\
\hline 98 & inheems & 3.Dieren & $\begin{array}{l}\text { 03.Holtedieren, neteldieren - } \\
\text { Cnidaria }\end{array}$ & 100927 & Peachia cylindrica (Reid, 1848) & & 1 & & 1 & & & & & 1 & 1 \\
\hline 99 & inheems & 3.Dieren & $\begin{array}{l}\text { 03.Holtedieren, neteldieren - } \\
\text { Cnidaria }\end{array}$ & 128517 & Pennatula phosphorea & & 1 & & 1 & & & & & & 1 \\
\hline 100 & inheems & 3.Dieren & $\begin{array}{l}\text { 03.Holtedieren, neteldieren - } \\
\text { Cnidaria }\end{array}$ & 100991 & Sagartia elegans (Dalyell, 1848) & Sierlijke slibanemoon & 1 & 1 & 1 & 1 & & & & 1 & 1 \\
\hline 101 & inheems & 3.Dieren & $\begin{array}{l}\text { 03. Holtedieren, neteldieren - } \\
\text { Cnidaria }\end{array}$ & 100994 & Sagartia troglodytes (Price in Johnston, 1847) & Slibanemoon & 1 & 1 & 1 & 1 & & & & 1 & 1 \\
\hline 102 & inheems & 3.Dieren & $\begin{array}{l}\text { 03.Holtedieren, neteldieren - } \\
\text { Cnidaria }\end{array}$ & 101002 & Sagartiogeton undatus (Müller, 1778) & Weduweroos & 1 & 1 & 1 & 1 & & & & 1 & 1 \\
\hline 103 & inheems & 3.Dieren & $\begin{array}{l}\text { 03.Holtedieren, neteldieren - } \\
\text { Cnidaria }\end{array}$ & 100854 & Stomphia coccinea & & 1 & & 1 & & & & & & 1 \\
\hline 104 & inheems & 3.Dieren & $\begin{array}{l}\text { 03.Holtedieren, neteldieren - } \\
\text { Cnidaria }\end{array}$ & 100834 & Urticina felina (Linnaeus, 1761) & Zeedahlia & 1 & 1 & 1 & 1 & & & & 1 & 1 \\
\hline 105 & inheems & 3.Dieren & $\begin{array}{l}\text { 03.Holtedieren, neteldieren - } \\
\text { Cnidaria }\end{array}$ & 117870 & Abietinaria abietina (Linnaeus, 1758) & & 1 & & 1 & & 1 & & & 1 & 1 \\
\hline 106 & inheems & 3.Dieren & $\begin{array}{l}\text { 03.Holtedieren, neteldieren - } \\
\text { Cnidaria }\end{array}$ & 117270 & Aequorea forskalea Péron \& Lesueur, 1810 & & 1 & 1 & 1 & 1 & 1 & & & & \\
\hline 107 & inheems & 3.Dieren & $\begin{array}{l}\text { 03. Holtedieren, neteldieren - } \\
\text { Cnidaria }\end{array}$ & 117273 & Aequorea vitrina Gosse, 1853 & Lampenkapje & 1 & 1 & 1 & 1 & 1 & & 1 & & 1 \\
\hline 108 & inheems & 3.Dieren & $\begin{array}{l}\text { 03.Holtedieren, neteldieren - } \\
\text { Cnidaria }\end{array}$ & 117849 & Aglantha digitale (O. F. Müller, 1776) & & 1 & 1 & & 1 & & & & & \\
\hline 109 & inheems & 3.Dieren & $\begin{array}{l}\text { 03.Holtedieren, neteldieren - } \\
\text { Cnidaria }\end{array}$ & 117283 & Aglaophenia pluma (Linnaeus, 1758) & & 1 & 1 & & & & & & & \\
\hline 110 & inheems & 3.Dieren & $\begin{array}{l}\text { 03.Holtedieren, neteldieren - } \\
\text { Cnidaria }\end{array}$ & 117320 & Bimeria vestita Wright, 1859 & & 1 & 1 & 1 & & 1 & 1 & & 1 & \\
\hline 111 & inheems & 3.Dieren & $\begin{array}{l}\text { 03.Holtedieren, neteldieren - } \\
\text { Cnidaria }\end{array}$ & 117321 & Bougainvillia britannica (Forbes, 1841) & & 1 & 1 & 1 & 1 & & & & & 1 \\
\hline 112 & inheems & 3.Dieren & $\begin{array}{l}\text { 03.Holtedieren, neteldieren - } \\
\text { Cnidaria }\end{array}$ & 117328 & Bougainvillia muscus (Allman, 1863) & & 1 & 1 & 1 & 1 & 1 & 1 & 1 & 1 & \\
\hline 113 & inheems & 3.Dieren & $\begin{array}{l}\text { 03.Holtedieren, neteldieren - } \\
\text { Cnidaria }\end{array}$ & 117329 & Bougainvillia principis (Steenstrup, 1850) & & 1 & 1 & & & & & & & \\
\hline 114 & inheems & 3.Dieren & $\begin{array}{l}\text { 03. Holtedieren, neteldieren - } \\
\text { Cnidaria }\end{array}$ & 117333 & Bougainvillia superciliaris (L. Agassiz, 1849) & & 1 & 1 & & 1 & & & & & \\
\hline 115 & inheems & 3.Dieren & $\begin{array}{l}\text { 03.Holtedieren, neteldieren - } \\
\text { Cnidaria }\end{array}$ & 117402 & Calycella syringa (Linnaeus, 1767) & & 1 & 1 & & 1 & 1 & 1 & 1 & 1 & 1 \\
\hline 116 & inheems & 3.Dieren & $\begin{array}{l}\text { 03.Holtedieren, neteldieren - } \\
\text { Cnidaria }\end{array}$ & 117426 & Clava multicornis (Forsskål, 1775) & & 1 & 1 & & 1 & 1 & 1 & 1 & & \\
\hline 117 & inheems & 3.Dieren & $\begin{array}{l}\text { 03.Holtedieren, neteldieren - } \\
\text { Cnidaria }\end{array}$ & 117367 & Clytia gracilis (Sars, 1850) & & 1 & 1 & & 1 & 1 & & & 1 & 1 \\
\hline 118 & inheems & 3.Dieren & $\begin{array}{l}\text { 03.Holtedieren, neteldieren - } \\
\text { Cnidaria }\end{array}$ & 117368 & Clytia hemisphaerica (Linnaeus, 1767) & & 1 & 1 & 1 & 1 & 1 & 1 & 1 & 1 & 1 \\
\hline 119 & exoot & 3.Dieren & $\begin{array}{l}\text { 03.Holtedieren, neteldieren - } \\
\text { Cnidaria }\end{array}$ & 117428 & Cordylophora caspia (Pallas, 1771) & & 1 & 1 & & 1 & & 1 & & & \\
\hline 120 & inheems & 3.Dieren & $\begin{array}{l}\text { 03.Holtedieren, neteldieren - } \\
\text { Cnidaria }\end{array}$ & 117452 & Corymorpha nutans M. Sars, 1835 & & 1 & 1 & 1 & 1 & 1 & & & 1 & 1 \\
\hline 121 & inheems & 3.Dieren & $\begin{array}{l}\text { 03.Holtedieren, neteldieren - } \\
\text { Cnidaria }\end{array}$ & 151860 & Coryne eximia Allman, 1859 & & 1 & 1 & & & & & & & \\
\hline 122 & inheems & 3.Dieren & $\begin{array}{l}\text { 03.Holtedieren, neteldieren - } \\
\text { Cnidaria }\end{array}$ & 117747 & Cosmetira pilosella Forbes, 1848 & & 1 & 1 & & & & & & & \\
\hline
\end{tabular}




\begin{tabular}{|c|c|c|c|c|c|c|c|c|c|c|c|c|c|c|c|}
\hline 123 & inheems & 3.Dieren & $\begin{array}{l}\text { 03. Holtedieren, neteldieren - } \\
\text { Cnidaria }\end{array}$ & 117888 & Dynamena pumila (Linnaeus, 1758) & & 1 & 1 & & 1 & 1 & 1 & 1 & & \\
\hline 124 & inheems & 3.Dieren & $\begin{array}{l}\text { 03.Holtedieren, neteldieren - } \\
\text { Cnidaria }\end{array}$ & 117982 & Ectopleura dumortierii (Van Beneden, 1844) & & 1 & 1 & & & 1 & & & & \\
\hline 125 & inheems & 3.Dieren & $\begin{array}{l}\text { 03.Holtedieren, neteldieren - } \\
\text { Cnidaria }\end{array}$ & 157933 & Ectopleura larynx (Ellis \& Solander, 1786) & Gorgelpijp & 1 & 1 & 1 & 1 & 1 & & & 1 & 1 \\
\hline 126 & inheems & 3.Dieren & $\begin{array}{l}\text { 03.Holtedieren, neteldieren - } \\
\text { Cnidaria }\end{array}$ & 117535 & Eucheilota maculata Hartlaub, 1894 & & 1 & 1 & & 1 & 1 & & & & \\
\hline 127 & inheems & 3.Dieren & $\begin{array}{l}\text { 03.Holtedieren, neteldieren - } \\
\text { Cnidaria }\end{array}$ & 117538 & Eudendrium album Nutting, 1898 & & 1 & 1 & 1 & & 1 & & & & \\
\hline 128 & inheems & 3.Dieren & $\begin{array}{l}\text { 03.Holtedieren, neteldieren - } \\
\text { Cnidaria }\end{array}$ & 284644 & Eudendrium arbuscula Wright, 1859 & & 1 & 1 & & & 1 & 1 & 1 & & \\
\hline 129 & inheems & 3.Dieren & $\begin{array}{l}\text { 03.Holtedieren, neteldieren - } \\
\text { Cnidaria }\end{array}$ & 117555 & Eudendrium ramosum (Linnaeus, 1758) & & 1 & 1 & & & & & & & \\
\hline 130 & inheems & 3.Dieren & $\begin{array}{l}\text { 03.Holtedieren, neteldieren - } \\
\text { Cnidaria }\end{array}$ & 117514 & Eutima gegenbauri (Haeckel, 1864) & & 1 & 1 & & & & & & & \\
\hline 131 & inheems & 3.Dieren & $\begin{array}{l}\text { 03.Holtedieren, neteldieren - } \\
\text { Cnidaria }\end{array}$ & 117515 & Eutima gracilis (Forbes \& Goodsir, 1853) & & 1 & 1 & & & & & & & \\
\hline 132 & inheems & 3.Dieren & $\begin{array}{l}\text { 03.Holtedieren, neteldieren - } \\
\text { Cnidaria }\end{array}$ & 117690 & Filellum serpens (Hassall, 1848) & & 1 & 1 & & & & & & & \\
\hline 133 & exoot & 3.Dieren & $\begin{array}{l}\text { 03.Holtedieren, neteldieren - } \\
\text { Cnidaria }\end{array}$ & 117768 & Gonionemus vertens A. Agassiz, 1862 & & 1 & & 1 & & 1 & & 1 & 1 & \\
\hline 134 & inheems & 3.Dieren & $\begin{array}{l}\text { 03.Holtedieren, neteldieren - } \\
\text { Cnidaria }\end{array}$ & 117377 & Gonothyraea loveni (Allman, 1859) & & 1 & 1 & & 1 & 1 & 1 & 1 & 1 & 1 \\
\hline 135 & inheems & 3.Dieren & $\begin{array}{l}\text { 03.Holtedieren, neteldieren - } \\
\text { Cnidaria }\end{array}$ & 117770 & Gossea corynetes (Gosse, 1853) & & 1 & 1 & & & & & & & \\
\hline 136 & inheems & 3.Dieren & $\begin{array}{l}\text { 03.Holtedieren, neteldieren - } \\
\text { Cnidaria }\end{array}$ & 117570 & Halammohydra coronata Clausen, 1967 & & 1 & 1 & 1 & & 1 & 1 & & & \\
\hline 137 & inheems & 3.Dieren & $\begin{array}{l}\text { 03.Holtedieren, neteldieren - } \\
\text { Cnidaria }\end{array}$ & 117573 & Halammohydra octopodides Remane, 1927 & & 1 & 1 & 1 & & 1 & 1 & & & \\
\hline 138 & inheems & 3.Dieren & $\begin{array}{l}\text { 03. Holtedieren, neteldieren - } \\
\text { Cnidaria }\end{array}$ & 117575 & $\begin{array}{l}\text { Halammohydra vermiformis Swedmark \& } \\
\text { Teissier, } 1957\end{array}$ & & 1 & 1 & 1 & & 1 & 1 & & & \\
\hline 139 & inheems & 3.Dieren & $\begin{array}{l}\text { 03.Holtedieren, neteldieren - } \\
\text { Cnidaria }\end{array}$ & 157947 & Halecium beanii (Johnston, 1838) & & 1 & 1 & 1 & & & & & 1 & \\
\hline 140 & inheems & 3.Dieren & $\begin{array}{l}\text { 03.Holtedieren, neteldieren - } \\
\text { Cnidaria }\end{array}$ & 231751 & Halecium halecinum (Linnaeus, 1758) & & 1 & 1 & 1 & & 1 & & 1 & 1 & 1 \\
\hline 141 & inheems & 3.Dieren & $\begin{array}{l}\text { 03. Holtedieren, neteldieren - } \\
\text { Cnidaria }\end{array}$ & 117378 & Hartlaubella gelatinosa (Pallas, 1766) & & 1 & 1 & & 1 & 1 & 1 & 1 & & 1 \\
\hline 142 & inheems & 3.Dieren & $\begin{array}{l}\text { 03.Holtedieren, neteldieren - } \\
\text { Cnidaria }\end{array}$ & 117988 & Hybocodon prolifer Agassiz, 1860 & & 1 & 1 & 1 & & 1 & & & 1 & \\
\hline 143 & inheems & 3.Dieren & $\begin{array}{l}\text { 03.Holtedieren, neteldieren - } \\
\text { Cnidaria }\end{array}$ & 117644 & Hydractinia echinata (Fleming, 1828) & Ruwe zeerasp & 1 & 1 & 1 & 1 & 1 & 1 & & 1 & 1 \\
\hline 144 & inheems & 3.Dieren & $\begin{array}{l}\text { 03.Holtedieren, neteldieren - } \\
\text { Cnidaria }\end{array}$ & 117890 & Hydrallmania falcata (Linnaeus, 1758) & & 1 & 1 & 1 & 1 & 1 & 1 & & 1 & 1 \\
\hline 145 & inheems & 3.Dieren & $\begin{array}{l}\text { 03.Holtedieren, neteldieren - } \\
\text { Cnidaria }\end{array}$ & 117674 & Kirchenpaueria pinnata (Linnaeus, 1758) & & 1 & & 1 & & 1 & 1 & & 1 & \\
\hline 146 & inheems & 3.Dieren & $\begin{array}{l}\text { 03. Holtedieren, neteldieren - } \\
\text { Cnidaria }\end{array}$ & 117382 & Laomedea flexuosa Alder, 1857 & & 1 & 1 & 1 & 1 & 1 & 1 & 1 & 1 & 1 \\
\hline 147 & inheems & 3.Dieren & $\begin{array}{l}\text { 03. Holtedieren, neteldieren - } \\
\text { Cnidaria }\end{array}$ & 117383 & Laomedea neglecta Alder, 1856 & & 1 & & & 1 & 1 & 1 & & & 1 \\
\hline 148 & inheems & 3.Dieren & $\begin{array}{l}\text { 03.Holtedieren, neteldieren - } \\
\text { Cnidaria }\end{array}$ & 117791 & Leuckartiara octona (Fleming, 1823) & & 1 & 1 & 1 & 1 & 1 & 1 & 1 & & \\
\hline 149 & inheems & 3.Dieren & $\begin{array}{l}\text { 03.Holtedieren, neteldieren - } \\
\text { Cnidaria }\end{array}$ & 117736 & Lovenella clausa (Lovén, 1836) & & 1 & 1 & 1 & & & & & & 1 \\
\hline 150 & inheems & 3.Dieren & $\begin{array}{l}\text { 03.Holtedieren, neteldieren - } \\
\text { Cnidaria }\end{array}$ & 117741 & Margelopsis haeckelii Hartlaub, 1897 & & 1 & 1 & & 1 & 1 & & & & \\
\hline 151 & inheems & 3.Dieren & $\begin{array}{l}\text { 03.Holtedieren, neteldieren - } \\
\text { Cnidaria }\end{array}$ & 117743 & Melicertum octocostatum (M. Sars, 1835) & & 1 & 1 & & 1 & & & & & \\
\hline 152 & inheems & 3.Dieren & $\begin{array}{l}\text { 03.Holtedieren, neteldieren - } \\
\text { Cnidaria }\end{array}$ & 117754 & Mitrocomella brownei (Kramp, 1930) & & 1 & 1 & & & & & & & \\
\hline
\end{tabular}

| 52 van 99 | Wageningen Marine Research rapport C125/16 


\begin{tabular}{|c|c|c|c|c|c|c|c|c|c|c|c|c|c|c|c|}
\hline 153 & inheems & 3.Dieren & $\begin{array}{l}\text { 03.Holtedieren, neteldieren - } \\
\text { Cnidaria }\end{array}$ & 117809 & Nemertesia antennina (Linnaeus, 1758) & & 1 & 1 & 1 & & 1 & & & & 1 \\
\hline 154 & inheems & 3.Dieren & $\begin{array}{l}\text { 03.Holtedieren, neteldieren - } \\
\text { Cnidaria }\end{array}$ & 117815 & Nemertesia ramosa (Lamarck, 1816) & & 1 & & 1 & & & & & & 1 \\
\hline 155 & inheems & 3.Dieren & $\begin{array}{l}\text { 03. Holtedieren, neteldieren - } \\
\text { Cnidaria }\end{array}$ & 117796 & Neoturris pileata (Forsskål, 1775) & Belletje & 1 & & 1 & & & & & 1 & \\
\hline 156 & inheems & 3.Dieren & $\begin{array}{l}\text { 03.Holtedieren, neteldieren - } \\
\text { Cnidaria }\end{array}$ & 117385 & Obelia bidentata Clark, 1875 & Tweetandschelpje & 1 & 1 & 1 & 1 & 1 & 1 & & 1 & 1 \\
\hline 157 & inheems & 3.Dieren & $\begin{array}{l}\text { 03.Holtedieren, neteldieren - } \\
\text { Cnidaria }\end{array}$ & 117386 & Obelia dichotoma (Linnaeus, 1758) & & 1 & 1 & 1 & 1 & 1 & 1 & 1 & 1 & 1 \\
\hline 158 & inheems & 3.Dieren & $\begin{array}{l}\text { 03.Holtedieren, neteldieren - } \\
\text { Cnidaria }\end{array}$ & 117388 & Obelia geniculata (Linnaeus, 1758) & & 1 & 1 & 1 & 1 & 1 & & & 1 & \\
\hline 159 & inheems & 3.Dieren & $\begin{array}{l}\text { 03.Holtedieren, neteldieren - } \\
\text { Cnidaria }\end{array}$ & 117389 & Obelia Iongissima (Pallas, 1766) & & 1 & 1 & 1 & 1 & 1 & & 1 & 1 & 1 \\
\hline 160 & inheems & 3.Dieren & $\begin{array}{l}\text { 03. Holtedieren, neteldieren - } \\
\text { Cnidaria }\end{array}$ & 117413 & Opercularella lacerata (Johnston, 1847) & & 1 & 1 & 1 & 1 & 1 & 1 & & 1 & \\
\hline 161 & inheems & 3.Dieren & $\begin{array}{l}\text { 03.Holtedieren, neteldieren - } \\
\text { Cnidaria }\end{array}$ & 117393 & Orthopyxis integra (MacGillivray, 1842) & & 1 & 1 & & & & & & & \\
\hline 162 & inheems & 3.Dieren & $\begin{array}{l}\text { 03.Holtedieren, neteldieren - } \\
\text { Cnidaria }\end{array}$ & 117804 & Phialella quadrata (Forbes, 1848) & & 1 & 1 & & 1 & & & & & 1 \\
\hline 163 & inheems & 3.Dieren & $\begin{array}{l}\text { 03.Holtedieren, neteldieren - } \\
\text { Cnidaria }\end{array}$ & 117824 & Plumularia setacea (Linnaeus, 1758) & & 1 & 1 & 1 & & & & & & \\
\hline 164 & inheems & 3.Dieren & $\begin{array}{l}\text { 03.Holtedieren, neteldieren - } \\
\text { Cnidaria }\end{array}$ & 117654 & Podocoryna borealis (Mayer, 1900) & & 1 & 1 & & & & & & & \\
\hline 165 & inheems & 3.Dieren & $\begin{array}{l}\text { 03. Holtedieren, neteldieren - } \\
\text { Cnidaria }\end{array}$ & 151718 & Podocoryna carnea M. Sars, 1846 & & 1 & & & 1 & 1 & & & & \\
\hline 166 & inheems & 3.Dieren & $\begin{array}{l}\text { 03. Holtedieren, neteldieren - } \\
\text { Cnidaria }\end{array}$ & 117848 & Rathkea octopunctata (M. Sars, 1835) & & 1 & 1 & & 1 & 1 & & 1 & & \\
\hline 167 & inheems & 3.Dieren & $\begin{array}{l}\text { 03.Holtedieren, neteldieren - } \\
\text { Cnidaria }\end{array}$ & 117491 & Sarsia tubulosa (M. Sars, 1835) & Klepelklokje & 1 & 1 & 1 & 1 & 1 & & 1 & 1 & 1 \\
\hline 168 & inheems & 3.Dieren & $\begin{array}{l}\text { 03. Holtedieren, neteldieren - } \\
\text { Cnidaria }\end{array}$ & 117906 & Sertularella polyzonias (Linnaeus, 1758) & & 1 & & 1 & & & & & 1 & \\
\hline 169 & inheems & 3.Dieren & $\begin{array}{l}\text { 03.Holtedieren, neteldieren - } \\
\text { Cnidaria }\end{array}$ & 117912 & Sertularia argentea Linnaeus, 1758 & & 1 & & & 1 & 1 & 1 & & & 1 \\
\hline 170 & inheems & 3.Dieren & $\begin{array}{l}\text { 03. Holtedieren, neteldieren - } \\
\text { Cnidaria }\end{array}$ & 117913 & Sertularia cupressina Linnaeus, 1758 & & 1 & 1 & 1 & 1 & 1 & 1 & 1 & 1 & 1 \\
\hline 171 & inheems & 3.Dieren & $\begin{array}{l}\text { 03.Holtedieren, neteldieren - } \\
\text { Cnidaria }\end{array}$ & 565161 & Stauridiosarsia gemmifera (Forbes, 1848) & & 1 & 1 & & & 1 & & & & \\
\hline 172 & inheems & 3.Dieren & $\begin{array}{l}\text { 03.Holtedieren, neteldieren - } \\
\text { Cnidaria }\end{array}$ & 117940 & Thuiaria thuja (Linnaeus, 1758) & & 1 & & 1 & 1 & & & & & 1 \\
\hline 173 & inheems & 3.Dieren & $\begin{array}{l}\text { 03. Holtedieren, neteldieren - } \\
\text { Cnidaria }\end{array}$ & 117527 & Tima bairdii (Johnston, 1833) & & 1 & 1 & & & & & & & \\
\hline 174 & inheems & 3.Dieren & $\begin{array}{l}\text { 03. Holtedieren, neteldieren - } \\
\text { Cnidaria }\end{array}$ & 117994 & Tubularia indivisa Linnaeus, 1758 & & 1 & 1 & 1 & 1 & 1 & 1 & 1 & 1 & 1 \\
\hline 175 & inheems & 3.Dieren & $\begin{array}{l}\text { 03.Holtedieren, neteldieren - } \\
\text { Cnidaria }\end{array}$ & 284468 & Turritopsis polycirrha (Keferstein, 1862) & & 1 & 1 & & & 1 & & & & \\
\hline 176 & inheems & 3.Dieren & $\begin{array}{l}\text { 03.Holtedieren, neteldieren - } \\
\text { Cnidaria }\end{array}$ & 135306 & Aurelia aurita (Linnaeus, 1758) & Oorkwal & 1 & 1 & 1 & 1 & & & & 1 & 1 \\
\hline 177 & inheems & 3.Dieren & $\begin{array}{l}\text { 03.Holtedieren, neteldieren - } \\
\text { Cnidaria }\end{array}$ & 135304 & Chrysaora hysoscella (Linnaeus, 1767) & Kompaskwal & 1 & 1 & 1 & 1 & & & & 1 & 1 \\
\hline 178 & inheems & 3.Dieren & $\begin{array}{l}\text { 03.Holtedieren, neteldieren - } \\
\text { Cnidaria }\end{array}$ & 135301 & Cyanea capillata (Linnaeus, 1758) & Gele haarkwal & 1 & & 1 & & & & & 1 & \\
\hline 179 & inheems & 3.Dieren & $\begin{array}{l}\text { 03.Holtedieren, neteldieren - } \\
\text { Cnidaria }\end{array}$ & 135302 & Cyanea lamarckii Péron \& Lesueur, 1810 & Blauwe haarkwal & 1 & 1 & 1 & 1 & & & & 1 & 1 \\
\hline 180 & inheems & 3.Dieren & $\begin{array}{l}\text { 03. Holtedieren, neteldieren - } \\
\text { Cnidaria }\end{array}$ & 135299 & Rhizostoma pulmo (Macri, 1778) & Zeepaddestoel & 1 & 1 & 1 & 1 & & & & & 1 \\
\hline 181 & inheems & 3.Dieren & 05.Platwormen - Platyhelminthes & 142827 & Leptoplana tremellaris (Müller OF, 1773) & & 1 & 1 & 1 & & & & & 1 & \\
\hline 182 & inheems & 3.Dieren & $\begin{array}{l}\text { 07.Kelkdiertjes, kelkwormen - } \\
\text { Entoprocta }\end{array}$ & 111806 & Pedicellina cernua (Pallas, 1774) & & 1 & & & & & & & & 1 \\
\hline
\end{tabular}




\begin{tabular}{|c|c|c|c|c|c|c|c|c|c|c|c|c|c|c|c|}
\hline 183 & inheems & 3.Dieren & 09.Mosdiertjes - Bryozoa & 111062 & Aetea anguina (Linnaeus, 1758) & & 1 & 1 & 1 & 1 & & & & & \\
\hline 184 & inheems & 3.Dieren & 09.Mosdiertjes - Bryozoa & 468026 & Alcyonidioides mytili (Dalyell, 1848) & Mosselmosdiertje & 1 & 1 & 1 & 1 & 1 & 1 & 1 & 1 & 1 \\
\hline 185 & inheems & 3.Dieren & 09.Mosdiertjes - Bryozoa & 111594 & Alcyonidium albidum Alder, 1857 & & 1 & & 1 & & & & & & \\
\hline 186 & inheems & 3.Dieren & 09.Mosdiertjes - Bryozoa & 153730 & Alcyonidium condylocinereum Porter, 2004 & Grijze zeevinger & 1 & 1 & 1 & & & & & 1 & 1 \\
\hline 187 & inheems & 3.Dieren & 09.Mosdiertjes - Bryozoa & 111597 & Alcyonidium diaphanum (Hudson) Lamouroux & Bruine zeevinger & 1 & 1 & 1 & & & 1 & & & 1 \\
\hline 188 & inheems & 3.Dieren & 09.Mosdiertjes - Bryozoa & 153734 & Alcyonidium hydrocoalitum Porter, 2004 & Penneschaft-mosdiertje & 1 & & & & 1 & 1 & & & 1 \\
\hline 189 & inheems & 3.Dieren & 09.Mosdiertjes - Bryozoa & 111602 & Alcyonidium mamillatum Alder, 1857 & Bultige zeevinger & 1 & 1 & 1 & 1 & 1 & & & 1 & \\
\hline 190 & inheems & 3.Dieren & 09.Mosdiertjes - Bryozoa & 111604 & Alcyonidium parasiticum (Fleming, 1828) & Overwoekerend mosdiertje & 1 & 1 & 1 & & 1 & & & 1 & 1 \\
\hline 191 & inheems & 3.Dieren & 09.Mosdiertjes - Bryozoa & 153717 & Alcyonidium polyoum (Hassall, 1841) & Wierzeevinger & 1 & & & 1 & 1 & & & & 1 \\
\hline 192 & exoot & 3.Dieren & 09.Mosdiertjes - Bryozoa & 851589 & Amathia gracilis (Leidy, 1855) & & 1 & 1 & & 1 & 1 & 1 & 1 & & \\
\hline 193 & exoot & 3.Dieren & 09.Mosdiertjes - Bryozoa & 851593 & Amathia imbricata (Adams, 1798) & & 1 & & 1 & 1 & 1 & 1 & & 1 & \\
\hline 194 & inheems & 3.Dieren & 09.Mosdiertjes - Bryozoa & 111607 & Arachnidium fibrosum Hincks, 1880 & & 1 & 1 & 1 & & 1 & & & 1 & \\
\hline 195 & inheems & 3.Dieren & 09.Mosdiertjes - Bryozoa & 111350 & Aspidelectra melolontha (Landsborough, 1852) & & 1 & 1 & & 1 & 1 & & & 1 & \\
\hline 196 & inheems & 3.Dieren & 09.Mosdiertjes - Bryozoa & 111147 & Bicellariella ciliata (Linnaeus, 1758) & Wimpermosdiertje & 1 & & 1 & 1 & 1 & 1 & & 1 & \\
\hline 197 & exoot & 3.Dieren & 09.Mosdiertjes - Bryozoa & 111158 & Bugula neritina (Linnaeus, 1758) & Paars vogelkopmosdiertje & 1 & 1 & 1 & & & & & 1 & \\
\hline 198 & inheems & 3.Dieren & 09.Mosdiertjes - Bryozoa & 833990 & Bugulina avicularia (Linnaeus, 1758) & & 1 & 1 & & & & & & & \\
\hline 199 & inheems & 3.Dieren & 09.Mosdiertjes - Bryozoa & 834002 & Bugulina flabellata (Thompson in Gray, 1848) & & 1 & 1 & 1 & 1 & & & & & \\
\hline 200 & exoot & 3.Dieren & 09.Mosdiertjes - Bryozoa & 834016 & Bugulina simplex (Hincks, 1886) & Geel vogelkopmosdiertje & 1 & & 1 & & 1 & & 1 & 1 & \\
\hline 201 & exoot & 3.Dieren & 09.Mosdiertjes - Bryozoa & 834018 & Bugulina stolonifera (Ryland, 1960) & Vogelkopmosdiertje & 1 & & 1 & 1 & 1 & 1 & 1 & 1 & \\
\hline 202 & inheems & 3.Dieren & 09.Mosdiertjes - Bryozoa & 834020 & Bugulina turbinata (Alder, 1857) & & 1 & & 1 & & & & & 1 & \\
\hline 203 & inheems & 3.Dieren & 09.Mosdiertjes - Bryozoa & 111196 & Callopora dumerilii (Audouin, 1826) & & 1 & 1 & 1 & & 1 & & & 1 & \\
\hline 204 & inheems & 3.Dieren & 09.Mosdiertjes - Bryozoa & 111268 & Cellepora pumicosa (Pallas, 1766) & Puimsteenmosdiertje & 1 & 1 & 1 & & & & & 1 & \\
\hline 205 & inheems & 3.Dieren & 09.Mosdiertjes - Bryozoa & 111397 & Celleporella hyalina (Linnaeus, 1767) & & 1 & 1 & 1 & & & & & 1 & 1 \\
\hline 206 & inheems & 3.Dieren & 09.Mosdiertjes - Bryozoa & 111351 & Conopeum reticulum (Linnaeus, 1767) & Zeekantwerk; zeevitrage & 1 & 1 & 1 & 1 & 1 & 1 & & 1 & 1 \\
\hline 207 & inheems & 3.Dieren & 09.Mosdiertjes - Bryozoa & 111352 & Conopeum seurati $($ Canu, 1928) & Brakwaterkantwerk & 1 & & & & & & & & 1 \\
\hline 208 & inheems & 3.Dieren & 09.Mosdiertjes - Bryozoa & 834039 & Crisularia plumosa (Pallas, 1766) & Spiraalmosdiertje & 1 & & 1 & & 1 & 1 & 1 & 1 & \\
\hline 209 & inheems & 3.Dieren & 09.Mosdiertjes - Bryozoa & 111343 & Cryptosula pallasiana (Moll, 1803) & Pallas' mosdiertje & 1 & 1 & 1 & 1 & & & & 1 & \\
\hline 210 & inheems & 3.Dieren & 09.Mosdiertjes - Bryozoa & 111730 & Disporella hispida (Fleming, 1828) & & 1 & & 1 & & & & & 1 & \\
\hline 211 & inheems & 3.Dieren & 09.Mosdiertjes - Bryozoa & 467577 & Einhornia crustulenta (Pallas, 1766) & Palingbrood & 1 & & & 1 & 1 & 1 & & & 1 \\
\hline 212 & inheems & 3.Dieren & 09.Mosdiertjes - Bryozoa & 111355 & Electra pilosa (Linnaeus, 1767) & $\begin{array}{l}\text { Harig mosdiertje; harig } \\
\text { kantmosdiertje }\end{array}$ & 1 & 1 & 1 & 1 & 1 & 1 & 1 & 1 & 1 \\
\hline 213 & inheems & 3.Dieren & 09.Mosdiertjes - Bryozoa & 111484 & Escharella immersa (Fleming, 1828) & & 1 & & 1 & 1 & 1 & 1 & 1 & 1 & \\
\hline 214 & inheems & 3.Dieren & 09.Mosdiertjes - Bryozoa & 111498 & Escharoides coccinea (Abildgaard, 1806) & & 1 & 1 & 1 & 1 & & & & & \\
\hline 215 & inheems & 3.Dieren & 09.Mosdiertjes - Bryozoa & 111652 & Farrella repens (Farre, 1837) & Bekermosdiertje & 1 & 1 & 1 & 1 & 1 & 1 & 1 & 1 & \\
\hline 216 & exoot & 3.Dieren & 09.Mosdiertjes - Bryozoa & 408266 & $\begin{array}{l}\text { Fenestrulina delicia Winston, Hayward \& Craig, } \\
2000\end{array}$ & Venstermosdiertje & 1 & 1 & 1 & & 1 & & & 1 & \\
\hline 217 & inheems & 3.Dieren & 09.Mosdiertjes - Bryozoa & 111367 & Flustra foliacea (Linnaeus, 1758) & Breedbladig mosdiertje & 1 & 1 & 1 & & & & & 1 & 1 \\
\hline 218 & inheems & 3.Dieren & 09.Mosdiertjes - Bryozoa & 111421 & Microporella ciliata (Pallas, 1766) & & 1 & 1 & 1 & & & & & 1 & \\
\hline 219 & inheems & 3.Dieren & 09.Mosdiertjes - Bryozoa & 111719 & Plagioecia patina (Lamarck, 1816) & Wrattig mosdiertje & 1 & 1 & 1 & & & & & 1 & \\
\hline 220 & inheems & 3.Dieren & 09.Mosdiertjes - Bryozoa & 862795 & $\begin{array}{l}\text { Schizomavella (Schizomavella) linearis } \\
\text { (Hassall, 1841) }\end{array}$ & Empingmosdiertje & 1 & 1 & 1 & & 1 & 1 & & 1 & \\
\hline 221 & inheems & 3.Dieren & 09.Mosdiertjes - Bryozoa & 111539 & Scruparia ambigua (d'Orbigny, 1841) & & 1 & 1 & 1 & & 1 & & & 1 & 1 \\
\hline 222 & inheems & 3.Dieren & 09.Mosdiertjes - Bryozoa & 111540 & Scruparia chelata (Linnaeus, 1758) & & 1 & 1 & 1 & & & & & 1 & \\
\hline 223 & inheems & 3.Dieren & 09.Mosdiertjes - Bryozoa & 111250 & Scrupocellaria scruposa (Linnaeus, 1758) & Steenmosdiertje & 1 & & 1 & 1 & 1 & 1 & & 1 & \\
\hline 224 & inheems & 3.Dieren & 09.Mosdiertjes - Bryozoa & 111374 & Securiflustra securifrons & & 1 & 1 & 1 & & & & & & 1 \\
\hline 225 & exoot & 3.Dieren & 09.Mosdiertjes - Bryozoa & 396735 & Smittoidea prolifica Osburn, 1952 & & 1 & 1 & 1 & 1 & 1 & & & 1 & \\
\hline 226 & inheems & 3.Dieren & 09.Mosdiertjes - Bryozoa & 111653 & Triticella flava Dalyell, 1848 & Molkreeftmosdiertje & 1 & 1 & 1 & & & & & & 1 \\
\hline 227 & inheems & 3.Dieren & 09.Mosdiertjes - Bryozoa & 111285 & Turbicellepora avicularis (Hincks, 1860) & & 1 & 1 & 1 & 1 & & & & & \\
\hline 228 & inheems & 3.Dieren & 09.Mosdiertjes - Bryozoa & 111669 & Vesicularia spinosa (Linnaeus, 1758) & Zijdemosdiertje & 1 & & 1 & & & & & & \\
\hline 229 & inheems & 3.Dieren & 10. Hoefijzerwormen - Phoronida & 128548 & Phoronis hippocrepia Wright, 1856 & & 1 & & 1 & & & & & 1 & \\
\hline 230 & inheems & 3.Dieren & 10. Hoefijzerwormen - Phoronida & 128549 & Phoronis muelleri Selys-Lonchamps, 1903 & & 1 & 1 & 1 & & & & & & 1 \\
\hline 231 & inheems & 3.Dieren & 12.Ringwormen - Annelida & 146469 & Abyssoninoe hibernica (McIntosh, 1903) & & 1 & & 1 & & & & & & 1 \\
\hline
\end{tabular}

| 54 van 99 | Wageningen Marine Research rapport C125/16 


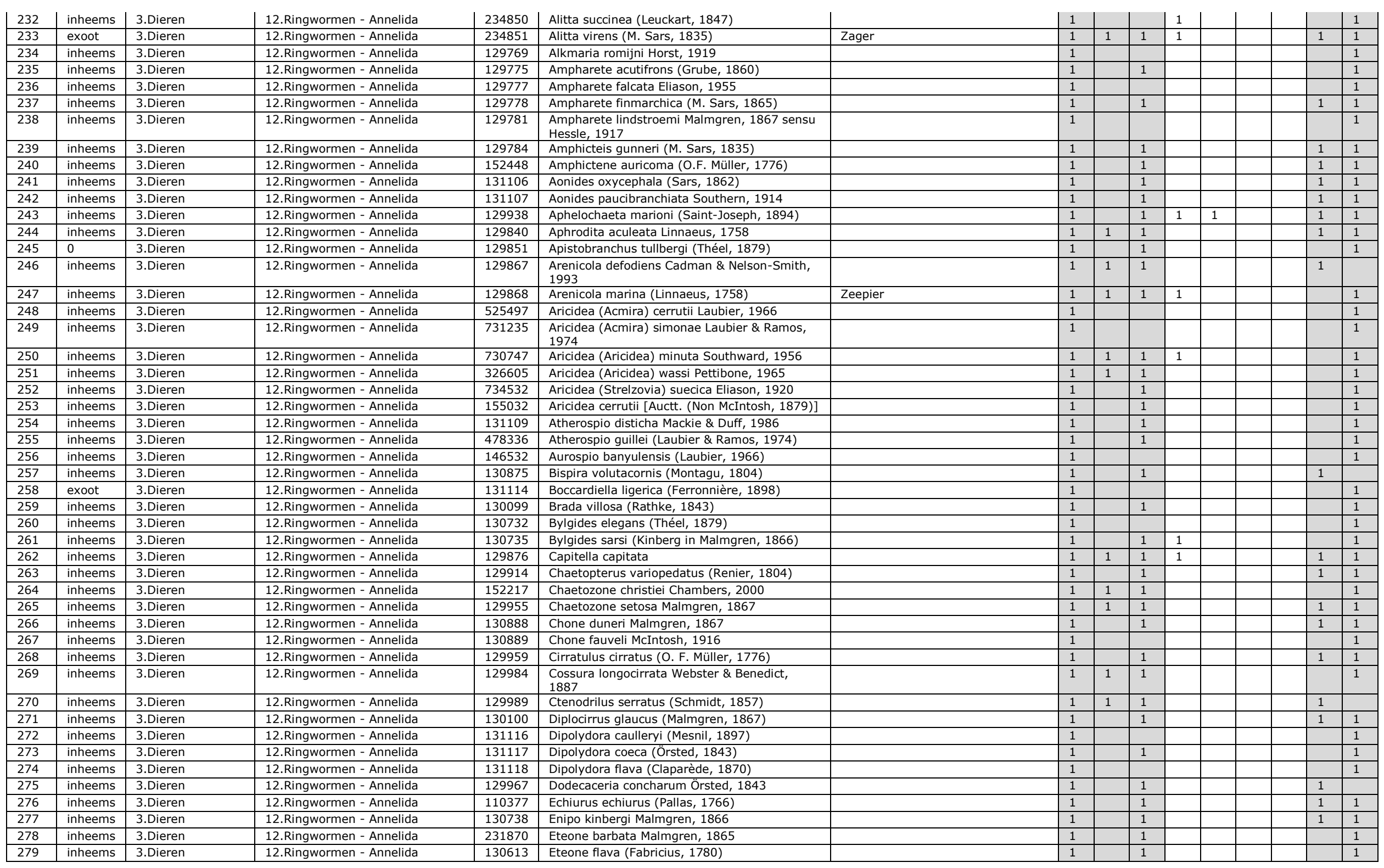




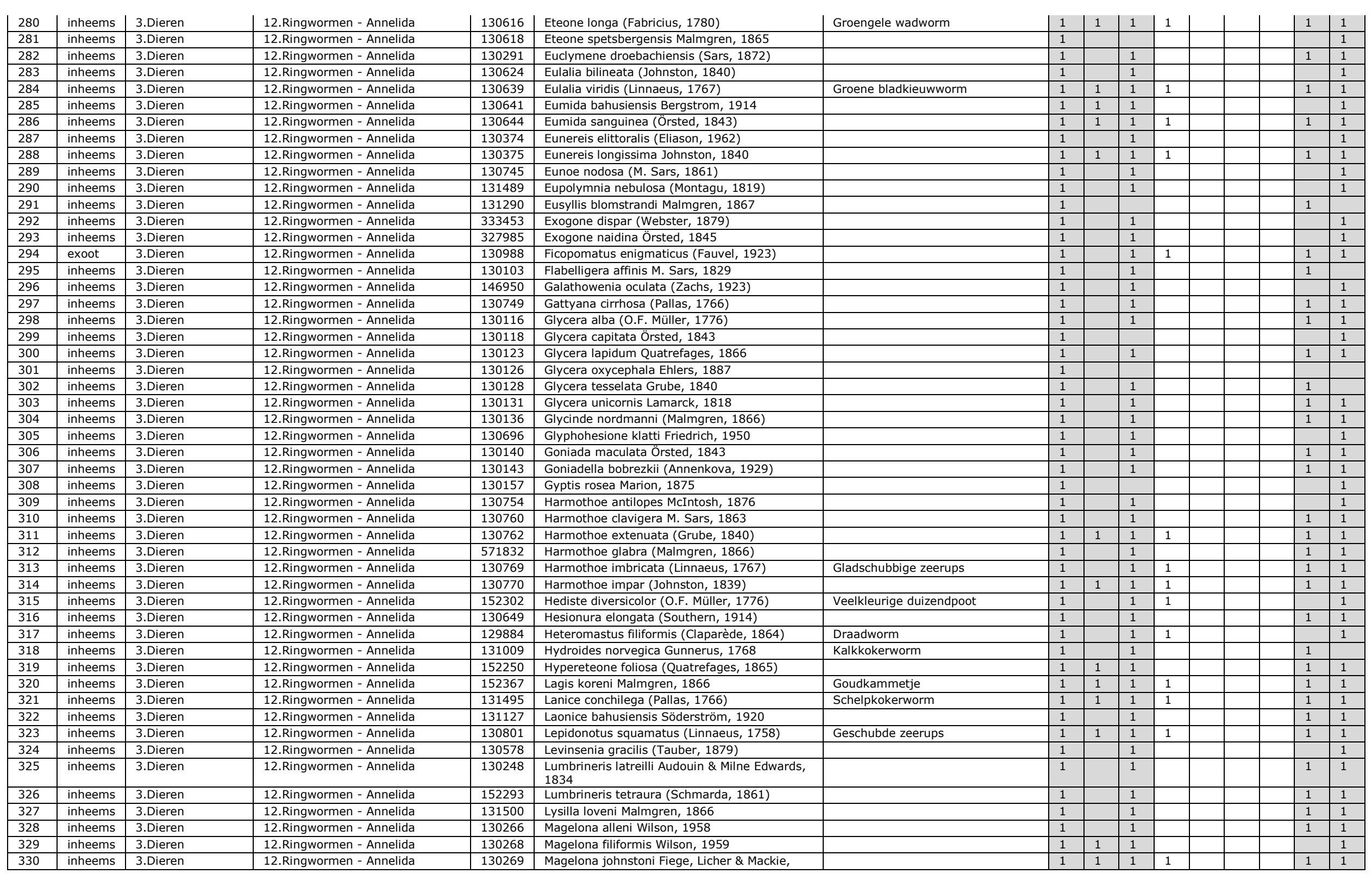

| 56 van 99 | Wageningen Marine Research rapport C125/16 


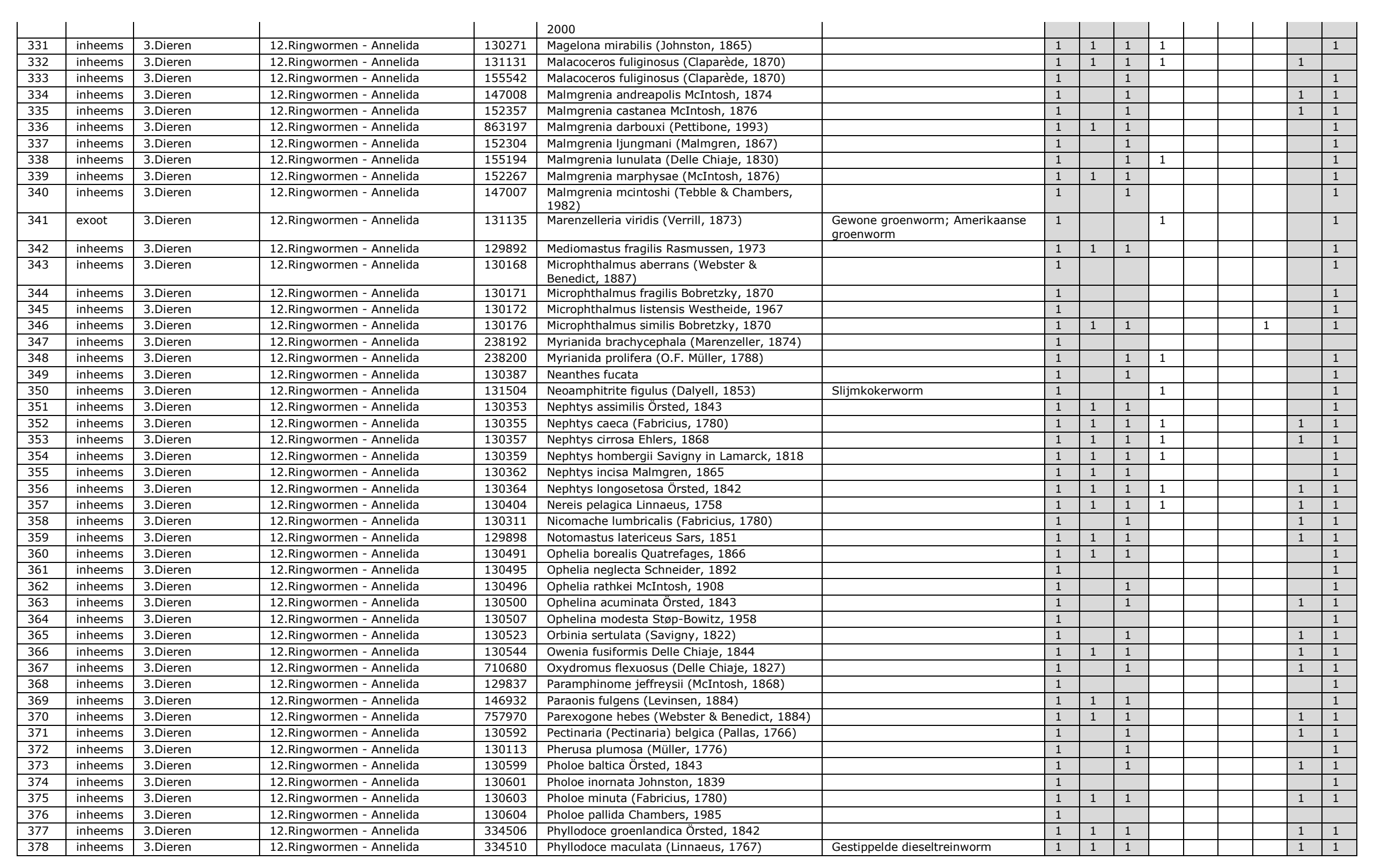




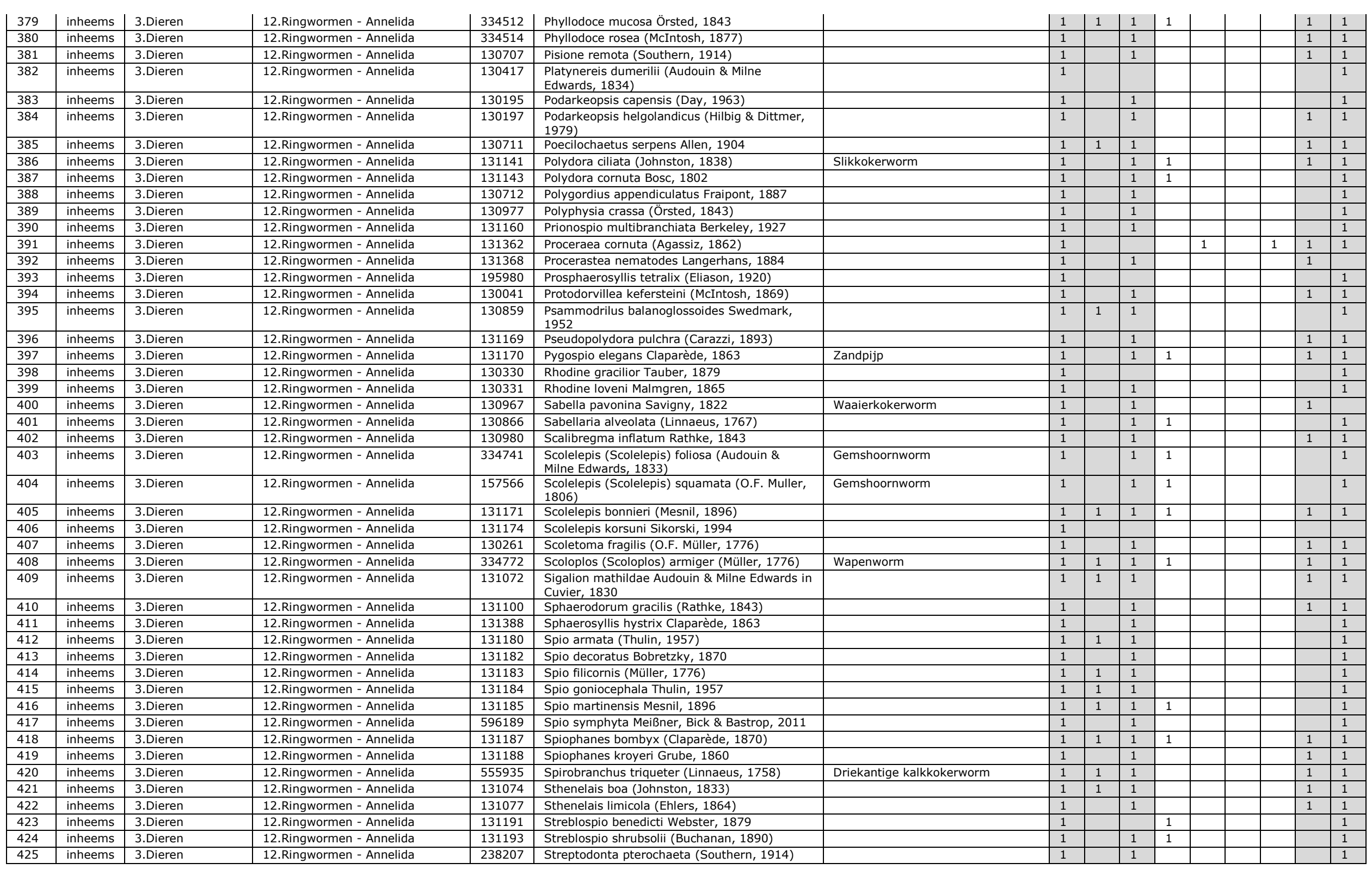

| 58 van 99 | Wageningen Marine Research rapport C125/16 


\begin{tabular}{|c|c|c|c|c|c|c|c|c|c|c|c|c|c|c|c|}
\hline 426 & inheems & 3.Dieren & 12.Ringwormen - Annelida & 131415 & Syllis armillaris (O.F. Müller, 1776) & & 1 & & 1 & & & & & 1 & 1 \\
\hline 427 & inheems & 3.Dieren & 12.Ringwormen - Annelida & 131435 & Syllis gracilis Grube, 1840 & & 1 & & 1 & & 1 & & & 1 & 1 \\
\hline 428 & inheems & 3.Dieren & 12.Ringwormen - Annelida & 131436 & Syllis hyalina Grube, 1863 & & 1 & & 1 & & & & & 1 & \\
\hline 429 & inheems & 3.Dieren & 12.Ringwormen - Annelida & 131452 & Syllis prolifera Krohn, 1852 & & 1 & 1 & 1 & & & & & 1 & 1 \\
\hline 430 & inheems & 3.Dieren & 12.Ringwormen - Annelida & 131573 & Terebellides stroemii Sars, 1835 & & 1 & & 1 & & & & & 1 & 1 \\
\hline 431 & inheems & 3.Dieren & 12.Ringwormen - Annelida & 152269 & Tharyx killariensis (Southern, 1914) & & 1 & & 1 & & & & & & 1 \\
\hline 432 & inheems & 3.Dieren & 12.Ringwormen - Annelida & 131543 & Thelepus cincinnatus (Fabricius, 1780) & & 1 & & 1 & & & & & 1 & 1 \\
\hline 433 & inheems & 3.Dieren & 12.Ringwormen - Annelida & 339492 & Thoracophelia flabellifera Ziegelmeier, 1955 & & 1 & & 1 & & & & & & 1 \\
\hline 434 & inheems & 3.Dieren & 12.Ringwormen - Annelida & 130512 & Travisia forbesii Johnston, 1840 & & 1 & 1 & 1 & & & & & 1 & 1 \\
\hline 435 & inheems & 3.Dieren & 12.Ringwormen - Annelida & 410717 & $\begin{array}{l}\text { Aspidosiphon (Aspidosiphon) muelleri muelleri } \\
\text { Diesing, } 1851\end{array}$ & & 1 & & 1 & & & & & 1 & \\
\hline 436 & inheems & 3.Dieren & 12.Ringwormen - Annelida & 175026 & $\begin{array}{l}\text { Golfingia (Golfingia) elongata (Keferstein, } \\
1862 \text { ) }\end{array}$ & & 1 & & 1 & & & & & 1 & 1 \\
\hline 437 & inheems & 3.Dieren & 12.Ringwormen - Annelida & 410724 & $\begin{array}{l}\text { Golfingia (Golfingia) vulgaris vulgaris (de } \\
\text { Blainville, 1827) }\end{array}$ & & 1 & & 1 & & & & & 1 & 1 \\
\hline 438 & inheems & 3.Dieren & 12.Ringwormen - Annelida & 410749 & $\begin{array}{l}\text { Phascolion (Phascolion) strombus strombus } \\
\text { (Montagu, 1804) }\end{array}$ & & 1 & & 1 & & & & & 1 & 1 \\
\hline 439 & inheems & 3.Dieren & 12.Ringwormen - Annelida & 136063 & Thysanocardia procera (Möbius, 1875) & & 1 & & 1 & & & & & & 1 \\
\hline 440 & inheems & 3.Dieren & 12.Ringwormen - Annelida & 743898 & Baltidrilus costatus (Claparède, 1863) & & 1 & & & & & & & & 1 \\
\hline 441 & inheems & 3.Dieren & 11.Snoerwormen - Nemertea & 122478 & Cerebratulus marginatus Renier, 1804 & & 1 & & 1 & & & & & & 1 \\
\hline 442 & inheems & 3.Dieren & 11.Snoerwormen - Nemertea & 122710 & Emplectonema gracile (Johnston, 1837) & & 1 & 1 & 1 & & & & & 1 & \\
\hline 443 & inheems & 3.Dieren & 12.Ringwormen - Annelida & 137416 & Grania postclitellochaeta (Knöllner, 1935) & & 1 & & & & & & & & \\
\hline 444 & inheems & 3.Dieren & 12.Ringwormen - Annelida & 388029 & Grania vikinga Rota \& Erséus, 2003 & & 1 & & 1 & & & & & & 1 \\
\hline 445 & inheems & 3.Dieren & 12.Ringwormen - Annelida & 147000 & Limnodriloides scandinavicus Erséus, 1982 & & 1 & & 1 & & & & & & 1 \\
\hline 446 & inheems & 3.Dieren & 12.Ringwormen - Annelida & 137556 & Limnodrilus hoffmeisteri Claparède, 1862 & & 1 & & & & & & & & 1 \\
\hline 447 & inheems & 3.Dieren & 12.Ringwormen - Annelida & 475838 & Limnodrilus profundicola (Verrill, 1873) & & 1 & & & & & & & & 1 \\
\hline 448 & inheems & 3.Dieren & 11.Snoerwormen - Nemertea & 122511 & Lineus bilineatus (Renier, 1804) & & 1 & 1 & 1 & & & & & & 1 \\
\hline 449 & inheems & 3.Dieren & 11.Snoerwormen - Nemertea & 122528 & Lineus longissimus (Gunnerus, 1770) & & 1 & 1 & 1 & & & & & 1 & \\
\hline 450 & inheems & 3.Dieren & 11.Snoerwormen - Nemertea & 122641 & Malacobdella grossa (Müller, 1776) & & 1 & & 1 & & & & & & 1 \\
\hline 451 & inheems & 3.Dieren & 11.Snoerwormen - Nemertea & 122817 & Oerstedia dorsalis (Abildgaard, 1806) & & 1 & & 1 & & & & & 1 & \\
\hline 452 & inheems & 3.Dieren & 12.Ringwormen - Annelida & 137563 & $\begin{array}{l}\text { Potamothrix moldaviensis Vejdovský \& } \\
\text { Mrázek, } 1903\end{array}$ & & 1 & & & & & & & & 1 \\
\hline 453 & inheems & 3.Dieren & 12.Ringwormen - Annelida & 137571 & Tubificoides benedii (Udekem, 1855) & & 1 & & & & & & & & 1 \\
\hline 454 & inheems & 3.Dieren & 12.Ringwormen - Annelida & 137574 & Tubificoides diazi Brinkhurst \& Baker, 1979 & & 1 & & 1 & & & & & & 1 \\
\hline 455 & inheems & 3.Dieren & 11.Snoerwormen - Nemertea & 122637 & Tubulanus polymorphus Renier, 1804 & & 1 & & 1 & & & & & & 1 \\
\hline 456 & inheems & 3.Dieren & 13.Weekdieren - Mollusca & 139106 & Chaetoderma nitidulum Lovén, 1844 & Glimmende franjeschildvoet & 1 & & 1 & & & & & & 1 \\
\hline 457 & inheems & 3.Dieren & 13.Weekdieren - Mollusca & 152774 & Lepidochitona cinerea (Linnaeus, 1767) & Asgrauwe keverslak & 1 & 1 & & 1 & 1 & 1 & 1 & & 1 \\
\hline 458 & inheems & 3.Dieren & 13.Weekdieren - Mollusca & 140199 & Leptochiton asellus (Gmelin, 1791) & Gewone pissebedkeverslak & 1 & & 1 & & & & & 1 & \\
\hline 459 & inheems & 3.Dieren & 13.Weekdieren - Mollusca & 140211 & Leptochiton scabridus (Jeffreys, 1880) & & 1 & & & & & & & & \\
\hline 460 & inheems & 3.Dieren & 13.Weekdieren - Mollusca & 141433 & Abra alba (W. Wood, 1802) & Witte dunschaal & 1 & 1 & 1 & 1 & 1 & 1 & 1 & 1 & 1 \\
\hline 461 & inheems & 3.Dieren & 13.Weekdieren - Mollusca & 141435 & Abra nitida (O. F. Müller, 1776) & Glanzende dunschaal & 1 & 1 & 1 & & 1 & 1 & 1 & 1 & 1 \\
\hline 462 & inheems & 3.Dieren & 13.Weekdieren - Mollusca & 141436 & Abra prismatica (Montagu, 1808) & Prismatische dunschaal & 1 & 1 & 1 & 1 & & & & 1 & 1 \\
\hline 463 & inheems & 3.Dieren & 13.Weekdieren - Mollusca & 141439 & Abra tenuis (Montagu, 1803) & Tere dunschaal & 1 & & 1 & 1 & 1 & 1 & 1 & & 1 \\
\hline 464 & inheems & 3.Dieren & 13.Weekdieren - Mollusca & 138990 & Acanthocardia aculeata (Linnaeus, 1758) & Grote hartschelp & 1 & & 1 & & & & & & 1 \\
\hline 465 & inheems & 3.Dieren & 13.Weekdieren - Mollusca & 140687 & Aequipecten opercularis (Linnaeus, 1758) & Wijde mantel & 1 & 1 & 1 & 1 & 1 & & 1 & 1 & 1 \\
\hline 466 & inheems & 3.Dieren & 13.Weekdieren - Mollusca & 152312 & Altenaeum dawsoni (Jeffreys, 1864) & Scheef bultschelpje & 1 & & 1 & & & & & & 1 \\
\hline 467 & inheems & 3.Dieren & 13.Weekdieren - Mollusca & 141577 & Arcopagia crassa (Pennant, 1777) & Stevige platschelp & 1 & & 1 & & & & & 1 & 1 \\
\hline 468 & inheems & 3.Dieren & 13.Weekdieren - Mollusca & 138802 & Arctica islandica (Linnaeus, 1767) & Noordkromp & 1 & 1 & 1 & & & & & 1 & 1 \\
\hline 469 & inheems & 3.Dieren & 13.Weekdieren - Mollusca & 138823 & Astarte montagui (Dillwyn, 1817) & Driehoekige astarte & 1 & & 1 & & & & & 1 & 1 \\
\hline 470 & inheems & 3.Dieren & 13.Weekdieren - Mollusca & 140767 & Barnea candida (Linnaeus, 1758) & Witte boormossel & 1 & 1 & 1 & 1 & 1 & 1 & & & 1 \\
\hline 471 & inheems & 3.Dieren & 13.Weekdieren - Mollusca & 138998 & Cerastoderma edule (Linnaeus, 1758) & Gewone kokkel; kokkel & 1 & 1 & 1 & 1 & 1 & 1 & 1 & 1 & 1 \\
\hline 472 & inheems & 3.Dieren & 13.Weekdieren - Mollusca & 138999 & Cerastoderma glaucum (Bruguière, 1789) & Brakwaterkokkel & 1 & 1 & & 1 & 1 & 1 & 1 & & \\
\hline 473 & inheems & 3.Dieren & 13.Weekdieren - Mollusca & 141908 & Chamelea striatula (da Costa, 1778$)$ & Gewone venusschelp; venusschelp & 1 & 1 & 1 & 1 & 1 & & & 1 & 1 \\
\hline
\end{tabular}




\begin{tabular}{|c|c|c|c|c|c|c|c|c|c|c|c|c|c|c|c|}
\hline 474 & inheems & 3.Dieren & 13.Weekdieren - Mollusca & 141909 & Clausinella fasciata (da Costa, 1778) & & 1 & & 1 & & & & & & \\
\hline 475 & inheems & 3.Dieren & 13.Weekdieren - Mollusca & 181373 & Cochlodesma praetenue (Pulteney, 1799) & Lepelschelp & 1 & & 1 & & & & & 1 & 1 \\
\hline 476 & exoot & 3.Dieren & 13.Weekdieren - Mollusca & 181580 & Corbicula fluminea (O. F. Müller, 1774) & & 1 & & & & & & & & 1 \\
\hline 477 & exoot & 3.Dieren & 13.Weekdieren - Mollusca & 140656 & Crassostrea gigas (Thunberg, 1793) & Japanse oester & 1 & 1 & 1 & 1 & 1 & 1 & 1 & 1 & 1 \\
\hline 478 & inheems & 3.Dieren & 13.Weekdieren - Mollusca & 140365 & Devonia perrieri (Malard, 1904) & Zeekomkommerschelpje & 1 & & 1 & & & & & & 1 \\
\hline 479 & inheems & 3.Dieren & 13.Weekdieren - Mollusca & 141883 & Diplodonta rotundata (Montagu, 1803) & Ronde komschelp & 1 & & 1 & & & & & & 1 \\
\hline 480 & inheems & 3.Dieren & 13.Weekdieren - Mollusca & 139604 & Donax vittatus (da Costa, 1778) & Zaagje & 1 & 1 & 1 & 1 & & 1 & & 1 & 1 \\
\hline 481 & inheems & 3.Dieren & 13.Weekdieren - Mollusca & 141911 & Dosinia exoleta (Linnaeus, 1758) & Gewone artemisschelp & 1 & & 1 & & & & & 1 & 1 \\
\hline 482 & inheems & 3.Dieren & 13.Weekdieren - Mollusca & 141912 & Dosinia lupinus (Linnaeus, 1758) & Dichtgestreepte artemisschelp & 1 & & 1 & & & & & 1 & 1 \\
\hline 483 & inheems & 3.Dieren & 13.Weekdieren - Mollusca & 140584 & Ennucula tenuis (Montagu, 1808) & & 1 & & 1 & & & & & & 1 \\
\hline 484 & inheems & 3.Dieren & 13.Weekdieren - Mollusca & 754176 & Ensis coseli Vierna, 2014 & & 1 & & & & & & & & 1 \\
\hline 485 & exoot & 3.Dieren & 13.Weekdieren - Mollusca & 140732 & Ensis directus (Conrad, 1843) & Amerikaanse zwaardschede & 1 & 1 & 1 & 1 & 1 & 1 & 1 & & 1 \\
\hline 486 & inheems & 3.Dieren & 13.Weekdieren - Mollusca & 140733 & Ensis ensis (Linnaeus, 1758) & Kleine zwaardschede & 1 & 1 & 1 & 1 & & & & 1 & 1 \\
\hline 487 & inheems & 3.Dieren & 13.Weekdieren - Mollusca & 160539 & Ensis magnus Schumacher, 1817 & Grote zwaardschede & 1 & 1 & 1 & & 1 & & 1 & & 1 \\
\hline 488 & inheems & 3.Dieren & 13.Weekdieren - Mollusca & 140734 & Ensis minor (Chenu, 1843) & Klein tafelmesheft & 1 & 1 & 1 & & & & & & 1 \\
\hline 489 & inheems & 3.Dieren & 13.Weekdieren - Mollusca & 140735 & Ensis siliqua (Linnaeus, 1758) & Groot tafelmesheft & 1 & 1 & 1 & & & & & 1 & 1 \\
\hline 490 & inheems & 3.Dieren & 13.Weekdieren - Mollusca & 140870 & Gari fervensis (Gmelin, 1791) & Geplooide zonneschelp & 1 & 1 & 1 & & & & & 1 & 1 \\
\hline 491 & inheems & 3.Dieren & 13.Weekdieren - Mollusca & 138831 & Goodallia triangularis (Montagu, 1803) & Kleine astarte & 1 & 1 & 1 & & & & & & 1 \\
\hline 492 & inheems & 3.Dieren & 13.Weekdieren - Mollusca & 246148 & Hemilepton nitidum (Turton, 1822) & Witte muntschelp & 1 & & 1 & & & & & & 1 \\
\hline 493 & inheems & 3.Dieren & 13.Weekdieren - Mollusca & 138749 & Heteranomia squamula (Linnaeus, 1758) & Schilferige dekschelp & 1 & 1 & 1 & 1 & & 1 & & 1 & \\
\hline 494 & inheems & 3.Dieren & 13.Weekdieren - Mollusca & 140103 & Hiatella arctica (Linnaeus, 1767) & Noordse rotsboorder & 1 & 1 & 1 & 1 & 1 & & & 1 & 1 \\
\hline 495 & inheems & 3.Dieren & 13.Weekdieren - Mollusca & 140161 & Kellia suborbicularis (Montagu, 1803) & Holteschelpje & 1 & 1 & 1 & & & & & 1 & 1 \\
\hline 496 & inheems & 3.Dieren & 13.Weekdieren - Mollusca & 345281 & Kurtiella bidentata (Montagu, 1803) & tweetandschelpje & 1 & 1 & 1 & 1 & 1 & 1 & 1 & 1 & 1 \\
\hline 497 & inheems & 3.Dieren & 13.Weekdieren - Mollusca & 139004 & Laevicardium crassum (Gmelin, 1791) & Noorse hartschelp & 1 & 1 & 1 & & 1 & & & 1 & 1 \\
\hline 498 & inheems & 3.Dieren & 13.Weekdieren - Mollusca & 140218 & Lepton squamosum (Montagu, 1803) & Stippelschelp & 1 & & 1 & 1 & & & & 1 & 1 \\
\hline 499 & inheems & 3.Dieren & 13.Weekdieren - Mollusca & 140283 & Lucinoma borealis (Linnaeus, 1767) & Noordse cirkelschelp & 1 & & 1 & & & & & 1 & 1 \\
\hline 500 & inheems & 3.Dieren & 13.Weekdieren - Mollusca & 140294 & Lutraria angustior Philippi, 1844 & & 1 & 1 & 1 & & & & & & \\
\hline 501 & inheems & 3.Dieren & 13.Weekdieren - Mollusca & 140295 & Lutraria lutraria (Linnaeus, 1758) & Gewone otterschelp; otterschelp & 1 & 1 & 1 & 1 & & 1 & & 1 & 1 \\
\hline 502 & inheems & 3.Dieren & 13.Weekdieren - Mollusca & 140291 & Lyonsia norwegica (Gmelin, 1791) & & 1 & & 1 & & & & & 1 & \\
\hline 503 & inheems & 3.Dieren & 13.Weekdieren - Mollusca & 141579 & Macoma balthica (Linnaeus, 1758) & Nonnetje & 1 & 1 & 1 & 1 & 1 & 1 & 1 & & 1 \\
\hline 504 & inheems & 3.Dieren & 13.Weekdieren - Mollusca & 140299 & Mactra stultorum (Linnaeus, 1758) & Grote strandschelp & 1 & 1 & 1 & & 1 & & & 1 & 1 \\
\hline 505 & inheems & 3.Dieren & 13.Weekdieren - Mollusca & 236719 & Mimachlamys varia (Linnaeus, 1758) & Bonte mantel & 1 & 1 & 1 & 1 & 1 & & 1 & 1 & 1 \\
\hline 506 & inheems & 3.Dieren & 13.Weekdieren - Mollusca & 140467 & Modiolus modiolus (Linnaeus, 1758) & $\begin{array}{l}\text { Gewone paardenmossel; } \\
\text { paardemossel }\end{array}$ & 1 & & 1 & 1 & & & & & 1 \\
\hline 507 & inheems & 3.Dieren & 13.Weekdieren - Mollusca & 147022 & Moerella pygmaea (Lovén, 1846) & Kleine platschelp & 1 & & 1 & 1 & & & & & 1 \\
\hline 508 & inheems & 3.Dieren & 13.Weekdieren - Mollusca & 153027 & Monia patelliformis (Linnaeus, 1761) & Manteldekschelp & 1 & & 1 & & & & & 1 & \\
\hline 509 & inheems & 3.Dieren & 13.Weekdieren - Mollusca & 153028 & Monia squama (Gmelin, 1791) & Groene dekschelp & 1 & & 1 & & & & & 1 & \\
\hline 510 & inheems & 3.Dieren & 13.Weekdieren - Mollusca & 140377 & Montacuta substriata (Montagu, 1808) & & 1 & 1 & & & & & & & 1 \\
\hline 511 & inheems & 3.Dieren & 13.Weekdieren - Mollusca & 140472 & Musculus discors (Linnaeus, 1767) & Gebochelde streepschelp & 1 & & 1 & & 1 & & & & 1 \\
\hline 512 & inheems & 3.Dieren & 13.Weekdieren - Mollusca & 140474 & Musculus niger (J.E. Gray, 1824) & Zwarte streepschelp & 1 & & 1 & & & & & & 1 \\
\hline 513 & inheems & 3.Dieren & 13.Weekdieren - Mollusca & 506128 & Musculus subpictus (Cantraine, 1835) & Gemarmerde streepschelp & 1 & & 1 & & & & & & \\
\hline 514 & exoot & 3.Dieren & 13.Weekdieren - Mollusca & 140430 & Mya arenaria Linnaeus, 1758 & Strandgaper & 1 & 1 & 1 & 1 & 1 & 1 & 1 & & 1 \\
\hline 515 & inheems & 3.Dieren & 13.Weekdieren - Mollusca & 140431 & Mya truncata Linnaeus, 1758 & Afgeknotte gaper & 1 & 1 & 1 & 1 & 1 & & & 1 & 1 \\
\hline 516 & inheems & 3.Dieren & 13.Weekdieren - Mollusca & 140728 & Mysia undata (Pennant, 1777) & Zandschelp & 1 & & 1 & 1 & & & & 1 & 1 \\
\hline 517 & exoot & 3.Dieren & 13.Weekdieren - Mollusca & 156887 & Mytilopsis leucophaeata (Conrad, 1831) & & 1 & & & & & 1 & & & 1 \\
\hline 518 & inheems & 3.Dieren & 13.Weekdieren - Mollusca & 140480 & Mytilus edulis Linnaeus, 1758 & Mossel & 1 & 1 & 1 & 1 & 1 & 1 & 1 & 1 & 1 \\
\hline 519 & inheems & 3.Dieren & 13.Weekdieren - Mollusca & 140588 & Nucula hanleyi Winckworth, 1931 & & 1 & & & & & & & & 1 \\
\hline 520 & inheems & 3.Dieren & 13.Weekdieren - Mollusca & 140589 & Nucula nitidosa Winckworth, 1930 & Driehoekige parelmoerneur & 1 & 1 & 1 & & & & & 1 & 1 \\
\hline 521 & inheems & 3.Dieren & 13.Weekdieren - Mollusca & 140590 & Nucula nucleus (Linnaeus, 1758) & Ovale parelmoerneut & 1 & & 1 & & & & & 1 & 1 \\
\hline 522 & inheems & 3.Dieren & 13.Weekdieren - Mollusca & 140592 & Nucula sulcata Bronn, 1831 & & 1 & & & & & & & & \\
\hline 523 & inheems & 3.Dieren & 13.Weekdieren - Mollusca & 140658 & Ostrea edulis Linnaeus, 1758 & Gewone oester & 1 & 1 & 1 & 1 & 1 & 1 & 1 & 1 & 1 \\
\hline 524 & inheems & 3.Dieren & 13.Weekdieren - Mollusca & 140710 & Palliolum tigerinum (O. F. Müller, 1776) & Tijgerpels & 1 & & 1 & & & & & 1 & \\
\hline
\end{tabular}

| 60 van 99 | Wageningen Marine Research rapport C125/16 


\begin{tabular}{|c|c|c|c|c|c|c|c|c|c|c|c|c|c|c|c|}
\hline 525 & inheems & 3.Dieren & 13.Weekdieren - Mollusca & 140105 & Panomya norvegica & & 1 & & 1 & & & & & & 1 \\
\hline 526 & exoot & 3.Dieren & 13.Weekdieren - Mollusca & 156961 & Petricolaria pholadiformis (Lamarck, 1818) & Amerikaanse boormossel & 1 & 1 & 1 & 1 & 1 & 1 & 1 & & 1 \\
\hline 527 & inheems & 3.Dieren & 13.Weekdieren - Mollusca & 140737 & Phaxas pellucidus (Pennant, 1777) & Sabelschede & 1 & 1 & 1 & & & 1 & & 1 & 1 \\
\hline 528 & inheems & 3.Dieren & 13.Weekdieren - Mollusca & 745846 & Polititapes rhomboides (Pennant, 1777) & Gevlamde tapijtschelp & 1 & & 1 & & & & & 1 & \\
\hline 529 & inheems & 3.Dieren & 13.Weekdieren - Mollusca & 140717 & Pseudamussium peslutrae & & 1 & & 1 & & & & & & 1 \\
\hline 530 & exoot & 3.Dieren & 13.Weekdieren - Mollusca & 156991 & Rangia cuneata (G. B. Sowerby I, 1832) & & 1 & 1 & 1 & 1 & & & & & \\
\hline 531 & inheems & 3.Dieren & 13.Weekdieren - Mollusca & 231749 & Ruditapes decussatus (Linnaeus, 1758) & Geruite tapijtschelp & 1 & & 1 & & 1 & & & & \\
\hline 532 & exoot & 3.Dieren & 13.Weekdieren - Mollusca & 231750 & $\begin{array}{l}\text { Ruditapes philippinarum (Adams \& Reeve, } \\
1850 \text { ) }\end{array}$ & Tapijtschelp; Filippijnse tapijtschelp & 1 & & 1 & & 1 & & 1 & & 1 \\
\hline 533 & inheems & 3.Dieren & 13.Weekdieren - Mollusca & 140108 & Saxicavella jeffreysi Winckworth, 1930 & Geplooide rotsboorder & 1 & 1 & 1 & & & & & & 1 \\
\hline 534 & inheems & 3.Dieren & 13.Weekdieren - Mollusca & 141424 & Scrobicularia plana (da Costa, 1778) & Platte slijkgaper & 1 & 1 & 1 & 1 & 1 & 1 & 1 & & 1 \\
\hline 535 & inheems & 3.Dieren & 13.Weekdieren - Mollusca & 141546 & Solen marginatus Pulteney, 1799 & Messchede & 1 & & 1 & & & & & & 1 \\
\hline 536 & inheems & 3.Dieren & 13.Weekdieren - Mollusca & 140432 & Sphenia binghami Turton, 1822 & Kleine gaper & 1 & & 1 & & & & & 1 & 1 \\
\hline 537 & inheems & 3.Dieren & 13.Weekdieren - Mollusca & 140300 & Spisula elliptica (Brown, 1827) & Ovale strandschelp & 1 & 1 & 1 & 1 & & & & 1 & 1 \\
\hline 538 & inheems & 3.Dieren & 13.Weekdieren - Mollusca & 140301 & Spisula solida (Linnaeus, 1758) & Stevige strandschelp & 1 & 1 & 1 & 1 & 1 & 1 & & 1 & 1 \\
\hline 539 & inheems & 3.Dieren & 13.Weekdieren - Mollusca & 140302 & Spisula subtruncata (da Costa, 1778) & Halfgeknotte strandschelp & 1 & 1 & 1 & 1 & 1 & 1 & 1 & 1 & 1 \\
\hline 540 & inheems & 3.Dieren & 13.Weekdieren - Mollusca & 140571 & Striarca lactea (Linnaeus, 1758) & Melkwitte arkschelp & 1 & 1 & 1 & & & & & & 1 \\
\hline 541 & inheems & 3.Dieren & 13.Weekdieren - Mollusca & 146952 & Tellimya ferruginosa (Montagu, 1808) & Ovaal zeeklitschelpje & 1 & 1 & 1 & 1 & 1 & 1 & 1 & 1 & 1 \\
\hline 542 & inheems & 3.Dieren & 13.Weekdieren - Mollusca & 152397 & Tellimya tenella (Lovén, 1846) & & 1 & & 1 & & & & & & 1 \\
\hline 543 & inheems & 3.Dieren & 13.Weekdieren - Mollusca & 141587 & Tellina fabula Gmelin, 1791 & Rechtsgestreepte platschelp & 1 & 1 & 1 & 1 & 1 & 1 & 1 & 1 & 1 \\
\hline 544 & inheems & 3.Dieren & 13.Weekdieren - Mollusca & 162581 & Tellina pygmaea Lovén, 1846 & & 1 & 1 & 1 & & & & & & \\
\hline 545 & inheems & 3.Dieren & 13.Weekdieren - Mollusca & 141595 & Tellina tenuis da Costa, 1778 & Tere platschelp & 1 & 1 & 1 & 1 & 1 & 1 & 1 & 1 & 1 \\
\hline 546 & exoot & 3.Dieren & 13.Weekdieren - Mollusca & 141607 & Teredo navalis Linnaeus, 1758 & Gewone paalworm; paalworm & 1 & 1 & 1 & 1 & 1 & 1 & & & 1 \\
\hline 547 & inheems & 3.Dieren & 13.Weekdieren - Mollusca & 141644 & Thracia convexa (W. Wood, 1815) & Bolle papierschelp & 1 & & 1 & & & & & 1 & 1 \\
\hline 548 & inheems & 3.Dieren & 13.Weekdieren - Mollusca & 152378 & Thracia phaseolina (Lamarck, 1818) & Gewone papierschelp & 1 & 1 & 1 & & & 1 & & 1 & 1 \\
\hline 549 & inheems & 3.Dieren & 13.Weekdieren - Mollusca & 141650 & Thracia pubescens (Pulteney, 1799) & Grote papierschelp & 1 & & 1 & & & & & & 1 \\
\hline 550 & inheems & 3.Dieren & 13.Weekdieren - Mollusca & 141651 & Thracia villosiuscula (MacGillivray, 1827) & & 1 & & & & & & & & \\
\hline 551 & inheems & 3.Dieren & 13.Weekdieren - Mollusca & 141662 & Thyasira flexuosa (Montagu, 1803) & Golfschelpje & 1 & & 1 & & & & & 1 & 1 \\
\hline 552 & inheems & 3.Dieren & 13.Weekdieren - Mollusca & 141929 & Timoclea ovata (Pennant, 1777) & Ovale venusschelp & 1 & & 1 & & & & & 1 & \\
\hline 553 & inheems & 3.Dieren & 13.Weekdieren - Mollusca & 181364 & Venerupis corrugata (Gmelin, 1791) & Gewone tapijtschelp; tapijtschelp & 1 & 1 & 1 & 1 & 1 & 1 & 1 & 1 & 1 \\
\hline 554 & inheems & 3.Dieren & 13.Weekdieren - Mollusca & 140771 & Zirfaea crispata (Linnaeus, 1758) & Ruwe boormossel & 1 & & 1 & 1 & 1 & & & & 1 \\
\hline 555 & inheems & 3.Dieren & 13.Weekdieren - Mollusca & 140627 & $\begin{array}{l}\text { Acanthodoris pilosa (Abildgaard in Müller, } \\
\text { 1789) }\end{array}$ & Egelslak & 1 & 1 & 1 & 1 & 1 & 1 & 1 & 1 & \\
\hline 556 & inheems & 3.Dieren & 13.Weekdieren - Mollusca & 138691 & Acteon tornatilis (Linnaeus, 1758) & Spoelhoren & 1 & & 1 & & & & & 1 & 1 \\
\hline 557 & inheems & 3.Dieren & 13.Weekdieren - Mollusca & 138709 & Aeolidia papillosa (Linnaeus, 1761) & Grote vlokslak & 1 & 1 & 1 & 1 & 1 & 1 & 1 & 1 & 1 \\
\hline 558 & inheems & 3.Dieren & 13.Weekdieren - Mollusca & 138711 & Aeolidiella glauca (Alder \& Hancock, 1845) & Kleine vlokslak & 1 & 1 & & & 1 & 1 & 1 & & 1 \\
\hline 559 & inheems & 3.Dieren & 13.Weekdieren - Mollusca & 141555 & Alderia modesta (Lovén, 1844) & Gewone kwelderslak; kwelderslak & 1 & 1 & & 1 & 1 & 1 & 1 & & \\
\hline 560 & inheems & 3.Dieren & 13.Weekdieren - Mollusca & 141203 & Alvania lactea (Michaud, 1830) & Melkwit traliedrijfhorentje & 1 & 1 & 1 & & & & & & 1 \\
\hline 561 & inheems & 3.Dieren & 13.Weekdieren - Mollusca & 138760 & Aporrhais pespelecani (Linnaeus, 1758) & Pelikaansvoet & 1 & 1 & 1 & & & & & 1 & 1 \\
\hline 562 & inheems & 3.Dieren & 13.Weekdieren - Mollusca & 138814 & Assiminea grayana Fleming, 1828 & Gray's kustslakje & 1 & 1 & & 1 & 1 & 1 & 1 & & \\
\hline 563 & inheems & 3.Dieren & 13.Weekdieren - Mollusca & 139217 & Bela nebula (Montagu, 1803 ) & Hoge trapgevel & 1 & & 1 & & & & & 1 & 1 \\
\hline 564 & inheems & 3.Dieren & 13.Weekdieren - Mollusca & 491650 & Brachystomia eulimoides (Hanley, 1844) & Glanzend tandhorentje & 1 & & 1 & & & & & & 1 \\
\hline 565 & inheems & 3.Dieren & 13.Weekdieren - Mollusca & 491633 & Brachystomia scalaris (MacGillivray, 1843) & Mosselslurpertje & 1 & 1 & 1 & 1 & 1 & 1 & & 1 & \\
\hline 566 & inheems & 3.Dieren & 13.Weekdieren - Mollusca & 138878 & Buccinum undatum Linnaeus, 1758 & Wulk & 1 & 1 & 1 & 1 & 1 & 1 & 1 & 1 & 1 \\
\hline 567 & inheems & 3.Dieren & 13.Weekdieren - Mollusca & 139134 & Cadlina laevis (Linnaeus, 1767) & Gewone kaalslak & 1 & & 1 & & & & & 1 & \\
\hline 568 & exoot & 3.Dieren & 13.Weekdieren - Mollusca & 141767 & Calliostoma zizyphinum (Linnaeus, 1758) & Priktolhoren & 1 & & 1 & & 1 & & & 1 & \\
\hline 569 & inheems & 3.Dieren & 13.Weekdieren - Mollusca & 139085 & Cerithiopsis tubercularis (Montagu, 1803) & Bruine sponshoren & 1 & & 1 & & & & & 1 & \\
\hline 570 & inheems & 3.Dieren & 13.Weekdieren - Mollusca & 138899 & Colus gracilis (da Costa, 1778) & Slanke noordhoren & 1 & & 1 & & & & & 1 & 1 \\
\hline 571 & inheems & 3.Dieren & 13.Weekdieren - Mollusca & 138902 & Colus islandicus (Mohr, 1786) & & 1 & & 1 & & & & & 1 & \\
\hline 572 & inheems & 3.Dieren & 13.Weekdieren - Mollusca & 138903 & Colus jeffreysianus (P. Fischer, 1868) & Gezwollen slanke noordhoren & 1 & & 1 & & & & & & \\
\hline 573 & exoot & 3.Dieren & 13.Weekdieren - Mollusca & 138963 & Crepidula fornicata (Linnaeus, 1758) & Muiltje & 1 & 1 & 1 & 1 & 1 & 1 & 1 & 1 & 1 \\
\hline 574 & inheems & 3.Dieren & 13.Weekdieren - Mollusca & 141280 & Crisilla semistriata (Montagu, 1808) & Gestreept traliedrijfhorentje & 1 & & 1 & & & & & 1 & \\
\hline
\end{tabular}




\begin{tabular}{|c|c|c|c|c|c|c|c|c|c|c|c|c|c|c|c|}
\hline 575 & inheems & 3.Dieren & 13.Weekdieren - Mollusca & 139431 & Cumanotus beaumonti (Eliot, 1906) & & 1 & 1 & & 1 & 1 & & & & \\
\hline 576 & inheems & 3.Dieren & 13.Weekdieren - Mollusca & 141618 & Cuthona concinna (Alder \& Hancock, 1843) & Zilverblauwe knotsslak & 1 & 1 & & 1 & 1 & 1 & & & \\
\hline 577 & inheems & 3.Dieren & 13.Weekdieren - Mollusca & 153380 & Cuthona gymnota (Couthouy, 1838) & $\begin{array}{l}\text { Gorgelpijpknotsslak } \\
\end{array}$ & 1 & 1 & 1 & 1 & 1 & 1 & 1 & 1 & \\
\hline 578 & inheems & 3.Dieren & 13.Weekdieren - Mollusca & 141627 & Cuthona nana (Alder \& Hancock, 1842) & & 1 & 1 & 1 & 1 & 1 & 1 & 1 & 1 & \\
\hline 579 & inheems & 3.Dieren & 13.Weekdieren - Mollusca & 139476 & Cylichna cylindracea (Pennant, 1777) & Valse oubliehoren & 1 & 1 & 1 & & & & & 1 & 1 \\
\hline 580 & inheems & 3.Dieren & 13.Weekdieren - Mollusca & 139523 & Dendronotus frondosus (Ascanius, 1774) & Boompjesslak & 1 & 1 & 1 & 1 & 1 & 1 & 1 & 1 & 1 \\
\hline 581 & inheems & 3.Dieren & 13.Weekdieren - Mollusca & 139557 & Diaphana minuta T. Brown, 1827 & & 1 & & & & & & & & 1 \\
\hline 582 & inheems & 3.Dieren & 13.Weekdieren - Mollusca & 181228 & Doris pseudoargus Rapp, 1827 & Citroenslak & 1 & & 1 & & 1 & 1 & & 1 & 1 \\
\hline 583 & inheems & 3.Dieren & 13.Weekdieren - Mollusca & 139631 & Doto coronata (Gmelin, 1791) & Roodgevlekte kroonslak & 1 & 1 & 1 & 1 & 1 & & & 1 & \\
\hline 584 & inheems & 3.Dieren & 13.Weekdieren - Mollusca & 139634 & Doto dunnei Lemche, 1976 & & 1 & & 1 & & & & & & \\
\hline 585 & inheems & 3.Dieren & 13.Weekdieren - Mollusca & 238104 & Ecrobia ventrosa (Montagu, 1803) & Opgezwollen brakwaterhorentje & 1 & & 1 & 1 & 1 & 1 & 1 & & 1 \\
\hline 586 & inheems & 3.Dieren & 13.Weekdieren - Mollusca & 139686 & Elysia viridis (Montagu, 1804) & Groene wierslak & 1 & 1 & & & 1 & 1 & 1 & & \\
\hline 587 & inheems & 3.Dieren & 13.Weekdieren - Mollusca & 139718 & Epitonium clathratulum (Kanmacher, 1798) & Witte wenteltrap & 1 & 1 & 1 & & 1 & 1 & & 1 & 1 \\
\hline 588 & inheems & 3.Dieren & 13.Weekdieren - Mollusca & 146905 & Epitonium clathrus (Linnaeus, 1758) & Gewone wenteltrap & 1 & 1 & 1 & & 1 & & 1 & 1 & 1 \\
\hline 589 & inheems & 3.Dieren & 13.Weekdieren - Mollusca & 139765 & Eubranchus exiguus (Alder \& Hancock, 1848) & Plompe knuppelslak & 1 & 1 & & 1 & 1 & 1 & 1 & 1 & \\
\hline 590 & inheems & 3.Dieren & 13.Weekdieren - Mollusca & 139770 & Eubranchus rupium (Møøler, 1842) & Noordelijke knuppelslak & 1 & 1 & & 1 & 1 & & 1 & & \\
\hline 591 & inheems & 3.Dieren & 13.Weekdieren - Mollusca & 140528 & Euspira catena (da Costa, 1778) & $\begin{array}{l}\text { Gewone tepelhoren; grote } \\
\text { tepelhoren }\end{array}$ & 1 & 1 & 1 & 1 & & & & 1 & 1 \\
\hline 592 & inheems & 3.Dieren & 13.Weekdieren - Mollusca & 151894 & Euspira nitida (Donovan, 1804) & Glanzende tepelhoren & 1 & 1 & 1 & 1 & & 1 & & 1 & 1 \\
\hline 593 & inheems & 3.Dieren & 13.Weekdieren - Mollusca & 139908 & Facelina bostoniensis (Couthouy, 1838) & Brede ringsprietslak & 1 & 1 & 1 & 1 & 1 & 1 & 1 & 1 & \\
\hline 594 & inheems & 3.Dieren & 13.Weekdieren - Mollusca & 156714 & Flabellina gracilis (Alder \& Hancock, 1844) & Slanke waaierslak & 1 & 1 & & 1 & 1 & 1 & 1 & & \\
\hline 595 & inheems & 3.Dieren & 13.Weekdieren - Mollusca & 181249 & Flabellina lineata (Lovén, 1846) & Witgestreepte waaierslak & 1 & & 1 & 1 & 1 & & & 1 & \\
\hline 596 & inheems & 3.Dieren & 13.Weekdieren - Mollusca & 139993 & Flabellina pedata (Montagu, 1816) & Paarse waaierslak & 1 & & 1 & & 1 & & & 1 & \\
\hline 597 & inheems & 3.Dieren & 13.Weekdieren - Mollusca & 139580 & Geitodoris planata (Alder \& Hancock, 1846) & Millenniumwratslak & 1 & & 1 & & 1 & & 1 & 1 & \\
\hline 598 & exoot & 3.Dieren & 13.Weekdieren - Mollusca & 141782 & Gibbula cineraria (Linnaeus, 1758) & Asgrauwe tolhoren & 1 & 1 & 1 & & 1 & & & 1 & \\
\hline 599 & inheems & 3.Dieren & 13.Weekdieren - Mollusca & 141799 & Gibbula tumida (Montagu, 1803) & Gezwollen tolhoren & 1 & & 1 & & & & & 1 & \\
\hline 600 & inheems & 3.Dieren & 13.Weekdieren - Mollusca & 140032 & Goniodoris castanea Alder \& Hancock, 1845 & Bruine plooislak & 1 & 1 & 1 & 1 & 1 & 1 & 1 & 1 & \\
\hline 601 & inheems & 3.Dieren & 13.Weekdieren - Mollusca & 867492 & Hermania scabra (O. F. Müller, 1784) & & 1 & & 1 & & & & & 1 & \\
\hline 602 & inheems & 3.Dieren & 13.Weekdieren - Mollusca & 140129 & Hyala vitrea (Montagu, 1803) & & 1 & & 1 & & & & & 1 & 1 \\
\hline 603 & inheems & 3.Dieren & 13.Weekdieren - Mollusca & 140855 & Janolus cristatus (Delle Chiaje, 1841) & Blauwtipje & 1 & 1 & 1 & 1 & 1 & 1 & 1 & 1 & \\
\hline 604 & inheems & 3.Dieren & 13.Weekdieren - Mollusca & 140857 & Janolus hyalinus (Alder \& Hancock, 1854) & Wrattig tipje & 1 & & 1 & & 1 & & 1 & 1 & \\
\hline 605 & inheems & 3.Dieren & 13.Weekdieren - Mollusca & 140173 & Lamellaria perspicua (Linnaeus, 1758) & & 1 & 1 & 1 & & 1 & & & 1 & \\
\hline 606 & inheems & 3.Dieren & 13.Weekdieren - Mollusca & 140830 & Limacia clavigera (O. F. Müller, 1776) & Wrattige mosdierslak & 1 & & 1 & & 1 & & & 1 & \\
\hline 607 & inheems & 3.Dieren & 13.Weekdieren - Mollusca & 140230 & Limapontia depressa Alder \& Hancock, 1862 & Kleine schorreslak & 1 & 1 & & 1 & 1 & 1 & & & \\
\hline 608 & inheems & 3.Dieren & 13.Weekdieren - Mollusca & 140261 & Littorina fabalis (Turton, 1825) & Vlakke alikruik & 1 & 1 & & & 1 & & & & \\
\hline 609 & inheems & 3.Dieren & 13.Weekdieren - Mollusca & 140262 & Littorina littorea (Linnaeus, 1758) & Gewone alikruik & 1 & 1 & 1 & 1 & 1 & 1 & 1 & & 1 \\
\hline 610 & inheems & 3.Dieren & 13.Weekdieren - Mollusca & 140263 & Littorina obtusata (Linnaeus, 1758) & Stompe alikruik & 1 & 1 & & 1 & 1 & 1 & 1 & & 1 \\
\hline 611 & inheems & 3.Dieren & 13.Weekdieren - Mollusca & 140264 & Littorina saxatilis (Olivi, 1792) & Ruwe alikruik & 1 & 1 & & 1 & 1 & 1 & & & \\
\hline 612 & inheems & 3.Dieren & 13.Weekdieren - Mollusca & 140266 & Melarhaphe neritoides (Linnaeus, 1758) & Kleine alikruik & 1 & 1 & & & & & & & 1 \\
\hline 613 & inheems & 3.Dieren & 13.Weekdieren - Mollusca & 139673 & Myosotella myosotis (Draparnaud, 1801) & Gewoon muizenoortje & 1 & 1 & & 1 & 1 & 1 & & & \\
\hline 614 & inheems & 3.Dieren & 13.Weekdieren - Mollusca & 140503 & Nassarius incrassatus (Strøm, 1768) & Verdikte fuikhoren & 1 & 1 & 1 & & & & & 1 & 1 \\
\hline 615 & inheems & 3.Dieren & 13.Weekdieren - Mollusca & 140509 & Nassarius nitidus (Jeffreys, 1867) & & 1 & 1 & & 1 & & & & & 1 \\
\hline 616 & inheems & 3.Dieren & 13.Weekdieren - Mollusca & 140512 & Nassarius pygmaeus (Lamarck, 1822) & Kleine fuikhoren & 1 & 1 & & & & & & & 1 \\
\hline 617 & inheems & 3.Dieren & 13.Weekdieren - Mollusca & 140513 & Nassarius reticulatus (Linnaeus, 1758) & Gevlochten fuikhoren & 1 & 1 & 1 & 1 & 1 & 1 & 1 & 1 & 1 \\
\hline 618 & inheems & 3.Dieren & 13.Weekdieren - Mollusca & 138920 & Neptunea antiqua (Linnaeus, 1758) & Noordhoren & 1 & & 1 & & & & & 1 & 1 \\
\hline 619 & inheems & 3.Dieren & 13.Weekdieren - Mollusca & 140403 & Nucella lapillus (Linnaeus, 1758) & Purperslak & 1 & 1 & & 1 & 1 & 1 & & & \\
\hline 620 & inheems & 3.Dieren & 13.Weekdieren - Mollusca & 150457 & Onchidoris bilamellata (Linnaeus, 1767) & Rosse sterslak & 1 & 1 & & 1 & 1 & 1 & 1 & 1 & \\
\hline 621 & inheems & 3.Dieren & 13.Weekdieren - Mollusca & 140640 & Onchidoris muricata (O. F. Müller, 1776) & Wrattige sterslak & 1 & 1 & 1 & & & & & 1 & 1 \\
\hline 622 & inheems & 3.Dieren & 13.Weekdieren - Mollusca & 141033 & Ondina divisa (J. Adams, 1797) & Stomp groeftandhorentje & 1 & & 1 & & & & & & 1 \\
\hline 623 & inheems & 3.Dieren & 13.Weekdieren - Mollusca & 140685 & Patella vulgata Linnaeus, 1758 & Schaalhoorn & 1 & 1 & 1 & 1 & & & & & 1 \\
\hline 624 & inheems & 3.Dieren & 13.Weekdieren - Mollusca & 151628 & Peringia ulvae (Pennant, 1777) & Wadslakje & 1 & 1 & 1 & 1 & 1 & 1 & 1 & & 1 \\
\hline 625 & inheems & 3.Dieren & 13.Weekdieren - Mollusca & 140747 & Philine catena (Montagu, 1803) & & 1 & & 1 & & & & & & \\
\hline
\end{tabular}

| 62 van 99 | Wageningen Marine Research rapport C125/16 


\begin{tabular}{|c|c|c|c|c|c|c|c|c|c|c|c|c|c|c|c|}
\hline 626 & inheems & 3.Dieren & 13.Weekdieren - Mollusca & 140758 & Philine punctata (J. Adams, 1800) & & 1 & 1 & & & & & & & \\
\hline 627 & inheems & 3.Dieren & 13.Weekdieren - Mollusca & 140834 & Polycera faeroensis Lemche, 1929 & Breedkopharlekijnslak & 1 & & 1 & & & & & 1 & \\
\hline 628 & inheems & 3.Dieren & 13.Weekdieren - Mollusca & 140838 & Polycera quadrilineata (O. F. Müller, 1776) & Harlekijnslak & 1 & & 1 & & 1 & & & 1 & \\
\hline 629 & exoot & 3.Dieren & 13.Weekdieren - Mollusca & 147123 & Potamopyrgus antipodarum (Gray, 1843) & Jenkins' waterhoren & 1 & & 1 & & & & & & 1 \\
\hline 630 & inheems & 3.Dieren & 13.Weekdieren - Mollusca & 160446 & Propebela turricula (Montagu, 1803) & Gewone trapgevel trapgevel & 1 & & 1 & & & & & & 1 \\
\hline 631 & inheems & 3.Dieren & 13.Weekdieren - Mollusca & 141134 & Retusa obtusa (Montagu, 1803) & Oubliehoren & 1 & & & 1 & 1 & 1 & 1 & & 1 \\
\hline 632 & inheems & 3.Dieren & 13.Weekdieren - Mollusca & 156376 & Retusa umbilicata (Montagu, 1803) & Ovale oubliehoren & 1 & & 1 & & & & & & 1 \\
\hline 633 & inheems & 3.Dieren & 13.Weekdieren - Mollusca & 139486 & Roxania utriculus (Brocchi, 1814) & & 1 & & 1 & & & & & & 1 \\
\hline 634 & inheems & 3.Dieren & 13.Weekdieren - Mollusca & 139488 & Scaphander lignarius (Linnaeus, 1758) & Boothoren & 1 & & 1 & & & & & 1 & 1 \\
\hline 635 & inheems & 3.Dieren & 13.Weekdieren - Mollusca & 140669 & Simnia patula (Pennant, 1777) & & 1 & & 1 & & & & & 1 & \\
\hline 636 & inheems & 3.Dieren & 13.Weekdieren - Mollusca & 141639 & Tenellia adspersa (Nordmann, 1845) & Brakwaterknotsslak & 1 & 1 & & 1 & 1 & 1 & & & \\
\hline 637 & inheems & 3.Dieren & 13.Weekdieren - Mollusca & 141641 & Tergipes tergipes (Forsskål in Niebuhr, 1775) & Slanke knotsslak & 1 & 1 & 1 & 1 & 1 & 1 & 1 & 1 & \\
\hline 638 & inheems & 3.Dieren & 13.Weekdieren - Mollusca & 140840 & Thecacera pennigera (Montagu, 1813) & Gestippelde mosdierslak & 1 & 1 & & & 1 & 1 & 1 & & \\
\hline 639 & inheems & 3.Dieren & 13.Weekdieren - Mollusca & 141690 & Tornus subcarinatus (Montagu, 1803) & Gekielde cirkelslak & 1 & 1 & 1 & & & & & & 1 \\
\hline 640 & inheems & 3.Dieren & 13.Weekdieren - Mollusca & 416648 & Tritonia hombergii Cuvier, 1803 & Grote tritonia & 1 & & 1 & & & & & 1 & \\
\hline 641 & inheems & 3.Dieren & 13.Weekdieren - Mollusca & 141738 & Tritonia plebeia Johnston, 1828 & Kleine tritonia & 1 & 1 & 1 & & 1 & 1 & 1 & 1 & \\
\hline 642 & inheems & 3.Dieren & 13.Weekdieren - Mollusca & 141741 & Trivia arctica (Pulteney, 1799) & Ongevlekt koffieboontje & 1 & 1 & 1 & & 1 & & & 1 & \\
\hline 643 & inheems & 3.Dieren & 13.Weekdieren - Mollusca & 141744 & Trivia monacha (da Costa, 1778) & Gevlekt koffieboontje & 1 & 1 & 1 & & 1 & & & 1 & \\
\hline 644 & inheems & 3.Dieren & 13.Weekdieren - Mollusca & 141072 & Turbonilla lactea (Linnaeus, 1758) & Melkwit priemhorentje & 1 & & 1 & & & & & & 1 \\
\hline 645 & inheems & 3.Dieren & 13.Weekdieren - Mollusca & 141086 & Turbonilla pusilla (Philippi, 1844) & & 1 & & 1 & & & & & & 1 \\
\hline 646 & inheems & 3.Dieren & 13.Weekdieren - Mollusca & 141872 & Turritella communis Risso, 1826 & Penhoren & 1 & 1 & 1 & 1 & & & & 1 & 1 \\
\hline 647 & exoot & 3.Dieren & 13.Weekdieren - Mollusca & 140429 & Urosalpinx cinerea (Say, 1822) & & 1 & & & & 1 & & & & 1 \\
\hline 648 & inheems & 3.Dieren & 13.Weekdieren - Mollusca & 139896 & Vitreolina antiflexa (Monterosato, 1884) & Zwakgebogen glanshorentje & 1 & & 1 & & & & & & 1 \\
\hline 649 & inheems & 3.Dieren & 13.Weekdieren - Mollusca & 153131 & Alloteuthis subulata (Lamarck, 1798) & Dwergpijlinktvis & 1 & 1 & 1 & 1 & 1 & & 1 & 1 & 1 \\
\hline 650 & inheems & 3.Dieren & 13.Weekdieren - Mollusca & 140600 & Eledone cirrhosa (Lamarck, 1798) & & 1 & 1 & 1 & 1 & & & & & 1 \\
\hline 651 & inheems & 3.Dieren & 13.Weekdieren - Mollusca & 416668 & Loligo forbesii Steenstrup, 1857 & & 1 & 1 & 1 & & & & & & 1 \\
\hline 652 & inheems & 3.Dieren & 13.Weekdieren - Mollusca & 140271 & Loligo vulgaris Lamarck, 1798 & Gewone pijlinktvis & 1 & 1 & 1 & & 1 & & 1 & 1 & 1 \\
\hline 653 & inheems & 3.Dieren & 13.Weekdieren - Mollusca & 141444 & Sepia officinalis Linnaeus, 1758 & Gewone zeekat & 1 & 1 & 1 & 1 & 1 & 1 & 1 & & 1 \\
\hline 654 & inheems & 3.Dieren & 13.Weekdieren - Mollusca & 141450 & Sepietta neglecta & & 1 & & 1 & & & & & & 1 \\
\hline 655 & inheems & 3.Dieren & 13.Weekdieren - Mollusca & 141454 & Sepiola atlantica & Dwerginktvis & 1 & 1 & 1 & 1 & 1 & 1 & 1 & 1 & 1 \\
\hline 656 & inheems & 3.Dieren & 13.Weekdieren - Mollusca & 140624 & Todarodes sagittatus (Lamarck, 1798) & & 1 & 1 & & & & & & & \\
\hline 657 & inheems & 3.Dieren & 13.Weekdieren - Mollusca & 140625 & Todaropsis eblanae (Ball, 1841) & & 1 & & 1 & & & & & & 1 \\
\hline 658 & inheems & 3.Dieren & 14.Cephalorhyncha & 101160 & Priapulus caudatus Lamarck, 1816 & & 1 & & 1 & & & & & 1 & 1 \\
\hline 659 & exoot & 3.Dieren & 15. Nematoden - Nematoda & 458994 & $\begin{array}{l}\text { Anguillicoloides crassus (Kuwahara, Niimi \& } \\
\text { Itagaki, 1974) }\end{array}$ & & 1 & 1 & 1 & 1 & 1 & 1 & 1 & & \\
\hline 660 & inheems & 3.Dieren & 15.Nematoden - Nematoda & 121783 & Enoplus brevis Bastian, 1865 & & 1 & & 1 & & & & & 1 & \\
\hline 661 & inheems & 3.Dieren & 17.Geleedpotigen - Arthropoda & 147032 & Nebalia bipes (Fabricius, 1780) & & 1 & & 1 & & & & & & 1 \\
\hline 662 & inheems & 3.Dieren & 17.Geleedpotigen - Arthropoda & 119936 & Lophogaster typicus M. Sars, 1857 & & 1 & & 1 & & & & & 1 & 1 \\
\hline 663 & inheems & 3.Dieren & 17.Geleedpotigen - Arthropoda & 134723 & Anoplodactylus petiolatus (Krøyer, 1844) & & 1 & & & & 1 & 1 & 1 & & 1 \\
\hline 664 & inheems & 3.Dieren & 17.Geleedpotigen - Arthropoda & 134674 & Endeis spinosa (Montagu, 1808) & Gedoornde zeespin & 1 & & 1 & & & & & & 1 \\
\hline 665 & inheems & 3.Dieren & 17.Geleedpotigen - Arthropoda & 150520 & Nymphon brevirostre Hodge, 1863 & & 1 & & 1 & & 1 & 1 & 1 & 1 & 1 \\
\hline 666 & inheems & 3.Dieren & 17.Geleedpotigen - Arthropoda & 134741 & Phoxichilidium femoratum (Rathke, 1799) & & 1 & & 1 & & 1 & 1 & & & 1 \\
\hline 667 & inheems & 3.Dieren & 17.Geleedpotigen - Arthropoda & 239867 & Pycnogonum litorale (Ström, 1762) & Michelinmannetje & 1 & & 1 & & 1 & 1 & 1 & 1 & \\
\hline 668 & inheems & 3.Dieren & 17.Geleedpotigen - Arthropoda & 114822 & Copidognathus brevirostris Viets, 1927 & & 1 & 1 & 1 & & 1 & & & & \\
\hline 669 & inheems & 3.Dieren & 17.Geleedpotigen - Arthropoda & 114830 & Copidognathus fabricii (Lohmann, 1889) & & 1 & 1 & 1 & 1 & 1 & 1 & & & \\
\hline 670 & inheems & 3.Dieren & 17.Geleedpotigen - Arthropoda & 114928 & Halacarellus floridiarum (Lohmann, 1889) & & 1 & 1 & 1 & 1 & & & & & \\
\hline 671 & inheems & 3.Dieren & 17.Geleedpotigen - Arthropoda & 114933 & Halacarellus micropectinatus Bartsch, 1972 & & 1 & 1 & 1 & & 1 & & & & \\
\hline 672 & inheems & 3.Dieren & 17.Geleedpotigen - Arthropoda & 114982 & Lohmannella falcata (Hodge, 1863) & & 1 & 1 & 1 & 1 & & 1 & & & \\
\hline 673 & inheems & 3.Dieren & 17.Geleedpotigen - Arthropoda & 114983 & Lohmannella kervillei (Trouessart, 1894) & & 1 & 1 & & & & & & & \\
\hline 674 & inheems & 3.Dieren & 17.Geleedpotigen - Arthropoda & 115006 & $\begin{array}{l}\text { Metarhombognathus armatus (Lohmann, } \\
\text { 1893) }\end{array}$ & & 1 & 1 & 1 & 1 & & & & & \\
\hline 675 & inheems & 3.Dieren & 17.Geleedpotigen - Arthropoda & 115011 & Rhombognathides mucronatus (Viets, 1927) & & 1 & 1 & 1 & 1 & & & & & \\
\hline
\end{tabular}




\begin{tabular}{|c|c|c|c|c|c|c|c|c|c|c|c|c|c|c|c|}
\hline 676 & inheems & 3.Dieren & 17.Geleedpotigen - Arthropoda & 115012 & Rhombognathides pascens (Lohmann, 1889) & & 1 & 1 & 1 & 1 & & & & & \\
\hline 677 & inheems & 3.Dieren & 17.Geleedpotigen - Arthropoda & 115013 & Rhombognathides seahami (Hodge, 1860) & & 1 & 1 & 1 & 1 & & & & & \\
\hline 678 & inheems & 3.Dieren & 17.Geleedpotigen - Arthropoda & 115014 & Rhombognathides spinipes (Viets, 1933) & & 1 & 1 & 1 & 1 & 1 & & & & \\
\hline 679 & inheems & 3.Dieren & 17.Geleedpotigen - Arthropoda & 115015 & Rhombognathides trionyx (Trouessart, 1899) & & 1 & 1 & 1 & & 1 & & & & \\
\hline 680 & inheems & 3.Dieren & 17.Geleedpotigen - Arthropoda & 114965 & Thalassarachna basteri (Johnston, 1836) & & 1 & 1 & & 1 & & 1 & & & \\
\hline 681 & inheems & 3.Dieren & 17.Geleedpotigen - Arthropoda & 118158 & $\begin{array}{l}\text { Thalassosmittia thalassophila (Bequaert \& } \\
\text { Goetghebuer, 1913) }\end{array}$ & & 1 & 1 & 1 & 1 & & & & 1 & \\
\hline 682 & inheems & 3.Dieren & 17.Geleedpotigen - Arthropoda & 136126 & Platysquilla eusebia (Risso, 1816) & & 1 & 1 & 1 & & 1 & 1 & & 1 & 1 \\
\hline 683 & inheems & 3.Dieren & 17.Geleedpotigen - Arthropoda & 119997 & Erythrops elegans (G.O. Sars, 1863) & & 1 & & 1 & & & & & & 1 \\
\hline 684 & inheems & 3.Dieren & 17.Geleedpotigen - Arthropoda & 120019 & Gastrosaccus sanctus (Van Beneden, 1861) & & 1 & & 1 & & & & & & 1 \\
\hline 685 & inheems & 3.Dieren & 17.Geleedpotigen - Arthropoda & 120020 & Gastrosaccus spinifer (Goës, 1864) & & 1 & & 1 & & & & & & 1 \\
\hline 686 & inheems & 3.Dieren & 17.Geleedpotigen - Arthropoda & 120024 & Hemimysis abyssicola G.O. Sars, 1869 & & 1 & & & & & & & & 1 \\
\hline 687 & inheems & 3.Dieren & 17.Geleedpotigen - Arthropoda & 120026 & Hemimysis lamornae (Couch, 1856) & Roodbuikaasgarnaal & 1 & 1 & 1 & & 1 & & 1 & 1 & 1 \\
\hline 688 & inheems & 3.Dieren & 17.Geleedpotigen - Arthropoda & 148701 & $\begin{array}{l}\text { Heteromysis (Heteromysis) formosa Smith, } \\
1873\end{array}$ & & 1 & & 1 & & & & & 1 & 1 \\
\hline 689 & inheems & 3.Dieren & 17.Geleedpotigen - Arthropoda & 120037 & $\begin{array}{l}\text { Heteromysis (Heteromysis) microps (G.O. } \\
\text { Sars, 1877) }\end{array}$ & & 1 & & & & & & & & 1 \\
\hline 690 & inheems & 3.Dieren & 17.Geleedpotigen - Arthropoda & 120054 & Leptomysis lingvura (G.O. Sars, 1866) & Witrugaasgarnaal & 1 & & 1 & 1 & & & & & 1 \\
\hline 691 & inheems & 3.Dieren & 17.Geleedpotigen - Arthropoda & 120072 & Mesopodopsis slabberi (Van Beneden, 1861) & & 1 & & 1 & 1 & & & & 1 & 1 \\
\hline 692 & 0 & 3.Dieren & 17.Geleedpotigen - Arthropoda & 120089 & Mysidopsis gibbosa G.O. Sars, 1864 & & 1 & & 1 & & & & & 1 & 1 \\
\hline 693 & exoot & 3.Dieren & 17.Geleedpotigen - Arthropoda & 157807 & Neomysis americana (S.I. Smith, 1873) & & 1 & & 1 & & & & & 1 & \\
\hline 694 & inheems & 3.Dieren & 17.Geleedpotigen - Arthropoda & 120177 & Praunus flexuosus (Müller, 1776) & Bochtige aasgarnaal & 1 & & 1 & 1 & & & & & 1 \\
\hline 695 & inheems & 3.Dieren & 17.Geleedpotigen - Arthropoda & 120178 & Praunus inermis (Rathke, 1843) & & 1 & 1 & & & & & & & 1 \\
\hline 696 & inheems & 3.Dieren & 17.Geleedpotigen - Arthropoda & 120180 & Praunus neglectus (G.O. Sars, 1869) & & 1 & & 1 & & 1 & & 1 & 1 & 1 \\
\hline 697 & inheems & 3.Dieren & 17.Geleedpotigen - Arthropoda & 120203 & Schistomysis kervillei (G.O. Sars, 1885) & & 1 & & 1 & & 1 & & & 1 & 1 \\
\hline 698 & inheems & 3.Dieren & 17.Geleedpotigen - Arthropoda & 120204 & Schistomysis ornata (G. O. Sars, 1864) & & 1 & & 1 & & & & & & 1 \\
\hline 699 & inheems & 3.Dieren & 17.Geleedpotigen - Arthropoda & 120206 & Schistomysis spiritus (Norman, 1860) & & 1 & & 1 & & & 1 & & & 1 \\
\hline 700 & inheems & 3.Dieren & 17.Geleedpotigen - Arthropoda & 120208 & Siriella armata (Milne Edwards, 1837) & & 1 & 1 & 1 & & & & & 1 & 1 \\
\hline 701 & inheems & 3.Dieren & 17.Geleedpotigen - Arthropoda & 226375 & Siriella clausii G.O. Sars, 1877 & & 1 & & & & & 1 & & & 1 \\
\hline 702 & inheems & 3.Dieren & 17.Geleedpotigen - Arthropoda & 102788 & Abludomelita obtusata (Montagu, 1813) & & 1 & & & 1 & & & & 1 & 1 \\
\hline 703 & inheems & 3.Dieren & 17.Geleedpotigen - Arthropoda & 102497 & Acidostoma obesum (Bate, 1862) & & 1 & 1 & 1 & & 1 & & & 1 & 1 \\
\hline 704 & inheems & 3.Dieren & 17.Geleedpotigen - Arthropoda & 101891 & Ampelisca brevicornis (Costa, 1853) & & 1 & & 1 & & & & & 1 & 1 \\
\hline 705 & inheems & 3.Dieren & 17.Geleedpotigen - Arthropoda & 101896 & Ampelisca diadema (Costa, 1853) & & 1 & 1 & & & & & & & 1 \\
\hline 706 & inheems & 3.Dieren & 17.Geleedpotigen - Arthropoda & 101908 & Ampelisca macrocephala Liljeborg, 1852 & & 1 & 1 & & & & & & & 1 \\
\hline 707 & inheems & 3.Dieren & 17.Geleedpotigen - Arthropoda & 101928 & Ampelisca spinipes Boeck, 1861 & & 1 & 1 & 1 & & & & & & 1 \\
\hline 708 & inheems & 3.Dieren & 17.Geleedpotigen - Arthropoda & 101930 & Ampelisca tenuicornis Lilljeborg, 1855 & & 1 & & 1 & & & & & 1 & 1 \\
\hline 709 & inheems & 3.Dieren & 17.Geleedpotigen - Arthropoda & 101933 & Ampelisca typica (Bate, 1856) & & 1 & & 1 & & & & & & 1 \\
\hline 710 & inheems & 3.Dieren & 17.Geleedpotigen - Arthropoda & 101960 & Amphilochoides boecki Sars, 1892 & & 1 & 1 & 1 & & 1 & 1 & & 1 & 1 \\
\hline 711 & inheems & 3.Dieren & 17.Geleedpotigen - Arthropoda & 102012 & Aora gracilis (Bate, 1857) & & 1 & & 1 & & & & & 1 & 1 \\
\hline 712 & inheems & 3.Dieren & 17.Geleedpotigen - Arthropoda & 102160 & Apherusa bispinosa (Bate, 1857) & & 1 & 1 & 1 & 1 & 1 & & 1 & & 1 \\
\hline 713 & inheems & 3.Dieren & 17.Geleedpotigen - Arthropoda & 102164 & Apherusa clevei G.O. Sars, 1904 & & 1 & 1 & 1 & & & & & & 1 \\
\hline 714 & inheems & 3.Dieren & 17.Geleedpotigen - Arthropoda & 102168 & Apherusa jurinei Milne Edwards, 1830 & & 1 & 1 & 1 & & 1 & 1 & 1 & & 1 \\
\hline 715 & inheems & 3.Dieren & 17.Geleedpotigen - Arthropoda & 102172 & Apherusa ovalipes Norman \& Scott, 1906 & & 1 & 1 & 1 & 1 & 1 & 1 & 1 & 1 & 1 \\
\hline 716 & inheems & 3.Dieren & 17.Geleedpotigen - Arthropoda & 148594 & Apocorophium lacustre (Vanhöffen, 1911) & & 1 & & 1 & 1 & 1 & 1 & & & 1 \\
\hline 717 & inheems & 3.Dieren & 17.Geleedpotigen - Arthropoda & 490616 & Apohyale prevostii (Milne Edwards, 1830) & & 1 & 1 & 1 & 1 & & & & 1 & 1 \\
\hline 718 & inheems & 3.Dieren & 17.Geleedpotigen - Arthropoda & 236495 & Apolochus neapolitanus (Della Valle, 1893) & & 1 & & 1 & & & & & & 1 \\
\hline 719 & inheems & 3.Dieren & 17.Geleedpotigen - Arthropoda & 102064 & Argissa hamatipes (Norman, 1869) & & 1 & & 1 & & & & & & 1 \\
\hline 720 & inheems & 3.Dieren & 17.Geleedpotigen - Arthropoda & 102132 & Atylus vedlomensis (Bate \& Westwood, 1862) & & 1 & & 1 & 1 & & & & 1 & 1 \\
\hline 721 & inheems & 3.Dieren & 17.Geleedpotigen - Arthropoda & 102021 & Autonoe longipes (Liljeborg, 1852) & & 1 & 1 & 1 & & & & & & 1 \\
\hline 722 & inheems & 3.Dieren & 17.Geleedpotigen - Arthropoda & 103058 & Bathyporeia elegans Watkin, 1938 & & 1 & & & & & & & & 1 \\
\hline 723 & inheems & 3.Dieren & 17.Geleedpotigen - Arthropoda & 103060 & Bathyporeia guilliamsoniana (Bate, 1857) & & 1 & 1 & 1 & 1 & 1 & 1 & & & 1 \\
\hline 724 & inheems & 3.Dieren & 17.Geleedpotigen - Arthropoda & 103064 & Bathyporeia nana Toulmond, 1966 & & 1 & 1 & & & 1 & & & & 1 \\
\hline
\end{tabular}

| 64 van 99 | Wageningen Marine Research rapport C125/16 


\begin{tabular}{|c|c|c|c|c|c|c|c|c|c|c|c|c|c|c|c|}
\hline 725 & inheems & 3.Dieren & 17.Geleedpotigen - Arthropoda & 103066 & Bathyporeia pelagica (Bate, 1856) & & 1 & & 1 & & & & & & 1 \\
\hline 726 & inheems & 3.Dieren & 17.Geleedpotigen - Arthropoda & 103068 & Bathyporeia pilosa Lindström, 1855 & & 1 & 1 & 1 & 1 & 1 & 1 & 1 & 1 & 1 \\
\hline 727 & inheems & 3.Dieren & 17.Geleedpotigen - Arthropoda & 103073 & Bathyporeia sarsi Watkin, 1938 & & 1 & & & 1 & & & & & 1 \\
\hline 728 & inheems & 3.Dieren & 17.Geleedpotigen - Arthropoda & 103076 & Bathyporeia tenuipes Meinert, 1877 & & 1 & & 1 & & & & & 1 & 1 \\
\hline 729 & inheems & 3.Dieren & 17.Geleedpotigen - Arthropoda & 744567 & Britorchestia brito (Stebbing, 1891) & & 1 & 1 & 1 & 1 & & & & 1 & 1 \\
\hline 730 & inheems & 3.Dieren & 17.Geleedpotigen - Arthropoda & 102178 & Calliopius laeviusculus (Krøyer, 1838) & & 1 & 1 & 1 & 1 & 1 & 1 & & 1 & \\
\hline 731 & inheems & 3.Dieren & 17.Geleedpotigen - Arthropoda & 101839 & Caprella linearis (Linnaeus, 1767) & Wandelend geraamte & 1 & 1 & 1 & 1 & 1 & 1 & 1 & 1 & 1 \\
\hline 732 & exoot & 3.Dieren & 17.Geleedpotigen - Arthropoda & 146768 & Caprella mutica Schurin, 1935 & & 1 & 1 & & 1 & & & & & 1 \\
\hline 733 & inheems & 3.Dieren & 17.Geleedpotigen - Arthropoda & 101851 & Caprella septentrionalis Krøyer, 1838 & & 1 & & & & & & & & \\
\hline 734 & inheems & 3.Dieren & 17.Geleedpotigen - Arthropoda & 101853 & Caprella tuberculata Guérin, 1836 & & 1 & & 1 & & 1 & 1 & 1 & 1 & 1 \\
\hline 735 & inheems & 3.Dieren & 17.Geleedpotigen - Arthropoda & 102798 & Cheirocratus sundevalli (Rathke, 1843) & & 1 & & 1 & & & & & & 1 \\
\hline 736 & exoot & 3.Dieren & 17.Geleedpotigen - Arthropoda & 148582 & Chelicorophium curvispinum (G.O. Sars, 1895) & & 1 & 1 & & 1 & 1 & 1 & 1 & & 1 \\
\hline 737 & inheems & 3.Dieren & 17.Geleedpotigen - Arthropoda & 102087 & Corophium arenarium Crawford, 1937 & & 1 & & & 1 & & & & & 1 \\
\hline 738 & exoot & 3.Dieren & 17.Geleedpotigen - Arthropoda & 102096 & Corophium multisetosum Stock, 1952 & & 1 & 1 & 1 & 1 & 1 & 1 & 1 & & 1 \\
\hline 739 & inheems & 3.Dieren & 17.Geleedpotigen - Arthropoda & 102101 & Corophium volutator (Pallas, 1766) & & 1 & 1 & 1 & 1 & & & & 1 & 1 \\
\hline 740 & inheems & 3.Dieren & 17.Geleedpotigen - Arthropoda & 237004 & $\begin{array}{l}\text { Crassicorophium bonellii (Milne Edwards, } \\
1830 \text { ) }\end{array}$ & & 1 & 1 & 1 & 1 & 1 & 1 & & 1 & 1 \\
\hline 741 & exoot & 3.Dieren & 17.Geleedpotigen - Arthropoda & 744647 & Cryptorchestia cavimana (Heller, 1865) & & 1 & 1 & 1 & 1 & 1 & 1 & 1 & 1 & 1 \\
\hline 742 & inheems & 3.Dieren & 17.Geleedpotigen - Arthropoda & 158320 & Cyamus boopis Lütken, 1870 & & 1 & & 1 & & & & & 1 & \\
\hline 743 & inheems & 3.Dieren & 17.Geleedpotigen - Arthropoda & 102135 & Dexamine spinosa (Montagu, 1813) & & 1 & & & 1 & & & & & 1 \\
\hline 744 & inheems & 3.Dieren & 17.Geleedpotigen - Arthropoda & 102408 & Ericthonius punctatus (Bate, 1857) & & 1 & & 1 & & & & & 1 & 1 \\
\hline 745 & inheems & 3.Dieren & 17.Geleedpotigen - Arthropoda & 102251 & Gammarellus angulosus (Rathke, 1843) & & 1 & & 1 & & & & & & 1 \\
\hline 746 & inheems & 3.Dieren & 17.Geleedpotigen - Arthropoda & 102367 & Gammaropsis nitida (Stimpson, 1853) & & 1 & & 1 & & & & & 1 & 1 \\
\hline 747 & inheems & 3.Dieren & 17.Geleedpotigen - Arthropoda & 102369 & $\begin{array}{l}\text { Gammaropsis palmata (Stebbing \& Robertson, } \\
1891 \text { ) }\end{array}$ & & 1 & & & & & & & & 1 \\
\hline 748 & inheems & 3.Dieren & 17.Geleedpotigen - Arthropoda & 102275 & Gammarus crinicornis Stock, 1966 & & 1 & 1 & 1 & 1 & & & & 1 & 1 \\
\hline 749 & inheems & 3.Dieren & 17.Geleedpotigen - Arthropoda & 102281 & Gammarus locusta (Linnaeus, 1758) & & 1 & & 1 & 1 & & & & & 1 \\
\hline 750 & inheems & 3.Dieren & 17.Geleedpotigen - Arthropoda & 102292 & Gammarus salinus Spooner, 1947 & & 1 & 1 & 1 & 1 & & & & 1 & 1 \\
\hline 751 & exoot & 3.Dieren & 17.Geleedpotigen - Arthropoda & 102296 & Gammarus tigrinus Sexton, 1939 & & 1 & & 1 & & & & & & 1 \\
\hline 752 & inheems & 3.Dieren & 17.Geleedpotigen - Arthropoda & 102299 & Gammarus zaddachi Sexton, 1912 & & 1 & 1 & 1 & & & & & 1 & 1 \\
\hline 753 & inheems & 3.Dieren & 17.Geleedpotigen - Arthropoda & 101977 & Gitana sarsi Boeck, 1871 & & 1 & 1 & 1 & & & & & 1 & 1 \\
\hline 754 & inheems & 3.Dieren & 17.Geleedpotigen - Arthropoda & 101958 & Haploops tubicola Liljeborg, 1856 & & 1 & & & 1 & & & & & 1 \\
\hline 755 & inheems & 3.Dieren & 17.Geleedpotigen - Arthropoda & 102960 & Harpinia antennaria Meinert, 1890 & & 1 & & & & & & & & 1 \\
\hline 756 & inheems & 3.Dieren & 17.Geleedpotigen - Arthropoda & 102963 & Harpinia crenulata (Boeck, 1871) & & 1 & & & & & & & & 1 \\
\hline 757 & inheems & 3.Dieren & 17.Geleedpotigen - Arthropoda & 102968 & Harpinia laevis Sars, 1891 & & 1 & & & & & & & & 1 \\
\hline 758 & inheems & 3.Dieren & 17.Geleedpotigen - Arthropoda & 102972 & Harpinia pectinata Sars, 1891 & & 1 & & & & & & & & 1 \\
\hline 759 & inheems & 3.Dieren & 17.Geleedpotigen - Arthropoda & 102317 & Haustorius arenarius (Slabber, 1769) & & 1 & 1 & & 1 & 1 & 1 & 1 & & 1 \\
\hline 760 & inheems & 3.Dieren & 17.Geleedpotigen - Arthropoda & 102570 & Hippomedon denticulatus (Bate, 1857) & & 1 & & & & & & & & 1 \\
\hline 761 & inheems & 3.Dieren & 17.Geleedpotigen - Arthropoda & 103251 & Hyperia galba (Montagu, 1815) & & 1 & & 1 & & & & 1 & 1 & 1 \\
\hline 762 & exoot & 3.Dieren & 17.Geleedpotigen - Arthropoda & 148579 & $\begin{array}{l}\text { Incisocalliope aestuarius (Watling \& Maurer, } \\
\text { 1973) }\end{array}$ & & 1 & 1 & & & & & & & \\
\hline 763 & inheems & 3.Dieren & 17.Geleedpotigen - Arthropoda & 102345 & Iphimedia minuta G. O. Sars, 1883 & & 1 & & 1 & & & & & & 1 \\
\hline 764 & inheems & 3.Dieren & 17.Geleedpotigen - Arthropoda & 102347 & Iphimedia obesa Rathke, 1843 & & 1 & & 1 & & & & & & 1 \\
\hline 765 & inheems & 3.Dieren & 17.Geleedpotigen - Arthropoda & 232008 & Isocyamus delphinii (Guérin-Méneville, 1836) & & 1 & & 1 & & & & & & 1 \\
\hline 766 & inheems & 3.Dieren & 17.Geleedpotigen - Arthropoda & 102431 & Jassa falcata (Montagu, 1808) & & 1 & 1 & & & & & & & 1 \\
\hline 767 & inheems & 3.Dieren & 17.Geleedpotigen - Arthropoda & 102432 & Jassa herdmani (Walker, 1893) & & 1 & & 1 & & & 1 & & 1 & 1 \\
\hline 768 & exoot & 3.Dieren & 17.Geleedpotigen - Arthropoda & 102433 & Jassa marmorata Holmes, 1905 & & 1 & & 1 & 1 & & & & 1 & 1 \\
\hline 769 & inheems & 3.Dieren & 17.Geleedpotigen - Arthropoda & 102599 & Lepidepecreum longicornis (Bate, 1862) & & 1 & 1 & 1 & & & & & 1 & 1 \\
\hline 770 & inheems & 3.Dieren & 17.Geleedpotigen - Arthropoda & 102036 & Leptocheirus hirsutimanus (Bate, 1862) & & 1 & & 1 & & 1 & & & 1 & 1 \\
\hline 771 & inheems & 3.Dieren & 17.Geleedpotigen - Arthropoda & 102040 & Leptocheirus pilosus Zaddach, 1844 & & 1 & & 1 & & & & & 1 & \\
\hline 772 & inheems & 3.Dieren & 17.Geleedpotigen - Arthropoda & 102460 & Leucothoe incisa (Robertson, 1892) & & 1 & & & & & & & & 1 \\
\hline 773 & inheems & 3.Dieren & 17.Geleedpotigen - Arthropoda & 102462 & Leucothoe lilljeborgi Boeck, 1861 & & 1 & 1 & & & 1 & 1 & & & 1 \\
\hline
\end{tabular}




\begin{tabular}{|c|c|c|c|c|c|c|c|c|c|c|c|c|c|c|c|}
\hline 774 & inheems & 3.Dieren & 17.Geleedpotigen - Arthropoda & 102470 & Leucothoe spinicarpa (Abildgaard, 1789) & & 1 & & & & & & & & 1 \\
\hline 775 & inheems & 3.Dieren & 17.Geleedpotigen - Arthropoda & 102783 & Megaluropus agilis Hoeck, 1889 & & 1 & & 1 & 1 & & & & & 1 \\
\hline 776 & inheems & 3.Dieren & 17.Geleedpotigen - Arthropoda & 102837 & Melita dentata (Krøyer, 1842) & & 1 & & & & & & & & 1 \\
\hline 777 & exoot & 3.Dieren & 17.Geleedpotigen - Arthropoda & 146922 & Melita nitida Smith, 1873 & & 1 & & & 1 & & 1 & & & 1 \\
\hline 778 & inheems & 3.Dieren & 17.Geleedpotigen - Arthropoda & 102843 & Melita palmata (Montagu, 1804) & & 1 & & & 1 & & & & & 1 \\
\hline 779 & inheems & 3.Dieren & 17.Geleedpotigen - Arthropoda & 102620 & Menigrates obtusifrons (Boeck, 1861) & & 1 & 1 & 1 & & & & & & 1 \\
\hline 780 & inheems & 3.Dieren & 17.Geleedpotigen - Arthropoda & 103116 & Metopa alderi (Bate, 1857) & & 1 & 1 & 1 & & 1 & 1 & & 1 & 1 \\
\hline 781 & inheems & 3.Dieren & 17.Geleedpotigen - Arthropoda & 103118 & Metopa borealis Sars, 1882 & & 1 & & & & & & & 1 & 1 \\
\hline 782 & inheems & 3.Dieren & 17.Geleedpotigen - Arthropoda & 103119 & Metopa bruzelii (Goës, 1866) & & 1 & & & & & & & 1 & 1 \\
\hline 783 & inheems & 3.Dieren & 17.Geleedpotigen - Arthropoda & 102048 & Microdeutopus gryllotalpa Costa, 1853 & & 1 & 1 & 1 & & & & & & 1 \\
\hline 784 & inheems & 3.Dieren & 17.Geleedpotigen - Arthropoda & 102380 & Microprotopus maculatus Norman, 1867 & & 1 & & 1 & & & & & 1 & 1 \\
\hline 785 & exoot & 3.Dieren & 17.Geleedpotigen - Arthropoda & 225814 & Monocorophium acherusicum (Costa, 1853) & & 1 & & 1 & 1 & & & & 1 & 1 \\
\hline 786 & inheems & 3.Dieren & 17.Geleedpotigen - Arthropoda & 148592 & Monocorophium insidiosum (Crawford, 1937) & & 1 & & & 1 & & & & 1 & 1 \\
\hline 787 & exoot & 3.Dieren & 17.Geleedpotigen - Arthropoda & 148603 & Monocorophium sextonae (Crawford, 1937) & & 1 & & 1 & & & & & 1 & 1 \\
\hline 788 & exoot & 3.Dieren & 17.Geleedpotigen - Arthropoda & 431365 & Monocorophium uenoi (Stephensen, 1932) & & 1 & & 1 & & & & & & 1 \\
\hline 789 & inheems & 3.Dieren & 17.Geleedpotigen - Arthropoda & 102882 & Monoculodes carinatus (Bate, 1857) & & 1 & & 1 & & & & & & 1 \\
\hline 790 & inheems & 3.Dieren & 17.Geleedpotigen - Arthropoda & 102139 & Nototropis falcatus (Metzger, 1871) & & 1 & 1 & 1 & & & & 1 & & 1 \\
\hline 791 & inheems & 3.Dieren & 17.Geleedpotigen - Arthropoda & 488966 & $\begin{array}{l}\text { Nototropis swammerdamei (Milne Edwards, } \\
1830 \text { ) }\end{array}$ & & 1 & 1 & 1 & 1 & 1 & 1 & 1 & 1 & 1 \\
\hline 792 & inheems & 3.Dieren & 17.Geleedpotigen - Arthropoda & 103208 & Orchestia mediterranea Costa, 1853 & & 1 & 1 & & 1 & 1 & 1 & & & 1 \\
\hline 793 & inheems & 3.Dieren & 17.Geleedpotigen - Arthropoda & 102665 & Orchomene humilis (Costa, 1853) & & 1 & 1 & 1 & 1 & 1 & & & 1 & 1 \\
\hline 794 & inheems & 3.Dieren & 17.Geleedpotigen - Arthropoda & 103008 & Parapleustes bicuspis (Krøyer, 1838) & & 1 & & 1 & & & & & 1 & 1 \\
\hline 795 & inheems & 3.Dieren & 17.Geleedpotigen - Arthropoda & 101857 & Pariambus typicus (Krøyer, 1884) & & 1 & & & & & & & & 1 \\
\hline 796 & inheems & 3.Dieren & 17.Geleedpotigen - Arthropoda & 102915 & $\begin{array}{l}\text { Perioculodes longimanus (Bate \& Westwood, } \\
1868 \text { ) }\end{array}$ & & 1 & & & & & & & & 1 \\
\hline 797 & inheems & 3.Dieren & 17.Geleedpotigen - Arthropoda & 102387 & Photis reinhardi Krøyer, 1842 & & 1 & 1 & 1 & 1 & & & & 1 & 1 \\
\hline 798 & inheems & 3.Dieren & 17.Geleedpotigen - Arthropoda & 101864 & Phtisica marina Slabber, 1769 & Teringlijdertje & 1 & 1 & 1 & 1 & 1 & 1 & 1 & 1 & 1 \\
\hline 799 & inheems & 3.Dieren & 17.Geleedpotigen - Arthropoda & 416579 & Platycyamus thompsoni (Gosse, 1855) & & 1 & 1 & 1 & 1 & 1 & 1 & 1 & 1 & 1 \\
\hline 800 & inheems & 3.Dieren & 17.Geleedpotigen - Arthropoda & 102916 & $\begin{array}{l}\text { Pontocrates altamarinus (Bate \& Westwood, } \\
\text { 1862) }\end{array}$ & & 1 & & 1 & & & & & 1 & 1 \\
\hline 801 & inheems & 3.Dieren & 17.Geleedpotigen - Arthropoda & 102917 & Pontocrates arcticus Sars, 1895 & & 1 & & & & 1 & & & & 1 \\
\hline 802 & inheems & 3.Dieren & 17.Geleedpotigen - Arthropoda & 102918 & Pontocrates arenarius (Bate, 1858) & & 1 & & & & & & & & 1 \\
\hline 803 & inheems & 3.Dieren & 17.Geleedpotigen - Arthropoda & 102720 & Scopelocheirus hopei (Costa, 1851) & & 1 & 1 & & & & & & & 1 \\
\hline 804 & 0 & 3.Dieren & 17.Geleedpotigen - Arthropoda & 416580 & Scutocyamus parvus Lincoln \& Hurley, 1974 & & 1 & 1 & 1 & & & & & & 1 \\
\hline 805 & inheems & 3.Dieren & 17.Geleedpotigen - Arthropoda & 102111 & $\begin{array}{l}\text { Siphonoecetes (Centraloecetes) kroyeranus } \\
\text { Bate, } 1856\end{array}$ & & 1 & 1 & 1 & & & & & & 1 \\
\hline 806 & inheems & 3.Dieren & 17.Geleedpotigen - Arthropoda & 103166 & Stenothoe marina (Bate, 1856 ) & & 1 & 1 & 1 & & & & & 1 & 1 \\
\hline 807 & inheems & 3.Dieren & 17.Geleedpotigen - Arthropoda & 103169 & Stenothoe monoculoides (Montagu, 1815) & & 1 & 1 & 1 & & & & & 1 & 1 \\
\hline 808 & inheems & 3.Dieren & 17.Geleedpotigen - Arthropoda & 103175 & Stenothoe valida Dana, 1852 & & 1 & & & & & 1 & & 1 & \\
\hline 809 & inheems & 3.Dieren & 17.Geleedpotigen - Arthropoda & 103178 & Stenula rubrovittata (Sars, 1882) & & 1 & 1 & 1 & & & & & & 1 \\
\hline 810 & inheems & 3.Dieren & 17.Geleedpotigen - Arthropoda & 102924 & Synchelidium haplocheles (Grube, 1864) & & 1 & & & & & & & & 1 \\
\hline 811 & inheems & 3.Dieren & 17.Geleedpotigen - Arthropoda & 102928 & Synchelidium maculatum Stebbing, 1906 & & 1 & & 1 & & & & & & 1 \\
\hline 812 & inheems & 3.Dieren & 17.Geleedpotigen - Arthropoda & 103220 & Talitrus saltator (Montagu, 1808) & & 1 & & 1 & & & & & 1 & 1 \\
\hline 813 & inheems & 3.Dieren & 17.Geleedpotigen - Arthropoda & 102748 & Tryphosa nana (Krøyer, 1846) & & 1 & & & 1 & & & & 1 & 1 \\
\hline 814 & inheems & 3.Dieren & 17.Geleedpotigen - Arthropoda & 102758 & Tryphosella horingi (Boeck, 1871) & & 1 & 1 & & 1 & 1 & & & & 1 \\
\hline 815 & inheems & 3.Dieren & 17.Geleedpotigen - Arthropoda & 102771 & Tryphosella sarsi Bonnier, 1893 & & 1 & & & & & & & & 1 \\
\hline 816 & inheems & 3.Dieren & 17.Geleedpotigen - Arthropoda & 102779 & Tryphosites longipes (Bate \& Westwood, 1861) & & 1 & & & & & & & & 1 \\
\hline 817 & inheems & 3.Dieren & 17.Geleedpotigen - Arthropoda & 102061 & Unciola planipes Norman, 1867 & & 1 & & & & & & & & 1 \\
\hline 818 & inheems & 3.Dieren & 17.Geleedpotigen - Arthropoda & 103226 & Urothoe brevicornis Bate, 1862 & & 1 & 1 & 1 & & & & & 1 & 1 \\
\hline 819 & inheems & 3.Dieren & 17.Geleedpotigen - Arthropoda & 103228 & Urothoe elegans (Bate, 1857) & & 1 & & & & & & & & 1 \\
\hline 820 & inheems & 3.Dieren & 17.Geleedpotigen - Arthropoda & 103233 & Urothoe marina (Bate, 1857) & & 1 & 1 & 1 & & 1 & 1 & 1 & 1 & 1 \\
\hline 821 & inheems & 3.Dieren & 17.Geleedpotigen - Arthropoda & 103235 & Urothoe poseidonis Reibish, 1905 & & 1 & 1 & 1 & 1 & 1 & 1 & 1 & 1 & 1 \\
\hline
\end{tabular}

| 66 van 99 | Wageningen Marine Research rapport C125/16 


\begin{tabular}{|c|c|c|c|c|c|c|c|c|c|c|c|c|c|c|c|}
\hline 822 & inheems & 3.Dieren & 17.Geleedpotigen - Arthropoda & 102932 & Westwoodilla caecula (Bate, 1857) & & 1 & & & 1 & & & & & 1 \\
\hline 823 & inheems & 3.Dieren & 17.Geleedpotigen - Arthropoda & 119024 & Astacilla Iongicornis (Sowerby, 1806) & & 1 & & 1 & & & & & 1 & \\
\hline 824 & inheems & 3.Dieren & 17.Geleedpotigen - Arthropoda & 118839 & Cirolana cranchi Leach, 1818 & & 1 & 1 & 1 & & & & & 1 & 1 \\
\hline 825 & inheems & 3.Dieren & 17.Geleedpotigen - Arthropoda & 118474 & Cyathura carinata (Krøyer, 1847) & Lijnpissebed & 1 & & 1 & & & & & & 1 \\
\hline 826 & exoot & 3.Dieren & 17.Geleedpotigen - Arthropoda & 118936 & Cymodoce truncata Leach, 1814 & & 1 & & 1 & & & & & & 1 \\
\hline 827 & exoot & 3.Dieren & 17.Geleedpotigen - Arthropoda & 256988 & Dynamene bidentata (Adams, 1800) & & 1 & & 1 & & & & & & 1 \\
\hline 828 & inheems & 3.Dieren & 17.Geleedpotigen - Arthropoda & 118843 & Eurydice affinis Hansen, 1905 & Bleke agaatpissebed & 1 & & 1 & & & & & & 1 \\
\hline 829 & inheems & 3.Dieren & 17.Geleedpotigen - Arthropoda & 118852 & Eurydice pulchra Leach, 1815 & Agaatpissebed & 1 & 1 & & 1 & 1 & 1 & & & 1 \\
\hline 830 & inheems & 3.Dieren & 17.Geleedpotigen - Arthropoda & 148637 & Eurydice spinigera Hansen, 1890 & & 1 & & & & & & & & 1 \\
\hline 831 & inheems & 3.Dieren & 17.Geleedpotigen - Arthropoda & 118990 & Gnathia dentata (Sars G.O., 1872) & & 1 & 1 & 1 & 1 & & & & 1 & 1 \\
\hline 832 & exoot & 3.Dieren & 17.Geleedpotigen - Arthropoda & 118994 & Gnathia maxillaris (Montagu, 1804) & & 1 & 1 & 1 & 1 & & & & 1 & 1 \\
\hline 833 & inheems & 3.Dieren & 17.Geleedpotigen - Arthropoda & 118216 & Gyge branchialis Cornalia \& Panceri, 1861 & & 1 & 1 & 1 & 1 & & 1 & & 1 & 1 \\
\hline 834 & exoot & 3.Dieren & 17.Geleedpotigen - Arthropoda & 255999 & Ianiropsis serricaudis Gurjanova, 1936 & & 1 & 1 & 1 & & & & & & 1 \\
\hline 835 & inheems & 3.Dieren & 17.Geleedpotigen - Arthropoda & 119039 & Idotea balthica (Pallas, 1772) & Gewone zeepissebed & 1 & & 1 & 1 & & & & 1 & 1 \\
\hline 836 & inheems & 3.Dieren & 17.Geleedpotigen - Arthropoda & 119044 & Idotea granulosa Rathke, 1843 & & 1 & 1 & 1 & & & & & & \\
\hline 837 & inheems & 3.Dieren & 17.Geleedpotigen - Arthropoda & 119046 & Idotea linearis (Linnaeus, 1766) & Staafpissebed & 1 & 1 & 1 & & & & & 1 & 1 \\
\hline 838 & exoot & 3.Dieren & 17.Geleedpotigen - Arthropoda & 119047 & Idotea metallica Bosc, 1802 & & 1 & 1 & 1 & 1 & 1 & 1 & 1 & 1 & 1 \\
\hline 839 & exoot & 3.Dieren & 17.Geleedpotigen - Arthropoda & 119048 & Idotea neglecta Sars, 1897 & & 1 & 1 & 1 & & & & & 1 & 1 \\
\hline 840 & inheems & 3.Dieren & 17.Geleedpotigen - Arthropoda & 119050 & Idotea pelagica Leach, 1815 & & 1 & & 1 & & & & & 1 & 1 \\
\hline 841 & inheems & 3.Dieren & 17.Geleedpotigen - Arthropoda & 118218 & Ione thoracica (Montagu, 1808) & & 1 & & 1 & & & & & & 1 \\
\hline 842 & inheems & 3.Dieren & 17.Geleedpotigen - Arthropoda & 264171 & Jaera (Jaera) albifrons Leach, 1814 & & 1 & 1 & 1 & 1 & 1 & & & 1 & 1 \\
\hline 843 & inheems & 3.Dieren & 17.Geleedpotigen - Arthropoda & 264818 & Jaera (Jaera) albifrons albifrons Leach, 1814 & & 1 & 1 & 1 & & & & & 1 & \\
\hline 844 & exoot & 3.Dieren & 17.Geleedpotigen - Arthropoda & 118732 & Janira maculosa Leach, 1814 & & 1 & 1 & 1 & & & & & 1 & \\
\hline 845 & inheems & 3.Dieren & 17.Geleedpotigen - Arthropoda & 118953 & Lekanesphaera hookeri (Leach, 1814) & Brakwateroproller & 1 & & 1 & 1 & & & & & 1 \\
\hline 846 & inheems & 3.Dieren & 17.Geleedpotigen - Arthropoda & 118958 & Lekanesphaera rugicauda (Leach, 1814) & Oproller & 1 & 1 & 1 & 1 & & & & 1 & 1 \\
\hline 847 & inheems & 3.Dieren & 17.Geleedpotigen - Arthropoda & 118917 & Limnoria lignorum (Rathke, 1799) & Boorpissebed & 1 & & 1 & & & & & & 1 \\
\hline 848 & exoot & 3.Dieren & 17.Geleedpotigen - Arthropoda & 118918 & Limnoria quadripunctata Holthuis, 1949 & & 1 & & 1 & & & & & 1 & \\
\hline 849 & inheems & 3.Dieren & 17.Geleedpotigen - Arthropoda & 118859 & Natatolana borealis (Lilljeborg, 1851) & & 1 & & & & 1 & & & & 1 \\
\hline 850 & inheems & 3.Dieren & 17.Geleedpotigen - Arthropoda & 119001 & Paragnathia formica (Hesse, 1864 ) & Zeebrems & 1 & 1 & 1 & 1 & 1 & 1 & 1 & & 1 \\
\hline 851 & inheems & 3.Dieren & 17.Geleedpotigen - Arthropoda & 118227 & Pleurocrypta microbranchiata G. O. Sars, 1898 & & 1 & 1 & 1 & 1 & & & & 1 & \\
\hline 852 & inheems & 3.Dieren & 17.Geleedpotigen - Arthropoda & 593521 & $\begin{array}{l}\text { Pleurocrypta porcellanaelongicornis Hesse, } \\
1876\end{array}$ & & 1 & & 1 & 1 & & & & 1 & 1 \\
\hline 853 & inheems & 3.Dieren & 17.Geleedpotigen - Arthropoda & 262440 & Porcellio scaber Latreille, 1804 & & 1 & 1 & 1 & 1 & 1 & 1 & 1 & 1 & 1 \\
\hline 854 & inheems & 3.Dieren & 17.Geleedpotigen - Arthropoda & 148658 & Priapion fraissei (Giard \& Bonnier, 1886) & & 1 & & 1 & & & & & 1 & \\
\hline 855 & inheems & 3.Dieren & 17.Geleedpotigen - Arthropoda & 148638 & Prodajus ostendensis Gilson, 1909 & & 1 & 1 & 1 & & & & & & 1 \\
\hline 856 & inheems & 3.Dieren & 17.Geleedpotigen - Arthropoda & 118235 & Pseudione borealis Caspers, 1939 & & 1 & & & & & & & & 1 \\
\hline 857 & inheems & 3.Dieren & 17.Geleedpotigen - Arthropoda & 118240 & $\begin{array}{l}\text { Pseudione hyndmanni (Bate \& Westwood, } \\
1867)\end{array}$ & & 1 & & 1 & & & & & 1 & 1 \\
\hline 858 & exoot & 3.Dieren & 17.Geleedpotigen - Arthropoda & 118375 & Uromunna Menzies, 1962 & & 1 & 1 & 1 & & & & & 1 & 1 \\
\hline 859 & inheems & 3.Dieren & 17.Geleedpotigen - Arthropoda & 136340 & Akanthophoreus gracilis (Krøyer, 1842) & & 1 & 1 & 1 & & 1 & & & & 1 \\
\hline 860 & inheems & 3.Dieren & 17.Geleedpotigen - Arthropoda & 136466 & Heterotanais oerstedii (Krøyer, 1842) & & 1 & 1 & 1 & & 1 & 1 & & 1 & 1 \\
\hline 861 & inheems & 3.Dieren & 17.Geleedpotigen - Arthropoda & 136546 & Tanais dulongii (Audouin, 1826) & & 1 & & 1 & & & & & & 1 \\
\hline 862 & inheems & 3.Dieren & 17.Geleedpotigen - Arthropoda & 136458 & Tanaopsis graciloides (Lilljeborg, 1864) & & 1 & & 1 & & & & & 1 & \\
\hline 863 & exoot & 3.Dieren & 17.Geleedpotigen - Arthropoda & 416601 & Zeuxo holdichi Bamber, 1990 & Schaarpissebed & 1 & 1 & 1 & 1 & 1 & 1 & & 1 & 1 \\
\hline 864 & inheems & 3.Dieren & 17.Geleedpotigen - Arthropoda & 110440 & Bodotria arenosa Goodsir, 1843 & & 1 & & 1 & & & & & 1 & 1 \\
\hline 865 & inheems & 3.Dieren & 17.Geleedpotigen - Arthropoda & 110444 & Bodotria pulchella (Sars, 1878) & & 1 & & & & & & & & 1 \\
\hline 866 & inheems & 3.Dieren & 17.Geleedpotigen - Arthropoda & 110445 & Bodotria scorpioides (Montagu, 1804) & & 1 & & 1 & 1 & & & & 1 & 1 \\
\hline 867 & inheems & 3.Dieren & 17.Geleedpotigen - Arthropoda & 110543 & Campylaspis glabra Sars, 1878 & & 1 & 1 & 1 & & & & & & 1 \\
\hline 868 & inheems & 3.Dieren & 17.Geleedpotigen - Arthropoda & 110465 & Cumopsis goodsir (Van Beneden, 1861) & & 1 & & 1 & 1 & & & 1 & 1 & 1 \\
\hline 869 & inheems & 3.Dieren & 17.Geleedpotigen - Arthropoda & 110471 & Diastylis boecki Zimmer, 1930 & & 1 & 1 & 1 & 1 & 1 & 1 & 1 & 1 & 1 \\
\hline 870 & inheems & 3.Dieren & 17.Geleedpotigen - Arthropoda & 110472 & Diastylis bradyi Norman, 1879 & & 1 & & & & & & 1 & & 1 \\
\hline 871 & inheems & 3.Dieren & 17.Geleedpotigen - Arthropoda & 110479 & Diastylis goodsiri (Bell, 1855) & & 1 & & & 1 & & & & & 1 \\
\hline
\end{tabular}




\begin{tabular}{|c|c|c|c|c|c|c|c|c|c|c|c|c|c|c|c|}
\hline 872 & inheems & 3.Dieren & 17.Geleedpotigen - Arthropoda & 110481 & Diastylis laevis Norman, 1869 & & 1 & 1 & 1 & 1 & 1 & 1 & & & 1 \\
\hline 873 & inheems & 3.Dieren & 17.Geleedpotigen - Arthropoda & 110483 & Diastylis lucifera (Krøyer, 1837) & & 1 & & & 1 & & & & & 1 \\
\hline 874 & inheems & 3.Dieren & 17.Geleedpotigen - Arthropoda & 110487 & Diastylis rathkei (Krøyer, 1841) & & 1 & & & & & & & & 1 \\
\hline 875 & inheems & 3.Dieren & 17.Geleedpotigen - Arthropoda & 148684 & Diastylis rathkei belgica Zimmer & & 1 & 1 & 1 & & 1 & & & 1 & 1 \\
\hline 876 & inheems & 3.Dieren & 17.Geleedpotigen - Arthropoda & 110488 & Diastylis rugosa Sars, 1865 & & 1 & 1 & & 1 & & & & & 1 \\
\hline 877 & inheems & 3.Dieren & 17.Geleedpotigen - Arthropoda & 110492 & Diastylis tumida (Liljeborg, 1855) & & 1 & 1 & 1 & 1 & 1 & 1 & 1 & 1 & 1 \\
\hline 878 & inheems & 3.Dieren & 17.Geleedpotigen - Arthropoda & 110524 & Eudorella emarginata (Krøyer, 1846) & & 1 & & & & & & & & 1 \\
\hline 879 & inheems & 3.Dieren & 17.Geleedpotigen - Arthropoda & 110535 & Eudorella truncatula $($ Bate, 1856$)$ & & 1 & & & & & & & & 1 \\
\hline 880 & inheems & 3.Dieren & 17.Geleedpotigen - Arthropoda & 110536 & Eudorellopsis deformis (Krøyer, 1846) & & 1 & & 1 & & & & & & 1 \\
\hline 881 & inheems & 3.Dieren & 17.Geleedpotigen - Arthropoda & 110462 & Iphinoe trispinosa (Goodsir, 1843) & & 1 & & & & & & & & 1 \\
\hline 882 & inheems & 3.Dieren & 17.Geleedpotigen - Arthropoda & 422916 & Monopseudocuma gilsoni (Gilson, 1906) & & 1 & & & & & & & & 1 \\
\hline 883 & inheems & 3.Dieren & 17.Geleedpotigen - Arthropoda & 110593 & Petalosarsia declivis (Sars, 1865) & & 1 & 1 & 1 & & 1 & & & 1 & 1 \\
\hline 884 & inheems & 3.Dieren & 17.Geleedpotigen - Arthropoda & 110627 & $\begin{array}{l}\text { Pseudocuma (Pseudocuma) longicorne (Bate, } \\
1858 \text { ) }\end{array}$ & & 1 & 1 & 1 & & & & & & 1 \\
\hline 885 & inheems & 3.Dieren & 17.Geleedpotigen - Arthropoda & 110628 & $\begin{array}{l}\text { Pseudocuma (Pseudocuma) simile G.O. Sars, } \\
1900\end{array}$ & & 1 & & 1 & & & & & & 1 \\
\hline 886 & inheems & 3.Dieren & 17.Geleedpotigen - Arthropoda & 110467 & Vaunthompsonia cristata Bate, 1858 & & 1 & 1 & 1 & & & & & 1 & 1 \\
\hline 887 & inheems & 3.Dieren & 17.Geleedpotigen - Arthropoda & 110690 & Meganyctiphanes norvegica (M. Sars, 1857) & & 1 & 1 & 1 & & & & 1 & 1 & 1 \\
\hline 888 & inheems & 3.Dieren & 17.Geleedpotigen - Arthropoda & 254316 & Nyctiphanes couchii (Bell, 1853) & & 1 & & 1 & & & & & & 1 \\
\hline 889 & inheems & 3.Dieren & 17.Geleedpotigen - Arthropoda & 107313 & Achaeus cranchii Leach, 1817 & & 1 & 1 & & & 1 & 1 & & & \\
\hline 890 & inheems & 3.Dieren & 17.Geleedpotigen - Arthropoda & 107273 & Atelecyclus rotundatus & & 1 & 1 & 1 & & & & & 1 & 1 \\
\hline 891 & inheems & 3.Dieren & 17.Geleedpotigen - Arthropoda & 107486 & $\begin{array}{l}\text { Athanas nitescens (Leach, } 1813 \text { [in Leach, } \\
1813-1814 \text { ]) }\end{array}$ & Kreeftgarnaal & 1 & 1 & 1 & 1 & & 1 & & 1 & 1 \\
\hline 892 & inheems & 3.Dieren & 17.Geleedpotigen - Arthropoda & 107729 & Callianassa subterranea (Montagu, 1808) & & 1 & 1 & 1 & 1 & & & & 1 & 1 \\
\hline 893 & exoot & 3.Dieren & 17.Geleedpotigen - Arthropoda & 107379 & Callinectes sapidus Rathbun, 1896 & Blauwe zwemkrab & 1 & 1 & 1 & & & & & & 1 \\
\hline 894 & inheems & 3.Dieren & 17.Geleedpotigen - Arthropoda & 107276 & Cancer pagurus Linnaeus, 1758 & Noordzeekrab & 1 & 1 & 1 & 1 & & & & 1 & 1 \\
\hline 895 & inheems & 3.Dieren & 17.Geleedpotigen - Arthropoda & 107381 & Carcinus maenas (Linnaeus, 1758) & Strandkrab & 1 & & & 1 & & & & & 1 \\
\hline 896 & inheems & 3.Dieren & 17.Geleedpotigen - Arthropoda & 107277 & Corystes cassivelaunus (Pennant, 1777) & Helmkrab & 1 & & & 1 & & & & & 1 \\
\hline 897 & inheems & 3.Dieren & 17.Geleedpotigen - Arthropoda & 107551 & Crangon allmanni Kinahan, 1860 & & 1 & & & & & & & & 1 \\
\hline 898 & inheems & 3.Dieren & 17.Geleedpotigen - Arthropoda & 107552 & Crangon crangon (Linnaeus, 1758) & Gewone garnaal & 1 & & & 1 & & & & & 1 \\
\hline 899 & inheems & 3.Dieren & 17.Geleedpotigen - Arthropoda & 107199 & Diogenes pugilator (Roux, 1829) & $\begin{array}{l}\text { Klein heremietkreeftje; kleine } \\
\text { heremietkreeft }\end{array}$ & 1 & 1 & 1 & & & & & & 1 \\
\hline 900 & inheems & 3.Dieren & 17.Geleedpotigen - Arthropoda & 107294 & Ebalia cranchii Leach, 1817 & Kleine kiezelkrab & 1 & & 1 & & & & & & 1 \\
\hline 901 & inheems & 3.Dieren & 17.Geleedpotigen - Arthropoda & 107301 & Ebalia tuberosa (Pennant, 1777) & Ruwe kiezelkrab & 1 & 1 & 1 & & 1 & 1 & & & 1 \\
\hline 902 & inheems & 3.Dieren & 17.Geleedpotigen - Arthropoda & 107302 & Ebalia tumefacta (Montagu, 1808) & Gladde kiezelkrab & 1 & 1 & 1 & & & & & & 1 \\
\hline 903 & exoot & 3.Dieren & 17.Geleedpotigen - Arthropoda & 107451 & Eriocheir sinensis H. Milne Edwards, 1853 & Chinese wolhandkrab & 1 & 1 & 1 & 1 & & & & 1 & 1 \\
\hline 904 & inheems & 3.Dieren & 17.Geleedpotigen - Arthropoda & 156083 & $\begin{array}{l}\text { Eualus cranchii (Leach, } 1817 \text { [in Leach, 1815- } \\
1875] \text { ) }\end{array}$ & & 1 & & 1 & & & & & & 1 \\
\hline 905 & inheems & 3.Dieren & 17.Geleedpotigen - Arthropoda & 107506 & Eualus occultus (Lebour, 1936) & & 1 & 1 & 1 & & & & & 1 & 1 \\
\hline 906 & inheems & 3.Dieren & 17.Geleedpotigen - Arthropoda & 107150 & Galathea intermedia Lilljeborg, 1851 & Rugstreep-oprolkreeft & 1 & 1 & 1 & 1 & & & & 1 & 1 \\
\hline 907 & inheems & 3.Dieren & 17.Geleedpotigen - Arthropoda & 107154 & Galathea squamifera Leach, 1814 & Oprolkreeft & 1 & 1 & & & & & & & \\
\hline 908 & exoot & 3.Dieren & 17.Geleedpotigen - Arthropoda & 158417 & Hemigrapsus sanguineus (De Haan, 1835) & Blaasjeskrab & 1 & 1 & 1 & 1 & & & & & 1 \\
\hline 909 & exoot & 3.Dieren & 17.Geleedpotigen - Arthropoda & 389288 & $\begin{array}{l}\text { Hemigrapsus takanoi Asakura \& Watanabe, } \\
2005\end{array}$ & Penseelkrab & 1 & & 1 & 1 & & & & & 1 \\
\hline 910 & inheems & 3.Dieren & 17.Geleedpotigen - Arthropoda & 107518 & $\begin{array}{l}\text { Hippolyte varians Leach, } 1814 \text { [in Leach, } \\
\text { 1813-1814] }\end{array}$ & Veranderlijke steurgarnaal & 1 & & & & & & & & 1 \\
\hline 911 & inheems & 3.Dieren & 17.Geleedpotigen - Arthropoda & 107253 & Homarus gammarus (Linnaeus, 1758) & Noordzeekreeft; zeekreeft & 1 & 1 & 1 & & & & & 1 & 1 \\
\hline 912 & inheems & 3.Dieren & 17.Geleedpotigen - Arthropoda & 107322 & Hyas araneus (Linnaeus, 1758) & Gewone spinkrab & 1 & 1 & 1 & & & & & 1 & 1 \\
\hline 913 & inheems & 3.Dieren & 17.Geleedpotigen - Arthropoda & 107327 & Inachus dorsettensis (Pennant, 1777) & Gestekelde sponspootkrab & 1 & & 1 & & & & & & 1 \\
\hline 914 & inheems & 3.Dieren & 17.Geleedpotigen - Arthropoda & 107333 & Inachus phalangium (Fabricius, 1775) & Gladde sponspootkrab & 1 & 1 & & & & & & & \\
\hline 915 & inheems & 3.Dieren & 17.Geleedpotigen - Arthropoda & 107387 & Liocarcinus depurator (Linnaeus, 1758) & Blauwpootzwemkrab & 1 & & 1 & & & & & 1 & 1 \\
\hline 916 & inheems & 3.Dieren & 17.Geleedpotigen - Arthropoda & 107388 & Liocarcinus holsatus (Fabricius, 1798) & Gewone zwemkrab & 1 & & 1 & & & & & & 1 \\
\hline 917 & inheems & 3.Dieren & 17.Geleedpotigen - Arthropoda & 107390 & Liocarcinus marmoreus (Leach, 1814) & Gemarmerde zwemkrab & 1 & 1 & 1 & & & & & & 1 \\
\hline
\end{tabular}

| 68 van 99 | Wageningen Marine Research rapport C125/16 


\begin{tabular}{|c|c|c|c|c|c|c|c|c|c|c|c|c|c|c|c|c|}
\hline 918 & inheems & 3.Dieren & 17.Geleedpotigen - Arthropoda & 107392 & Liocarcinus navigator (Herbst, 1794) & Gewimperde zwemkrab & 1 & 1 & 1 & & & & & & 1 & 1 \\
\hline 919 & inheems & 3.Dieren & 17.Geleedpotigen - Arthropoda & 107393 & Liocarcinus pusillus (Leach, 1816) & Kleine zwemkrab & 1 & & 1 & & & & & & 1 & 1 \\
\hline 920 & inheems & 3.Dieren & 17.Geleedpotigen - Arthropoda & 107394 & Liocarcinus vernalis (Risso, 1816) & & 1 & & 1 & & & & & & 1 & 1 \\
\hline 921 & inheems & 3.Dieren & 17.Geleedpotigen - Arthropoda & 107345 & Macropodia rostrata (Linnaeus, 1761) & Gewone hooiwagenkrab & 1 & & 1 & 1 & & & & & & 1 \\
\hline 922 & inheems & 3.Dieren & 17.Geleedpotigen - Arthropoda & 107350 & Maja squinado (Herbst, 1788) & Grote spinkrab & 1 & & & & & & & & & \\
\hline 923 & inheems & 3.Dieren & 17.Geleedpotigen - Arthropoda & 107398 & Necora puber (Linnaeus, 1767) & Fluwelen zwemkrab & 1 & & 1 & & & & & & 1 & 1 \\
\hline 924 & inheems & 3.Dieren & 17.Geleedpotigen - Arthropoda & 107254 & Nephrops norvegicus (Linnaeus, 1758) & Noors kreeftje; Noorse kreeft & 1 & & & & & & & & & 1 \\
\hline 925 & inheems & 3.Dieren & 17.Geleedpotigen - Arthropoda & 107232 & Pagurus bernhardus (Linnaeus, 1758) & $\begin{array}{l}\text { Gewone heremietkreeft; grote } \\
\text { heremietkreeft }\end{array}$ & 1 & & & 1 & & & & & 1 & 1 \\
\hline 926 & inheems & 3.Dieren & 17.Geleedpotigen - Arthropoda & 107237 & Pagurus forbesii Bell, 1846 & & 1 & 1 & 1 & & & & & & 1 & 1 \\
\hline 927 & inheems & 3.Dieren & 17.Geleedpotigen - Arthropoda & 107615 & $\begin{array}{l}\text { Palaemon longirostris H. Milne Edwards, } 1837 \\
\text { [in H. Milne Edwards, } 1834-1840]\end{array}$ & Langneussteurgarnaal & 1 & 1 & 1 & & & & & & & 1 \\
\hline 928 & inheems & 3.Dieren & 17.Geleedpotigen - Arthropoda & 107616 & Palaemon serratus (Pennant, 1777) & Gezaagde steurgarnaal & 1 & 1 & 1 & 1 & & & 1 & & 1 & \\
\hline 929 & inheems & 3.Dieren & 17.Geleedpotigen - Arthropoda & 587704 & $\begin{array}{l}\text { Palaemon varians Leach, } 1813 \text { [in Leach, } \\
1813-1814 \text { ] }\end{array}$ & Brakwatersteurgarnaal & 1 & 1 & $\frac{1}{1}$ & 1 & & & 1 & & 1 & \\
\hline 930 & inheems & 3.Dieren & 17.Geleedpotigen - Arthropoda & 107647 & Pandalina brevirostris (Rathke, 1843) & & 1 & & 1 & & & & & & & 1 \\
\hline 931 & inheems & 3.Dieren & 17.Geleedpotigen - Arthropoda & 107649 & Pandalus borealis & & 1 & & 1 & & & & & & & 1 \\
\hline 932 & inheems & 3.Dieren & 17.Geleedpotigen - Arthropoda & 107651 & $\begin{array}{l}\text { Pandalus montagui Leach, } 1814 \text { [in Leach, } \\
1813-1814 \text { ] }\end{array}$ & Ringsprietgarnaal & 1 & 1 & 1 & & & & & & 1 & 1 \\
\hline 933 & inheems & 3.Dieren & 17.Geleedpotigen - Arthropoda & 238027 & Pestarella tyrrhena (Petagna, 1792) & & 1 & & & & & & & & & 1 \\
\hline 934 & inheems & 3.Dieren & 17.Geleedpotigen - Arthropoda & 108207 & $\begin{array}{l}\text { Philocheras bispinosus bispinosus (Hailstone, } \\
1835 \text { ) }\end{array}$ & & 1 & & & & & & & & & 1 \\
\hline 935 & inheems & 3.Dieren & 17.Geleedpotigen - Arthropoda & 107562 & $\begin{array}{l}\text { Philocheras trispinosus (Hailstone in Hailstone } \\
\& \text { Westwood, 1835) }\end{array}$ & Driepuntsgarnaal & 1 & & & & & & & & & 1 \\
\hline 936 & inheems & 3.Dieren & 17.Geleedpotigen - Arthropoda & 107418 & Pilumnus hirtellus (Linnaeus, 1761) & Ruig krabbetje; ruigkrabje & 1 & 1 & 1 & 1 & & & & & 1 & 1 \\
\hline 937 & inheems & 3.Dieren & 17.Geleedpotigen - Arthropoda & 107473 & Pinnotheres pisum (Linnaeus, 1767) & Erwtenkrabbetje & 1 & & 1 & & & & & & 1 & 1 \\
\hline 938 & inheems & 3.Dieren & 17.Geleedpotigen - Arthropoda & 107278 & Pirimela denticulata (Montagu, 1808) & Gezaagde krab & 1 & 1 & 1 & 1 & & & & & 1 & 1 \\
\hline 939 & inheems & 3.Dieren & 17.Geleedpotigen - Arthropoda & 107188 & Pisidia Iongicornis (Linnaeus, 1767) & $\begin{array}{l}\text { Gewoon porceleinkrabbetje; } \\
\text { porseleinkrabbetje }\end{array}$ & $\frac{1}{1}$ & & $\frac{1}{1}$ & & & & & & $\frac{1}{1}$ & $\frac{1}{1}$ \\
\hline 940 & inheems & 3.Dieren & 17.Geleedpotigen - Arthropoda & 107462 & Planes minutus (Linnaeus, 1758) & Columbuskrab & 1 & 1 & 1 & & & & & 1 & & 1 \\
\hline 941 & inheems & 3.Dieren & 17.Geleedpotigen - Arthropoda & 107564 & Pontophilus spinosus (Leach, 1816) & & 1 & 1 & 1 & & & & & & 1 & 1 \\
\hline$\frac{741}{942}$ & inheems & 3.Dieren & 17.Geleedpotigen - Arthropoda & 107190 & Porcellana platycheles (Pennant, 1777) & $\begin{array}{l}\text { Harig porceleinkrabbetje; harige } \\
\text { porseleinkrab }\end{array}$ & $\frac{1}{1}$ & & $\frac{1}{1}$ & 1 & & & & & $\frac{1}{1}$ & $\frac{1}{1}$ \\
\hline 943 & inheems & 3.Dieren & 17.Geleedpotigen - Arthropoda & 107400 & Portumnus latipes (Pennant, 1777) & Breedpootkrab & 1 & & 1 & & & & & & 1 & 1 \\
\hline 944 & inheems & 3.Dieren & 17.Geleedpotigen - Arthropoda & 107682 & $\begin{array}{l}\text { Processa canaliculata Leach, } 1815 \text { [in Leach, } \\
1815-1875 \text { ] }\end{array}$ & & 1 & & 1 & & & & & & 1 & 1 \\
\hline 945 & inheems & 3.Dieren & 17.Geleedpotigen - Arthropoda & 108336 & $\begin{array}{l}\text { Processa edulis crassipes Nouvel \& Holthuis, } \\
1957\end{array}$ & & 1 & 1 & 1 & & & & & & 1 & 1 \\
\hline 946 & inheems & 3.Dieren & 17.Geleedpotigen - Arthropoda & 108337 & Processa edulis edulis (Risso, 1816) & & 1 & 1 & 1 & & & & & & 1 & 1 \\
\hline$\frac{740}{947}$ & inheems & 3.Dieren & 17.Geleedpotigen - Arthropoda & 108344 & $\begin{array}{l}\text { Processa nouveli holthuisi Al-Adhub \& } \\
\text { Williamson, } 1975\end{array}$ & & $\frac{1}{1}$ & $\frac{1}{1}$ & $\frac{1}{1}$ & & & & & & & $\frac{1}{1}$ \\
\hline 948 & inheems & 3.Dieren & 17.Geleedpotigen - Arthropoda & 108345 & $\begin{array}{l}\text { Processa nouveli nouveli Al-Adhub \& } \\
\text { Williamson, } 1975\end{array}$ & & 1 & 1 & 1 & 1 & & & 1 & & & 1 \\
\hline 949 & inheems & 3.Dieren & 17.Geleedpotigen - Arthropoda & 107690 & Processa parva Holthuis, 1951 & & 1 & & 1 & & & & & & 1 & 1 \\
\hline 950 & exoot & 3.Dieren & 17.Geleedpotigen - Arthropoda & 107414 & Rhithropanopeus harrisii (Gould, 1841) & Zuiderzeekrabbetje & $\frac{1}{1}$ & & 1 & & & & & & $\frac{1}{1}$ & $\frac{1}{1}$ \\
\hline 951 & inheems & 3.Dieren & 17.Geleedpotigen - Arthropoda & 107531 & Spirontocaris liljeborgii (Danielssen, 1859) & & 1 & 1 & 1 & 1 & & & 1 & 1 & & 1 \\
\hline 952 & inheems & 3.Dieren & 17.Geleedpotigen - Arthropoda & 107281 & Thia scutellata (Fabricius, 1793) & Nagelkrab & 1 & & & & & & & & & 1 \\
\hline 953 & inheems & 3.Dieren & 17.Geleedpotigen - Arthropoda & 107739 & Upogebia deltaura (Leach, 1815) & & 1 & & & & & & & & & 1 \\
\hline 954 & inheems & 3.Dieren & 17.Geleedpotigen - Arthropoda & 107742 & Upogebia stellata (Montagu, 1808) & & 1 & & 1 & & & & & & 1 & 1 \\
\hline 955 & exoot & 3.Dieren & 17.Geleedpotigen - Arthropoda & 421139 & Amphibalanus improvisus (Darwin, 1854) & Brakwaterpok; brakwaterzeepok & 1 & 1 & 1 & 1 & & & 1 & 1 & 1 & 1 \\
\hline 956 & exoot & 3.Dieren & 17.Geleedpotigen - Arthropoda & 712167 & Austrominius modestus (Darwin, 1854) & Sterretje; Nieuw-Zeelandse zeepok & 1 & 1 & 1 & 1 & & & & & 1 & 1 \\
\hline 957 & inheems & 3.Dieren & 17.Geleedpotigen - Arthropoda & 106215 & Balanus crenatus Bruquière, 1789 & Gekartelde zeepok & 1 & 1 & 1 & 1 & & & & & 1 & 1 \\
\hline 958 & inheems & 3.Dieren & 17.Geleedpotigen - Arthropoda & 106148 & Dosima fascicularis (Ellis \& Solander, 1786) & Geplooide eendemossel & 1 & & 1 & & & & & & & 1 \\
\hline 959 & inheems & 3.Dieren & 17.Geleedpotigen - Arthropoda & 106210 & Semibalanus balanoides (Linnaeus, 1767) & Gewone zeepok & 1 & & 1 & 1 & & & & & 1 & 1 \\
\hline
\end{tabular}




\begin{tabular}{|c|c|c|c|c|c|c|c|c|c|c|c|c|c|c|}
\hline 960 & inheems & 3.Dieren & 17.Geleedpotigen - Arthropoda & 733226 & $\begin{array}{l}\text { Stomatolepas dermochelys Monroe \& Limpus, } \\
1979\end{array}$ & & 1 & 1 & 1 & & & & 1 & \\
\hline 961 & inheems & 3.Dieren & 17.Geleedpotigen - Arthropoda & 106257 & Verruca stroemia (O.F. Müller, 1776) & Ritspok & 1 & & & & & & 1 & \\
\hline 962 & inheems & 3.Dieren & 17.Geleedpotigen - Arthropoda & 134796 & Parthenopea subterranea Kossmann, 1874 & & 1 & 1 & 1 & 1 & & & 1 & 1 \\
\hline 963 & inheems & 3.Dieren & 17.Geleedpotigen - Arthropoda & 106142 & Trypetesa lampas (Hancock, 1849) & & 1 & 1 & 1 & & & & 1 & \\
\hline 964 & inheems & 3.Dieren & $\begin{array}{l}\text { 18.Stekelhuidigen - } \\
\text { Echinodermata }\end{array}$ & 236130 & Acrocnida brachiata (Montagu, 1804) & & 1 & 1 & 1 & & & & 1 & 1 \\
\hline 965 & inheems & 3.Dieren & $\begin{array}{l}\text { 18.Stekelhuidigen - } \\
\text { Echinodermata }\end{array}$ & 125064 & Amphipholis squamata (Delle Chiaje, 1828) & Levendbarende slangster & 1 & 1 & 1 & & & & 1 & 1 \\
\hline 966 & inheems & 3.Dieren & $\begin{array}{l}\text { 18.Stekelhuidigen - } \\
\text { Echinodermata }\end{array}$ & 125073 & Amphiura chiajei Forbes, 1843 & & 1 & & 1 & & & & & 1 \\
\hline 967 & inheems & 3.Dieren & $\begin{array}{l}\text { 18.Stekelhuidigen - } \\
\text { Echinodermata }\end{array}$ & 125080 & Amphiura filiformis (O.F. Müller, 1776) & & 1 & 1 & 1 & & & & 1 & 1 \\
\hline 968 & inheems & 3.Dieren & $\begin{array}{l}\text { 18.Stekelhuidigen - } \\
\text { Echinodermata }\end{array}$ & 124850 & Ophiocten affinis (Lütken, 1858) & & 1 & & 1 & & & & 1 & 1 \\
\hline 969 & inheems & 3.Dieren & $\begin{array}{l}\text { 18.Stekelhuidigen - } \\
\text { Echinodermata }\end{array}$ & 125131 & $\begin{array}{l}\text { Ophiothrix fragilis (Abildgaard, in O.F. Müller, } \\
1789 \text { ) }\end{array}$ & Brokkelster & 1 & 1 & 1 & 1 & & & 1 & 1 \\
\hline 970 & inheems & 3.Dieren & $\begin{array}{l}\text { 18.Stekelhuidigen - } \\
\text { Echinodermata }\end{array}$ & 124913 & Ophiura albida Forbes, 1839 & Kleine slangster & 1 & 1 & 1 & 1 & & & 1 & 1 \\
\hline 971 & inheems & 3.Dieren & $\begin{array}{l}\text { 18.Stekelhuidigen - } \\
\text { Echinodermata }\end{array}$ & 124929 & Ophiura ophiura (Linnaeus, 1758) & Gewone slangster & 1 & 1 & 1 & 1 & & & 1 & 1 \\
\hline 972 & inheems & 3.Dieren & $\begin{array}{l}\text { 18.Stekelhuidigen - } \\
\text { Echinodermata }\end{array}$ & 124373 & Brissopsis lyrifera (Forbes, 1841) & & 1 & & 1 & 1 & & & 1 & 1 \\
\hline 973 & inheems & 3.Dieren & $\begin{array}{l}\text { 18. Stekelhuidigen - } \\
\text { Echinodermata }\end{array}$ & 124392 & Echinocardium cordatum (Pennant, 1777) & Zeeklit & 1 & 1 & 1 & 1 & & & 1 & 1 \\
\hline 974 & inheems & 3.Dieren & $\begin{array}{l}\text { 18.Stekelhuidigen - } \\
\text { Echinodermata }\end{array}$ & 124394 & Echinocardium flavescens (O.F. Müller, 1776) & & 1 & & 1 & & & & 1 & 1 \\
\hline 975 & inheems & 3.Dieren & $\begin{array}{l}\text { 18.Stekelhuidigen - } \\
\text { Echinodermata }\end{array}$ & 124273 & Echinocyamus pusillus (O.F. Müller, 1776) & Zeeboontje & 1 & & 1 & & & & 1 & 1 \\
\hline 976 & inheems & 3.Dieren & $\begin{array}{l}\text { 18.Stekelhuidigen - } \\
\text { Echinodermata }\end{array}$ & 124287 & Echinus esculentus Linnaeus, 1758 & & 1 & & 1 & & & & & 1 \\
\hline 977 & inheems & 3.Dieren & $\begin{array}{l}\text { 18.Stekelhuidigen - } \\
\text { Echinodermata }\end{array}$ & 124319 & Psammechinus miliaris (P.L.S. Müller, 1771) & Gewone zeeappel & 1 & 1 & 1 & 1 & & & 1 & 1 \\
\hline 978 & inheems & 3.Dieren & $\begin{array}{l}\text { 18. Stekelhuidigen - } \\
\text { Echinodermata }\end{array}$ & 124418 & Spatangus purpureus & & 1 & 1 & 1 & & & & 1 & 1 \\
\hline 979 & inheems & 3.Dieren & $\begin{array}{l}\text { 18.Stekelhuidigen - } \\
\text { Echinodermata }\end{array}$ & 124612 & Cucumaria frondosa (Gunnerus, 1767) & & 1 & & 1 & & & & & 1 \\
\hline 980 & inheems & 3.Dieren & $\begin{array}{l}\text { 18.Stekelhuidigen - } \\
\text { Echinodermata }\end{array}$ & 124455 & Labidoplax buskii (McIntosh, 1866) & & 1 & & 1 & & & & & 1 \\
\hline 981 & inheems & 3.Dieren & $\begin{array}{l}\text { 18.Stekelhuidigen - } \\
\text { Echinodermata }\end{array}$ & 124635 & $\begin{array}{l}\text { Leptopentacta elongata (Düben \& Koren, } \\
1846 \text { ) }\end{array}$ & & 1 & & 1 & & & & 1 & 1 \\
\hline 982 & inheems & 3.Dieren & $\begin{array}{l}\text { 18.Stekelhuidigen - } \\
\text { Echinodermata }\end{array}$ & 124465 & Leptosynapta inhaerens (O.F. Müller, 1776) & & 1 & & 1 & & & & 1 & 1 \\
\hline 983 & inheems & 3.Dieren & $\begin{array}{l}\text { 18.Stekelhuidigen - } \\
\text { Echinodermata }\end{array}$ & 123776 & Asterias rubens Linnaeus, 1758 & Gewone zeester & 1 & 1 & 1 & 1 & & & 1 & 1 \\
\hline 984 & inheems & 3.Dieren & $\begin{array}{l}\text { 18.Stekelhuidigen - } \\
\text { Echinodermata }\end{array}$ & 123867 & Astropecten irregularis (Pennant, 1777) & Kleine kamster & 1 & 1 & 1 & 1 & & & 1 & 1 \\
\hline 985 & inheems & 3.Dieren & $\begin{array}{l}\text { 18.Stekelhuidigen - } \\
\text { Echinodermata }\end{array}$ & 124043 & Hippasteria phrygiana & & 1 & & 1 & & & & & 1 \\
\hline 986 & inheems & 3.Dieren & $\begin{array}{l}\text { 18.Stekelhuidigen - } \\
\text { Echinodermata }\end{array}$ & 125158 & Leptasterias (Leptasterias) muelleri & & 1 & & 1 & & & & & 1 \\
\hline 987 & inheems & 3.Dieren & $\begin{array}{l}\text { 18.Stekelhuidigen - } \\
\text { Echinodermata }\end{array}$ & 123922 & Luidia sarsii & & 1 & & 1 & & & & 1 & 1 \\
\hline 988 & inheems & 3.Dieren & 19.Eikelwormen - Enteropneusta & 137604 & Stereobalanus canadensis Spengel, 1893 & & 1 & & & & & & & 1 \\
\hline 989 & exoot & 3.Dieren & 20.Chordadieren - Chordata & 103647 & Aplidium glabrum (Verrill, 1871) & Glanzende bolzakpijp & 1 & & 1 & 1 & 1 & 1 & 1 & \\
\hline 990 & inheems & 3.Dieren & 20.Chordadieren - Chordata & 103717 & Ascidia virginea Müller, 1776 & & 1 & 1 & 1 & & & & & 1 \\
\hline 991 & inheems & 3.Dieren & 20.Chordadieren - Chordata & 103718 & Ascidiella aspersa (Müller, 1776) & Ruwe zakpijp & 1 & 1 & 1 & & & & 1 & 1 \\
\hline 992 & inheems & 3.Dieren & 20.Chordadieren - Chordata & 103719 & Ascidiella scabra (Müller, 1776) & Harige zakpijp & 1 & & 1 & & & & 1 & 1 \\
\hline
\end{tabular}

| 70 van 99 | Wageningen Marine Research rapport C125/16 


\begin{tabular}{|c|c|c|c|c|c|c|c|c|c|c|c|c|c|c|c|}
\hline 993 & exoot & 3.Dieren & 20.Chordadieren - Chordata & 103862 & Botryllus schlosseri (Pallas, 1766) & Gesterde geleikorst & 1 & & 1 & 1 & & & & 1 & 1 \\
\hline 994 & inheems & 3.Dieren & 20.Chordadieren - Chordata & 103732 & Ciona intestinalis (Linnaeus, 1767) & Doorschijnende zakpijp & 1 & 1 & 1 & 1 & & & & 1 & 1 \\
\hline 995 & inheems & 3.Dieren & 20.Chordadieren - Chordata & 103552 & Clavelina lepadiformis (Müller, 1776) & & 1 & & 1 & & & & & 1 & \\
\hline 996 & inheems & 3.Dieren & 20.Chordadieren - Chordata & 103882 & Dendrodoa grossularia (Van Beneden, 1846) & Zeebes & 1 & & 1 & & & & & 1 & \\
\hline 997 & exoot & 3.Dieren & 20.Chordadieren - Chordata & 250126 & Didemnum vexillum Kott, 2002 & Druipzakpijp & 1 & & 1 & 1 & & & & 1 & \\
\hline 998 & exoot & 3.Dieren & 20.Chordadieren - Chordata & 103579 & Diplosoma listerianum (Milne Edwards, 1841) & Grijze korstzakpijp & 1 & 1 & 1 & 1 & 1 & 1 & & 1 & 1 \\
\hline 999 & inheems & 3.Dieren & 20.Chordadieren - Chordata & 103776 & Molgula complanata Alder \& Hancock, 1870 & Dwergzijker & 1 & & 1 & & & & & 1 & \\
\hline 1000 & exoot & 3.Dieren & 20.Chordadieren - Chordata & 103788 & Molgula manhattensis (De Kay, 1843) & Ronde zakpijp & 1 & 1 & 1 & 1 & 1 & 1 & 1 & & 1 \\
\hline 1001 & inheems & 3.Dieren & 20.Chordadieren - Chordata & 103894 & Pelonaia corrugata Goodsir \& Forbes, 1841 & & 1 & & 1 & & & & & 1 & 1 \\
\hline 1002 & exoot & 3.Dieren & 20.Chordadieren - Chordata & 103925 & $\begin{array}{l}\text { Styela calva Monniot C., Monniot F. \& Millar, } \\
1976\end{array}$ & & 1 & 1 & & 1 & 1 & 1 & & & \\
\hline 1003 & exoot & 3.Dieren & 20.Chordadieren - Chordata & 103929 & Styela clava Herdman, 1881 & Knotszakpijp Japanse knotszakpijp & 1 & 1 & & 1 & 1 & & 1 & & 1 \\
\hline 1004 & inheems & 3.Dieren & 20.Chordadieren - Chordata & 104906 & Branchiostoma lanceolatum (Pallas, 1774) & Lancetvisje & 1 & & 1 & & & & & 1 & 1 \\
\hline 1005 & inheems & 3.Dieren & 20.Chordadieren - Chordata & 101172 & Lampetra fluviatilis (Linnaeus, 1758) & Rivierprik & 1 & 1 & 1 & 1 & & & & & 1 \\
\hline 1006 & inheems & 3.Dieren & 20.Chordadieren - Chordata & 101174 & Petromyzon marinus Linnaeus, 1758 & Zeeprik & 1 & 1 & 1 & 1 & & & & & 1 \\
\hline 1007 & inheems & 3.Dieren & 20.Chordadieren - Chordata & 105836 & Alopias vulpinus (Bonnaterre, 1788) & Voshaai & 1 & 1 & 1 & & & & & & \\
\hline 1008 & inheems & 3.Dieren & 20.Chordadieren - Chordata & 105865 & Amblyraja radiata (Donovan, 1808) & Sterrog & 1 & & 1 & & & & & & 1 \\
\hline 1009 & inheems & 3.Dieren & 20.Chordadieren - Chordata & 105837 & Cetorhinus maximus (Gunnerus, 1765) & Reuzenhaai & 1 & & & & & & & & \\
\hline 1010 & inheems & 3.Dieren & 20.Chordadieren - Chordata & 105910 & Dalatias licha (Bonnaterre, 1788) & Zwarte haai & 1 & & & & & & & & \\
\hline 1011 & inheems & 3.Dieren & 20.Chordadieren - Chordata & 105851 & Dasyatis pastinaca (Linnaeus, 1758) & Pijlstaartrog & 1 & & & & & & & & 1 \\
\hline 1012 & inheems & 3.Dieren & 20.Chordadieren - Chordata & 105869 & Dipturus batis (Linnaeus, 1758) & Vleet & 1 & & & & & & & & \\
\hline 1013 & inheems & 3.Dieren & 20.Chordadieren - Chordata & 105820 & Galeorhinus galeus (Linnaeus, 1758) & Ruwe haai & 1 & 1 & 1 & & & & & & 1 \\
\hline 1014 & inheems & 3.Dieren & 20.Chordadieren - Chordata & 105841 & Lamna nasus (Bonnaterre, 1788) & Haringhaai & 1 & & & & & & & & \\
\hline 1015 & inheems & 3.Dieren & 20.Chordadieren - Chordata & 105873 & Leucoraja circularis (Couch, 1838) & Zandrog & 1 & & & & & & & & \\
\hline 1016 & inheems & 3.Dieren & 20.Chordadieren - Chordata & 105876 & Leucoraja naevus (Müller \& Henle, 1841) & Grootoogrog & 1 & & 1 & & & & & & 1 \\
\hline 1017 & inheems & 3.Dieren & 20.Chordadieren - Chordata & 105821 & Mustelus asterias Cloquet, 1819 & Gevlekte gladde haai & 1 & & 1 & & & & & & 1 \\
\hline 1018 & inheems & 3.Dieren & 20.Chordadieren - Chordata & 367297 & Raja brachyura Lafont, 1871 & Blonde rog & 1 & & 1 & & & & & & 1 \\
\hline 1019 & inheems & 3.Dieren & 20.Chordadieren - Chordata & 105883 & Raja clavata Linnaeus, 1758 & Stekelrog & 1 & 1 & 1 & & & & & & 1 \\
\hline 1020 & inheems & 3.Dieren & 20.Chordadieren - Chordata & 105885 & Raja microocellata Montagu, 1818 & Kleinoogrog & 1 & & & & & & & & \\
\hline 1021 & inheems & 3.Dieren & 20.Chordadieren - Chordata & 105887 & Raja montagui Fowler, 1910 & Gevlekte rog & 1 & & 1 & & & & & & 1 \\
\hline 1022 & inheems & 3.Dieren & 20.Chordadieren - Chordata & 105891 & Raja undulata Lacepède, 1802 & Golfrog & 1 & & & & & & & & \\
\hline 1023 & inheems & 3.Dieren & 20.Chordadieren - Chordata & 105894 & Rajella fyllae (Lütken, 1887) & Fylla's rog & 1 & & & & & & & & \\
\hline 1024 & inheems & 3.Dieren & 20.Chordadieren - Chordata & 105896 & Rostroraja alba (Lacepède, 1803) & Witte rog & 1 & & & & & & & & \\
\hline 1025 & inheems & 3.Dieren & 20.Chordadieren - Chordata & 105814 & Scyliorhinus canicula (Linnaeus, 1758) & Hondshaai & 1 & 1 & 1 & & & & & 1 & 1 \\
\hline 1026 & inheems & 3.Dieren & 20.Chordadieren - Chordata & 105815 & Scyliorhinus stellaris (Linnaeus, 1758) & Kathaai & 1 & & & & & & & & \\
\hline 1027 & inheems & 3.Dieren & 20.Chordadieren - Chordata & 105919 & $\begin{array}{l}\text { Somniosus microcephalus (Bloch \& Schneider, } \\
1801 \text { ) }\end{array}$ & Groenlandse haai & 1 & & & & & & & & \\
\hline 1028 & inheems & 3.Dieren & 20.Chordadieren - Chordata & 105923 & Squalus acanthias Linnaeus, 1758 & Doornhaai & 1 & 1 & 1 & & & & & & 1 \\
\hline 1029 & inheems & 3.Dieren & 20.Chordadieren - Chordata & 105928 & Squatina squatina (Linnaeus, 1758) & Zee-engel & 1 & & & & & & & & \\
\hline 1030 & inheems & 3.Dieren & 20.Chordadieren - Chordata & 321911 & Tetronarce nobiliana (Bonaparte, 1835 ) & Sidderrog & 1 & & & & & & & & \\
\hline 1031 & inheems & 3.Dieren & 20.Chordadieren - Chordata & 271684 & Torpedo marmorata Risso, 1810 & Gemarmerde sidderrog & 1 & & & & & & & & \\
\hline 1032 & inheems & 3.Dieren & 20.Chordadieren - Chordata & 127190 & Agonus cataphractus (Linnaeus, 1758) & Harnasmannetje & 1 & 1 & 1 & 1 & & & & & 1 \\
\hline 1033 & inheems & 3.Dieren & 20.Chordadieren - Chordata & 126415 & Alosa fallax & & 1 & 1 & 1 & 1 & & & & & 1 \\
\hline 1034 & inheems & 3.Dieren & 20.Chordadieren - Chordata & 126751 & Ammodytes marinus Raitt, 1934 & Noorse zandspiering & 1 & 1 & 1 & & & & & & 1 \\
\hline 1035 & inheems & 3.Dieren & 20.Chordadieren - Chordata & 126752 & Ammodytes tobianus Linnaeus, 1758 & Zandspiering & 1 & 1 & 1 & 1 & & & & & 1 \\
\hline 1036 & inheems & 3.Dieren & 20.Chordadieren - Chordata & 126758 & Anarhichas lupus Linnaeus, 1758 & Zeewolf & 1 & 1 & 1 & & & & & & 1 \\
\hline 1037 & inheems & 3.Dieren & 20.Chordadieren - Chordata & 126281 & Anguilla anguilla (Linnaeus, 1758) & Paling & 1 & 1 & 1 & 1 & & & & & 1 \\
\hline 1038 & inheems & 3.Dieren & 20.Chordadieren - Chordata & 126868 & Aphia minuta (Risso, 1810) & Glasgrondel & 1 & 1 & 1 & 1 & & & & 1 & 1 \\
\hline 1039 & inheems & 3.Dieren & 20.Chordadieren - Chordata & 126716 & Argentina sphyraena Linnaeus, 1758 & Kleine zilversmelt & 1 & & & & & & & & \\
\hline 1040 & inheems & 3.Dieren & 20.Chordadieren - Chordata & 127007 & Argyrosomus regius (Asso, 1801) & Ombervis & 1 & & & & & & & & \\
\hline 1041 & inheems & 3.Dieren & 20.Chordadieren - Chordata & 127126 & Arnoglossus laterna (Walbaum, 1792) & Schurftvis & 1 & 1 & 1 & 1 & & & & & 1 \\
\hline 1042 & inheems & 3.Dieren & 20.Chordadieren - Chordata & 272027 & Atherina boyeri Risso, 1810 & Kleine koornaarvis & 1 & & & & & & & & \\
\hline
\end{tabular}




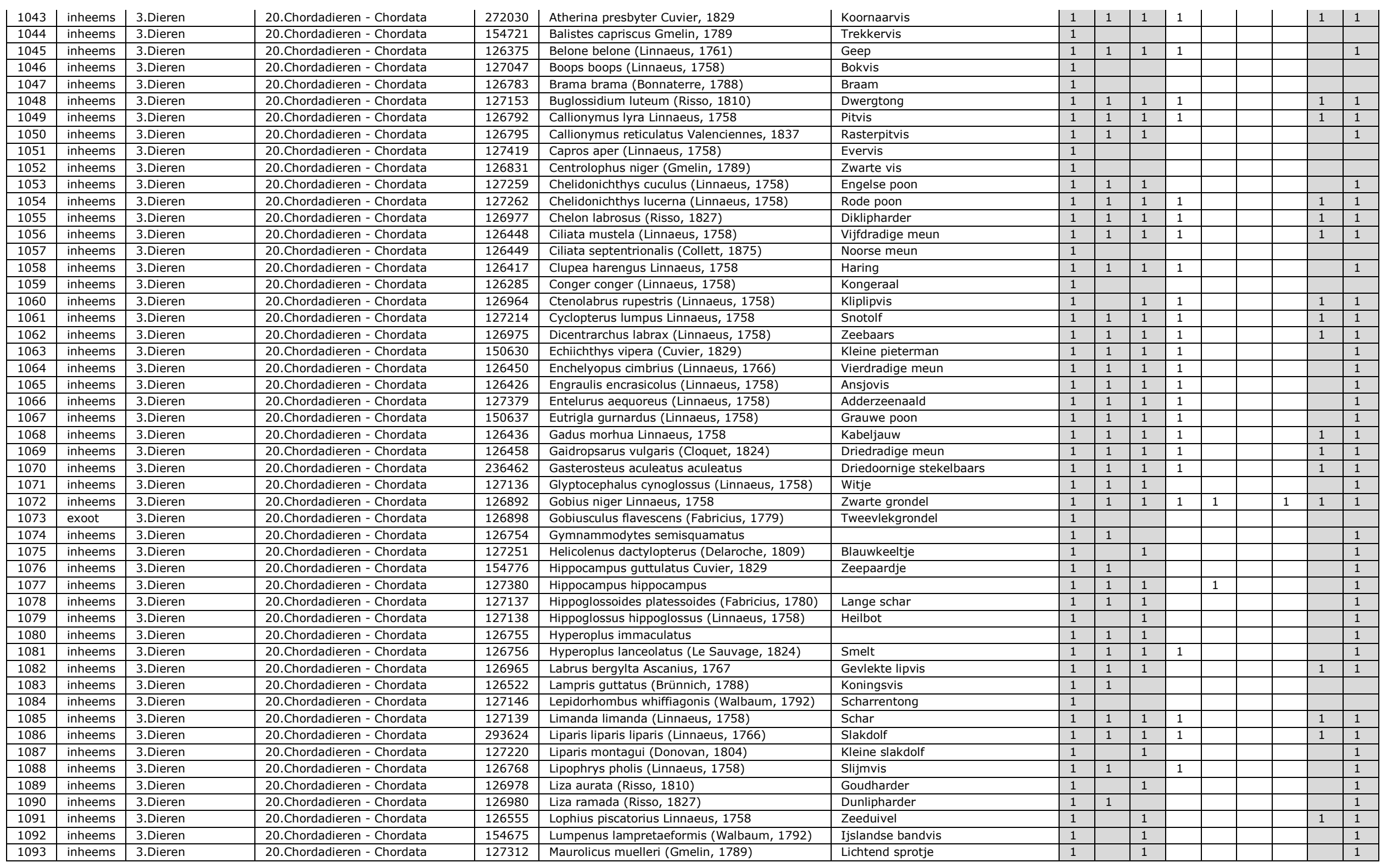

| 72 van 99 | Wageningen Marine Research rapport C125/16 


\begin{tabular}{|c|c|c|c|c|c|c|c|c|c|c|c|c|c|c|c|}
\hline 1094 & inheems & 3.Dieren & 20.Chordadieren - Chordata & 126438 & Merlangius merlangus (Linnaeus, 1758) & Wijting & 1 & 1 & 1 & 1 & & & & 1 & 1 \\
\hline 1095 & inheems & 3.Dieren & 20.Chordadieren - Chordata & 126484 & Merluccius merluccius (Linnaeus, 1758) & Heek & 1 & & 1 & & & & & & 1 \\
\hline 1096 & inheems & 3.Dieren & 20.Chordadieren - Chordata & 127201 & Micrenophrys lilljeborgii (Collett, 1875) & & 1 & & 1 & & & & & 1 & \\
\hline 1097 & inheems & 3.Dieren & 20.Chordadieren - Chordata & 126439 & Micromesistius poutassou (Risso, 1827) & Blauwe wijting & 1 & & 1 & & & & & & 1 \\
\hline 1098 & inheems & 3.Dieren & 20.Chordadieren - Chordata & 127140 & Microstomus kitt (Walbaum, 1792) & Tongschar & 1 & 1 & 1 & 1 & & & & 1 & 1 \\
\hline 1099 & inheems & 3.Dieren & 20.Chordadieren - Chordata & 127405 & Mola mola (Linnaeus, 1758) & Maanvis & 1 & & 1 & & & & & & 1 \\
\hline 1100 & inheems & 3.Dieren & 20.Chordadieren - Chordata & 126461 & Molva molva (Linnaeus, 1758) & Leng & 1 & 1 & 1 & & & & & 1 & 1 \\
\hline 1101 & inheems & 3.Dieren & 20.Chordadieren - Chordata & 126986 & Mullus surmuletus Linnaeus, 1758 & Mul & 1 & 1 & 1 & 1 & & & & 1 & 1 \\
\hline 1102 & inheems & 3.Dieren & 20.Chordadieren - Chordata & 127203 & Myoxocephalus scorpius (Linnaeus, 1758) & Zeedonderpad & 1 & 1 & 1 & 1 & & & & 1 & 1 \\
\hline 1103 & exoot & 3.Dieren & 20.Chordadieren - Chordata & 126916 & Neogobius melanostomus & & 1 & 1 & & 1 & & & & & 1 \\
\hline 1104 & inheems & 3.Dieren & 20.Chordadieren - Chordata & 126736 & $\begin{array}{l}\text { Osmerus eperlanus } \\
\end{array}$ & Spiering & 1 & 1 & 1 & 1 & & & & & 1 \\
\hline 1105 & inheems & 3.Dieren & 20.Chordadieren - Chordata & 127057 & Pagellus acarne (Risso, 1827) & Spaanse zeebrasem & 1 & 1 & & & & & & & 1 \\
\hline 1106 & inheems & 3.Dieren & 20.Chordadieren - Chordata & 127059 & Pagellus bogaraveo (Brünnich, 1768) & Zeebrasem & 1 & & & 1 & & & & & 1 \\
\hline 1107 & inheems & 3.Dieren & 20.Chordadieren - Chordata & 127060 & Pagellus erythrinus & & 1 & & 1 & & & & & & 1 \\
\hline 1108 & inheems & 3.Dieren & 20.Chordadieren - Chordata & 126770 & Parablennius gattorugine (Linnaeus, 1758) & Gehoornde slijmvis & 1 & 1 & 1 & 1 & & & & 1 & 1 \\
\hline 1109 & inheems & 3.Dieren & 20.Chordadieren - Chordata & 127156 & Pegusa lascaris (Risso, 1810) & Franse tong & 1 & 1 & 1 & & & & & & 1 \\
\hline 1110 & inheems & 3.Dieren & 20.Chordadieren - Chordata & 126996 & Pholis gunnellus (Linnaeus, 1758) & Botervis & 1 & 1 & 1 & 1 & & & & 1 & 1 \\
\hline 1111 & inheems & 3.Dieren & 20.Chordadieren - Chordata & 127147 & Phrynorhombus norvegicus (Günther, 1862) & Dwergbot & 1 & 1 & 1 & 1 & & & & & 1 \\
\hline 1112 & inheems & 3.Dieren & 20.Chordadieren - Chordata & 126501 & Phycis blennoides (Brünnich, 1768) & Gaffelkabeljauw & 1 & & & & & & & & \\
\hline 1113 & inheems & 3.Dieren & 20.Chordadieren - Chordata & 127141 & Platichthys flesus & Bot & 1 & 1 & 1 & 1 & & & & 1 & 1 \\
\hline 1114 & inheems & 3.Dieren & 20.Chordadieren - Chordata & 127143 & Pleuronectes platessa Linnaeus, 1758 & Schol & 1 & 1 & 1 & 1 & & & & 1 & 1 \\
\hline 1115 & inheems & 3.Dieren & 20.Chordadieren - Chordata & 126925 & Pomatoschistus Iozanoi (de Buen, 1923) & Lozano's grondel & 1 & 1 & 1 & 1 & & & & & 1 \\
\hline 1116 & inheems & 3.Dieren & 20.Chordadieren - Chordata & 126927 & Pomatoschistus microps (Krøyer, 1838) & Brakwatergrondel & 1 & 1 & 1 & 1 & & & & 1 & 1 \\
\hline 1117 & inheems & 3.Dieren & 20.Chordadieren - Chordata & 126928 & Pomatoschistus minutus (Pallas, 1770) & Dikkopje & 1 & 1 & 1 & 1 & & & & & 1 \\
\hline 1118 & inheems & 3.Dieren & 20.Chordadieren - Chordata & 126930 & Pomatoschistus pictus (Malm, 1865) & Kleurige grondel & 1 & & 1 & & & & & 1 & 1 \\
\hline 1119 & inheems & 3.Dieren & 20.Chordadieren - Chordata & 126442 & Raniceps raninus (Linnaeus, 1758) & Vorskwab & 1 & 1 & 1 & & & & & 1 & 1 \\
\hline 1120 & inheems & 3.Dieren & 20.Chordadieren - Chordata & 127186 & Salmo salar & & 1 & 1 & 1 & & & & & & 1 \\
\hline 1121 & inheems & 3.Dieren & 20.Chordadieren - Chordata & 223866 & Salmo trutta trutta & Zeeforel & 1 & & & & & & & & \\
\hline 1122 & inheems & 3.Dieren & 20.Chordadieren - Chordata & 126421 & Sardina pilchardus (Walbaum, 1792) & Sardien & 1 & 1 & 1 & 1 & & & & & 1 \\
\hline 1123 & inheems & 3.Dieren & 20.Chordadieren - Chordata & 127064 & Sarpa salpa (Linnaeus, 1758) & Gestreepte bokvis & 1 & & 1 & & & & & & \\
\hline 1124 & inheems & 3.Dieren & 20.Chordadieren - Chordata & 127022 & Scomber japonicus Houttuyn, 1782 & Spaanse makreel & 1 & 1 & 1 & & & & & & \\
\hline 1125 & inheems & 3.Dieren & 20.Chordadieren - Chordata & 127023 & Scomber scombrus Linnaeus, 1758 & Makreel & 1 & 1 & 1 & 1 & & & & & 1 \\
\hline 1126 & inheems & 3.Dieren & 20.Chordadieren - Chordata & 236461 & Scomberesox saurus saurus (Walbaum, 1792) & Makreelgeep & 1 & & & & & & & & \\
\hline 1127 & inheems & 3.Dieren & 20.Chordadieren - Chordata & 127149 & Scophthalmus maximus (Linnaeus, 1758) & Tarbot & 1 & 1 & 1 & 1 & & & & & 1 \\
\hline 1128 & inheems & 3.Dieren & 20.Chordadieren - Chordata & 127150 & Scophthalmus rhombus (Linnaeus, 1758) & Griet & 1 & 1 & 1 & 1 & & & & & 1 \\
\hline 1129 & inheems & 3.Dieren & 20.Chordadieren - Chordata & 151324 & Sebastes norvegicus (Ascanius, 1772) & Roodbaars & 1 & & & & & & & & \\
\hline 1130 & inheems & 3.Dieren & 20.Chordadieren - Chordata & 127255 & Sebastes viviparus Krøyer, 1845 & Kleine roodbaars & 1 & & 1 & & & & & & 1 \\
\hline 1131 & inheems & 3.Dieren & 20.Chordadieren - Chordata & 127160 & Solea solea (Linnaeus, 1758) & Tong & 1 & 1 & 1 & 1 & & & & 1 & 1 \\
\hline 1132 & inheems & 3.Dieren & 20.Chordadieren - Chordata & 126508 & Spinachia spinachia (Linnaeus, 1758) & Zeestekelbaars & 1 & & & 1 & & & & & 1 \\
\hline 1133 & inheems & 3.Dieren & 20.Chordadieren - Chordata & 127066 & Spondyliosoma cantharus (Linnaeus, 1758) & Zeekarper & 1 & 1 & 1 & & & & & & 1 \\
\hline 1134 & inheems & 3.Dieren & 20.Chordadieren - Chordata & 126425 & Sprattus sprattus (Linnaeus, 1758) & Sprot & 1 & 1 & 1 & 1 & & & & & 1 \\
\hline 1135 & inheems & 3.Dieren & 20.Chordadieren - Chordata & 273566 & Symphodus bailloni (Valenciennes, 1839) & Baillon's lipvis & 1 & & 1 & & & & & 1 & \\
\hline 1136 & inheems & 3.Dieren & 20.Chordadieren - Chordata & 273571 & Symphodus melops (Linnaeus, 1758) & Zwartooglipvis & 1 & 1 & 1 & & & & & 1 & 1 \\
\hline 1137 & inheems & 3.Dieren & 20.Chordadieren - Chordata & 127387 & Syngnathus acus Linnaeus, 1758 & Grote zeenaald & 1 & 1 & 1 & 1 & & & & & 1 \\
\hline 1138 & inheems & 3.Dieren & 20.Chordadieren - Chordata & 127389 & Syngnathus rostellatus Nilsson, 1855 & Kleine zeenaald & 1 & 1 & 1 & 1 & & & & & 1 \\
\hline 1139 & inheems & 3.Dieren & 20.Chordadieren - Chordata & 127393 & Syngnathus typhle Linnaeus, 1758 & Trompetterzeenaald & 1 & & & & & & & & \\
\hline 1140 & inheems & 3.Dieren & 20.Chordadieren - Chordata & 127204 & Taurulus bubalis (Euphrasen, 1786) & Groene zeedonderpad & 1 & 1 & 1 & 1 & & & & 1 & 1 \\
\hline 1141 & inheems & 3.Dieren & 20.Chordadieren - Chordata & 126937 & Thorogobius ephippiatus (Lowe, 1839) & & 1 & & 1 & & & & & 1 & \\
\hline 1142 & inheems & 3.Dieren & 20.Chordadieren - Chordata & 127082 & Trachinus draco Linnaeus, 1758 & Grote pieterman & 1 & & 1 & & & & & & 1 \\
\hline 1143 & inheems & 3.Dieren & 20.Chordadieren - Chordata & 126822 & Trachurus trachurus (Linnaeus, 1758) & Horsmakreel & 1 & 1 & 1 & 1 & & & & 1 & 1 \\
\hline 1144 & inheems & 3.Dieren & 20.Chordadieren - Chordata & 154462 & Trigloporus lastoviza (Bonnaterre, 1788) & Gestreepte poon & 1 & & & & & & & & \\
\hline
\end{tabular}




\begin{tabular}{|c|c|c|c|c|c|c|c|c|c|c|c|c|c|}
\hline 1145 & inheems & 3.Dieren & 20.Chordadieren - Chordata & 126445 & Trisopterus luscus (Linnaeus, 1758) & Steenbolk & 1 & 1 & 1 & 1 & & 1 & 1 \\
\hline 1146 & inheems & 3.Dieren & 20.Chordadieren - Chordata & 126446 & Trisopterus minutus (Linnaeus, 1758) & Dwergbolk & 1 & 1 & 1 & 1 & & 1 & 1 \\
\hline 1147 & inheems & 3.Dieren & 20.Chordadieren - Chordata & 127094 & Xiphias gladius Linnaeus, 1758 & Zwaardvis & 1 & 1 & 1 & & & & \\
\hline 1148 & inheems & 3.Dieren & 20.Chordadieren - Chordata & 127151 & Zeugopterus punctatus (Bloch, 1787) & Gevlekte griet & 1 & & & & & & \\
\hline 1149 & inheems & 3.Dieren & 20.Chordadieren - Chordata & 127427 & Zeus faber Linnaeus, 1758 & Zonnevis & 1 & & 1 & & & & 1 \\
\hline 1150 & inheems & 3.Dieren & 20.Chordadieren - Chordata & 127123 & Zoarces viviparus (Linnaeus, 1758) & Puitaal & 1 & 1 & 1 & 1 & & 1 & 1 \\
\hline 1151 & inheems & 3.Dieren & 20.Chordadieren - Chordata & 137079 & Erignathus barbatus (Erxleben, 1777) & Baardrob & 1 & 1 & & 1 & & & \\
\hline 1152 & inheems & 3.Dieren & 20.Chordadieren - Chordata & 137097 & Globicephala melas (Traill, 1809) & Griend & 1 & 1 & 1 & & 1 & & \\
\hline 1153 & inheems & 3.Dieren & 20.Chordadieren - Chordata & 137098 & Grampus griseus (G. Cuvier, 1812) & Grijze dolfijn & 1 & & & & & & \\
\hline 1154 & inheems & 3.Dieren & 20.Chordadieren - Chordata & 137080 & Halichoerus grypus (Fabricius, 1791) & Grijze zeehond & 1 & & & & & & \\
\hline 1155 & inheems & 3.Dieren & 20.Chordadieren - Chordata & 343899 & Hyperoodon ampullatus (Forster, 1770 ) & Butskop & 1 & 1 & & & 1 & & \\
\hline 1156 & inheems & 3.Dieren & 20.Chordadieren - Chordata & 137113 & Kogia breviceps (de Blainville, 1838) & Dwergpotvis & 1 & 1 & & & & & \\
\hline 1157 & inheems & 3.Dieren & 20.Chordadieren - Chordata & 137100 & Lagenorhynchus acutus (Gray, 1828) & Witflankdolfijn & 1 & 1 & 1 & 1 & 1 & & \\
\hline 1158 & inheems & 3.Dieren & 20.Chordadieren - Chordata & 137101 & Lagenorhynchus albirostris (Gray, 1846) & Witsnuitdolfijn & 1 & 1 & 1 & 1 & 1 & & \\
\hline 1159 & inheems & 3.Dieren & 20.Chordadieren - Chordata & 137092 & Megaptera novaeangliae (Borowski, 1781) & Bultrug & 1 & 1 & & & & & \\
\hline 1160 & inheems & 3.Dieren & 20.Chordadieren - Chordata & 137121 & Mesoplodon bidens (Sowerby, 1804) & Gewone spitssnuitdolfijn & 1 & 1 & 1 & & & & \\
\hline 1161 & inheems & 3.Dieren & 20.Chordadieren - Chordata & 137122 & Mesoplodon densirostris (de Blainville, 1817) & Spitssnuitdolfijn van De Blainville & 1 & 1 & & & & & \\
\hline 1162 & inheems & 3.Dieren & 20.Chordadieren - Chordata & 137124 & Mesoplodon grayi von Haast, 1876 & Grays spitssnuitdolfijn & 1 & 1 & & & & & \\
\hline 1163 & inheems & 3.Dieren & 20.Chordadieren - Chordata & 137077 & Odobenus rosmarus (Linnaeus, 1758) & Walrus & 1 & 1 & & 1 & & & \\
\hline 1164 & inheems & 3.Dieren & 20.Chordadieren - Chordata & 137102 & Orcinus orca (Linnaeus, 1758) & Zwaardwalvis & 1 & 1 & 1 & & & & \\
\hline 1165 & inheems & 3.Dieren & 20.Chordadieren - Chordata & 159019 & Pagophilus groenlandicus (Erxleben, 1777) & Zadelrob & 1 & 1 & & 1 & & & \\
\hline 1166 & inheems & 3.Dieren & 20.Chordadieren - Chordata & 137084 & Phoca vitulina Linnaeus, 1758 & Gewone zeehond & 1 & & & & & & \\
\hline 1167 & inheems & 3.Dieren & 20.Chordadieren - Chordata & 137117 & Phocoena phocoena (Linnaeus, 1758) & Bruinvis & 1 & 1 & & & & & 1 \\
\hline 1168 & inheems & 3.Dieren & 20.Chordadieren - Chordata & 137104 & Pseudorca crassidens (Owen, 1846) & Kleine zwaardwalvis & 1 & 1 & & & & & \\
\hline 1169 & inheems & 3.Dieren & 20.Chordadieren - Chordata & 159021 & Pusa hispida Schreber, 1775 & Ringelrob & 1 & 1 & & 1 & & & \\
\hline 1170 & inheems & 3.Dieren & 20.Chordadieren - Chordata & 137107 & Stenella coeruleoalba (Meyen, 1833) & Gestreepte dolfijn & 1 & 1 & & & & & \\
\hline 1171 & inheems & 3.Dieren & 20.Chordadieren - Chordata & 137111 & Tursiops truncatus (Montagu, 1821) & Tuimelaar & 1 & 1 & 1 & & & & \\
\hline 1172 & inheems & 3.Dieren & 20.Chordadieren - Chordata & 137127 & Ziphius cavirostris Cuvier, 1823 & Dolfijn van Cuvier & 1 & 1 & & & & & \\
\hline 1173 & inheems & 3.Dieren & 20.Chordadieren - Chordata & 137205 & Caretta caretta (Linnaeus, 1758) & Dikkopschildpad & 1 & 1 & & & & & \\
\hline 1174 & inheems & 3.Dieren & 20.Chordadieren - Chordata & 137206 & Chelonia mydas (Linnaeus, 1758) & Soepschildpad & 1 & 1 & & & & & \\
\hline 1175 & inheems & 3.Dieren & 20.Chordadieren - Chordata & 137209 & Dermochelys coriacea (Vandelli, 1761) & Lederschildpad & 1 & 1 & & & & & \\
\hline 1176 & inheems & 3.Dieren & 20.Chordadieren - Chordata & 137208 & Lepidochelys kempii (Garman, 1880) & Kemps zeeschildpad & 1 & 1 & & & & & \\
\hline
\end{tabular}

| 74 van 99 | Wageningen Marine Research rapport C125/16 


\begin{tabular}{|c|c|c|c|c|c|c|c|c|c|c|}
\hline $\begin{array}{l}\mathrm{Nr} \\
\text { (vervolg } \\
\text { op vorige } \\
\text { tabel) }\end{array}$ & inheems/exoot & rijk & phylum & wetenschappelijke naam (NSR) & $\begin{array}{l}\text { Nederlandse naam } \\
\text { (NSR) }\end{array}$ & 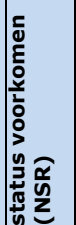 & $\stackrel{\frac{5}{0}}{\frac{5}{\pi}}$ & $\frac{10}{50}$ & ఫ్ & 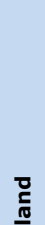 \\
\hline 1177 & inheems & Animalia & Chordata & Alca torda islandica C.L. Brehm, 1831 & Zuidelijke alk & $1 \mathrm{~b}$ & 1 & & & \\
\hline 1178 & inheems & Animalia & Chordata & Alca torda torda Linnaeus, 1758 & Alk & $1 \mathrm{~b}$ & 1 & & & \\
\hline 1179 & inheems & Animalia & Chordata & Alle alle (Linnaeus, 1758) & Kleine alk & $1 \mathrm{~b}$ & 1 & & & 1 \\
\hline 1180 & inheems & Animalia & Chordata & Anas acuta Linnaeus, 1758 & 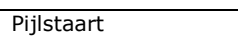 & $1 \mathrm{a}$ & 1 & & 1 & 1 \\
\hline 1181 & inheems & Animalia & Chordata & Anas penelope Linnaeus, 1758 & Smient & $1 a$ & 1 & 1 & 1 & 1 \\
\hline 1182 & inheems & Animalia & Chordata & Arenaria interpres (Linnaeus, 1758) & Steenloper & $1 \mathrm{~b}$ & 1 & & & 1 \\
\hline 1183 & inheems & Animalia & Chordata & Aythya marila (Linnaeus, 1761) & Topper & $1 \mathrm{~b}$ & 1 & & 1 & 1 \\
\hline 1184 & inheems & Animalia & Chordata & Branta bernicla (Linnaeus, 1758) & Rotgans & $1 \mathrm{~b}$ & 1 & & & 1 \\
\hline 1185 & inheems & Animalia & Chordata & Branta leucopsis (Bechstein, 1803) & Brandgans & $1 \mathrm{~b}$ & 1 & & 1 & 1 \\
\hline 1186 & inheems & Animalia & Chordata & Bucephala clangula (Linnaeus, 1758) & Brilduiker & $1 \mathrm{a}$ & 1 & 1 & 1 & 1 \\
\hline 1187 & inheems & Animalia & Chordata & Calidris alba (Pallas, 1764) & Drieteenstrandloper & $1 \mathrm{~b}$ & 1 & & & 1 \\
\hline 1188 & inheems & Animalia & Chordata & Calidris alpina (Linnaeus, 1758) & Bonte strandloper & $1 \mathrm{~b}$ & 1 & & 1 & 1 \\
\hline 1189 & inheems & Animalia & Chordata & Calidris alpina arctica (Schiøler, 1922) & $\begin{array}{l}\text { Arctische bonte } \\
\text { strandloper }\end{array}$ & $1 \mathrm{~b}$ & 1 & & 1 & 1 \\
\hline 1190 & inheems & Animalia & Chordata & Calidris alpina schinzii (C.L. Brehm, 1822) & $\begin{array}{l}\text { Zuidelijke bonte } \\
\text { strandloper }\end{array}$ & $1 \mathrm{~b}$ & 1 & & & 1 \\
\hline 1191 & inheems & Animalia & Chordata & Calidris canutus (Linnaeus, 1758) & Kanoet & $1 \mathrm{~b}$ & 1 & & & 1 \\
\hline 1192 & inheems & Animalia & Chordata & Calidris canutus islandica (Linnaeus, 1767) & Groenlandse kanoet & $1 \mathrm{~b}$ & 1 & & & 1 \\
\hline 1193 & inheems & Animalia & Chordata & Calidris maritima (Brünnich, 1764) & Paarse strandloper & $1 \mathrm{~b}$ & 1 & & & 1 \\
\hline 1194 & inheems & Animalia & Chordata & Calonectris borealis (Cory, 1881) & Kuhls pijlstormvogel & $1 \mathrm{~b}$ & 1 & & & \\
\hline 1195 & inheems & Animalia & Chordata & Cepphus grylle (Linnaeus, 1758) & Zwarte zeekoet & $1 \mathrm{~b}$ & 1 & & & \\
\hline 1196 & inheems & Animalia & Chordata & Charadrius alexandrinus Linnaeus, 1758 & Strandplevier & $1 \mathrm{a}$ & 1 & & & 1 \\
\hline 1197 & inheems & Animalia & Chordata & Charadrius hiaticula Linnaeus, 1758 & Bontbekplevier & $1 \mathrm{a}$ & 1 & & & 1 \\
\hline 1198 & inheems & Animalia & Chordata & Chlidonias niger (Linnaeus, 1758) & Zwarte stern & $1 \mathrm{a}$ & 1 & & 1 & 1 \\
\hline 1199 & inheems & Animalia & Chordata & Chroicocephalus genei (Brème, 1839) & Dunbekmeeuw & $1 \mathrm{~b}$ & 1 & & & \\
\hline 1200 & inheems & Animalia & Chordata & Chroicocephalus philadelphia (Ord, 1815) & Kleine kokmeeuw & $1 \mathrm{~b}$ & 1 & & & \\
\hline
\end{tabular}




\begin{tabular}{|c|c|c|c|c|c|c|c|c|c|c|}
\hline 1201 & inheems & Animalia & Chordata & Chroicocephalus ridibundus (Linnaeus, 1766) & Kokmeeuw & 1a & 1 & & 1 & 1 \\
\hline 1202 & inheems & Animalia & Chordata & Clangula hyemalis (Linnaeus, 1758) & IJseend & $1 \mathrm{~b}$ & 1 & 1 & 1 & 1 \\
\hline 1203 & inheems & Animalia & Chordata & Egretta garzetta (Linnaeus, 1758) & Kleine zilverreiger & $1 \mathrm{a}$ & 1 & & 1 & 1 \\
\hline 1204 & inheems & Animalia & Chordata & Fratercula arctica (Linnaeus, 1758) & Papegaaiduiker & $1 \mathrm{~b}$ & 1 & & & \\
\hline 1205 & inheems & Animalia & Chordata & Fulmarus glacialis (Linnaeus, 1761) & Noordse stormvogel & $1 \mathrm{~b}$ & 1 & & & \\
\hline 1206 & inheems & Animalia & Chordata & Gavia adamsii (Gray, 1859) & Geelsnavelduiker & $1 \mathrm{~b}$ & 1 & & 1 & \\
\hline 1207 & inheems & Animalia & Chordata & Gavia arctica (Linnaeus, 1758) & Parelduiker & $1 \mathrm{~b}$ & 1 & & 1 & \\
\hline 1208 & inheems & Animalia & Chordata & Gavia immer (Brünnich, 1764) & IJsduiker & $1 \mathrm{~b}$ & 1 & & 1 & 1 \\
\hline 1209 & inheems & Animalia & Chordata & Gavia stellata (Pontoppidan, 1763) & Roodkeelduiker & $1 \mathrm{~b}$ & 1 & & & \\
\hline 1210 & inheems & Animalia & Chordata & Gelochelidon nilotica (Gmelin, 1789) & Lachstern & $1 \mathrm{~b}$ & 1 & & 1 & 1 \\
\hline 1211 & inheems & Animalia & Chordata & Haematopus ostralegus Linnaeus, 1758 & Scholekster & $1 \mathrm{a}$ & 1 & & 1 & 1 \\
\hline 1212 & inheems & Animalia & Chordata & Histrionicus histrionicus (Linnaeus, 1758) & Harlekijneend & $1 \mathrm{~b}$ & 1 & & & \\
\hline 1213 & inheems & Animalia & Chordata & Hydrobates pelagicus (Linnaeus, 1758) & Stormvogeltje & $1 \mathrm{~b}$ & 1 & & & \\
\hline 1214 & inheems & Animalia & Chordata & Hydrocoloeus minutus (Pallas, 1776) & Dwergmeeuw & $1 \mathrm{a}$ & 1 & & 1 & 1 \\
\hline 1215 & inheems & Animalia & Chordata & $\begin{array}{l}\text { Larus argentatus argentatus (Pontoppidan, } \\
1763 \text { ) }\end{array}$ & $\begin{array}{l}\text { Scandinavische } \\
\text { zilvermeeuw }\end{array}$ & $1 \mathrm{~b}$ & 1 & & 1 & 1 \\
\hline 1216 & inheems & Animalia & Chordata & $\begin{array}{l}\text { Larus argentatus argenteus (Brehm \& } \\
\text { Schilling, 1822) }\end{array}$ & Zilvermeeuw & $1 a$ & 1 & & 1 & 1 \\
\hline 1217 & inheems & Animalia & Chordata & Larus atricilla Linnaeus, 1758 & Lachmeeuw & $1 \mathrm{~b}$ & 1 & & 1 & 1 \\
\hline 1218 & inheems & Animalia & Chordata & Larus audouinii Payraudeau, 1826 & Audouins meeuw & $1 \mathrm{~b}$ & 1 & & 1 & 1 \\
\hline 1219 & inheems & Animalia & Chordata & Larus cachinnans Pallas, 1811 & Pontische meeuw & $1 \mathrm{~b}$ & 1 & & 1 & 1 \\
\hline 1220 & inheems & Animalia & Chordata & Larus canus canus Linnaeus, 1758 & Stormmeeuw & $1 \mathrm{a}$ & 1 & & 1 & 1 \\
\hline 1221 & inheems & Animalia & Chordata & Larus canus heinei Homeyer, 1853 & Russische stormmeeuw & $1 \mathrm{~b}$ & 1 & & 1 & 1 \\
\hline 1222 & inheems & Animalia & Chordata & Larus delawarensis Ord, 1815 & Ringsnavelmeeuw & $1 \mathrm{~b}$ & 1 & & 1 & 1 \\
\hline 1223 & inheems & Animalia & Chordata & Larus fuscus fuscus Linnaeus, 1758 & Baltische mantelmeeuw & $1 \mathrm{~b}$ & 1 & & 1 & 1 \\
\hline 1224 & inheems & Animalia & Chordata & Larus fuscus graellsii A.E. Brehm, 1857 & Kleine mantelmeeuw & $1 a$ & 1 & & 1 & 1 \\
\hline 1225 & inheems & Animalia & Chordata & Larus fuscus intermedius Schiøler, 1922 & Kleine mantelmeeuw & $1 \mathrm{a}$ & 1 & & 1 & 1 \\
\hline 1226 & inheems & Animalia & Chordata & Larus glaucoides glaucoides Meyer, 1822 & Kleine burgemeester & $1 \mathrm{~b}$ & 1 & & & 1 \\
\hline 1227 & inheems & Animalia & Chordata & Larus glaucoides kumlieni Brewster, 1883 & Kumliens meeuw & $1 \mathrm{~b}$ & 1 & & 1 & 1 \\
\hline 1228 & inheems & Animalia & Chordata & Larus hyperboreus Gunnerus, 1767 & Grote burgemeester & $1 \mathrm{~b}$ & 1 & & & 1 \\
\hline 1229 & inheems & Animalia & Chordata & Larus marinus Linnaeus, 1758 & Grote mantelmeeuw & $1 \mathrm{a}$ & 1 & & 1 & 1 \\
\hline 1230 & inheems & Animalia & Chordata & Larus melanocephalus Temminck, 1820 & Zwartkopmeeuw & $1 \mathrm{a}$ & 1 & & 1 & 1 \\
\hline 1231 & inheems & Animalia & Chordata & Larus michahellis Naumann, 1840 & Geelpootmeeuw & $1 \mathrm{~b}$ & 1 & & 1 & 1 \\
\hline 1232 & inheems & Animalia & Chordata & Larus pipixcan Wagler, 1831 & Franklins meeuw & $1 \mathrm{~b}$ & 1 & & 1 & 1 \\
\hline
\end{tabular}




\begin{tabular}{|c|c|c|c|c|c|c|c|c|c|c|}
\hline 1233 & inheems & Animalia & Chordata & Limosa lapponica (Linnaeus, 1758) & Rosse grutto & $1 \mathrm{~b}$ & 1 & & & 1 \\
\hline 1234 & inheems & Animalia & Chordata & Melanitta americana (Swainson, 1832) & Amerikaanse zee-eend & $1 \mathrm{~b}$ & 1 & & & \\
\hline 1235 & inheems & Animalia & Chordata & Melanitta fusca (Linnaeus, 1758) & Grote zee-eend & $1 \mathrm{~b}$ & 1 & & 1 & 1 \\
\hline 1236 & inheems & Animalia & Chordata & Melanitta nigra (Linnaeus, 1758) & Zwarte zee-eend & $1 \mathrm{~b}$ & 1 & & & \\
\hline 1237 & inheems & Animalia & Chordata & Melanitta perspicillata (Linnaeus, 1758) & Brilzee-eend & $1 \mathrm{~b}$ & 1 & & & \\
\hline 1238 & inheems & Animalia & Chordata & Mergus serrator Linnaeus, 1758 & Middelste zaagbek & $1 \mathrm{a}$ & 1 & 1 & 1 & 1 \\
\hline 1239 & inheems & Animalia & Chordata & Morus bassanus (Linnaeus, 1758) & Jan-van-gent & $1 \mathrm{~b}$ & 1 & & & \\
\hline 1240 & inheems & Animalia & Chordata & Numenius arquata (Linnaeus, 1758) & Wulp & $1 \mathrm{a}$ & 1 & & 1 & 1 \\
\hline 1241 & inheems & Animalia & Chordata & Oceanites oceanicus (Kuhl, 1820) & Wilsons stormvogeltje & $1 \mathrm{~b}$ & 1 & & & \\
\hline 1242 & inheems & Animalia & Chordata & Oceanodroma leucorhoa (Vieillot, 1817) & Vaal stormvogeltje & $1 \mathrm{~b}$ & 1 & & & \\
\hline 1243 & inheems & Animalia & Chordata & $\begin{array}{l}\text { Onychoprion anaethetus melanoptera } \\
\text { (Swainson, 1837) }\end{array}$ & Brilstern & $1 \mathrm{~b}$ & 1 & & & \\
\hline 1244 & inheems & Animalia & Chordata & Onychoprion fuscatus (Linnaeus, 1766) & Bonte stern & $1 \mathrm{~b}$ & 1 & & & \\
\hline 1245 & inheems & Animalia & Chordata & Pagophila eburnea (Phipps, 1774) & Ivoormeeuw & $1 \mathrm{~b}$ & 1 & & & \\
\hline 1246 & inheems & Animalia & Chordata & Phalacrocorax aristotelis (Linnaeus, 1761) & Kuifaalscholver & $1 \mathrm{~b}$ & 1 & & & 1 \\
\hline 1247 & inheems & Animalia & Chordata & Phalacrocorax carbo (Linnaeus, 1758) & Aalscholver & $1 \mathrm{a}$ & 1 & & 1 & 1 \\
\hline 1248 & inheems & Animalia & Chordata & Phalaropus fulicarius (Linnaeus, 1758) & Rosse franjepoot & $1 \mathrm{~b}$ & 1 & & & \\
\hline 1249 & inheems & Animalia & Chordata & Platalea leucorodia Linnaeus, 1758 & Lepelaar & 1a & 1 & & 1 & 1 \\
\hline 1250 & inheems & Animalia & Chordata & Pluvialis squatarola (Linnaeus, 1758) & Zilverplevier & $1 \mathrm{~b}$ & 1 & & 1 & 1 \\
\hline 1251 & inheems & Animalia & Chordata & Podiceps auritus (Linnaeus, 1758) & Kuifduiker & $1 \mathrm{~b}$ & 1 & 1 & 1 & 1 \\
\hline 1252 & inheems & Animalia & Chordata & Podiceps cristatus (Linnaeus, 1758) & Fuut & $1 \mathrm{a}$ & 1 & 1 & 1 & 1 \\
\hline 1253 & inheems & Animalia & Chordata & Podiceps grisegena (Boddaert, 1783) & Roodhalsfuut & $1 \mathrm{a}$ & 1 & & 1 & 1 \\
\hline 1254 & inheems & Animalia & Chordata & Podiceps nigricollis C. L. Brehm, 1831 & Geoorde fuut & $1 \mathrm{a}$ & 1 & & 1 & 1 \\
\hline 1255 & inheems & Animalia & Chordata & Polysticta stelleri (Pallas, 1769) & Stellers eider & $1 \mathrm{~b}$ & 1 & & & \\
\hline 1256 & inheems & Animalia & Chordata & Pterodroma feae (Salvadori, 1899) & Gon-gon & $1 \mathrm{~b}$ & 1 & & & \\
\hline 1257 & inheems & Animalia & Chordata & Puffinus gravis (O'Reilly, 1818) & Grote pijlstormvogel & $1 \mathrm{~b}$ & 1 & & & \\
\hline 1258 & inheems & Animalia & Chordata & Puffinus griseus (Gmelin, 1789) & Grauwe pijlstormvogel & $1 \mathrm{~b}$ & 1 & & & \\
\hline 1259 & inheems & Animalia & Chordata & Puffinus mauretanicus Lowe, 1921 & Vale pijlstormvogel & $1 \mathrm{~b}$ & 1 & & & \\
\hline 1260 & inheems & Animalia & Chordata & Puffinus puffinus (Brünnich, 1764) & Noordse pijlstormvogel & $1 \mathrm{~b}$ & 1 & & & \\
\hline 1261 & inheems & Animalia & Chordata & Recurvirostra avosetta Linnaeus, 1758 & Kluut & $1 \mathrm{a}$ & 1 & & 1 & 1 \\
\hline 1262 & inheems & Animalia & Chordata & Rhodostethia rosea (MacGillivray, 1824) & Ross' meeuw & $1 \mathrm{~b}$ & 1 & & & \\
\hline 1263 & inheems & Animalia & Chordata & Rissa tridactyla (Linnaeus, 1758) & Drieteenmeeuw & $1 \mathrm{~b}$ & 1 & & & \\
\hline 1264 & inheems & Animalia & Chordata & Somateria mollissima (Linnaeus, 1758) & Eider & $1 \mathrm{a}$ & 1 & & & 1 \\
\hline
\end{tabular}




\begin{tabular}{|c|c|c|c|c|c|c|c|c|c|}
\hline 1265 & inheems & Animalia & Chordata & Somateria spectabilis (Linnaeus, 1758) & Koningseider & $1 \mathrm{~b}$ & 1 & & \\
\hline 1266 & inheems & Animalia & Chordata & Stercorarius longicaudus Vieillot, 1819 & Kleinste jager & $1 \mathrm{~b}$ & 1 & & \\
\hline 1267 & inheems & Animalia & Chordata & Stercorarius parasiticus (Linnaeus, 1758) & Kleine jager & $1 \mathrm{~b}$ & 1 & & \\
\hline 1268 & inheems & Animalia & Chordata & Stercorarius pomarinus (Temminck, 1815) & Middelste jager & $1 \mathrm{~b}$ & 1 & & \\
\hline 1269 & inheems & Animalia & Chordata & Stercorarius skua (Brünnich, 1764) & Grote jager & $1 \mathrm{~b}$ & 1 & & \\
\hline 1270 & inheems & Animalia & Chordata & Sterna acuflavida Cabot, 1847 & Amerikaanse grote stern & $1 \mathrm{~b}$ & 1 & & \\
\hline 1271 & inheems & Animalia & Chordata & Sterna dougallii Montagu, 1813 & Dougalls stern & $1 \mathrm{~b}$ & 1 & & \\
\hline 1272 & inheems & Animalia & Chordata & Sterna forsteri Nuttall, 1834 & Forsters stern & $1 \mathrm{~b}$ & 1 & 1 & \\
\hline 1273 & inheems & Animalia & Chordata & Sterna hirundo Linnaeus, 1758 & Visdief & $1 \mathrm{a}$ & 1 & 1 & 1 \\
\hline 1274 & inheems & Animalia & Chordata & Sterna paradisaea Pontoppidan, 1763 & Noordse stern & $1 \mathrm{a}$ & 1 & & 1 \\
\hline 1275 & inheems & Animalia & Chordata & Sterna sandvicensis acuflavida Cabot, 1848 & Amerikaanse grote stern & $1 \mathrm{~b}$ & 1 & & 1 \\
\hline 1276 & inheems & Animalia & Chordata & Sternula albifrons (Pallas, 1764) & Dwergstern & $1 \mathrm{a}$ & 1 & & 1 \\
\hline 1277 & inheems & Animalia & Chordata & Tadorna tadorna (Linnaeus, 1758) & Bergeend & $1 \mathrm{a}$ & 1 & 1 & 1 \\
\hline 1278 & inheems & Animalia & Chordata & Tringa totanus robusta (Schiøler, 1919) & IJslandse tureluur & $1 \mathrm{~b}$ & 1 & & 1 \\
\hline 1279 & inheems & Animalia & Chordata & Tringa totanus totanus (Linnaeus, 1758 ) & Tureluur & $1 a$ & 1 & 1 & 1 \\
\hline 1280 & inheems & Animalia & Chordata & Uria aalge aalge (Pontoppidan, 1763) & Zeekoet & $1 \mathrm{~b}$ & 1 & & \\
\hline 1281 & inheems & Animalia & Chordata & Uria aalge albionis Witherby, 1923 & Britse zeekoet & $1 \mathrm{~b}$ & 1 & & \\
\hline 1282 & inheems & Animalia & Chordata & Uria aalge hyperborea Salomonsen, 1832 & Noordelijke zeekoet & $1 \mathrm{~b}$ & 1 & & \\
\hline 1283 & inheems & Animalia & Chordata & Uria lomvia (Linnaeus, 1758) & Kortbekzeekoet & $1 \mathrm{~b}$ & 1 & & \\
\hline 1284 & inheems & Animalia & Chordata & Xema sabini (Sabine, 1819) & Vorkstaartmeeuw & $1 \mathrm{~b}$ & 1 & & \\
\hline
\end{tabular}




\section{Bijlage 2 Beleidssoorten}

Tabel B2.1 Legenda behorende bij onderstaande tabellen B2.2 t/m B2.6 met beleidssoorten.

\begin{tabular}{|c|c|}
\hline \multicolumn{2}{|l|}{ Categorie } \\
\hline II = Soorten uit Habitatrichtlijnbijlage II relevant voor Nederland & $\begin{array}{l}\text { European Topic Centre on Biological Diversity (2016) Marine Atlantic region - reference list March } 2016 . \\
\text { (http://bd.eionet.europa.eu/activities/Natura_2000/pdfs/Marine_Atlantic.pdf). }\end{array}$ \\
\hline IV,$V=$ Soorten uit Habitatrichtlijnbijlagen IV en V & $\begin{array}{l}\text { Raad van de Europese Gemeenschappen (1992) Richtlijn 92/43/ EEG van de Raad van } 21 \text { mei } 1992 \text { inzake de } \\
\text { instandhouding van de natuurlijke habitats en de wilde flora en fauna. Publicatieblad van de Europese } \\
\text { Gemeenschappen Nr. L206/7. ( (tttp://eur-lex.europa.eu/legal- } \\
\text { content/NL/TXT/PDF/? ?uri=CELEX:31992L0043\&from=EN). }\end{array}$ \\
\hline 7 = Noordzeekustzone $(\mathrm{VR}+\mathrm{HR})$ & $\begin{array}{l}\text { Ministerie van Landbouw, Natuur en Voedselkwaliteit (2009) Aanwijzingsbesluit Natura 2000-gebied } \\
\text { Noordzeekustzone } \\
\text { (http://www.synbiosys.alterra.n//natura2000/documenten/gebieden/007/n2k_007_db_hvn_noordzeekustzone.pdf). }\end{array}$ \\
\hline $113=$ Voordelta $(V R+H R)$ & $\begin{array}{l}\text { Ministerie Landbouw, Natuurbeheer en Visserij (2001) Aanwijzingsbesluit Vogelrichtlijngebied Voordelta. } \\
\text { (http://www.synbiosys.alterra.nl/natura2000/documenten/gebieden/113/vogelrichtlijn-36.pdf). }\end{array}$ \\
\hline $113=$ Voordelta $(\mathrm{VR}+\mathrm{HR})$ & $\begin{array}{l}\text { Ministerie van Landbouw, Natuur en Voedselkwaliteit (2008) Aanwijzingsbesluit Habitatrichtlijngebied Voordelta. } \\
\text { (http://www.synbiosys.alterra.n//natura2000/documenten/gebieden/113/Besluit\%20Voordelta.pdf) }\end{array}$ \\
\hline $163=$ Vlakte van de Raan & $\begin{array}{l}\text { Ministerie van Economische Zaken, Landbouw \& Innovatie (2010) Aanwijzingsbesluit Habitatrichtlijngebied Vlakte van } \\
\text { de Raan. } \\
\text { (http://www.synbiosys.alterra.nl/natura2000/documenten/gebieden/163/n2k163\%20vlakte\%20van\%20de\%20raan_d } \\
\text { efinitief\%20aanwijzingsbesluit_03dec10.pdf). }\end{array}$ \\
\hline $165=$ Klaverbank $(H R)$ & $\begin{array}{l}\text { Ministerie van Economische Zaken (2014) Aanwijzingsbesluit Natura 2000-gebied Klaverbank } \\
\text { (http://www.synbiosys.alterra.nl/natura2000/documenten/gebieden/165/PUBLICATIEVERSIE_N2K165_definitief\%20be } \\
\text { sluit\%20Klaverbank\%20met\%20kaart.pdf). }\end{array}$ \\
\hline
\end{tabular}




\begin{tabular}{|c|c|}
\hline $166=$ Friese Front $(V R)$ & $\begin{array}{l}\text { Ministerie van Economische Zaken (2014) Aanwijzingsbesluit Natura 2000-gebied Friese Front < } \\
\text { http://www.synbiosys.alterra.nl/natura2000/documenten/gebieden/166/PUBLICATIEVERSIE_N2K166_definitief\%20bes } \\
\text { luit\%20Friese\%20Front\%20met\%20kaart.pdf }>\text {. }\end{array}$ \\
\hline $\begin{array}{l}\text { 3. Typische soort voor habitattypen van bijlage I van de } \\
\text { Habitatrichtlijn }\end{array}$ & $\begin{array}{l}\text { Habitatrichtlijn: typische soorten } \\
\text { per habitattype }\end{array}$ \\
\hline H1110A, B, C = Typische soorten voor habitattype H1110A, B, C & $\begin{array}{l}\text { Ministerie van Economische Zaken (2014) Profieldocument Permanent overstroomde zandbanken (H1110) } \\
\text { (http://www.synbiosys.alterra.nl/natura2000/documenten/profielen/habitattypen/Profiel_habitattype_1110_2014.pdf). }\end{array}$ \\
\hline $\mathrm{H} 1130=$ Typische soorten voor habitattype H1130 & $\begin{array}{l}\text { Ministerie van Landbouw, Natuur en Voedselkwaliteit (2008) Profieldocument Estuaria (H1130) } \\
\text { (http://www.synbiosys.alterra.nl/natura2000/documenten/profielen/habitattypen/Profiel_habitattype_1130.pdf). }\end{array}$ \\
\hline H1140A, B = Typische soorten voor habitattype H1140A, B & $\begin{array}{l}\text { Ministerie van Landbouw, Natuur en Voedselkwaliteit (2008) Profieldocument Bij eb droogvallende slikwadden en } \\
\text { zandplaten (H1140) } \\
\text { (http://www.synbiosys.alterra.nl/natura2000/documenten/profielen/habitattypen/Profiel_habitattype_1140.pdf). }\end{array}$ \\
\hline H1160= Typische soorten voor habitattype H1160 & $\begin{array}{l}\text { Ministerie van Landbouw, Natuur en Voedselkwaliteit (2008) Profieldocument Grote, ondiepe kreken en baaien (H1160) } \\
\text { (http://www.synbiosys.alterra.nl/natura2000/documenten/profielen/habitattypen/Profiel_habitattype_1160.pdf). }\end{array}$ \\
\hline $\mathrm{H} 1170=$ Typische soorten voor habitattype H1170 & $\begin{array}{l}\text { Ministerie van Economische Zaken (2014) Profieldocument Riffen (H1170) } \\
\text { (http://www.synbiosys.alterra.nl/natura2000/documenten/profielen/habitattypen/Profiel_habitattype_1170_2014.pdf). }\end{array}$ \\
\hline H1310A, B = Typische soorten voor habitattype H1310A, B & $\begin{array}{l}\text { Ministerie van Landbouw, Natuur en Voedselkwaliteit (2008) Profieldocument Eénjarige pioniersvegetaties van slik- en } \\
\text { zandgebieden met Salicornia spp. en andere zoutminnende soorten (H1310) } \\
\text { (http://www.synbiosys.alterra.nl/natura2000/documenten/profielen/habitattypen/Profiel_habitattype_1310.pdf). }\end{array}$ \\
\hline $\mathrm{H} 1320=$ Typische soorten voor habitattype H1320 & $\begin{array}{l}\text { Ministerie van Landbouw, Natuur en Voedselkwaliteit (2008) Schorren met slijkgrasvegetaties (Spartinion maritimae) } \\
\text { (H1320) } \\
\text { (http://www.synbiosys.alterra.nl/natura2000/documenten/profielen/habitattypen/Profiel_habitattype_1320.pdf). }\end{array}$ \\
\hline $\mathrm{H} 1330=$ Typische soorten voor habitattype H1330 & $\begin{array}{l}\text { Ministerie van Landbouw, Natuur en Voedselkwaliteit (2008) Atlantische schorren (Glauco-Puccinellietalia maritimae) } \\
\text { (H1330) } \\
\text { (http://www.synbiosys.alterra.nl/natura2000/documenten/profielen/habitattypen/Profiel_habitattype_1330.pdf). }\end{array}$ \\
\hline 4. KRM-indicatorsoort voor habitatcategorie & Nederlandse indicatorsoorten voor de Kaderrichtlijn Mariene Strategie (KRM) \\
\hline H1110B = Indicatorsoort voor N2000-habitattype H1110B & $\begin{array}{l}\text { Ministerie van Infrastructuur en Milieu \& Ministerie van Economische Zaken (2014) Mariene Strategie voor het } \\
\text { Nederlandse deel van de Noordzee 2012-2020, Deel } 2 \text { KRM-monitoringprogramma. Den Haag. } \\
\text { (https://www.noordzeeloket.nl/images/Mariene\%20Strategie\%20voor\%20het\%20Nederlandse\%20deel\%20van\%20de } \\
\% 20 \text { Noordzee\%202012-2020\%2C\%20Deel\%202\%20KRM-monitoringprogramma_3335.pdf). }\end{array}$ \\
\hline H1110C = Indicatorsoort voor N2000-habitattype H1110C . & $\begin{array}{l}\text { Ministerie van Infrastructuur en Milieu \& Ministerie van Economische Zaken (2014) Mariene Strategie voor het } \\
\text { Nederlandse deel van de Noordzee 2012-2020, Deel } 2 \text { KRM-monitoringprogramma. Den Haag. } \\
\text { (https://www.noordzeeloket.nl/images/Mariene\%20Strategie\%20voor\%20het\%20Nederlandse\%20deel\%20van\%20de } \\
\% 20 \text { Noordzee\%202012-2020\%2C\%20Deel\%202\%20KRM-monitoringprogramma_3335.pdf). }\end{array}$ \\
\hline H1170 = Indicatorsoort voor N2000-habitattype H1170 & $\begin{array}{l}\text { Ministerie van Infrastructuur en Milieu \& Ministerie van Economische Zaken (2014) Mariene Strategie voor het } \\
\text { Nederlandse deel van de Noordzee 2012-2020, Deel } 2 \text { KRM-monitoringprogramma. Den Haag. } \\
\text { (https://www.noordzeeloket.nl/images/Mariene\%20Strategie\%20voor\%20het\%20Nederlandse\%20deel\%20van\%20de } \\
\% 20 \text { Noordzee\%202012-2020\%2C\%20Deel\%202\%20KRM-monitoringprogramma_3335.pdf). }\end{array}$ \\
\hline
\end{tabular}

| 80 van 99 | Wageningen Marine Research rapport C125/16 
OG = Oestergronden. Indicatorsoort voor KRM

bodembeschermingsgebied Oestergronden

$\mathrm{FF}=$ Friese Front. Indicatorsoort voor KRM bodembeschermingsgebied Friese Front

$\mathrm{ZB}(\mathrm{BB})=$ Zuidelijke Bocht (Bruine Bank). Indicatorsoort voor

toekomstig N2000 (Vogelrichtlijn) gebied Bruine Bank.

5. Soort van beleidsplan

Beleidsvoornemens herintroductie platte oester

Bruinvisbeschermingsplan

6. OSPAR-soorten relevant voor $\mathrm{NL}$

Lijst van OSPAR bedreigde soorten en habitats
Ministerie van Infrastructuur en Milieu \& Ministerie van Economische Zaken (2014) Mariene Strategie voor het

Nederlandse deel van de Noordzee 2012-2020, Deel 2 KRM-monitoringprogramma. Den Haag.

(https://www.noordzeeloket.nl/images/Mariene\%20Strategie\%20voor\%20het\%20Nederlandse\%20deel\%20van\%20de \%20Noordzee\%202012-2020\%2C\%20Deel\%202\%20KRM-monitoringprogramma_3335.pdf).

Ministerie van Infrastructuur en Milieu \& Ministerie van Economische Zaken (2014) Mariene Strategie voor het

Nederlandse deel van de Noordzee 2012-2020, Deel 2 KRM-monitoringprogramma. Den Haag.

(https://www.noordzeeloket.nl/images/Mariene\%20Strategie\%20voor\%20het\%20Nederlandse\%20deel\%20van\%20de

\%20Noordzee\%202012-2020\%2C\%20Deel\%202\%20KRM-monitoringprogramma_3335.pdf).

Ministerie van Infrastructuur en Milieu \& Ministerie van Economische Zaken (2014) Mariene Strategie voor het

Nederlandse deel van de Noordzee 2012-2020, Deel 2 KRM-monitoringprogramma. Den Haag.

(https://www.noordzeeloket.nl/images/Mariene\%20Strategie\%20voor\%20het\%20Nederlandse\%20deel\%20van\%20de \%20Noordzee\%202012-2020\%2C\%20Deel\%202\%20KRM-monitoringprogramma_3335.pdf).

Soorten die genoemd worden in een van deze beleidsplannen

Ministerie van Infrastructuur en Milieu \& Ministerie van Econmische Zaken (2015) Beleidsnota Noordzee 2016-2021. Den Haag. (https://www.rijksoverheid.nl/binaries/rijksoverheid/documenten/beleidsnota-s/2015/12/14/beleidsnotanoordzee-2016-2021/nz-nl-beeldscherm.pdf).

Ministerie van Infrastructuur en Milieu \& Ministerie van Economische Zaken (2015) Mariene Strategie voor het Nederlandse deel van de Noordzee 2012-2020, deel 3. Den Haag;

(https://www.rijksoverheid.nl/binaries/rijksoverheid/documenten/beleidsnota-s/2015/12/14/mariene-strategie-voor-

het-nederlandse-deel-van-de-noordzee-2012-2020-deel-3/mariene-strategie-voor-het-nederlandse-deel-van-de-

noordzee-2012-2020-deel-3.pdf).

Ministerie van Economische Zaken (2016) Brief d.d. 13 mei 2016 van de Staatssecretaris van Economische Zaken

over het KRM-haaienactieplan. Tweede Kamer, vergaderjaar 2015-2016, 33 450, nr. 48.

(https://zoek.officielebekendmakingen.nl/kst-33450-48.html).

Walker, P., Kingma, I Van de Water, M. De Blaeij, A. \& Strietman, W. J. (2015) Voorwaarden voor herstel van haaienen roggenpopulaties in de Noordzee. Nederlandse Elasmo-branchen Vereniging. Amsterdam.

(https://www.elasmobranch.nl/Eindrapportage\%20KRM\%20haaienroggen\%20fase\%202-\%20FINAL.pdf).

Ministerie van Economische Zaken, Landbouw \& Innovatie (2011) Brief d.d. 5 december 2011 van de Staatssecretaris van Ecomomische Zaken, Landbouw en Innovatie over het Bruinvisbeschermingsplan. Tweede Kamer, vergaderjaar 2011-2012, 29 675, nr. 138. (https://zoek.officielebekendmakingen.nl/kst-29675-138).

Camphuysen C.J. \& Siemensma, M.L. (2011) Conservation plan for the Harbour Porpoise Phocoena phocoena in The Netherlands: towards a favourable conservation status. NIOZ Report 2011-07, Royal Netherlands Institute for Sea Research, Texel. (https://zoek.officielebekendmakingen.nl/blg-143146).

Soorten van de lijst 'OSPAR threatened and/or declining

species and habitats' die relevant zijn voor Nederland

O OSPAR Commission (2008) OSPAR List of Threatened and/or Declining Species and Habitats. Reference Number:

2008-6. (http://www.ospar.org/documents?d=32794). 


\begin{tabular}{|c|c|}
\hline OSPAR soorten in Nederland & $\begin{array}{l}\text { Bos, O.G., Van Hal, R., Van Bemmelen, R., Paijmans, A.J., \& Van der Sluis, M.T. (2012) OSPAR threatened and/ or } \\
\text { declining species and habitats in the Netherlands. IMARES-rapport C134/12. (http://edepot.wur.nl/248714). }\end{array}$ \\
\hline 7. Rodelijststatus & Soorten van rode lijsten met hun status \\
\hline \multicolumn{2}{|l|}{$\begin{array}{l}\mathrm{VN}=\text { verdwenen uit Nederland } \\
\mathrm{EB}=\text { ernstig bedreigd } \\
\mathrm{BE}=\text { bedreigd } \\
\mathrm{KW}=\text { kwetsbaar } \\
\mathrm{GE}=\text { gevoelig }\end{array}$} \\
\hline \multicolumn{2}{|l|}{ De Rode Lijsten en achtergrondrapporten zijn: } \\
\hline Rode Lijst vissen en planten & $\begin{array}{l}\text { Ministerie van Economische Zaken (2015) Besluit van de Staatssecretaris van Economische Zaken van } 15 \text { oktober } \\
\text { 2015, DGAN-PDJNG / 15129301, houdende vaststelling van geactualiseerde Rode lijsten flora en fauna Staatscourant } \\
\text { 2015, nr. 36471. (https://zoek.officielebekendmakingen.nl/stcrt-2015-36471.html). }\end{array}$ \\
\hline Advies over Rode Lijst vissen & $\begin{array}{l}\text { Gmelig Meyling, A.W. \& Van Moorsel, G.W.N.M. (2013) Aanbevelingen voor aanpassingen Rode lijst mariene vissen. } \\
\text { Achtergronddocument voor het supplement bij het Basisrapport Rode lijst vissen. Lisse: Stichting ANEMOON, Doorn: } \\
\text { Ecosub. Eindconcept. }\end{array}$ \\
\hline Achtergronddocument Rode Lijst vissen & $\begin{array}{l}\text { Kranenbarg, J. \& Spikmans, F. (2013) Achtergronddocument Rode lijst vissen 2011: zoetwatervissen. Nijmegen: } \\
\text { Stichting RAVON. Rapport 2010.001. }\end{array}$ \\
\hline Achtergronddocument Rode Lijst vissen & $\begin{array}{l}\text { Tien, N.S.H., Heessen, H., Kranenbarg, J. \& Trapman, B. (2016) Achtergronddocument Rode lijst vissen 2011: } \\
\text { zoutwatervissen. Ijmuiden: IMARES Wageningen UR. IMARES-rapport C021/16. } \\
\text { (http://library.wur.nl/WebQuery/wurpubs/fulltext/378196). }\end{array}$ \\
\hline Rode Lijst zoogdieren & $\begin{array}{l}\text { Ministerie van Landbouw, Natuur en Voedselkwaliteit (2009b). Besluit van de Minister van Landbouw, Natuur en } \\
\text { Voedselkwaliteit van } 28 \text { augustus 2009, nr. 25344, houdende vaststelling van geactualiseerde Rode lijsten flora en } \\
\text { fauna. Staatscourant } 2009, \mathrm{nr} \text {. 13201. (https://zoek.officielebekendmakingen.nl/stcrt-2009-13201.html) en } \\
\text { (https://www.rijksoverheid.nl/binaries/rijksoverheid/documenten/besluiten/2009/09/07/besluit-vaststelling- } \\
\text { geactualiseerde-rode-lijsten-flora-en-fauna/besluit-vaststelling-rode-lijsten-sept2009.pdf). }\end{array}$ \\
\hline Basisrapport Rode Lijst zoogdieren & $\begin{array}{l}\text { Zoogdiervereniging VZZ (2007) Basisrapport voor de Rode Lijst Zoogdieren volgens Nederlandse en IUCN-criteria. VZZ } \\
\text { rapport 2006.027. Tweede, herziene druk. Arnhem: Zoogdiervereniging VZZ. } \\
\text { (http://www.zoogdiervereniging.nl/sites/default/files/imce/nieuwesite/Projecten/downloads/RL\%20Zoogdieren\%20Hig } \\
\text { h\%20Res\%20versie\%20\%28D\%20Bal\%2013\%20dec\%2007\%29.pdf). }\end{array}$ \\
\hline 8. Vogelrichtlijn: NL soorten van art. 12 & Vogelrichtlijnsoorten waarover volgens Art. 12 van de Vogelrichtlijn moet worden gerapporteerd \\
\hline \multicolumn{2}{|l|}{$\begin{array}{l}\text { Vogelrichtlijn ex art } 12=\text { Vogelrichtlijnsoorten waarover volgens Art. } \\
12 \text { van de Vogelrichtlijn elke } 3 \text { jaar door een lidstaat moet worden } \\
\text { gerapporteerd }\end{array}$} \\
\hline $\begin{array}{l}\text { Advies monitoring vogelsoorten van Vogelrichtlijn artikel } 12 \text { voor } \\
\text { Nederland }\end{array}$ & $\begin{array}{l}\text { Van Roomen, M., Stahl, J, Schekkerman, H, Van Turnhout, C \& Vogel, R. (2013) Advies ten behoeve van het opstellen } \\
\text { van een monitoringsplan voor vogels van het Nederlandse Noordzeegebied. Nijmegen: Sovon Vogelonderzoek } \\
\text { Nederland. Sovon-rapport 2013/22. (https://www.sovon.nl/sites/default/files/doc/Rap_2013- } \\
\text { 22_monitoringplan_noordzee.pdf). }\end{array}$ \\
\hline Soorten van Vogelrichtlijnbijlagen gerapporteerd door Nederland & $\begin{array}{l}\text { European Commission (2014) National Summary for Article 12; National Summary 2008-2012 the Netherlands. } \\
\text { (https://circabc.europa.eu/sd/a/46b22c56-9da5-44b8-8bc5-21987fff9b8b/NL_A12NatSum_20141031.pdf). }\end{array}$ \\
\hline
\end{tabular}

| 82 van 99 | Wageningen Marine Research rapport C125/16 
Soorten van Vogelrichtlijnbijlage I voor NL = Soorten die zijn betrokken bij de selectie en begrenzing van speciale

beschermingszones (Vogelrichtlijngebieden).

10. Vogelrichtlijngebieden voor soort

Zie bovenin deze tabel ('N2000-gebieden voor de soort')
Zie literatuur hierboven

Speciale beschermingszones (Vogelrichtlijngebieden) per soort 
Tabel B2.2 Meercellige planten en wieren en hun beleidsstatus. Lege lichtgrijze cellen = categorie niet relevant voor de soort. Legenda: zie Tabel B2.1

\begin{tabular}{|l|l|l|l|l|l|l|l|}
\hline Naam (wetenschappelijk) & Naam (Nederlands) & $\begin{array}{l}\text { HR- } \\
\text { bijlagen }\end{array}$ & $\begin{array}{l}\text { N2000- } \\
\text { gebieden } \\
\text { voor } \\
\text { soort }\end{array}$ & $\begin{array}{l}\text { Typisch } \\
\text { e } \\
\text { soort } \\
\text { voor } \\
\text { habitatt } \\
\text { ype } \\
\text { (HR) }\end{array}$ & $\begin{array}{l}\text { KRM } \\
\text { indicator- } \\
\text { soort } \\
\text { voor } \\
\text { habitat- } \\
\text { categorie }\end{array}$ & $\begin{array}{l}\text { Soort van } \\
\text { beleidsplan }\end{array}$ & $\begin{array}{l}\text { OSPAR- } \\
\text { soorten } \\
\text { relevant } \\
\text { voor NL }\end{array}$ \\
\hline PLANTEN EN WIEREN & & & & H1320 & & \\
\hline Spartina maritima & Klein slijkgras & & & H1170 & H1170 & \\
\hline Lithothamnion sonderi & & & & & \\
\hline
\end{tabular}

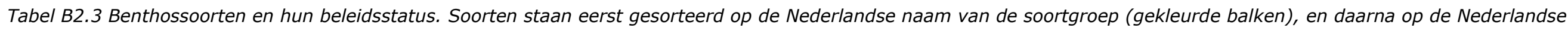
naam. Lege lichtgrijze cellen = categorie niet relevant voor de soort. Legenda: zie Tabel B2.1.

\begin{tabular}{|l|l|l|l|l|l|l|l|}
\hline $\begin{array}{l}\text { Naam } \\
\text { (wetenschappelijk) }\end{array}$ & Naam (Nederlands) & $\begin{array}{l}\text { HR- } \\
\text { bijlagen }\end{array}$ & $\begin{array}{l}\text { N2000- } \\
\text { gebiede } \\
\text { voor } \\
\text { soort }\end{array}$ & $\begin{array}{l}\text { Typische } \\
\text { soort voor } \\
\text { habitattyp } \\
\text { e (HR) }\end{array}$ & $\begin{array}{l}\text { KRM } \\
\text { indicator- } \\
\text { soort } \\
\text { voor } \\
\text { habitat- } \\
\text { categorie }\end{array}$ & $\begin{array}{l}\text { Soort van } \\
\text { beleidsplan } \\
\text { us }\end{array}$ & $\begin{array}{l}\text { OSPAR- } \\
\text { soorten } \\
\text { relevant } \\
\text { voor NL }\end{array}$ \\
\hline BLOEMDIEREN & & & & & H1170 & H1170 & \\
\hline Urticina felina & zeedahlia & dodemansduim & & & $\begin{array}{l}\text { H1110C, } \\
\text { H1170 }\end{array}$ & H1170 & \\
\hline Alcyonium digitatum & & & & & H1170 & H1170 & \\
\hline BORSTELWORMEN & & & & H1110C & & \\
\hline Chone duneri & & & & H1110BC & & \\
\hline Goniada maculata & & & & H1110BC & ZB(BB) & \\
\hline Magelona papillicornis & & & & \\
\hline Nephtys assimilis & & & & \\
\hline Nephtys cirrosa & & & & \\
\hline
\end{tabular}

| 84 van 99 | Wageningen Marine Research rapport C125/16 


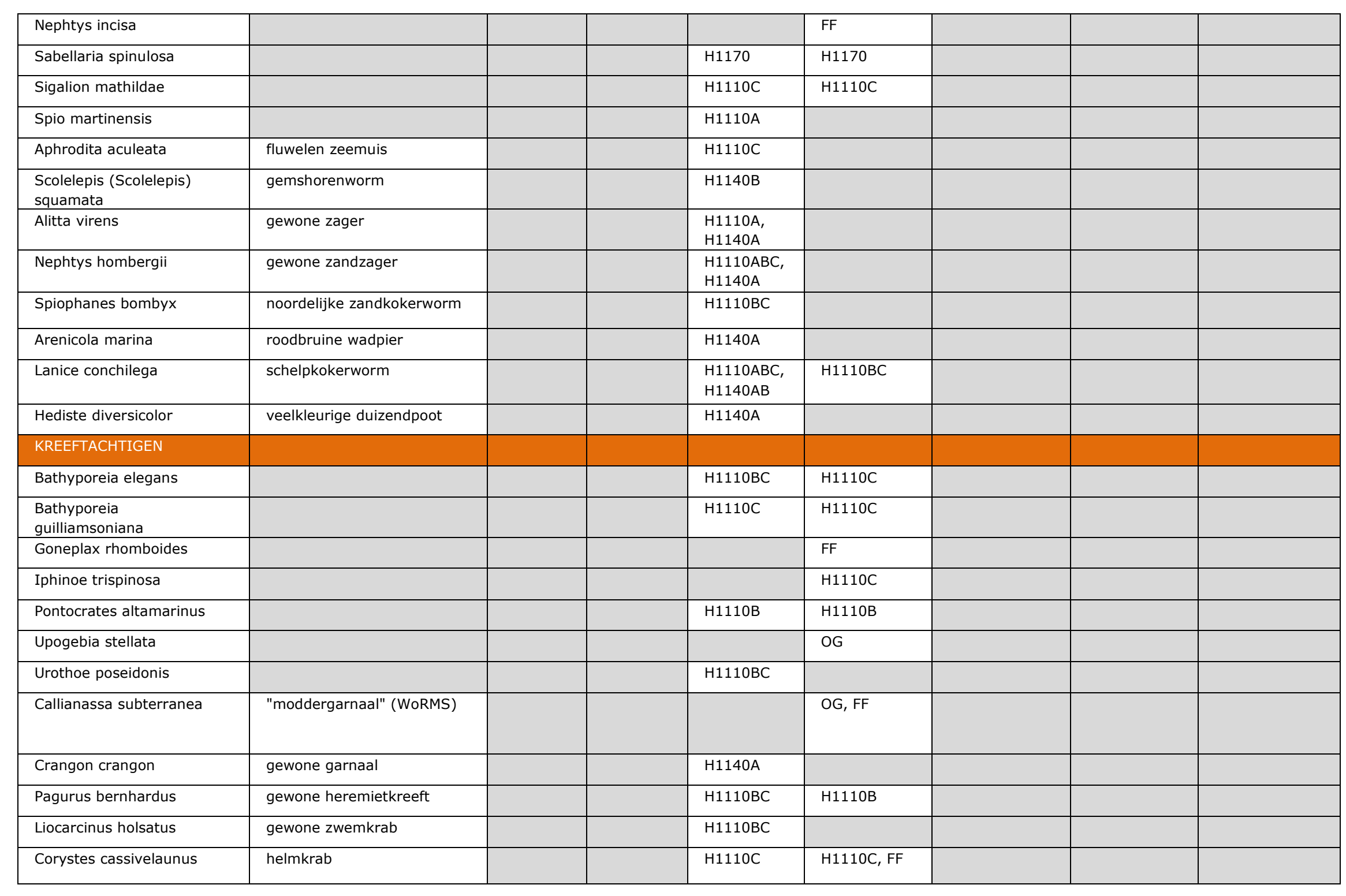




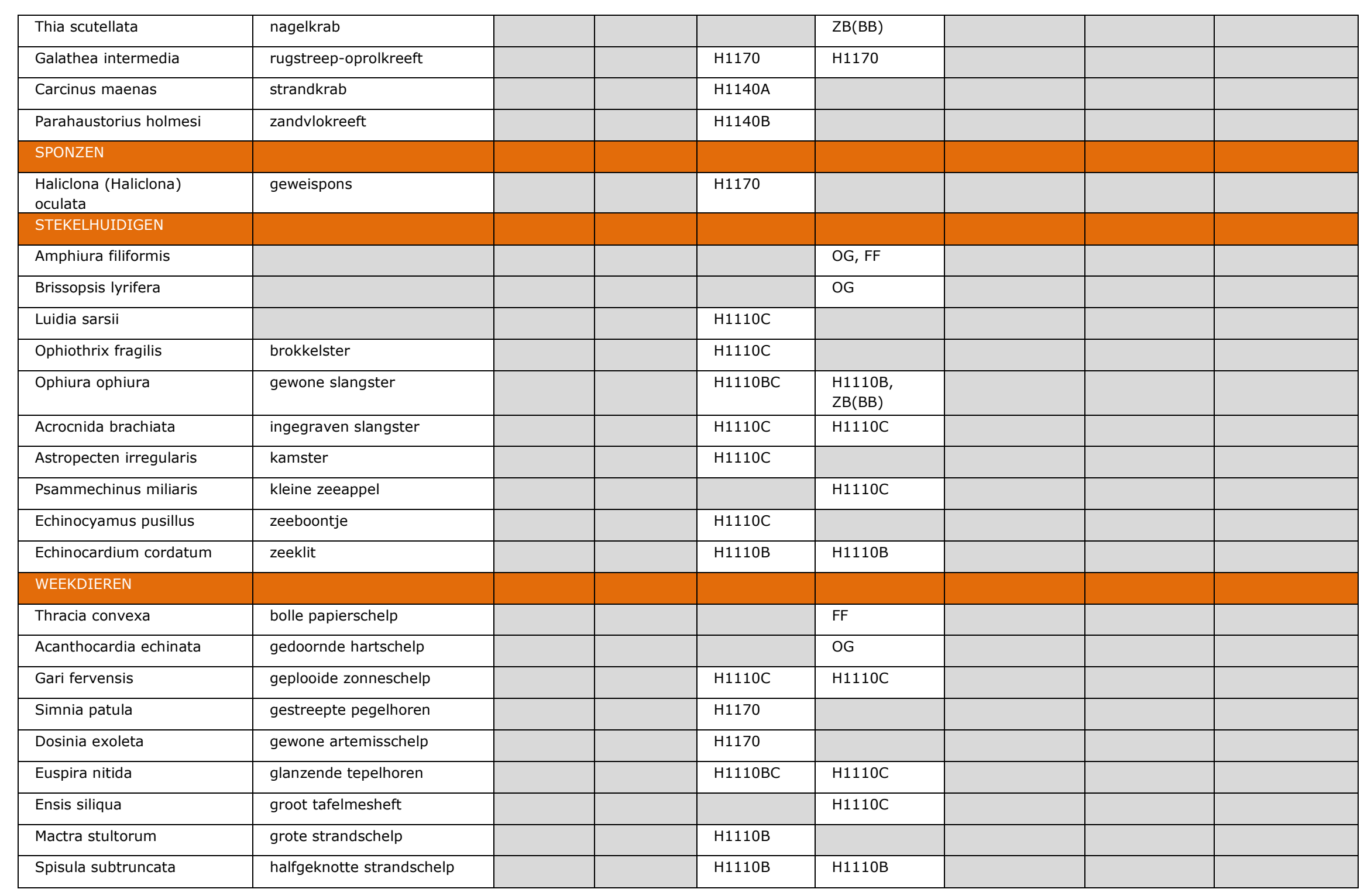

| 86 van 99 | Wageningen Marine Research rapport C125/16 


\begin{tabular}{|c|c|c|c|c|c|}
\hline Ensis ensis & kleine zwaardschede & $\mathrm{H} 1110 \mathrm{C}$ & $\mathrm{H} 1110 \mathrm{C}$ & & \\
\hline Cerastoderma edule & kokkel & $\begin{array}{l}\text { H1110A, } \\
\text { H1140A }\end{array}$ & & & \\
\hline Corbula gibba & korfschelp & & OG & & \\
\hline Monia patelliformis & mantel-dekschelp & & $\mathrm{H} 1170$ & & \\
\hline Mytilus edulis & mossel & $\begin{array}{l}\text { H1110A, } \\
\text { H1140A }\end{array}$ & & & \\
\hline Neptunea antiqua & noordhoren & $\mathrm{H} 1110 \mathrm{C}$ & & & \\
\hline Arctica islandica & noordkromp & $\mathrm{H} 1110 \mathrm{C}$ & & & OSPAR \\
\hline Aporrhais pespelecani & pelikaansvoet & $\mathrm{H} 1170$ & & & \\
\hline Turritella communis & penhoren & & OG & & \\
\hline Ostrea edulis & platte oester & & & $\begin{array}{l}\text { Herintroductie } \\
\text { Platte Oester }\end{array}$ & OSPAR \\
\hline Scrobicularia plana & platte slijkgaper & H1140A & & & \\
\hline Nucella lapillus & purperslak & & & & OSPAR \\
\hline Arcopagia crassa & stevige platschelp & $\mathrm{H} 1170$ & & & \\
\hline Mya arenaria & strandgaper & $\begin{array}{l}\text { H1110A, } \\
\text { H1140A }\end{array}$ & & & \\
\hline Kurtiella bidentata & tweetandschelpje & $\mathrm{H} 1110 \mathrm{C}$ & & & \\
\hline Aequipecten opercularis & wijde mantel & $\mathrm{H} 1170$ & & & \\
\hline Abra alba & witte dunschaal & H1110B & & & \\
\hline Buccinum undatum & wulk & $\begin{array}{l}\text { H1110ABC, } \\
\text { H1140A, } \\
\text { H1170 }\end{array}$ & & & \\
\hline Donax vittatus & zaagje & H1110B & $\mathrm{ZB}(\mathrm{BB})$ & & \\
\hline
\end{tabular}




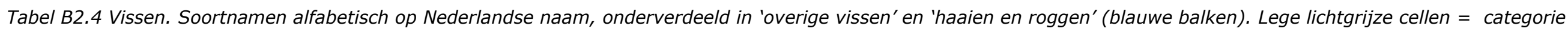
niet relevant voor de soort. Legenda: zie Tabel B2.1.

\begin{tabular}{|c|c|c|c|c|c|c|c|c|}
\hline Naam (wetenschappelijk) & Naam (Nederlands) & $\begin{array}{l}\text { HR- } \\
\text { bijlagen }\end{array}$ & $\begin{array}{l}\text { N2000- } \\
\text { gebieden } \\
\text { voor } \\
\text { soort }\end{array}$ & $\begin{array}{l}\text { Typische } \\
\text { soort } \\
\text { voor } \\
\text { habitatty } \\
\text { pe (HR) }\end{array}$ & $\begin{array}{l}\text { KRM } \\
\text { indicator- } \\
\text { soort } \\
\text { voor } \\
\text { habitat- } \\
\text { categ orie }\end{array}$ & $\begin{array}{l}\text { Soort van } \\
\text { beleidsplan }\end{array}$ & $\begin{array}{l}\text { OSPAR- } \\
\text { soorten } \\
\text { relevant } \\
\text { voor NL }\end{array}$ & $\begin{array}{l}\text { Rodelijststai } \\
\text { us }\end{array}$ \\
\hline \multicolumn{9}{|l|}{ OVERIGE VISSEN } \\
\hline Micrenophrys lilljeborgii & & & & $\mathrm{H} 1170$ & & & & \\
\hline Platichthys flesus & bot & & & $\begin{array}{l}\text { H1110A, } \\
\text { H1140A }\end{array}$ & & & & \\
\hline Pholis gunnellus & botervis & & & $\mathrm{H} 1110 \mathrm{~A}$ & & & & \\
\hline Chelon labrosus & diklipharder & & & $\mathrm{H} 1140 \mathrm{~A}$ & & & & \\
\hline Trisopterus minutus & dwergbolk & & & & & & & GE \\
\hline Phrynorhombus norvegicus & dwergbot & & & & & & & GE \\
\hline Buglossidium luteum & dwergtong & & & $\mathrm{H} 1110 \mathrm{BC}$ & & & & \\
\hline Alosa fallax & fint & II, V & $\begin{array}{l}7,113, \\
163\end{array}$ & & & & & $\mathrm{VN}$ \\
\hline Belone belone & geep & & & & & & & $\mathrm{BE}$ \\
\hline Eutrigla gurnardus & grauwe poon & & & $\mathrm{H} 1110 \mathrm{C}$ & & & & \\
\hline Trachinus draco & grote pieterman & & & & & & & EB \\
\hline Clupea harengus & haring & & & $\mathrm{H} 1110 \mathrm{AB}$ & & & & \\
\hline Agonus cataphractus & harnasmannetje & & & H1110AB & & & & \\
\hline Trachurus trachurus & horsmakreel & & & & & & & KW \\
\hline Coregonus oxyrinchus & houting & IV & & & & & OSPAR & GE \\
\hline Gadus morhua & kabeljauw & & & $\mathrm{H} 1110 \mathrm{C}$ & & & OSPAR & GE \\
\hline Atherina boyeri & kleine koornaarvis & & & & & & & GE \\
\hline Echiichthys vipera & kleine pieterman & & & $\mathrm{H} 1110 \mathrm{~B}$ & & & & \\
\hline Hippocampus hippocampus & kortsnuitzeepaardje & & & & & & OSPAR & GE \\
\hline Scomber scombrus & makreel & & & & & & & KW \\
\hline Anguilla anguilla & paling & & & & & & OSPAR & \\
\hline
\end{tabular}




\begin{tabular}{|c|c|c|c|c|c|c|c|}
\hline Callionymus lyra & pitvis & & & $\mathrm{H} 1110 \mathrm{BC}$ & & & \\
\hline Zoarces viviparus & puitaal & & & $\mathrm{H} 1110 \mathrm{~A}$ & & & $\mathrm{KW}$ \\
\hline Lampetra fluviatilis & rivierprik & II, V & $\begin{array}{l}7,113, \\
163\end{array}$ & & & & GE \\
\hline Limanda limanda & schar & & & H1110AC & & & \\
\hline Pleuronectes platessa & schol & & & $\begin{array}{l}\text { H1110ABC, } \\
\text { H1140A }\end{array}$ & & & \\
\hline Arnoglossus laterna & schurftvis & & & $\mathrm{H} 1110 \mathrm{BC}$ & & & \\
\hline Liparis liparis liparis & slakdolf & & & H1110AB & & & KW \\
\hline Lipophrys pholis & $\begin{array}{l}\text { slijmvis [naam conform } \\
\text { NSR] }\end{array}$ & & & & & & GE \\
\hline Osmerus eperlanus & spiering & & & & & & $\mathrm{KW}$ \\
\hline Solea solea & tong & & & H1110B & & & \\
\hline Microstomus kitt & tongschar & & & $\mathrm{H} 1110 \mathrm{C}$ & & & GE \\
\hline Syngnathus typhle & trompetterzeenaald & & & & & & $\mathrm{VN}$ \\
\hline Ciliata mustela & vijfdradige meun & & & $\mathrm{H} 1110 \mathrm{AB}$ & & & \\
\hline Raniceps raninus & vorskwab & & & & & & $\mathrm{BE}$ \\
\hline Merlangius merlangus & wijting & & & $\mathrm{H} 1110 \mathrm{BC}$ & & & GE \\
\hline Salmo salar & zalm & $\mathrm{V}$ & & & & OSPAR & \\
\hline Myoxocephalus scorpius & zeedonderpad & & & H1110AB & & & \\
\hline Lophius piscatorius & zeeduivel & & & $\mathrm{H} 1170$ & & & \\
\hline Hippocampus guttulatus & zeepaardje & & & & & OSPAR & \\
\hline Petromyzon marinus & zeeprik & II & $\begin{array}{l}7,113, \\
163\end{array}$ & & & OSPAR & GE \\
\hline Spinachia spinachia & zeestekelbaars & & & & & & VN \\
\hline Symphodus melops & zwartooglipvis & & & & & & GE \\
\hline \multicolumn{8}{|l|}{ HAAIEN EN ROGGEN } \\
\hline Raja brachyura & blonde rog & & & & Haaienactieplan & & \\
\hline Squalus acanthias & doornhaai & & & & Haaienactieplan & OSPAR & EB \\
\hline Mustelus asterias & gevlekte gladde haai & & & & Haaienactieplan & & \\
\hline Raja montagui & gevlekte rog & & & & Haaienactieplan & OSPAR & EB \\
\hline
\end{tabular}




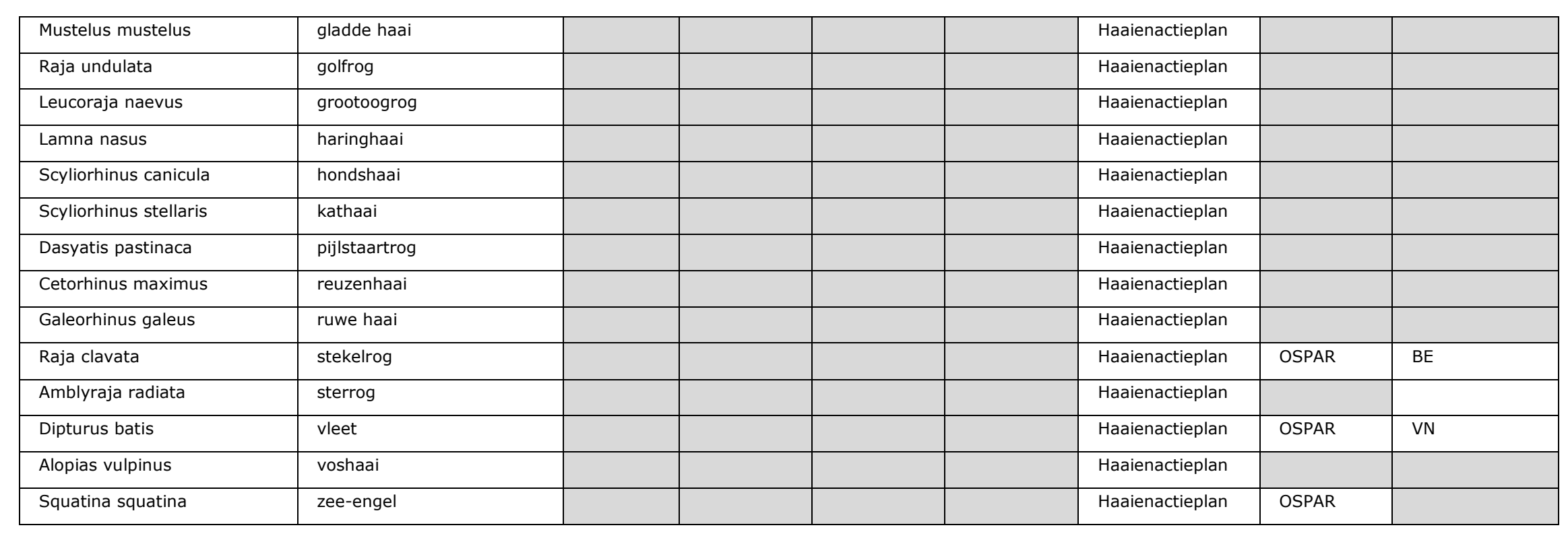


Tabel B2.5 Zeezoogdieren. Soortnamen alfabetisch op Nederlandse naam. Lege lichtgrijze cellen = categorie niet relevant voor de soort. Legenda: zie Tabel B2.1.

\begin{tabular}{|c|c|c|c|c|c|c|c|c|}
\hline Naam (wetenschappelijk) & Naam (Nederlands) & $\begin{array}{l}\text { HR- } \\
\text { bijlagen }\end{array}$ & $\begin{array}{l}\text { N2000- } \\
\text { gebieden } \\
\text { voor } \\
\text { soort }\end{array}$ & $\begin{array}{l}\text { Typische } \\
\text { soort } \\
\text { voor } \\
\text { habitatty } \\
\text { pe (HR) }\end{array}$ & $\begin{array}{l}\text { KRM } \\
\text { indicator- } \\
\text { soort } \\
\text { voor } \\
\text { habitat- } \\
\text { categorie }\end{array}$ & $\begin{array}{l}\text { Soort van } \\
\text { beleidsplan }\end{array}$ & $\begin{array}{l}\text { OSPAR- } \\
\text { soorten } \\
\text { relevant } \\
\text { voor NL }\end{array}$ & Rodelijststatus \\
\hline \multicolumn{9}{|l|}{ ZOOGDIEREN } \\
\hline Phocoena phocoena & bruinvis & II, IV & $\begin{array}{l}7,163, \\
164,165 \\
166\end{array}$ & $\mathrm{H} 1170$ & & $\begin{array}{l}\text { Bruinvis- } \\
\text { beschermingsplan }\end{array}$ & OSPAR & KW \\
\hline Delphinus delphis & gewone dolfijn & IV & & $\begin{array}{l}\text { H1110A, } \\
\text { H1140A }\end{array}$ & & & & \\
\hline Phoca vitulina & gewone zeehond & II, V & $\begin{array}{l}7,113, \\
163,164, \\
165,166\end{array}$ & $\mathrm{H} 1110 \mathrm{~A}$ & & & & $\mathrm{KW}$ \\
\hline Halichoerus grypus & grijze zeehond & II, V & $\begin{array}{l}7,113, \\
163,164, \\
165,166\end{array}$ & $\mathrm{H} 1140 \mathrm{~A}$ & & & & GE \\
\hline Tursiops truncatus & tuimelaar & IV & & & & & & VN \\
\hline Lagenorhynchus acutus & witflankdolfijn & IV & & & & & & \\
\hline Lagenorhynchus albirostris & witsnuitdolfijn & IV & $\begin{array}{l}7,163, \\
164,165, \\
166\end{array}$ & $\mathrm{H} 1110 \mathrm{BC}$ & & & & \\
\hline
\end{tabular}


Tabel B2.6 Vogels. Soortnamen alfabetisch op Nederlandse naam. Lege cellen = categorie niet relevant voor de soort. Legenda: zie Tabel B2.1.

\begin{tabular}{|c|c|c|c|c|}
\hline Naam (NL) & Naam (Wetenschappelijk) & $\begin{array}{l}\text { Valt onder } \\
\text { Vogelrichtlijn } \\
\text { ex art 12? }\end{array}$ & $\begin{array}{l}\text { Valt onder } \\
\text { Vogelrichtijn- } \\
\text { bijlage I } \\
\text { (voor NL) }\end{array}$ & $\begin{array}{l}\text { Aangewezen } \\
\text { Vogelrichtlijn- } \\
\text { gebieden } \\
\text { voor soort }\end{array}$ \\
\hline Aalscholver & Phalacrocorax carbo (Linnaeus, 1758) & ja & $\mathrm{N}$ & 7,113 \\
\hline Alk & Alca torda torda Linnaeus, 1758 & ja & & \\
\hline Amerikaanse grote stern & Sterna acuflavida Cabot, 1847 & ja & & \\
\hline Amerikaanse grote stern & Sterna sandvicensis acuflavida Cabot, 1848 & ja & & \\
\hline Amerikaanse zee-eend & Melanitta americana (Swainson, 1832) & ja & & \\
\hline Arctische bonte strandloper & Calidris alpina arctica (Schiøler, 1922) & ja & & \\
\hline Audouins meeuw & Larus audouinii Payraudeau, 1826 & ja & & \\
\hline Baltische mantelmeeuw & Larus fuscus fuscus Linnaeus, 1758 & ja & & \\
\hline Bergeend & Tadorna tadorna (Linnaeus, 1758) & ja & $\mathrm{N}$ & 7,113 \\
\hline Bontbekplevier & Charadrius hiaticula Linnaeus, 1758 & ja & $\mathrm{N}$ & 7,113 \\
\hline Bonte stern & Onychoprion fuscatus (Linnaeus, 1766) & ja & & \\
\hline Bonte strandloper & Calidris alpina (Linnaeus, 1758) & ja & $\mathrm{N}$ & 7,113 \\
\hline Brandgans & Branta leucopsis (Bechstein, 1803) & ja & & \\
\hline Brilduiker & Bucephala clangula (Linnaeus, 1758) & ja & $\mathrm{N}$ & 113 \\
\hline Brilstern & Onychoprion anaethetus melanoptera (Swainson, 1837) & ja & & \\
\hline Brilzee-eend & Melanitta perspicillata (Linnaeus, 1758) & ja & & \\
\hline Britse zeekoet & Uria aalge albionis Witherby, 1923 & ja & & \\
\hline Dougalls stern & Sterna dougallii Montagu, 1813 & ja & & \\
\hline Drieteenmeeuw & Rissa tridactyla (Linnaeus, 1758) & ja & & \\
\hline Drieteenstrandloper & Calidris alba (Pallas, 1764) & ja & $\mathrm{N}$ & 7,113 \\
\hline Dunbekmeeuw & Chroicocephalus genei (Brème, 1839) & ja & & \\
\hline Dwergmeeuw & Hydrocoloeus minutus (Pallas, 1776) & ja & $\mathrm{Y}$ & 7,113 \\
\hline
\end{tabular}




\begin{tabular}{|c|c|c|c|c|}
\hline Dwergstern & Sternula albifrons (Pallas, 1764) & ja & $\mathrm{Y}$ & 7 \\
\hline Eider & Somateria mollissima (Linnaeus, 1758) & ja & $\mathrm{N}$ & 7,113 \\
\hline Forsters stern & Sterna forsteri Nuttall, 1834 & ja & & \\
\hline Franklins meeuw & Larus pipixcan Wagler, 1831 & ja & & \\
\hline Fuut & Podiceps cristatus (Linnaeus, 1758) & ja & $\mathrm{N}$ & 113 \\
\hline Geelpootmeeuw & Larus michahellis Naumann, 1840 & ja & & \\
\hline Geelsnavelduiker & Gavia adamsii (Gray, 1859) & ja & & \\
\hline Geoorde fuut & Podiceps nigricollis C. L. Brehm, 1831 & ja & & \\
\hline Gon-gon & Pterodroma feae (Salvadori, 1899) & ja & & \\
\hline Grauwe pijlstormvogel & Puffinus griseus (Gmelin, 1789) & ja & & \\
\hline Groenlandse kanoet & Calidris canutus islandica (Linnaeus, 1767) & ja & & \\
\hline Grote burgemeester & Larus hyperboreus Gunnerus, 1767 & ja & & \\
\hline Grote jager & Stercorarius skua (Brünnich, 1764) & ja & & \\
\hline Grote mantelmeeuw & Larus marinus Linnaeus, 1758 & ja & & \\
\hline Grote pijlstormvogel & Puffinus gravis (O'Reilly, 1818) & ja & & \\
\hline Grote zee-eend & Melanitta fusca (Linnaeus, 1758) & ja & & \\
\hline Harlekijneend & Histrionicus histrionicus (Linnaeus, 1758) & ja & & \\
\hline IJsduiker & Gavia immer (Brünnich, 1764) & ja & & \\
\hline IJseend & Clangula hyemalis (Linnaeus, 1758) & ja & & \\
\hline IJslandse tureluur & Tringa totanus robusta (Schiøler, 1919) & ja & & \\
\hline Ivoormeeuw & Pagophila eburnea (Phipps, 1774) & ja & & \\
\hline Jan-van-gent & Morus bassanus (Linnaeus, 1758) & ja & & \\
\hline Kanoet & Calidris canutus (Linnaeus, 1758) & ja & $\mathrm{N}$ & 7 \\
\hline Kleine alk & Alle alle (Linnaeus, 1758) & ja & & \\
\hline Kleine burgemeester & Larus glaucoides glaucoides Meyer, 1822 & ja & & \\
\hline Kleine jager & Stercorarius parasiticus (Linnaeus, 1758) & ja & & \\
\hline Kleine kokmeeuw & Chroicocephalus philadelphia (Ord, 1815) & ja & & \\
\hline Kleine mantelmeeuw & Larus fuscus graellsii A.E. Brehm, 1857 & ja & & \\
\hline
\end{tabular}




\begin{tabular}{|c|c|c|c|c|}
\hline Kleine mantelmeeuw & Larus fuscus intermedius Schiøler, 1922 & ja & & \\
\hline Kleine zilverreiger & Egretta garzetta (Linnaeus, 1758) & ja & & \\
\hline Kleinste jager & Stercorarius longicaudus Vieillot, 1819 & ja & & \\
\hline Kluut & Recurvirostra avosetta Linnaeus, 1758 & ja & Y & 7,113 \\
\hline Kokmeeuw & Chroicocephalus ridibundus (Linnaeus, 1766) & ja & & \\
\hline Koningseider & Somateria spectabilis (Linnaeus, 1758) & ja & & \\
\hline Kortbekzeekoet & Uria lomvia (Linnaeus, 1758) & ja & & \\
\hline Krakeend & Anas strepera Linnaeus, 1758 & ja & $\mathrm{N}$ & 113 \\
\hline Kuhls pijlstormvogel & Calonectris borealis (Cory, 1881) & ja & & \\
\hline Kuifaalscholver & Phalacrocorax aristotelis (Linnaeus, 1761) & ja & & \\
\hline Kuifduiker & Podiceps auritus (Linnaeus, 1758) & ja & $\mathrm{Y}$ & 113 \\
\hline Kumliens meeuw & Larus glaucoides kumlieni Brewster, 1883 & ja & & \\
\hline Lachmeeuw & Larus atricilla Linnaeus, 1758 & ja & & \\
\hline Lachstern & Gelochelidon nilotica (Gmelin, 1789) & ja & & \\
\hline Lepelaar & Platalea leucorodia Linnaeus, 1758 & ja & $\mathrm{Y}$ & 113 \\
\hline Middelste jager & Stercorarius pomarinus (Temminck, 1815) & ja & & \\
\hline Middelste zaagbek & Mergus serrator Linnaeus, 1758 & ja & $\mathrm{N}$ & 113 \\
\hline Noordelijke zeekoet & Uria aalge hyperborea Salomonsen, 1832 & ja & & \\
\hline Noordse pijlstormvogel & Puffinus puffinus (Brünnich, 1764) & ja & & \\
\hline Noordse stern & Sterna paradisaea Pontoppidan, 1763 & ja & & \\
\hline Noordse stormvogel & Fulmarus glacialis (Linnaeus, 1761) & ja & & \\
\hline Paarse strandloper & Calidris maritima (Brünnich, 1764) & ja & & \\
\hline Papegaaiduiker & Fratercula arctica (Linnaeus, 1758) & ja & & \\
\hline Parelduiker & Gavia arctica (Linnaeus, 1758) & ja & Y & 7 \\
\hline Pijlstaart & Anas acuta Linnaeus, 1758 & ja & $\mathrm{N}$ & 113 \\
\hline Pontische meeuw & Larus cachinnans Pallas, 1811 & ja & & \\
\hline Ringsnavelmeeuw & Larus delawarensis Ord, 1815 & ja & & \\
\hline Roodhalsfuut & Podiceps grisegena (Boddaert, 1783) & ja & & \\
\hline
\end{tabular}




\begin{tabular}{|c|c|c|c|c|}
\hline Roodkeelduiker & Gavia stellata (Pontoppidan, 1763) & ja & Y & 7,113 \\
\hline Ross' meeuw & Rhodostethia rosea (MacGillivray, 1824) & ja & & \\
\hline Rosse franjepoot & Phalaropus fulicarius (Linnaeus, 1758) & ja & & \\
\hline Rosse grutto & Limosa lapponica (Linnaeus, 1758) & ja & $\mathrm{Y}$ & 7,113 \\
\hline Rotgans & Branta bernicla (Linnaeus, 1758) & ja & & \\
\hline Russische stormmeeuw & Larus canus heinei Homeyer, 1853 & ja & & \\
\hline Scandinavische zilvermeeuw & Larus argentatus argentatus & ja & & \\
\hline Scholekster & Haematopus ostralegus Linnaeus, 1758 & ja & $\mathrm{N}$ & 7,113 \\
\hline Smient & Anas penelope Linnaeus, 1758 & ja & $\mathrm{N}$ & 113 \\
\hline Steenloper & Arenaria interpres (Linnaeus, 1758) & ja & $\mathrm{N}$ & 7,113 \\
\hline Stellers eider & Polysticta stelleri (Pallas, 1769) & ja & & \\
\hline Stormmeeuw & Larus canus canus Linnaeus, 1758 & ja & & \\
\hline Stormvogeltje & Hydrobates pelagicus (Linnaeus, 1758) & ja & & \\
\hline Strandplevier & Charadrius alexandrinus Linnaeus, 1758 & ja & & \\
\hline Thayers meeuw & Larus thayeri Brooks, 1915 & ja & & \\
\hline Topper & Aythya marila (Linnaeus, 1761) & ja & $\mathrm{N}$ & 7,113 \\
\hline Tureluur & Tringa totanus totanus (Linnaeus, 1758 ) & ja & & \\
\hline Vaal stormvogeltje & Oceanodroma leucorhoa (Vieillot, 1817) & ja & & \\
\hline Vale pijlstormvogel & Puffinus mauretanicus Lowe, 1921 & ja & & \\
\hline Visdief & Sterna hirundo Linnaeus, 1758 & ja & $\mathrm{Y}$ & 113 \\
\hline Vorkstaartmeeuw & Xema sabini (Sabine, 1819) & ja & & \\
\hline Wilsons stormvogeltje & Oceanites oceanicus (Kuhl, 1820) & ja & & \\
\hline Wulp & Numenius arquata (Linnaeus, 1758) & ja & $\mathrm{N}$ & 7, 113 \\
\hline Zeekoet & Uria aalge aalge (Pontoppidan, 1763) & ja & & \\
\hline Zilvermeeuw & Larus argentatus argenteus & ja & & \\
\hline Zilverplevier & Pluvialis squatarola (Linnaeus, 1758) & ja & $\mathrm{N}$ & 7, 113 \\
\hline Zuidelijke alk & Alca torda islandica C.L. Brehm, 1831 & ja & & \\
\hline Zuidelijke bonte strandloper & Calidris alpina schinzii (C.L. Brehm, 1822) & ja & & \\
\hline
\end{tabular}




\begin{tabular}{|l|l|l|l|l|}
\hline Zwarte stern & Chlidonias niger (Linnaeus, 1758) & ja & \\
\hline Zwarte zee-eend & Melanitta nigra (Linnaeus, 1758) & ja & $\mathrm{N}$ \\
\hline Zwarte zeekoet & Cepphus grylle (Linnaeus, 1758) & ja & & \\
\hline Zwartkopmeeuw & Larus melanocephalus Temminck, 1820 & ja & \\
\hline
\end{tabular}


Wageningen Marine Research

T: +31(0)317480900

E: marine-research@wur.nl

www.wur.nl/marine-research

Visitors address

- Ankerpark 271781 AG Den Helder

- Korringaweg 5, 4401 NT Yerseke

- Haringkade 1, 1976 CP IJmuiden
Wageningen Marine Research is the Netherlands research institute established to provide the scientific support that is essential for developing policies and innovation in respect of the marine environment, fishery activities, aquaculture and the maritime sector.

Wageningen University \& Research is specialised in the domain of healthy food and living environment.

The Wageningen Marine Research vision:

'To explore the potential of marine nature to improve the quality of life.'

The Wageningen Marine Research mission

- To conduct research with the aim of acquiring knowledge and offering advice on the sustainable management and use of marine and coastal areas.

- Wageningen Marine Research is an independent, leading scientific research institute.

Wageningen Marine Research is part of the international knowledge organisation Wageningen UR (University \& Research centre). Within Wageningen UR, nine specialised research institutes of Stichting Wageningen Research (a Foundation) have joined forces with Wageningen University to help answer the most important questions in the domain of healthy food and living environment. 
